\title{
Bile reflux in GERD: Pathophysiological mechanism, clinical relevance and therapeutic implications
}

Citation for published version (APA):

Koek, G. H. (2004). Bile reflux in GERD: Pathophysiological mechanism, clinical relevance and therapeutic implications. [Doctoral Thesis, Maastricht University]. Maastricht. https://doi.org/10.26481/dis.20040206gk

Document status and date:

Published: 01/01/2004

DOI:

10.26481/dis.20040206gk

Document Version:

Publisher's PDF, also known as Version of record

\section{Please check the document version of this publication:}

- A submitted manuscript is the version of the article upon submission and before peer-review. There can be important differences between the submitted version and the official published version of record. People interested in the research are advised to contact the author for the final version of the publication, or visit the DOI to the publisher's website.

- The final author version and the galley proof are versions of the publication after peer review.

- The final published version features the final layout of the paper including the volume, issue and page numbers.

Link to publication

\footnotetext{
General rights rights.

- You may freely distribute the URL identifying the publication in the public portal. please follow below link for the End User Agreement:

www.umlib.nl/taverne-license

Take down policy

If you believe that this document breaches copyright please contact us at:

repository@maastrichtuniversity.nl

providing details and we will investigate your claim.
}

Copyright and moral rights for the publications made accessible in the public portal are retained by the authors and/or other copyright owners and it is a condition of accessing publications that users recognise and abide by the legal requirements associated with these

- Users may download and print one copy of any publication from the public portal for the purpose of private study or research.

- You may not further distribute the material or use it for any profit-making activity or commercial gain

If the publication is distributed under the terms of Article $25 \mathrm{fa}$ of the Dutch Copyright Act, indicated by the "Taverne" license above, 


\section{Bile reflux in GERD: \\ Pathophysiological mechanism, clinical relevance and therapeutic implications}


(C) Ger H Koek, Maastricht 2004

ISBN 90-9017712-4

Cover design: Rik de Brauwer

Production: Datawyse | Universitaire Pers Maastricht 


\title{
Bile reflux in GERD: \\ Pathophysiological mechanism, clinical relevance and therapeutic implications
}

\author{
PROEFSCHRIFT \\ ter verkrijging van de graad van doctor \\ aan de Universiteit Maastricht, \\ op gezag van de Rector Magnificus, Prof. Mr. G.P.M.F. Mols, \\ volgens het besluit van het College van Decanen, \\ in het openbaar te verdedigen \\ op vrijdag 6 februari 2004 om 14.00 uur
}

door

Ger H Koek 


\section{Promotores}

Prof. dr. R.W. Stockbrügger

Prof. dr. J. Tack (Leuven)

\section{Beoordelingscommissie}

Prof. dr. J.J. Manni (voorzitter)

Prof. dr. J.P. Galmiche, Nantes

Dr. J.W. Greve

Prof. dr. P.W. de Leeuw

Prof. dr. A.J. Smout, Universiteit Utrecht 
"Luctor ef Emergo"

Ter nagedachtenis aan mijn moeder, Voor mijn vader, Els, Astrid en Claro. 


\section{Abbreviations}

\begin{tabular}{|c|c|}
\hline ACT & $=$ acid clearance fime \\
\hline AVCT & $=$ acid volume clearance time \\
\hline CCK & $=$ cholecystokinin \\
\hline Cmax & $=$ maximum count activity \\
\hline $\operatorname{cox}-2$ & $=$ cyclooxygenase 2 \\
\hline DC & $=$ duodenal content \\
\hline $\mathrm{DCCT}$ & $=$ duodenal content clearance time \\
\hline DCVCT & $=$ duodenal content volume clearance time \\
\hline DGER & $=$ duodeno-gastro-esophageal reflux \\
\hline DGR & $=$ duodeno-gastric reflux \\
\hline EG & $=$ esophago-gastric junction \\
\hline EGF & $=$ epidermal growth factor \\
\hline GERD & $=$ gastroesophageal reflux disease \\
\hline $\mathrm{H}_{2}$ blockers & $=$ histamine 2 receptor antagonist \\
\hline $\mathrm{HH}$ & $=$ hiatus hernia \\
\hline LES & $=$ lower esophagus sphincter \\
\hline MLM & $=$ mixed liquid meal \\
\hline$M M C$ & $=$ migrating motor complex \\
\hline PPI & $=$ proton pump inhibitor \\
\hline SAP & $=$ symptom association probability \\
\hline SI & $=$ symptom index \\
\hline SS! & $=$ symptom-sensitivity index \\
\hline${ }^{99} \mathrm{~m} \cdot \mathrm{TC}_{\mathrm{C}} \mathrm{HIDA}$ & $={ }^{99 \mathrm{~m}} \mathrm{Tc}-[\mathrm{N}-(2,6-$ dimethylphenylcarbamoylmethyl $)$ iminodiacetic acid $]$ \\
\hline TLESR & $=$ transient lower esophagus sphincter relaxation \\
\hline UES & $=$ upper esophagus sphincter \\
\hline VCT & $=$ volume clearance time \\
\hline
\end{tabular}




\section{Contents}

Chapter 1 Duodeno-gastro-esophageal reflux disease, a review.

Chapter 2 Aims of the study and outline of the thesis.

Chapter 3 Mechanisms underlying duodeno-gastric reflux in man.

Chapter 4 Esophageal clearance of acid and bile: a combined radionuclide, $\mathrm{pH}$ and Bilitec $\mathrm{c}^{8}$ study.

Chapter 5 Dietary restrictions during ambulatory monitoring of duodeno-gastro-esophageal reflux.

Chapter 6 Analysis of ambulatory duodeno-gastro-esophageal reflux monitoring.

Chapter 7 The role of acid-and duodeno-gastro-esophageal reflux in symptomatic gastro-esophageal reflux disease.

Chapter 8 Determining factors in the etiology of esophagitis and Barrett's esophagus.

Chapter 9 Gastro-esophageal reflux disease refractory to proton pump inhibitors: acid reflux, bile reflux, or both?

Chapter $10 \quad \mathrm{GABA}_{\mathrm{B}}$ agonist Baclofen reduces gastro-esophageal reflux in patients with therapy resistant duodeno-gastroesophageal reflux.

Chapter 11 General discussion and conclusions.

Chapter 12 Summary.

Chapter 13 Samenvatting.

Dankwoord.

Curriculum vitae.

Publications. 



\section{Chapter 1}

Duodeno-gastro-esophageal reflux disease, a review 
Chapter 1 


\section{Introduction}

Diseases associated with the reflux of duodenal and gastric contents into the esophagus play an important role in the daily gastroenterological practice. In the Dutch society the general practitioner is the first to be confronted with typical or atypical reflux complaints. Many patients without alarm symptoms and signs as weight loss or dysphagia are treated empirically with proton pump inhibitors (PPIs) for 4-6 weeks. An endoscopist or gastroenterologist only sees those patients who are refractory to therapy or experience recurrent symptoms after stopping therapy.

In this chapter a review is given about gastro-esophageal reflux disease (GERD) and duodeno-gastro-esophageal reflux disease (DGER); the signs and symptoms, the pathophysiology, the different methods to investigate reflux and the therapeutical options.

\section{Clinical expression of reflux}

A variety of symptoms are found in patients with reflux disease. The patient's medical history is the cornerstone to differentiate between typical and atypical reflux symptoms. The two most important typical symptoms are heartburn and acid regurgitation. Furthermore a number of atypical symptoms can be attributed to GERD as discussed below. In the clinical signs of reflux disease a difference can be made between esophageal and extra-esophageal manifestations for example esophagitis and asthma, respectively.

\section{Typical symptoms}

Heartburn, a retrosternal burning sensation that radiates towards the throat or mouth, is the most prominent symptom of reflux. It occurs after meals, in supine position and after bending over or heavy lifting. Eating and drinking of hot, spicy, acidic food or drinks often provokes it.

Regurgitation is the effortless return of gastric content into the esophagus and frequently into the mouth. This fluid can be acid, food or bitter and can appear during the day or at night. Sometimes it causes acute dyspnea, choking and coughing.

Less typical symptoms are chest pain in which a cardiac origin must be excluded and obstructive dysphagia that can be an alarm symptom of a mechanical obstruction. Non-obstructive dysphagia is a frequent sign 
accompanying reflux disease, and is not necessary an alarm sign. Nonspecific upper gastrointestinal symptoms are nausea, dyspepsia, bloating, belching or indigestion. ${ }^{1,2}$

\section{Atypical symptoms}

Symptoms of reflux disease, which cannot be attributed to the esophagus, are called extra-esophageal or atypical symptoms. They point to involvement of other organs in reflux disease.

Pulmonary symptoms that have been attributed to reflux disease include chronic cough, wheezing and dyspnoe at night. ${ }^{3}$ Reflux-related otorhinolaryngological and oral symptoms are hoarseness ${ }^{4}$, dysphonia, postnasal drip, globus feeling ${ }^{5}$, halitosis and water brash. These symptoms are probably caused by nocturnal reflux. ${ }^{6}$

\section{Esophageal manifestations of reflux}

Erosive esophagitis, esophageal strictures and motility disturbances, Barrett's esophagus ${ }^{7}$ and esophagus carcinoma ${ }^{8}$ are structural lesions which are at least in part caused by reflux disease.

Overwhelming evidence suggests that Barrett's esophagus is an acquired condition secondary to chronic GERD and DGER.

Prospective studies in patients with frequent heartburn showed a prevalence of Barrett's esophagus in $11-12 \% .{ }^{9}$ With reflux symptoms once a week, a prevalence of Barrett's esophagus was found in $3.5 \%$. Regarding symptoms, only a few patients with severe Barrett's esophagus have no reflux symptoms.

\section{Extra-esophageal manifestations}

The extra-esophageal manifestations of reflux are now becoming more and more elucidated. Pulmonary expressions of reflux are asthma ${ }^{10}$, nonallergic asthma", recurrent aspiration and pulmonary fibrosis. In $39 \%$ of the asthmatic patients an esophagitis was diagnosed. ${ }^{12}$ Otorhinolaryngological abnormalities like vocal cord disease ${ }^{13}$, chronic laryngitis, laryngeal and subglottis stenosis ${ }^{14}$, chronic middle ear disease $^{15}$, laryngeal cancer $^{16,17}$, sinusitis, pharyngitis and otalgia are more often recognized and successfully treated with proton pump inhibitors. Dental erosions are potential oral complications of reflux. ${ }^{18}$ 


\section{Epidemiology}

Epidemiological data about the prevalence of GERD are rather scarce. A recent investigation in Belgium showed that the prevalence of heartburn, as the most important GERD symptom, was experienced in $28.4 \%$ of the interviewed persons older than 15 years during the previous 12 months. ${ }^{19}$ Comparable prevalence were found in Finland $30 \%{ }^{20}$, France $27.1 \%{ }^{21}$ and Sweden $25 \% .{ }^{22}$ In the United Kingdom $10 \%$ of the population has GERD. Using a validated questionnaire, Locke found a prevalence of heartburn and acid regurgitation at least once a year in $58.7 \%$ and at least once a week in $19.8 \%$ of persons. ${ }^{23}$

The prevalence in North-America was found to be higher: 4-7\% experienced heartburn daily, 14-30\% weekly and $15-44 \%$ monthly. ${ }^{24-26}$ Esophageal lesions, as a consequence of reflux, were described as early as 2500 BC. $^{27}$ In 1929, Jackson wrote a case report about peptic ulcers of the esophagus ${ }^{28}$ and in 1932 Mallory and Weiss ${ }^{29}$ described chronic ulcers of the cardia, which they suggested were caused by regurgitation of gastric juice and the corrosive effect of alcohol. It was 1935 when Winkelstein set the trend for our present concept of reflux disease, writing his paper on peptic esophagitis suggesting that this was caused by the irritant action on the mucosa of free hydrochloric acid and pepsin. ${ }^{30}$

\section{Physiology of antireflux mechanisms}

Reflux of duodenal content to the stomach (DGR) or gastric content to the esophagus is a physiological process. During DGR bilirubin, bile salts, and pancreas juices passed via the pylorus to the stomach, mainly in the postprandial period..$^{31.34}$

Gastro-esophageal reflux is the process in which stomach content moves into the esophagus. Such reflux, if limited, is physiological in the postprandial period, during vomiting and with belching.

Different mechanisms are involved in reflux and the defense against it. The anatomical and esophageal defense mechanisms are briefly discussed.

\section{Esophageal anatomy and motility}

After mastication, a bolus of food, mixed with saliva, passes the upper esophagus sphincter (UES) by swallowing. The bolus is propagated through the body of the esophagus by the muscular layer, which consists of striated muscle in the upper part and smooth muscle in the lower part, 
to pass the relaxed lower esophagus sphincter (LES). In response to distention by a bolus, propagating aboral contractions are generated within the body of the esophagus. ${ }^{35,30}$

Reflux of content from the stomach to the esophagus triggers closure of the UES and generation of a secondary peristaltic contraction to clear the fluid from the esophagus into the stomach. It is bolus distention rather than the acidic content of the refluxate that causes this motility reaction of the esophagus. ${ }^{37,38}$

The role of gastric motility in reflux has been suggested by the fact that about $50 \%$ of patients with GERD have an abnormal gastric emptying. ${ }^{39}$ Postprandial reflux may be increased because of delayed gastric emptying. An increase in the rate of reflux during transient lower esophagus sphincter relaxations (TLESRs) is more likely to occur (see page 15). In GERD patients, a disturbed gastric accommodation to a meal and a prolonged postprandial fundic relaxation has been described. ${ }^{40,41}$ A recent study showed a correlation between esophageal acid exposure and gastric emptying time of the proximal stomach. ${ }^{42}$ These studies suggest that postprandial fundic volumes and pressure may affect the rate of distention induced triggering of TLESRs and the volume of the gastro-esophageal refluxate.

The crural diaphragm

The crural diaphragm acts as the extrinsic sphincter mechanism and is formed primarily by the right crux of the diaphragm. ${ }^{43}$ The phrenoesophageal ligament anchors the LES and crural diaphragm to each other. The phrenic nerves from both sides innervate the crural diaphragm. The change in position of the crural diaphragm plays an important role in the anti-reflux barrier function; the crural diaphragm contracts a fraction of a second earlier than the costal diaphragm. ${ }^{44}$

Reflux episodes are associated with TLESRs and marked inhibition of the crural diaphragm. Increased intra-abdominal pressure induces contraction of the crural diaphragm.

Selective inhibition of the crural diaphragm that is characteristic of TLESRs also occurs during vomiting ${ }^{45}$, esophageal distention ${ }^{46}$ and, to a certain degree, during swallowing. ${ }^{46.48}$ This inhibition is probably coordinated in the brain stem.

\section{Lower esophagus sphincter}

The anti-reflux barrier is situated in the esophago-gastric junction; an anatomical barrier preventing reflux to occur. The LES is a physiological sphincter, normally $4 \mathrm{~cm}$ long, which consists of a dual-sphincter 
mechanism composed of intrinsic smooth muscles and extrinsic skeletal muscles of the crural diaphragm. ${ }^{49}$

The vagus nerve plays an important role in the relaxation of the LES; it mediates swallow-induced LES relaxation ${ }^{50-53}$ and inhibition of gastric tone.

The LES functions like a valve, which is dependent on the intraabdominal pressure on the abdominal part of the esophagus, the intrinsic sphincter pressure and to a lesser extent the diaphragm. The LES pressure is measured in reference to the intra-gastric pressure and varies in rest between $5-10 \mathrm{mmHg}$. The LES pressure can rise to $80 \mathrm{mmHg}$ during phase III of the migrating motor complex (MMC) in the stomach; a physiological mechanism to prevent reflux of gastric content to the esophagus after meals and with changes in position. ${ }^{54,55}$

At least two types of LES relaxations have been described: the swallowinduced LES relaxations and LES relaxations not induced by swallowing called TLESR. The TLESRs probably play the most important role in reflux disease.

\section{Transient lower esophagus sphincter relaxation}

TLESR is defined as an abrupt decrease in LES pressure to the level of intra-gastric pressure that is not triggered by swallowing. TLESRs are typically of longer duration than swallow-induced LES relaxations, lasting from 10 to 60 seconds. ${ }^{56.57}$ TLESRs usually end with a primary or, less commonly, secondary peristaltic sequence. A prominent after-contraction at the termination of the relaxation is also a characteristic feature of TLESRs. ${ }^{55}$

The mechanism of TLESR is complex; an interaction is suggested between the esophagus, the LES, the crural diaphragm and the stomach and current evidence suggests that TLESRs is predominantly vagal reflex, stimulated by tension receptors in the sub-cardiac region of the stomach $^{58-61}$ and pharynx. The coordination is located in the brain stem. TLESR is thought to represent a physiological mechanism for venting gas (belching) and during vomiting. ${ }^{62}$ It appears most frequently in the postprandial period ${ }^{63,64}$ and is almost totally suppressed in supine position. ${ }^{62 ; 65}$

The factors that determine whether reflux occurs during TLESRs have not been studied systematically. These factors include abdominal straining, the presence of hiatus hernia, the degree of esophageal shortening, food intake (mainly fat), gastric emptying and abnormal modulation of the TLESRs duration. 
Esophageal mucosal resisłance

The esophagus mucosa consists of a non-keratinizing squamous epithelium, which changes abruptly to a columnar epithelium at the gastro-esophageal junction (Z-line). The esophageal mucosal barrier consists of three layers; the stratum corneum with cell layers which are bound together by tight junctions. This relatively impermeable zona occludens lays above the stratum spinosum followed by the basal cell layer which is situated on the basal membrane above the submucosal layer in which submucosal glands are situated. ${ }^{66}$

In contrast to the stomach and duodenum, only a very thin mucusbicarbonate barrier has been found in the human esophagus. ${ }^{67}$ Local esophageal defense mechanisms are mucus secretion ${ }^{68}$, mucosal cellular resistance $^{66}$, mucosal permeability ${ }^{69}$, and esophageal vascularisation. ${ }^{70}$

\section{Esophageal submucosal glands}

In the opossum it was shown for the first time that the esophagus secreted alkali. ${ }^{71}$ This was confirmed in the human esophagus, which secretes bicarbonate at about $400 \mu \mathrm{mol} /$ hour $/ 10 \mathrm{~cm} .^{71}$ The esophageal submucosal glands provide the intrinsic bicarbonate and mucous secretion of the esophagus. ${ }^{72}$ The glands are under control of alpha adrenoreceptors on the vagal nerve. ${ }^{73}$ During sleep the local alkali production within the esophagus is an important defense mechanism. ${ }^{74}$

When an acid bolus enters the esophagus, the greater part of the fluid is expelled from the esophagus by secondary contractions. The thin residual acid film on the mucosa is normally neutralized by the protective bicarbonate mucous layer. ${ }^{75}$

In response to luminal acidification an increase in esophagus blood flow occurs $^{76}$ probably to provide bicarbonate ions to neutralize protons and limit tissue injury. ${ }^{77}$

\section{Saliva}

Saliva plays a role in the lubrification and digestion of food and facilitates the passage of a bolus through the esophagus.

During the postprandial period the intra-esophagus $\mathrm{pH}$ is normally around 6.5 , determined by bicarbonate content of saliva. ${ }^{78}$ Swallowed saliva has also an important role in neutralizing acid in the esophagus and is therefore an important extra-esophageal defense mechanism against reflux. ${ }^{79,80}$ Saliva not only contains bicarbonate but also mucus glycoprotein and epidermal growth factor (EGF), which probably have a cytoprotective effect. ${ }^{81}$ 
Saliva secretion is stimulated by thinking, viewing and tasting food, by the masticatory movement, by somatostatin and after acidification of the esophagus.

An esophago-salivary reflex has been suggested by experiments with acid infusion at night that caused increased arousal and swallow frequency. ${ }^{82,83}$ Vagal reflexes can increase salivary alkali output by $35 \%{ }^{73}$ The mechanism is probably controlled by mixed cholinergic adrenergic fibers. ${ }^{84}$

\section{Pathophysiology of reflux disease}

Pathological reflux is defined as any symptomatic condition or histopathologic alteration as a result of episodes of duodeno- and gastro-esophageal reflux. In the spectrum of reflux disease a distinction can be made between duodeno-gastric reflux, gastro-esophageal reflux disease and duodeno-gastro-esophageal reflux.

The pathophysiological mechanisms of reflux are still not completely clear today, however, it is apparent that gastro-esophageal reflux is a multifactorial disease. Esophagus dependent factors like motility, mucosal defense mechanisms and anatomical abnormalities play an important role. On the other hand the severity of reflux disease is dependent of refluxate factors like the composition of the fluid, the duration and frequency of the reflux episode.

In earlier studies, pathological reflux of duodenal content to the stomach has been suggested to contribute to the development of gastritis ${ }^{85}$, gastric ulcer disease ${ }^{86,87}$ and gastric cancer. ${ }^{88,89}$ Gastric reflux to the esophagus may play a role in the development of esophagitis ${ }^{90.93}$, Barrett's esophagus $^{94,95}$ and esophagus adenocarcinoma. ${ }^{88,96,97}$ Different pathophysiological aspects of reflux to the esophagus are briefly discussed.

\section{Hiatus hernia}

Hiatus hernia $(\mathrm{HH})$ refers to herniation of elements of the abdominal cavity through the esophageal hiatus of the diaphragm. Four types are defined; type I or sliding $\mathrm{HH}$, in which a widening of the muscular hiatal tunnel and circumferential laxity of the phreno-esophageal membrane allows a portion of the gastric cardia to herniate upwards. If a $\mathrm{HH}$ enlarges more than $3 \mathrm{~cm}$ a gastric pouch is herniated upward and its presence is easily visualized with different types of investigations e.g. gastroscopy and radiography. Different para-esophageal hernias are classified as type II-IV and are less common. 
The prevalence of $\mathrm{HH}$ is suggested to be between $54-94 \%$ in patients with esophagitis diagnosed by endoscopy and radiology and is higher compared to controls without esophagitis $(8-60 \%) .{ }^{98-101}$

$\mathrm{HH}$ is associated with more severe esophagitis ${ }^{98,99,102-104}$ and Barrett's esophagus. ${ }^{105}$ In patients with GERD and $\mathrm{HH}$ the exposure to acid is significantly longer than in patients without a $\mathrm{HH} .{ }^{99,106-110}$

Radiological studies showed that barium is trapped in the nonreducible hiatal sac and that reflux of content from the sac into the proximal esophagus occurs during a second swallow. ${ }^{56,103,111}$ Van Herwaarden ef al. recently showed that patients with $\mathrm{HH}$ had a higher incidence of acid reflux episodes whereas the duration of the reflux episodes was not influenced and no increase in the number of TLESRs was observed. Patients without a HH TLESRs were responsible for $80 \%$ of acid reflux events, whereas in $\mathrm{HH}$ patients a more heterogeneous pattern of motor mechanism was observed. ${ }^{109}$

These observations suggest that an abnormal position of the crural diaphragm to the LES could facilitate the occurrence of reflux during each LES relaxation. ${ }^{48,112,113}$ Abdominal straining, coughing, forced exhalation against a closed glottis (Valsalva maneuver) and an inspiratory effort with closed glottis after expiration (Müller maneuver) were associated with a higher number of reflux episodes. ${ }^{114}$ This suggests that when the position of the LES to the crural diaphragm is altered, the additive effect from the intrinsic, LES, and the extrinsic, crural, pressures are lost and that esophageal reflux can occur more easily during increased intra-abdominal pressure.

The role of transient lower esophagus sphincter relaxations in the reflux process

TLESRs are on the one hand normal physiological events, but on the other hand play the most important role in the pathogenesis of reflux events. ${ }^{115}$ Less important mechanisms facilitating reflux are a weak LES and/or crural diaphragm, a hypotensive LES zone and a hiatus hernia, but these aspects are not the main mechanism in GERD.

Schoeman et al. recorded LES pressure in a 24 hours ambulatory manometry system in healthy volunteers and showed that the majority of reflux episodes occurred in the postprandial period with TLESRs as the main underlying mechanism in $82 \%$. Swallow-related LES relaxations and persistently absent LES pressure occurred in $13 \%$ and $1 \%$ respectively. ${ }^{116}$

Trudgill found no difference in the frequency of TLESRs between GERD patients and healthy volunteers, but the TLESRs in GERD patients were accompanied with acid reflux. ${ }^{17}$ This was confirmed in observations from 
Sifrim ef al. who studied the postprandial refluxate in healthy volunteers and GERD patients with $\mathrm{pH}$ measurement and intraluminal electrical impedance. They observed that TLESRs and reflux of gastric contents are similarly frequent in patients with GERD and controls but that patients with GERD had more acid reflux and less non-acid reflux. ${ }^{118}$ In patients with reflux disease acid reflux during TLESRs was found in $60-70 \%$ compared to $40-50 \%$ in healthy controls.

In GERD patients, TLESRs occur significantly less frequently in the supine $^{109}$ and lateral recumbent position ${ }^{122}$ compared to the sitting position. TLESRs associated with reflux are slightly but significantly longer than those without reflux, although there is substantial overlap. ${ }^{116}$

Meals are also associated with a significantly increase in the proportion of TLESRs associated with reflux ${ }^{56,63,116,123}$, and it has been suggested that this effect rather than an increase in the rate of TLESRs is responsible for the postprandial increase in reflux. ${ }^{56}$ In experimental conditions, a $750-1000 \mathrm{ml}$ volume increase in the human stomach content caused a fourfold increase in the rate of TLESRs within the first 10 minutes. In other studies, a similar effect has been reported after meals ${ }^{63,123,124}$, although others have not found any increase. ${ }^{40,56}$

Thus, gastric distention and meals have been the most important triggers for TLESRs. Delayed gastric emptying as Penagini showed in a study, increased the number of TLESRs in patients with reflux disease. He suggesting that reflux disease is associated with delayed recovery of proximal gastric tone after a meal probably by an increased visceral sensitivity. ${ }^{125}$ In one study these findings ${ }^{126}$ were confirmed, in another this was not confirmed. ${ }^{127}$ Although conflicting data exists, the majority of evidence suggest that gastric distention appears to be a major impuls ${ }^{128}$ probably by activating the mechano-receptors in the proximal stomach. ${ }^{129}$

In healthy subjects two sorts of reflux mechanisms have been described: the majority are TLESRs (70-100\%) ${ }^{64,120,130}$ and to a lesser extent swallowinduced LES relaxation associated with failed or incomplete primary peristalsis. In one study swallow-related LES relaxations was found to be a more common mechanism of reflux. ${ }^{131}$ Persistently absent basal LES pressure, straining during deep inspiration and an increased intraabdominal pressure are probably other less important factors for GERD. ${ }^{116.132}$

These data suggest that most patients have a mixed picture with TLESRs as the most common mechanism of reflux in $63-74 \% .55,119,130$ The high proportion of reflux episodes during TLESR underscores the importance of these events in the pathogenesis of reflux disease. Dent suggested that the portion of reflux episodes that can be ascribed to TLESRs varies 
inversely with the severity of reflux disease ${ }^{130}$, presumably because of the increasing prevalence of defective basal LES pressure as the severity of esophagitis increases. ${ }^{133}$

Results of medical therapy to influence TLESRs are sparse. A few studies have addressed the effect of the $G_{A B A}$ agonist baclofen that decreases the frequency of TLESRs both in animals and in man. ${ }^{134.137}$ Future research will be addressed on exploring the therapeutic effect of baclofen on therapy resistant patients as an add-on treatment.

Another therapeutic option is fundoplication that has two major effects; a $50 \%$ reduction in the rate of TLESRs and a reduction in the proportion of TLESRs that were accompanied by reflux from $47 \%$ to $17 \%$. The mechanism underlying these effects most likely includes the creation of an artificial high-pressure zone around the LES by the fundoplication wrap, which persists during both transient and swallow-induced LES relaxation $^{138}$ and possibly a reduction in the degree of distention of the gastric cardia by the gastric wrap ${ }^{139}$ which may reduce the gastric distention-induced stimulation of TLESRs.

\section{Acid reflux}

The role of acid reflux in the development of esophagitis and symptoms has been established in different animal and human studies in the past.

The normal esophagus mucosa is relatively impermeable to luminal acid. ${ }^{140.143}$ From animal studies it was suggested that acid alone is probably not caustic to the mucosa when the $\mathrm{pH}$ is above 1. 144 Pepsin in combination with acid plays the most important factor in the pathogenesis of esophagitis. ${ }^{145-147}$ The proteolytic activity of pepsin is only active in an acidic milieu with a $\mathrm{pH}$ between 1.5-2.5.143.145.148-150 Therefore severe esophagitis should be related to the prolonged contact and concentration of pepsin in a low $\mathrm{pH}$ environment. However, Hirchowitz et al. showed that the severity of GERD was not related to pepsin concentration ${ }^{151}$ suggesting other factors playing a role in the damage to the mucosa.

Different theories exist about the pathophysiological mechanism of the refluxate on mucosal cells. One hypothesis suggests that prolonged acid exposure or higher acid concentration inhibits the activity of the esophageal mucosal cellular $\mathrm{Na}^{+}-\mathrm{K}^{+}$ATP-ase. This leads to an increase of intra-cellular $\mathrm{Na}^{+}$which results in swelling and necrosis of cells. ${ }^{69}$

The toxicity of $\mathrm{H}^{+}$ions is higher when they enter via the paracellular and basolateral membranes. In the normal situation, when cellular adhesions are intact, no injury can take place. The cellular integrity first has to be disrupted before acid can enter the paracellular and basolateral 
compartment. Pepsin probably plays a role in the breakdown of the cellular adhesion proteins. The observations suggest that esophagus cells are very sensitive to the basolateral acidification. ${ }^{152}$ A defense mechanism against the basolateral acidification is the secretion of bicarbonate ions out of the circulation in this area. ${ }^{153}$

Minor important pathophysiological aspects are defective or diminished salivation that plays a role in the severity of esophagitis as was observed in the elderly ${ }^{154,155}$, and a decline in mucosal resistance. ${ }^{38,156}$

Acid esophageal clearance is reduced in $50 \%$ of patients with reflux disease. ${ }^{38,157}$ It is unknown whether this is a consequence or cause of the reflux disease. Mechanical inefficiency of both primary and secondary esophagus body peristalsis ${ }^{158,159}$ and diminished salivation ${ }^{38,156,160}$ have been claimed to be factors, which are likely to contribute to the impaired clearance. Recently, using multichannel intraluminal impedance monitoring, Shay et al. were able to demonstrate that many prolonged reflux episodes in GERD patients with apparent slow clearance were actually composed of repetitive reflux events (so-called acid re-reflux) superimposed upon each other. ${ }^{161}$

Controversy exists about whether gastric acid hypersecretion occurs in patients with reflux disease. Hirschowitz et al. suggest that gastric acid secretion is normal in the vast majority of patients with reflux disease. ${ }^{162}$ However, a subset of patients with reflux disease have an increased basal acid secretion. ${ }^{163}$ More recently, acid secretion level was shown to be an independent pathophysiological factor in a multivariate logistic regression analysis. ${ }^{164}$ In support of a contributing role of acid secretion, gastric hypersecretion in the Zollinger-Ellisson syndrome is associated with a $40-60 \%$ incidence of esophagitis. ${ }^{165}$

Recently, a difference in postprandial acid distribution has been suggested to play a role in the pathogenesis of GERD. ${ }^{166}$ With single photon computed tomography using radiolabeled technetium, Boeckxstaens et al. reported the existence of an acid layer on top of the food within the stomach. ${ }^{167}$ This suggests that a disturbed mixing pattern of the stomach could be responsible for the different layers in the stomach which has been observed in scintigraphic ${ }^{168}$ and gastric magnetic resonance imaging studies of the stomach. ${ }^{169}$

It is thus clear from both animal and human studies that acid and pepsin play an important role in GERD symptoms and mucosal injury. However, it has been observed that the non-acid component of the refluxate may also play a role in damage to the esophagus ${ }^{170}$ suggesting a more complex pathophysiological mechanism in GERD patients. In the next section the role of duodeno-gastro-esophageal reflux is discussed. 


\section{Duodeno-gastro-esophageal reflux}

Reflux of duodenal contents (DC) via the stomach into the esophagus has long been suspected to be of pathophysiological relevance to mucosal lesions in GERD. Cross and Wangenstein first described in 1957 a relation between esophagitis and bilirubin containing fluid in cat and dog models. ${ }^{171}$

In 1958 Helsingen observed severe esophagitis in patients after a total gastrectomy concluding that not only acid and pepsin could cause esophageal lesion. ${ }^{172}$ Several other authors ${ }^{173-175}$ confirmed this finding and observed that patients with achlorhydria associated with pernicious anemia could also suffer from reflux esophagitis. ${ }^{85,173,176}$ From these observations it can be concluded that a more complex mechanism in the pathogenesis of reflux esophagitis and its complications exists. Thus, the toxic synergism of acid, pepsin and duodenal fluid including bilirubin, bile acids and pancreatic enzymes should be seriously considered taking part in the development of reflux diseases.

In patients esophageal aspirates with esophagitis showed the presence of bilirubin. ${ }^{91,177}$ Others showed that patients with more complicated GERD had increased esophagus exposure of mixed DC and acid. ${ }^{97,177.181}$ Using the Bilitec ${ }^{\text {क }}$ probe, several studies have demonstrated a progressive increase in duodeno-gastro-esophageal reflux across the spectrum of GERD, with a particularly high prevalence in patients with Barrett's esophagus. ${ }^{182 \cdot 185}$

These observations suggest that reflux of DC plays a role in esophageal mucosal lesions although the mechanism is still debated. A summary of animal and human studies in relation to DGER is given below to evaluate the role of DC.

Animal studies

Bile salts are produced in the liver by converting cholesterol into the primary bile acids cholate and chenodeoxycholate. Intestinal bacteria produce the secondary bile acids including deoxycholic- and lithocholic acids as by-products of metabolism, which are reabsorbed (enterohepatic circulation). Bile salts, the major constituent of DC, are highly effective detergents because they contain polar and non-polar regions and solubilize dietary lipids. Bile fluid consists in $80 \%$ of cholate and chenodeoxycholate, in about $20 \%$ of deoxycholate and only in $1-2 \%$ of lithocholate. ${ }^{186}$ Before secretion into the biliary tract, $98 \%$ of bile acids are conjugated with amino acids taurine or glycine at a ratio $3: 1$. Conjugation, which lowers the pKa, increases the solubility of bile salts. Conjugated bile acids, which have a pKa of 1.9, are in ionized forms at 
an alkaline $\mathrm{pH}$, unconjugated bile acids on the other hand have a pKa of 5.1 and are in unionized form at alkaline $\mathrm{pH}$.

Precipitation of bile acids is seen; for taurine-conjugates this happens when the $\mathrm{pH}$ comes below 2, for glycine-conjugated bile acids this is around $\mathrm{pH} 5$ and the deconjugated bile acids precipitate around $\mathrm{pH} 6$. Precipitation of bile acids is irriversible and this probably makes them not toxic to the mucosa anymore.

The mechanism of bile salt toxicity has been studied in different animal models. The injurious effect of bile salts depends on the type and state of the bile salt. Conjugated bile salts as mentioned above are lipophylic close to their pKa. In this situation it has been hypothesized that they diffuse across the epithelial cell membranes. This was confirmed in a study, which showed a concentration of taurocholic acid that was seven times higher in the rabbit esophagus mucosal cells when incubated at $\mathrm{pH}$ 2. It was explained that the higher $\mathrm{pH}$ intra-cellular ionized the bile salts and in this way the salt was trapped and accumulated in the cell. ${ }^{187}$ This high intra-cellular level can interfere with cellular metabolism, disorganize intra-cellular membranes and can dissolve cell membranes in tight junctions. ${ }^{187-189}$ Severe disturbance of calcium homeostasis after bile salt and acid perfusion have been observed in the cat. ${ }^{190}$

Safaie-Shirazi et al. showed an increase in ionic permeability with bileacid mixtures in comparison to acidic fluid alone. ${ }^{141,191}$ This was confirmed by Kivilaakso et al. by studying the mucosal potential difference, tissue electrical resistance and, when acid was present, the tissue permeability to $\mathrm{H}^{+}$suggesting that several agents, which are usually present in gastric and duodenal juice, can increase the mucosal permeability. ${ }^{145}$ Different investigators confirmed the fact that conjugated bile salts cause damage in acidic conditions but not at a neutral $\mathrm{pH}$, suggesting that the combined acid and non-acid reflux is more harmful. ${ }^{145,149,150,188,191-195}$ As has been discussed above, acid in normal physiological situations has a limited toxic effect on esophageal mucosa in animal and humans. In combination with pepsin it can cause severe mucosal lesions. Kivilaakso demonstrated that regurgitation of pepsin and conjugated bile salts into the esophagus contributed significantly to the development of reflux esophagitis in the presence of gastric acid. ${ }^{145,196}$ Salo confirmed these findings in a rabbit model and suggested that pepsin has an effect on intercellular substances that makes that epithelial cells shed. ${ }^{197}$

Although unconjugated bile salts in normal physiological situation are present only in minimal concentration (about $2 \%$ ), it can be different in patients who have achlorhydria or are under strong acid suppressive therapy. Under these conditions small intestinal bacterial overgrowth 
may occur. ${ }^{198}$ Certain bacteria like bacteroides, clostridia and lactobacilli are capable of deconjugating bile salts. ${ }^{199,200}$ Deconjugated bile salts are strong detergent especially deoxycholate which gives cell lysis by removing membrane bound phospholipids, proteins and enzymes. ${ }^{150}$

In neutral $\mathrm{pH}$ the refluxate also contains pancreatic enzymes. The toxic effect of pancreatic enzymes in the pathogenesis of esophagitis has been suggested by Cross. ${ }^{171}$ Lysolecithin, a phospholipid formed by the hydrolytic action of a pancreatic phopho-lipase on lecithin is a powerful "barrier breaker". ${ }^{201}$ In the presence of acid the injurious effect of pancreatic enzymes to the mucosa is weak. ${ }^{145}$

DC mainly contains the pancreatic enzyme trypsin, which is inactivated at acidic $\mathrm{pH}$, whereas it can cause significant mucosal injury by proteolysis at $\mathrm{pH} 7.5$. $^{148,149}$ This was studied in a rat animal model where an esophagojejunal anastomosis was created. The study elegantly showed that mixed pancreatic and bile reflux caused the most severe esophagitis. ${ }^{202}$ These observations were confirmed in other studies. ${ }^{203,204}$ Lillemoe showed in a neutral milieu that combined trypsin and taurodeoxycholic acid produced more damage than either of the substances alone. ${ }^{149}$ Especially unconjugated bile salts enhance the damaging effect of trypsin on dog esophagus mucosa in a dose dependent fashion. ${ }^{204}$ These findings were confirmed in other animal studies. $^{92,205}$

From these studies it is suggested that the pancreatic enzyme trypsin plays a role in the mucosal lesions only in a neutral environment. Trypsin affects primarily the intercellular substances of the esophagus mucosa. ${ }^{200}$ Trypsin is also an activator of Proteinase-activated receptors (PAR-2), which have been implicated in gastrointestinal inflammation, but a role in esophagitis has not been studied yet. ${ }^{207}$

From the animal studies it can be concluded that DC has the potential to damage the mucosa both in an acidic and neutral environment. Although experimental studies in animals do not fully reflect that what happens in humans, and concentrations not always resemble the normal physiology, it has been suggested that comparable effects can be observed in the human esophagus. Therefore, studies have been conducted to investigate the hypothesis that mixed reflux is more harmful than acid reflux alone. A summary of human studies is given below.

Human studies: in vitro and in vivo

Because extrapolating animal studies to the human situation is difficult, human studies have been performed both on biopsy specimens and in vivo. 
Results of biopsy studies are conflicting: Gotley found no enhancement of the damaging effect on biopsy specimens with $\mathrm{pH} 2$ and pepsin in combination with bile salts, in physiological concentrations, suggesting that a mixture of the refluxate was not important in the toxic effect to the mucosa. ${ }^{208}$

Bateson on the other hand found no significant effect of HCL on human biopsy material in contrast to mixed pepsin and acid and bile salts and trypsin. ${ }^{209}$ Hopwood confirmed these findings showing that high concentrations of conjugated bile acids $(20 \mathrm{mmol} / \mathrm{L})$ were capable of causing cellular disruption of esophagus mucosa biopsy material in contrast to low concentrations $(0.2 \mathrm{mmol} / \mathrm{L})$. Considerable more mucosal damage was observed with the combination of conjugated bile acid at a low $\mathrm{pH}$ than with acid alone with $\mathrm{pH} 1$ and conjugated bile acids at $\mathrm{pH} 7$ which had no disruptive effect. ${ }^{210}$ In human esophagus resection material taurine and glycine conjugates at $\mathrm{pH} 7.4$ were toxic to the mucosa in a concentration of $3 \mathrm{mmol} / \mathrm{L}$. ${ }^{211}$

lonic permeability of human esophageal mucosa to hydrogen ions was significantly increased with bile acid mixtures. ${ }^{191}$ These data suggest that bile salts can cause lesions in the human mucosa, however, these experiments were not performed on the intact mucosa.

An in vivo study in patients with a hiatus hernia compared to healthy volunteers showed the occurrence of more severe symptoms when the lower esophagus was infused by acidified taurine solutions in a concentration of $1 \mathrm{mmol} / \mathrm{L}$ compared to acid fluid alone. In a concentration of $2 \mathrm{mmol} / \mathrm{L}$, the healthy volunteers experienced symptoms of heartburn. ${ }^{212}$

The question whether reflux of DC to the esophagus occurs in health or in disease requires direct measurement techniques. Several methods have been used in healthy volunteers and GERD patients.

Esophageal aspiration was one of the earliest methods to detect duodenal fluid. By continuous suction, bile salts in a concentration varying from 0.5 to $64 \mu \mathrm{mol} / \mathrm{L}$ were found in the esophageal aspirates of patients with esophagitis grade 1 or 2 (Savary and Miller classification) in contrast to healthy volunteers who had no bile salts in the aspirate. ${ }^{91}$ Mittal on the other hand found no bile acids in esophagus aspirates three hours postprandially in GERD patients. ${ }^{90}$ This was not confirmed in a study over 16 hours in GERD patients and healthy controls in which continuous aspiration revealed an increased concentration of unconjugated bile acids. $^{21}$

Two studies showed that the occurrence of bile reflux in GERD patients was significantly more frequent in comparison to healthy controls $185 \%$ versus $50 \%$ respectively). ${ }^{213,214}$ |ftikhar on the other hand found no 
difference in bile reflux between healthy volunteers and GERD patients, which included patients with a Barrett's esophagus. ${ }^{215}$ Nehra found that bile reflux occurring at variable $\mathrm{pH}$ could damage esophageal mucosal when the $\mathrm{pH}$ was above four. ${ }^{216}$ Vaezi showed that fasting gastric bile acid levels were higher in complicated versus uncomplicated Barrett's esophagus, but in both groups significantly higher compared to healthy controls. Both acid and bile reflux were increased in Barrett's esophagus ${ }^{217}$, which was confirmed in another study. ${ }^{218}$ The data are sometimes conflicting partly because the aspiration method has the disadvantage that the irritation of the tube can activate saliva secretion and swallow frequency and that the short duration of measurement limits the interpretation of the actual reflux occurring throughout the day-and nighttime.

Although DC is normally mainly present postprandially in the human stomach $^{219}$, no information is yet available about the physiological concentrations and duration of DC in the stomach. Different gastric bilirubin concentrations varying from $50-500 \mu \mathrm{mol} / \mathrm{L}$ to $20 \mathrm{mmol} / \mathrm{L}$ have been found in aspiration studies. ${ }^{210,220-224}$

With the introduction of the Bilitec" method it was possible to measure the reflux of DC continuously with a probe in an ambulatory way. Different studies were performed which are summarized.

Champion ef al. combined 24 hours $\mathrm{pH}$ and Bilitec $\mathrm{c}^{-\mathrm{s}}$ in patients with GERD, Barrett's esophagus and healthy volunteers. They observed that the mean percentage of time with a $\mathrm{pH}$ below four was longest in Barrett's esophagus, less in GERD patient and the least in controls. ${ }^{182}$ DGER was four times higher in Barrett's esophagus patients compared to GERD patients. DGER occurred in both diseased groups mainly at night. Bile acid concentration was most frequent in the Barrett group, less in the GERD group and least in the healthy volunteers. ${ }^{182}$ This was confirmed in several other combined studies. ${ }^{34,183,185,217,218,225,226}$

The majority of DGER was observed in combination with acid reflux. ${ }^{217.225,226}$ Omeprazole reduced acid and bile reflux markedly. ${ }^{182,183,225}$ From these studies it is clear that more clinical studies are needed to establish the role of DGER in reflux disease and its role in complications like Barrett's esophagus. 
Studies suggest that the occurrence of DC reflux to the esophagus is probably not infrequently in normal individuals and that DGER plays at least an additional role in the pathogenesis of esophageal mucosal lesions.

\section{Methods to investigate (duodeno-) gastro-esophageal reflux}

During the last 25 years different methods to investigate reflux to stomach and esophagus have been developed, radiography, gastroduodenoscopy, gastric- and esophageal fluid aspiration, scintigraphy, $\mathrm{pH}$ - and Bilite $\mathrm{c}^{*}$ measurement, Bernstein test and recently, intraluminal electrical impedance. ${ }^{227}$ Until now no diagnostic gold standard for the diagnosis of reflux disease exists.

Below the different methods used to investigate reflux disease are described and discussed.

\section{Barium investigation}

The barium esophagogram can be used to evaluate patients with dysphagia and GERD symptoms. It is a physiological way to study the passage of a liquid or barium mixed food bolus through the upper esophagus sphincter (UES), esophagus body, LES and stomach. It is a good way to diagnose a hiatus hernia, esophageal strictures and webs ${ }^{28}$ and gives information about reflux after provocation by abdominal straining

However, studies showed that barium investigations are of limited use in the evaluation of patients with GERD, reflux could only be demonstrated in $25.75 \%$ of symptomatic patients and false positive results were seen in $20 \%$ of normal controls. ${ }^{229}$ The most important disadvantage of the test is the fact that the study period is rather short, lasting a few seconds or minutes. No information is obtained on the different time periods during the day in combination with meals and different positions. ${ }^{230,231}$

\section{Gastro-duodenoscopy}

In the evaluation of patients suspected of having reflux disease an endoscopy is the first investigation to be carried out. It is easy to perform and a minor invasive way to diagnose the grade of esophagitis and to find complications of reflux e.g. Barrett's esophagus, esophageal stenosis and carcinoma. The Savary and Miller classification ${ }^{232}$ (Table 1.1) and 
recently the Los Angeles criteria (Table 1.2) were developed to grade the severity of reflux.

A normal endoscopy is found in up to $50 \%$ of patients with GERD symptoms ${ }^{233}$ and symptoms are often not related to the severity of the esophagitis $^{234}$ therefore additional investigations are performed in the diagnostic work-up of patients suspected to have reflux disease.

Table 1.1. Savary and Miller classification of reflux.

Grade 0: normal mucosa

Grade 1: single or isolated erosions, oval or linear, over less than $10 \%$ of the esophageal circumference

Grade 2: multiple erosions, confluent over more than $10 \%$ but less than $50 \%$ of the esophageal circumference

Grade 3: multiple erosions over more than 50\% of the esophageal circumference

Grade 4: complications of esophagitis such as ulcers, strictures or columnar-lined mucosa

Savary M, Miller G. L'oesophage. Manuel et Atlas d'Edoscopie. Solothurn, Switzerland: Verlag Gassmann, 1977.

Table 1.2. Los Angeles classification.

Grade A: one (or more) mucosal break no longer than $5 \mathrm{~mm}$ that does not extend between the tops of two mucosal folds

Grade B: one (or more) mucosal break more than $5 \mathrm{~mm}$ long, that does not extend between the tops of two mucosal folds

Grade C: one (or more) mucosal break that is continuous between the tops of two or more mucosal folds, but which involves less than $75 \%$ of the circumference

Grade D: one (or more) mucosal break, which involves at least $75 \%$ of the esophageal circumference

Gastroenterology 1996;1 11 1:85-92.

Provocative test

The infusion of $0,1 \mathrm{~N}$ hydrochloric acid into the esophagus with a saline infusion as control (Bernstein test) is used as a provocative test to prove that esophageal symptoms are due to reflux. ${ }^{235}$ In the daily practice the test is more or less abandoned because of low sensitivity and replaced by the 24 hours $\mathrm{pH}$ monitoring with a better sensitivity and specificity for reflux and symptoms.

Aspiration and scintigraphic investigations

Aspiration of gastric and esophageal content to determine the constitution of the fluid has been used in the diagnosis of reflux diseases. The aspiration 
method has the disadvantage that it cannot be performed in an ambulatory setting and that therefore the investigation is of short duration.

Another, non-invasive semi-quantitative, method which has been used in the diagnosis of reflux disease is scintigraphy. With ${ }^{99}$ 'Tc-HIDA and phenol red aspiration Tolin et al. showed a good correlation between DGER and scintigraphy ${ }^{236}$; this was confirmed in other studies. ${ }^{237,238}$ In scintigraphic studies, it was shown that DGER is a common phenomenon in normal individuals postprandially. ${ }^{31,32}$ Pathological DGER was found in patients with Barrett's esophagus ${ }^{95}$, but others found no evidence for DGER in patients with hiatus hernia and esophagitis. ${ }^{239,240}$ Liron on the other hand found with scintigraphy significant higher DGER in patients with Barrett's esophagus compared to GERD patients and healthy controls. ${ }^{247}$ Interpretation of the scintigraphy is often difficult because in about $36 \%$ overlap of small bowel and stomach occurs; making a correct interpretation of the results difficult. This method is thus not performed routinely to study DGER in daily practice. ${ }^{242}$ Other important disadvantages of this method are the rather high costs and the radiation exposure.

\section{Esophageal manometry}

Although the pull-through manometry of the esophagus with a Dent sleeve is not a diagnostic tool in the search for reflux, this method is often used to determine the position of the LES before the $\mathrm{pH}$ probe is introduced. ${ }^{243}$ Esophageal manometry gives information about the LES sphincter pressure, the esophageal peristalsis, the existence of hiatus hernia and the presence of achalasia.

\section{Esophageal 24 hours pH measurement}

The ambulatory $\mathrm{pH}$ monitoring is a widely used tool to quantitate esophageal acid exposure for clinical and research purposes. The 24 hours ambulatory $\mathrm{pH}$ monitoring is mainly used to analyze patients with typical symptoms without endoscopic abnormalities, patients refractory to standard therapy, patients in whom anti-reflux surgery is considered and patients with putative atypical symptoms and signs of reflux disease.

A uniform method has been developed; the $\mathrm{pH}$ electrode is placed $5 \mathrm{~cm}$ above the LES, which is determined manometrically and controlled by fluoroscopy. Two types of electrodes are available; the glass and the antimony $\mathrm{pH}$ electrode (Figure 1.1 A) with a separate skin reference electrode (Synectics Medical, Stockholm, Sweden). The data are stored on a portable digital recorder (Digitrapper Mk III, Synectics Medical, Stockholm, Sweden)(Figure 1.1B). Before each study, the $\mathrm{pH}$ probe is 
calibrated in buffer solutions of $\mathrm{pH} 7$ and 1. An episode of acid reflux was defined as a decrease in esophageal $\mathrm{pH}$ to 4 or below during more than 10 seconds. ${ }^{234,244}$
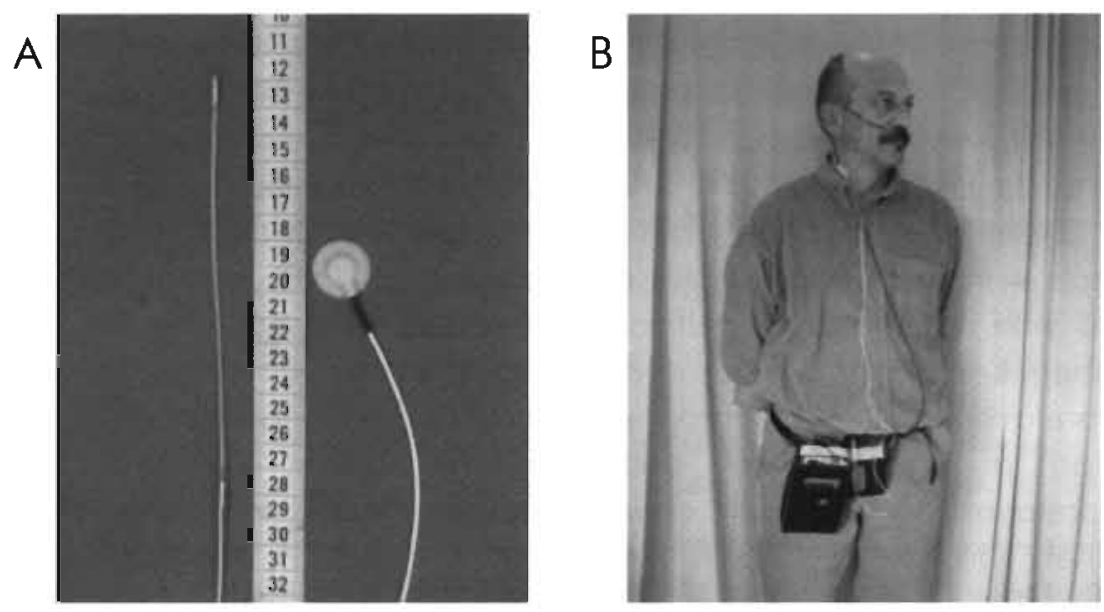

Figure 1.1. $\mathrm{pH}$-electrode and skin reference electrode (A). Patient with combined $\mathrm{pH}$ and Bilitec ${ }^{i p}$ monitoring system. Both catheters are fixed together and put into the esophagus via right nasal orifice. Recording systems are worm in a belt around the hip (B).

The collected data are read with a computer program (Synectics Medical, Stockholm, Sweden) and the data are summarized into a report with a graphic plot of the $\mathrm{pH}$ monitoring (Figure 1.2).

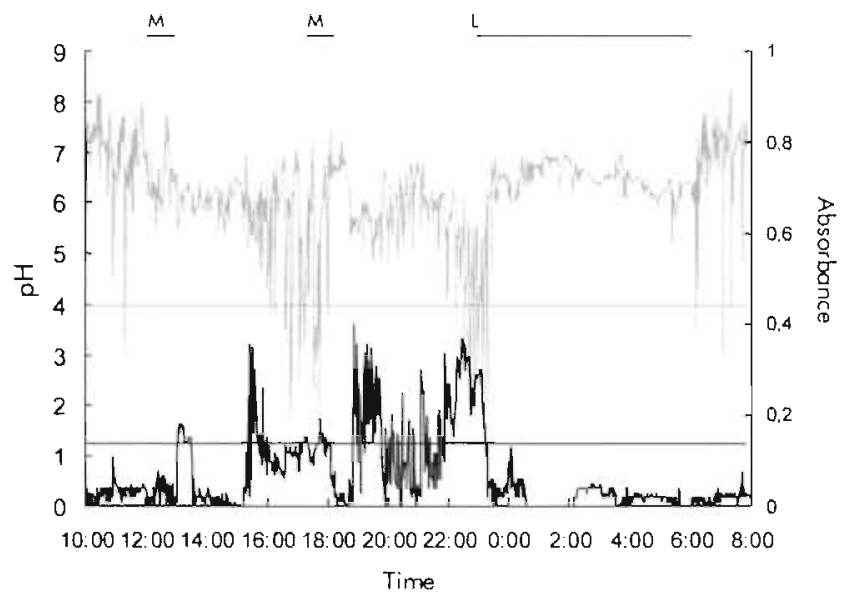

Figure 1.2. Combined 24 hours traicing: $\mathrm{pH}$ (gray line) and Bilitec (black line). $M=$ meal; $L=$ supine position. 
Different variables are assessed; percentage total time $\mathrm{pH} \leq 4$, percentage upright time $\mathrm{pH} \leq 4$, percentage recumbent time $\mathrm{pH} \leq 4$, number of reflux episodes, number of reflux episodes with $\mathrm{pH} \leq 4$ for five or more minutes and period of the longest single acid exposure episode. ${ }^{234,245,246}$ As the normal values in the literature differ strongly between centers, many authors use the values determined by the group of Demeester, which were calculated from studies in healthy volunteers. ${ }^{234}$ However, preferably each center should establish it's own normal range. In the present studies we used values of $95^{\text {th }}$ percentile, which were calculated from studies in healthy volunteers from the University Hospital Gasthuisberg Leuven Belgium (Table 1.3).

Table 1.3. Upper limits of normal values $\left(95^{\text {th }}\right.$ percentile) in healthy volunteers of the University Hospital Gasthuisberg Leuven Belgium. ${ }^{264}$

\begin{tabular}{|c|c|c|c|c|}
\hline & \multicolumn{2}{|c|}{ Percentage of time with reflux } & \multicolumn{2}{|c|}{ Reflux episodes (n) } \\
\hline & $\mathrm{PH}$ monitoring & Bilitec: & $\mathrm{PH}$ monitoring & Bilitec ${ }^{\text {is }}$ \\
\hline Total & 4.7 & 4.6 & 72.2 & 24.4 \\
\hline Upright & 5.1 & 7.8 & 71.2 & 23.4 \\
\hline Supine & 5.2 & 0.0 & 11.2 & 1.0 \\
\hline Postprandial & 7.0 & 11.8 & 16.7 & 6.1 \\
\hline
\end{tabular}

Studies have been performed to determine the sensitivity, which range from $84 \%$ to $96 \%$ and specificity that varies from $91 \%$ to $98 \%$. ${ }^{233,247-250}$

The 24 hours $\mathrm{pH}$ monitoring has its limitations with regard to GERD; in $25 \%$ of patients with normal $\mathrm{pH}$ monitoring esophagitis has been found. ${ }^{233,245,246}$ Different studies have been performed concerning the reproducibility, one showing a reproducibility of $85 \%{ }^{251}$ and another showing more variance when simultaneously measuring with two different $\mathrm{pH}$ probes. ${ }^{252}$

Alkaline episodes during esophageal $\mathrm{pH}$ monitoring do not represent non-acid reflux such as duodeno-gastro-esophageal reflux ${ }^{180}$, but are due to swallowed saliva and represent natural neutralisation. ${ }^{215,253,254}$

\section{Symptom scores}

The instruction given to patients when they start the measurement period is that they press a marker button on the portable digital recorder when they experience heartburn or the complaints they usually have. At the same time they are asked to write down the time and nature of the complaint and the periods they eat and sleep.

The relation between symptoms and reflux has been expressed in different formulas. To correlate symptoms and reflux episodes, the symptom index (SI) was the first attempt to determine a relation. The SI 
expresses the number of reflux-related symptom episodes divided by the total number of symptom episodes multiplied by $100 \%$. A SI more than $50 \%$ is pathological. ${ }^{251,255}$

The shortcoming of this method is that it does not take in account the total number of reflux episodes.

Breumelhof suggested the symptom-sensitivity index (SSI) as a better method to find an association between symptoms and reflux. ${ }^{256}$ The SSI is calculated by dividing the number of symptom-associated reflux episodes by the total number of reflux episodes multiplied by $100 \%$. A SSI value of $10 \%$ or more is positive. Unfortunately the SSI has similar shortcoming as the SI.

Therefore the "symptom association probability" (SAP) was developed. ${ }^{257}$ The SAP is calculated by dividing the 24 hours $\mathrm{pH}$ data into two minutes segments. Then for each of the two minutes segments it is determined whether reflux occurred in it and whether a symptom was reported. A $2 \times 2$ contingency table is made in which the number of two minutes segments with and without reflux and with and without symptoms are tabulated. A modified chi-square test is used to calculate the probability (P) that the observed distribution could have been brought about by chance. The SAP is calculated as $(1-P) \times 100 \%$. By statistical convention SAP values greater than $95 \%$ are positive.

\section{Esophageal 24 hours Bilitec ${ }^{(i)} 2000$ measurement}

In 1988 Baldine ef al. developed a fiber-optic spectrophotometer system (Bilitec $^{8}$ 2000, Synectics, Stockholm, Sweden) to measure bile reflux. ${ }^{258}$

The Bilitec ${ }^{(1)}$ is used to quantify DGR and DGER in an ambulatory fashion. The system consists of a miniaturized probe of $5 \mathrm{~mm}$ diameter with an open grove of $2 \mathrm{~mm}$ across which two wavelengths of light are emitted and material sampled (Figure 1.3). Bilirubin, the most common pigment in bile, has a characteristic absorbance spectrum, and by continuous monitoring of the absorbance of two light emitting diodes at two different wavelengths $(470 \mathrm{~nm}$ with a reference pulse of $565 \mathrm{~nm}$ ), the presence of bilirubin in the refluxate can be detected. The portable photodiode system converts the light into an electrical signal and after amplification, the signals are processed by an integrated microcomputer and the difference in absorption between the two diodes is calculated. The period between the two successive pulses from the same source, representing the sampling time is eight seconds. A total of 5400 sample recordings can be stored during a 24 hours period. 


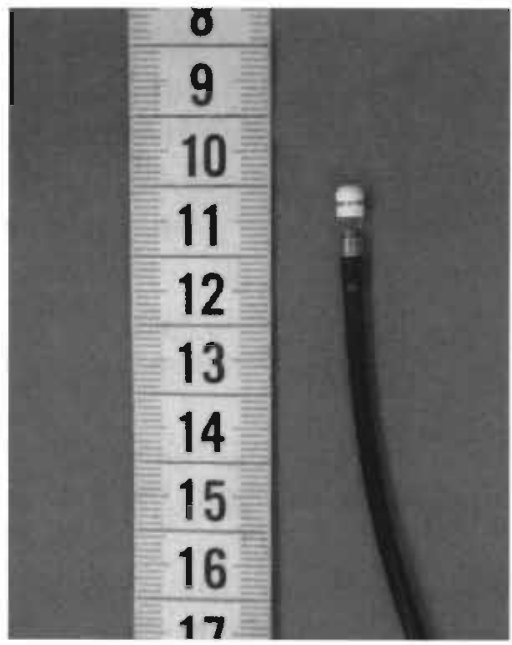

Figure 1.3. Bilitec probe: the head is made of Teflon with a length of $9.5 \mathrm{~mm}$ and 5 $\mathrm{mm}$ diameter with an open grove of $2 \mathrm{~mm}$ across which two wavelength of light are emitted (470 and $560 \mathrm{~nm}$ ).

Before each study, the probe is calibrated in water. A symptom episode of DGER is defined as an increase in esophageal bilirubin absorbance above $\geq 0.14$ for more than 10 seconds. ${ }^{258,259}$

With a computer program (Synectics Medical, Stockholm, Sweden) the following parameters are measured: percentage total time absorbance units above $\geq 0.14$; percentage upright time absorbance units $\geq 0.14$; percentage recumbent time absorbance units $\geq 0.14$; number of reflux episodes; number of reflux episodes with absorbance units $\geq 0.14$ for five or more minutes and period of the longest single DGER exposure episode ${ }^{260}$ In most patients a simultaneous $\mathrm{pH}$ and Bilitec ${ }^{80}$ measurement was performed and combined in a visual plot (Figure 1.2).

In vitro validation studies confirmed a good correlation between Bilitec ${ }^{\circ}$ measurements and bile acid concentrations ${ }^{34,258,261}$ which was confirmed in aspiration studies. ${ }^{258,261,262}$ Vaezi showed that Bilitec ${ }^{\text {(5) }}$ reading correspond to bile acid concentrations between 0.01 and $0.60 \mathrm{mM}$, but that with a pH below 3.5 the correlation was less strong and the Bilitec ${ }^{\infty}$ underestimates absorption by at least $30 \%$ probably due to the dimerisation of bilirubin, which occurs at a $\mathrm{pH}$ below 3.5. ${ }^{261}$

Although bilirubin itself is probably not the caustic agent in the duodenogastro-esophageal refluxate, its concentration has been shown to correlate well with the concentration of putative caustic factors such as bile acids and pancreatic enzymes. ${ }^{258,261}$ 
In an attempt to standardize the Bilite ${ }^{\text {E }}$ measurements, Bechi defined $\geq 0.14$ as the lowest value where the absorbance can be considered as an actual measurement of bilirubin. ${ }^{258}$ Fein et al. defined the threshold $\geq 0.25$ as the maximum absorbance measured with fluid and food, as the lowest absorbance unit avoiding most of the interference with food. ${ }^{259}$ In the patient studies performed in our hospital we used liquid meals, not interfering with the measurements. In the presented studies we used normal values, which were calculated from studies in healthy volunteers from the University Hospital Gasthuisberg Leuven Belgium, using the $95^{\text {th }}$ percentile (Table 1.3). ${ }^{263}$

The collected data are read with a computer program (Synectics Medical, Stockholm, Sweden) and put into a report with a graphic plot of the $\mathrm{pH}$ monitoring (Figure 1.2).

Different variables are assessed; percentage total time $\mathrm{pH} \leq 4$, percentage upright time $\mathrm{pH} \leq 4$, percentage recumbent time $\mathrm{pH} \leq 4$, number of reflux episodes, number of reflux episodes with $\mathrm{pH} \leq 4$ for five or more minutes and period of the longest single acid exposure episode. ${ }^{235,246,247}$ As the normal values in the literature differ strongly between centers, many authors use the values determined by the group of Demeester, which were calculated from studies in healthy volunteers. ${ }^{235}$ However, preferably each center should establish it's own normal range. In the present studies we used values of $95^{\text {th }}$ percentile, which were calculated from studies in healthy volunteers from the University Hospital Gasthuisberg Leuven Belgium (Table 1.3).

\section{Therapy}

The aim of the treatment in patients with GERD is to relieve symptoms, to heal the complications of chronic reflux like esophagitis and to prevent complications and recurrence of symptoms and lesions.

\section{Lifestyle measures}

Cornerstone in the treatment of reflux disease is modifications in the way of life. Although no controlled trials have been performed, lifestyle modifications are advised because they seem logic in the context of GERD and it has been proven that most patients are asymptomatic when they are treated with medication alone (full information at: www.Medscape.com/viewprogram/136).

The patients are advised to stop smoking ${ }^{264}$ because chronic cigarette smoking compromises LES function. During coughing it has been 
observed that the LES pressure is lower and that more sphincter relaxations take place.

Dietary restrictions are: lowering fat intake ${ }^{40}$, because high caloric diets delay gastric emptying and increase TLESRs, lowering alcohol intake, because alcohol decreases LES pressure and impairs normal esophageal clearance and to abandon eating and drinking alcoholic beverages 2-3 hours before sleeping

In proven $\mathrm{HH}$ the advice to elevate the head site of the bed with 15-20 $\mathrm{cm}$ is given although no controlled study has been performed to prove the usefulness of this advice.

Obese patients are advised to lose weight although it has not been proven that thereafter reflux disease will disappear. ${ }^{265}$

\section{Medical therapy}

At first colloidal bismuth and sucralfate that binds epidermal growth factor and elevates concentration of peptide in ulcerated areas of gastrointestinal mucosa ${ }^{266 \cdot 268}$ were given as a therapy.

Although the treatment success of $\mathrm{H}_{2}$ blockers was significantly greater than the above mentioned therapy, with the introduction of PPls, the strong acid suppressing capacity brought great relief to many GERD patients. ${ }^{269,270}$ Standard doses of different PPls have been established providing symptom relief and healing of lesions in up to $85 \%$ of patients. ${ }^{269-274}$ In a subset of patients, however, persistent reflux symptoms remained in spite of therapy with standard doses of PPIs. ${ }^{275,276,}$ In about half of the patients with persistent esophagitis and reflux symptoms in spite of standard dose PPI therapy, persisting acid reflux can be demonstrated. ${ }^{275,276}$ In a subset of patients nocturnal acid breakthrough has been observed defined as the occurrence of an intragastric $\mathrm{pH}$ lower then four during at least one hour at night. Additional suppression of nocturnal acid breakthrough can be achieved when an $\mathrm{H}_{2}$-receptorantagonist at night is added to the optimal PPI dose twice daily 271,277 , although rapid tolerance to the effect of the $\mathrm{H}_{2}$ receptorantagonist occurs. ${ }^{277}$

Although effective medical therapy is available today, in a subset of patients complaints or lesions persist under standard or high dose PPI. In this subgroup of patients another therapy is warranted. Also in young patients who do not want to take medication and in those with severe Barrett's esophagus other therapies should be searched for. New local therapies have been developed; the endoscopic suturing device: (Endocinch ${ }^{1}$ ), the temperature-controlled radiofrequency energy system $\left(\text { Stretta }{ }^{8}\right)^{278}$ and the local submucosal deposition of Ethylene-vinylalcohol implantation (Enterix ${ }^{\text {) }}$. 
The therapeutical role of these recently developed endoscopic anti-reflux procedures will require additional evaluation. ${ }^{279}$

Antireflux surgery

The antireflux surgery has improved and gained importance in the last 10 years partly because of the laparoscopic approach. Success depends on the experience of the surgeon and the correct indication. The most frequently performed procedures are the Nissen-Rosetti $\left(360^{\circ}\right)$, Toupet $\left(270^{\circ}\right)$ and Belsey Mark IV repair. The Nissen fundoplication is the most popular procedure for patients with severe therapy refractory reflux with a normally functioning esophageal body but with proven pathological reflux, insufficient LES or hiatus hernia. More recently, the efficacy of antireflux surgery in long-term reflux control and prevention of esophageal adenocarcinoma in Barrett's has been challenged. ${ }^{280,281}$

\section{Conclusion}

Although the pathological effect of acid and pepsin seems clear in the genesis of esophagitis and its complications the role of DC has to be further elucidated. DGER is probably underestimated and may play an important role in esophagitis and Barrett's esophagus. 


\section{References}

1. Brzana RJ, Koch KL. Gastroesophageal reflux disease presenting with intractable nausea. Ann Intern Med 1997;126:704-7.

2. Small PK, Loudon MA, Waldron B, Smith D, Campbell FC. Importance of reflux symptoms in functional dyspepsia. Gut 1995;36:189-92.

3. Allen ML, Castell JA, DiMarino AJ, Jr. Mechanisms of gastroesophageal acid reflux and esophageal acid clearance in heartburn patients. Am J Gastroenterol 1996;91:1739-44.

4. Micklefield $\mathrm{GH}$. [Clinical, diagnostic and pathogenetic aspects of reflux-associated cough]. Z Arztl Fortbild Qualitatssich 1998;92:195-8.

5. Woo P, Noordzii P, Ross JA. Association of esophageal reflux and globus symptom: comparison of laryngoscopy and 24-hour pH manometry. Otolaryngol Head Neck Surg 1996;115:502-7.

6. Klinkenberg-Knol EC. Otolaryngologic manifestations of gastro-oesophageal reflux disease. Scand J Gastroenterol Suppl 1998;225:24-8.

7. Spechler SJ, Zeroogian JM, Antonioli DA, Wang HH, Goyal RK. Prevalence of metaplasia at the gastro-oesophageal junction. Lancet 1994;344:1533-6.

8. Peters FT, Kleibeuker $\mathrm{JH}$. Barrett's oesophagus and carcinoma. Recent insights into its development and possible prevention. Scand J Gastroenterol Suppl 1993;200:59-64.

9. Mann NS, Tsai MF, Nair PK. Barrett's esophagus in patients with symptomatic reflux esophagitis. Am J Gastroenterol 1989;84:1494-6.

10. Field SK, Underwood M, Brant R, Cowie RL. Prevalence of gastroesophageal reflux symptoms in asthma. Chest 1996;109:316-22.

11. Ducolone A, Vandevenne A, Jouin H, Grob JC, Coumaros D, Meyer C, Burghard G, Methlin G, Hollender L. Gastroesophageal reflux in patients with asthma and chronic bronchitis. Am Rev Respir Dis 1987;135:327-32.

12. Sontag SJ, Schnell TG, Miller TQ, Khandelwal S, O'Connell S, Chejfec G, Greenlee $H$, Seidel UJ, Brand L. Prevalence of oesophagitis in asthmatics. Gut 1992;33: 872-6.

13. Kuhn J, Toohill RJ, Ullualp SO, Kulpa J, Hofmann C, Arndorfer R, Shaker R. Pharyngeal acid reflux events in patients with vocal cord nodules. Laryngoscope 1998; 108:1 146-9.

14. Jindal JR, Milbrath MM, Shaker R, Hogan WJ, Toohill RJ. Gastroesophageal reflux disease as a likely cause of "idiopathic" subglottic stenosis. Ann Otol Rhinol Laryngol 1994;103:186-91.

15. Poelmans J, Tack J, Feenstra L. Chronic middle ear disease and gastroesophageal reflux disease: a causal relation? Otol Neurotol $2001 ; 22: 447-50$. 
16. Freiie JE, Beatty TW, Campbell BH, Woodson BT, Schultz CJ, Toohill RJ. Carcinoma of the larynx in patients with gastroesophageal reflux. Am J Otolaryngol $1996 ; 17: 386-90$.

17. Koufman JA. The otolaryngologic manifestations of gastroesophageal reflux disease (GERD): a clinical investigation of 225 patients using ambulatory 24-hour $\mathrm{pH}$ monitoring and an experimental investigation of the role of acid and pepsin in the development of laryngeal injury. Laryngoscope 1991;101:1-78.

18. Gudmundsson K, Kristleifsson G, Theodors A, Holbrook WP. Tooth erosion, gastroesophageal reflux, and salivary buffer capacity. Oral Surg Oral Med Oral Pathol Oral Radiol Endod 1995;79:185-9.

19. Louis E, DeLooze D, Deprez P, Hiele M, Urbain D, Pelckmans P, Deviere J, Deltenre $M$. Heartburn in Belgium: prevalence, impact on daily life, and utilization of medical resources. Eur J Gastroenterol Hepatol 2002;14:279-84.

20. Isolauri J, Laippala P. Prevalence of symptoms suggestive of gastro-oesophageal reflux disease in an adult population. Ann Med 1995;27:67-70.

21. Bruley des Varannes S, Galmiche JP, Bernades P, Bader JP. Douleurs epigastriques et regurgitations. Epidemiologe descriptive dans un echantillon representatif de la population francaise adulte. Gastroenterol Clin Biol 1988;12:721-8.

22. Ruth M, Mansson I, Sandberg N. The prevalence of symptoms suggestive of esophageal disorders. Scand J Gastroenterol 1991;26:73-81.

23. Locke GR, Talley NJ, Fett SL, Zinsmeister AR, Melton $\amalg$. Prevalence and clinical spectrum of gastroesophageal reflux: a population-based study in Olmsted County, Minnesota. Gastroenterology 1997;112:1448-56.

24. Nebel OT, Fornes MF, Castell DO. Symptomatic gastroesophageal reflux: incidence and precipitating factors. Am J Dig Dis 1976;21:953-6.

25. Gallup survey on heartburn across America. Princeton, NJ.: The Callup Organization, Inc., 1988.

26. Thompson WG, Heaton KW. Heartburn and globus in apparently healthy people. Can Med Assoc J 1982;126:46-8.

27. Breasted JH. The Edwin Smith surgical papyrus, 1930.

28. Jackson C. Peptic ulcer of the esophagus. Jama 1929;92:369-72.

29. Weiss S, Mallory GK. Lesions of the cardiac orifice of the stomach produced by vomiting. Jama 1932;98:1353-5.

30. Winkelstein A. Peptic esophagitis. A new clinical entity. JAMA 1935;104:906-9.

31. Mackie C, Hulks G, Cuschieri A. Enterogastric reflux and gastric clearance of refluxate in normal subjects and in patients with and without bile vomiting following peptic ulcer surgery. Ann Surg 1986;204:537-42.

32. Müller-Lissner SA, Fimmel CJ, Sonnenberg A, Will N, Müller-Duysing W, Heinzel F, Müller R, Blum AL. Novel approach to quantify duodenogastric reflux in healthy volunteers and in patients with type I gastric ulcer. Gut 1983;24:510-8.

33. King PM, Pryde A, Heading RC. Transpyloric fluid movement and antroduodenal motility in patients with gastro-oesophageal reflux. Gut 1987;28:545-8. 
34. Caldwell MT, Byrne PJ, Brazil N, Crowley V, Attwood SE, Walsh TN, Hennessy TP. An ambulatory bile reflux monitoring system: an in vitro appraisal. Physiol Meas $1994 ; 15: 57-65$.

35. Williams RB, Ali GN, Wallace KL, Wilson JS, De Carle DJ, Cook IJ. Esophagopharyngeal acid regurgitation: dual $\mathrm{pH}$ monitoring criteria for its detection and insights into mechanisms. Gastroenterology 1999;117:1051-61.

36. Williams D, Thompson DG, Heggie L, Bancewicz J. Responses of the human esophagus to experimental intraluminal distension. Am J Physiol 1993;265:G196203.

37. Thompson DG, Andreollo NA, Mclntyre AS, Earlam RJ. Studies of the oesophageal clearance responses to intraluminal acid. Gut 1988;29:881-5.

38. Kahrilas PJ. Esophageal motor activity and acid clearance. Gastroenterol Clin North Am 1990; 19:537-50.

39. McCallum RW, Berkowitz DM, Lerner E. Gastric emptying in patients with gastroesophageal reflux. Gastroenterology 1981;80:285-91.

40. Penagini R, Mangano $M$, Bianchi PA. Effect of increasing the fat content but not the energy load of a meal on gastro-oesophageal reflux and lower oesophageal sphincter motor function. Gut 1998;42:330-3.

41. Zerbib F, des Varannes SB, Ropent A, Lamouliatie H, Quinton A, Galmiche IP. Proximal gastric tone in gastro-oesophageal reflux disease. Eur J Gastroenterol Hepatol 1999;11:511-5.

42. Stacher $G$, Lenglinger J, Bergmann $H$, Schneider $C$, Hoffmann $M$, Wolf $G$, StacherJanotta $G$. Gastric emptying: a contributory factor in gastro-oesophageal reflux activity? Gut 2000;47:661-6.

43. Delattre JF, Palot JP, Ducasse A, Flament JB, Hureau J. The crura of the diaphragm and diaphragmatic passage. Anat Clin 1985;4:271-83.

44. Darian GB, DiMarco AF, Kelsen SG, Supinski GS, Gotffried SB. Effects of progressive hypoxia on parasternal, costal and crural diaphragm activation. J Appl Physiol $1989 ; 66: 2579-84$.

45. Monges $H$, Salducci J, Naudy B. Dissociation between the electrical activity of the diaphragmatic dome and crura muscular fibers during esophageal distension, vomiting and eructation. An electromyographic study in the dog. J Physiol (Paris) 1978;74:541-54.

46. Altschuler SM, Boyle JT, Nixon TE, Pack Al, Cohen S. Simultaneous reflex inhibition of lower esophageal sphincter and crural diaphragm in cats. Am J Physiol 1985;249:G586-91.

47. Mittal RK. Current concepts of the antireflux barrier. Gastroenterol Clin North Am 1990;19:501-16.

48. Martin CJ, Dodds WJ, Liem HH, Dantas RO, layman RD, Dent J. Diaphragmatic contribution to gastroesophageal competence and reflux in dogs. Am J Physiol 1992;263:G551-7. 
49. Mittal RK. The crural diaphragm, an external lower esophageal sphincter: a definitive study. Gastroenterology 1993; 105:1565-7.

50. Rattan S, Goyal RK. Neural control of the lower esophageal sphincter: influence of the vagus nerves. J Clin Invest 1974;54:899-906.

51. Ryan IP, Snape WJ, Jr., Cohen S. Influence of vagal cooling on esophageal function. Am J Physiol 1977;232:E159-64.

52. Paterson WG, Anderson MA, Anand N. Pharmacological characterization of lower esophageal sphincter relaxation induced by swallowing, vagal efferent nerve stimulation, and esophageal distention. Can J Physiol Pharmacol 1992;70:1011-5.

53. Yamato S, Saha JK, Goyal RK. Role of nitric oxide in lower esophageal sphincter relaxation to swallowing. Life Sci 1992;50:1263-72.

54. Dent J. Recent views on the pathogenesis of gastro-oesophageal reflux disease. Baillieres Clin Gastroenterol 1987;1:727-45.

55. Dent J, Holloway RH, Toouli J, Dodds WJ. Mechanisms of lower oesophageal sphincter incompetence in patients with symptomatic gastroesophageal reflux. Gut 1988;29:1020-8.

56. Mittal RK, McCallum RW. Characteristics of transient lower esophageal sphincter relaxation in humans. Am J Physiol 1987;252:G636-41.

57. Holloway RH, Penagini R, Ireland AC. Criteria for objective definition of transient lower esophageal sphincter relaxation. Am J Physiol 1995;268:G128-33.

58. Franzi SJ, Martin CJ, Cox MR, Dent J. Response of canine lower esophageal sphincter to gastric distension. Am J Physial 1990;259:G380-5.

59. Holloway RH, Blank E, Takahashi I, Dodds WJ, Hogan WJ, Dent J. Variability of lower esophageal sphincter pressure in the fasted unanesthetized opossum. Am J Physiol 1985;248:G398-406.

60. Blackshaw LA, Grundy D, Scratcherd T. Involvement of gastrointestinal mechanoand intestinal chemorecepiors in vagal reflexes: an electrophysiological study. J Auton Nerv Syst 1987; 18:225-34.

61. Andrews PL, Bingham S, Wood KL. Modulation of the vagal drive to the intramural cholinergic and non-cholinergic neurones in the ferret stomach by baclofen. J Physiol 1987;388:25-39.

62. Wyman JB, Dent J, Heddle R, Dodds WJ, Toouli J, Downton J. Control of belching by the lower oesophageal sphincter. Gut 1990;31:639-46.

63. Holloway RH, Kocyan P, Dent J. Provocation of transient lower esophageal sphincter relaxations by meals in patients with symptomatic gastroesophageal reflux. Dig Dis Sci 1991;36:1034-9.

64. Dent J, Dodds WJ, Friedman RH, Sekiguchi T, Hogan WJ, Arndorfer RC, Petrie DJ. Mechanism of gastroesophageal reflux in recumbent asymptomatic human subjects. J Clin Invest 1980;65:256-67.

65. Little AF, Cox MR, Martin CJ, Dent J, Franzi SJ, Lavelle R. Influence of posture on transient lower oesophageal sphincter relaxation and gastro-esophageal reflux in the dog. J Gastroenterol Hepatol 1989;4:49-54. 
66. Powell DW, Orlando BC, Carney CN. Acid injury of the esophageal epithelium. Basic mechanism of gastrointestinal mucosal cell injury and protection. Harmon JW ed. Baltimore, William and Wilkins 1981.

67. Quigley EM, Turnberg LA. $\mathrm{pH}$ of the microclimate lining human gastric and duodenal mucosa in vivo. Studies in control subjects and in duodenal ulcer patients. Gastroenterology 1987;92:1876-84.

68. Sarosiek J, Marshall BJ, Peura DA, Hoffman S, Feng T, McCallum RW. Gastroduodenal mucus gel thickness in patients with Helicobacter pylori: a method for assessment of biopsy specimens. Am J Gastroenterol 1991;86:729-34.

69. Orlando RC, Bryson JC, Powell DW. Mechanisms of $\mathrm{H}^{+}$injury in rabbit esophageal epithelium. Am J Physiol 1984;246:G718-24.

70. Duda G, Huesken JE, Harmon JW. Effects of prostaglandins on esophageal blood flow. J Surg Res 1988;44:371-81.

71. Hamilton $\mathrm{BH}$, Orlando RC. In vivo alkaline secretion by mammalian esophagus. Gastroenterology 1989;97:640-8.

72. Namiot Z, Sarosiek J, Rourk RM, Hetzel DP, McCallum RW. Human esophageal secretion: mucosal response to luminal acid and pepsin. Gastroenterology $1994 ; 106: 973-81$

73. Meyers RL, Orlando RC. In vivo bicarbonate secretion by human esophagus. Gastroenterology 1992;103:1174-8.

74. Brown CM, Rees WD. Review article: factors protecting the oesophagus against acidmediated injury. Aliment Pharmacol Ther 1995;9:251-62.

75. De Backer A, Haentjens P, Willems G. Hydrochloric acid. A trigger of cell proliferation in the esophagus of dogs. Dig Dis Sci 1985;30:884-90.

76. Hollwarth ME, Smith M, Kvietys PR, Granger DN. Esophageal blood flow in the cat. Normal distribution and effects of acid perfusion. Gastroenterology 1986;90:622-7.

77. Zijlstra FG, Hynna-Liepert TT, Dinda PK, Beck IT, Paterson WG. Microvascular permeability increases early in the course of acid-induced esophageal injury. Gastroenterology 1991;101:295-302.

78. de Caestecker JS, Heading RC. Esophageal pH monitoring. Gastroenterol Clin North Am 1990;19:645-69.

79. Helm JF, Dodds WJ, Hogan WJ. Salivary response to esophageal acid in normal subjects and patients with reflux esophagitis. Gastroenterology 1987;93:1393-7.

80. Shaker R, Kahrilas PJ, Dodds WJ, Hogan WJ. Oesophageal clearance of small amounts of equal or less than one millilitre of acid. Gut 1992;33:7-10.

81. Olsen PS, Poulsen SS, Kirkegaard P, Nexo E. Role of submandibular saliva and epidermal growth factor in gastric cytoprotection. Gastroenterology 1984;87:103-8.

82. Orr WC, Johnson LF, Robinson MG. Effect of sleep on swallowing, esophageal peristalsis, and acid clearance. Gastroenterology 1984;86:814-9.

83. Helm JF, Dodds WJ, Hogan WJ, Soergel KH, Egide MS, Wood CM. Acid neutralizing capacity of human saliva. Gastroenterology 1982;83:69-74. 
84. Young LD, Richter JE, Anderson KO, Bradley LA, Katz PO, McElveen L, Obrecht WF, Dalion C, Snyder RM. The effects of psychological and environmental stressors on perisfaltic esophageal contractions in healthy volunteers. Psychophysiology 1987;24:132-41.

85. Schindlbeck NE, Heinrich C, Stellaard F, Paumgartner G, Müller-Lissner SA. Healthy controls have as much bile reflux as gasfric ulcer patienfs. Gut 1987;28:1577-83.

86. Capper WM. Factors in the pathogenesis of gastric ulcer. Hunterian lecture delivered at the Royal College of Surgeons of England on 18th January 1966. Ann R Coll Surg Engl 1967;40:21-35.

87. DuPlessis DJ. Pathogenesis of gastric ulceration. Lancet 1965;1:974.

88. Miwa K, Hattori T, Miyazaki I. Duodenogastric reflux and foregut carcinogenesis. Cancer 1995;75:1426-32.

89. Mason RC, Taylor PR, Rowe. PH, Aston NO, Filipe MI, Owen WJ. Genesis of gastric stump carcinoma. Lancet 1986;1:1381.

90. Mittal RK, Reuben A, Whitney JO, McCallum RW. Do bile acids reflux into the esophagus? A study in normal subjects and patients with gastroesophageal reflux disease. Gastroenterology 1987;92:371-5.

91. Johnsson F, Joelsson B, Floren $\mathrm{CH}$, Nilsson A. Bile salts in the esophagus of patients with esophagitis. Scand J Gastroenterol 1988;23:712-6.

92. Moffat RC, Berkas EM. Bile esophagifis. Arch Surg 1965;91:963-6.

93. Little AG, Martinez El, DeMeester TR, Blough RM, Skinner DB. Duodenogastric reflux and reflux esophagitis. Surgery 1984;96:447-54.

94. Iftikhar SY, Ledingham S, Steele RJ, Evans DF, Lendrum K, Atkinson M, Hardcastle JD. Bile reflux in columnar-lined Barrett's oesophagus. Ann R Coll Surg Engl 1993;75:411-6.

95. Waring JP, Legrand J, Chinichian A, Sanowski RA. Duodenogastric reflux in patients with Barrett's esophagus. Dig Dis. Sci 1990;35:759-62.

96. Pera M, Trastek VF, Caipenter HA, Fernandez PL, Cardesa A, Mohr U, Pairolero PC. Influence of pancreatic and biliary reflux on the development of esophageal carcinoma. Ann Thorac Surg 1993;55:1386-92.

97. Attwood SE, Ball CS, Barlow AP, Jenkinson L, Norris TL, Watson A. Role of intragastric and intraoesophageal alkalinisation in the genesis of complications in Barrett's columnar lined lower oesophagus. Gut 1993;34:11-5.

98. Berstad A, Weberg R, Froyshov Larsen I, Hoel B, Haver-Jensen M. Relationship of hiatus hernia to reflux oesophagitis. A prospective study of coincidence, using endoscopy. Scand J Gastroenterol 1986;21:55-8.

99. Sontag SJ, Schnell TG, Miller TQ, Nemchausky B, Serlovsky R, O'Connell S, Cheifec G, Seidel UJ, Brand L. The importance of hiatal hernia in reflux esophagitis compared with lower esophageal sphincter pressure or smoking. J Clin Gastroenterol 1991;13:628-43.

100. Wright RA, Hurwitz AL. Relationship of hiatal hernia to endoscopically proved reflux esophagitis. Dig Dis Sci 1979;24:311-3. 
101. OH DJ, Gelfand DW, Chen YM, Wu WC, Munitz HA. Predictive relationship of hiatal hernia to reflux esophagitis. Gastrointest Radiol 1985;10:317-20.

102. Kaul B, Petersen H, Grette K, Myrvold HE. Reproducibility of gasfroesophageal reflux scintigraphy and the standard acid reflux test. Scand J Gastroenterol 1986;21: 795-8.

103. Sloan S, Rademaker AW, Kahrilas PJ. Determinants of gastroesophogeal junction incompetence: hiatal hernia, lower esophageal sphincter, or both? Ann Intern Med $1992 ; 117: 977-82$.

104. Petersen $H_{\text {s }}$ Johannessen T, Sandvik AK, Kleveland PM, Brenna $E_{\text {, Waldum }} H_{\text {, }}$ Dybdahl JD. Relationship between endoscopic hiafus hernia and gastroesophageal reflux symptoms. Scand J Gastroenterol 1991;26:921-6.

105. Patti MG, Goldberg HI, Arcerito M, Bortolasi L, Tong J, Way LW. Hiaial hernia size. affects lower esophageal sphincter function, esophageal acid exposure, and the degree of mucosal injury. Am J Surg 1996;171:182-6.

106. DeMeester TR, Lafontaine E, Joelsson BE, Skinner DB, Ryan JW, O'Sullivan GC, Brunsden BS, Johnson LF. Relationship of a hiatal hernia to the function of the body of the esophagus and the gastroesophageal junction. J Thorac Cardiovasc Surg 1981;82:547-58.

107. Kasapidis P, Vassilakis JS, Tzovaras G, Chrysos E, Xynos E. Effect of hiatal hernia on esophageal manometry and $\mathrm{pH}$-metry in gastroesophageal reflux. disease. Dig Dis Sci 1995;40:2724-30.

108. Kahrilas PJ, Lin S, Chen J, Manka M. The effect of hiatus hernia on gastro. oesophageal junction pressure. Gut 1999;44:476-82.

109. van Herwaarden MA, Katzka DA, Smout AJ, Samsom M, Gideon M, Casfell DO. Effect of different recumbent positions on postprandial gastroesophageal reflux in norrnal subjects. Am J Gastroenterol 2000;95:2731-6.

110. Kahrilas PJ. The role of hiatus hernia in GERD. Yale J Biol Med 1999;72:101-11.

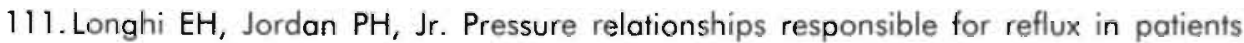
with hiafal hernia. Surg Gynecol Obstet 1969;129:734-48.

112. Mittal RK, Chiareli C: Liu J, Shaker R. Characteristics of lower esophageal sphincter relaxation induced by pharyngeal stimulation with minute amounis of water. Gastroenterology 1996;1 11:378-84.

113. Mittal RK, Shaffer HA, Parollisi S, Baggeit L. Influence of breathing pattern on the. esophagogastric junction pressure and esophageal transit. Am J Physiol 1995;269:G577-83.

114. Sloane PM, Griffin JF, O'Dwryer TP, Griffin JM. Esophageal insufflation and videofluoroscopy for evaluation of esophageall speech in laryngectomy patients: clinical implications. Radiology 1991;181:433-7.

115. Mittal RK, Holloway R, Dent J. Effect of atropine on the frequency of reflux and transient lower esophageal sphincter relaxation in normal subjects. Gastroenterology 1995;109:1547-54 
116. Schoeman MN, Tippett MD, Akkermans LM, Dent J, Holloway RH. Mechanisms of gastroesophageal reflux. in ambulant healthy human subjects. Gastroenterology 1995; 108:83-91.

117. Trudgill NJ, Riley SA. Transient lower esophageal sphincter relaxations are no more frequent in patients with gastroesophageal reflux disease than in asymptomatic volunteers. Am J Gastroenterol 2001;96:2569-74.

118. Sifrim D, Holloway R, Silny J, Tack J, Lerut A, Janssens J. Composition of the postprandial refluxate in patients with gastroesophageal reflux disease. Am J Gastroenterol 2001;96:647-55.

119. Mittal RK, Rochester DF, McCallum RW. Electrical and mechanical activity in the human lower esophageal sphincter during diaphragmatic contraction. J Clin Invest 1988;81:1182-9.

120. Dodds WJ, Dent J, Hogan WJ, Helm JF, Hauser R, Parel GK, Egide MS. Mechanisms of gastroesophageal reflux in patients with reflux esophagitis. $\mathrm{N}$ Engl J Med 1982;307:1547-52.

121. Gotley DC, Morgan AP, Cooper MJ. Bile acid concentrations in the refluxate of patients with reflux oesophagitis. Br J Surg 1988;75:587-90.

122. Freidin N, Mittal RK, MCCallum RW. Does body posture affect the incidence and mechanism of gastro-oesophageal reflux? Gut 1991;32:133-6.

123. Cucchiara S, Bortolotti M, Minella R, Auricchio S. Fasting and postprandial mechanisms of gastroesophageal reflux in children with gastroesophageal reflux disease. Dig Dis Sci 1993;38:86-92.

124. Penagini R, Bartesaghi B, Bianchi PA. Importance of oesophageal manometry in the diagnosis of oesophageal motility disorders. Report of two cases. Panminerva Med $1992 ; 34: 81-4$.

125. Penagini R, Hebbard G, Horowitz M, Denł J, Bermingham H, Jones K, Holloway RH. Motor function of the proximal stomach and visceral perception in gastrooesophageal reflux disease. Gut 1998;42:251-7.

126. Estevao-Costa J, Campos M. Dias JA, Trindade E, Medina AM, Carvalho JL. Delayed gastric emptying and gastroesophageal reflux: a pathophysiologic relationship. J Pediatr Gastroenterol Nutr 2001;32:471-4.

127. Pehl C, Waizenhoefer A, Wendl B, Schmidt T, Schepp W, Pfeiffer A. Effect of low and high fat meals on lower esophageal sphincter motility and gastroesophageal reflux in heaithy subjects. Am J Gastroenterol 1999;94:1 192-6.

128. Holloway RH, Hongo M, Berger K, McCallum RW. Gastric distention: a mechanism for postprandial gastroesophageal reflux. Gastroenterology 1985;89:779-84.

129. Mittal RK, Holloway RH, Penagini R, Blackshaw LA, Dent J. Transient lower esophageal sphincter relaxation. Gastroenterology 1995;109:601-10.

130. Dent J, Dodds WJ, Hogan WJ, Toouli J. Factors that influence induction of gastroesophageal reflux in normal human subjects. Dig Dis Sci 1988;33:270-5.

131. Kahrilas PJ, Dodds WJ, Dent J, Wyman JB, Hogan WJ, Arndorfer RC. Upper esophageal sphincter function during belching. Gastroenterology 1986;91:133-40. 
132. Penagini R, Bartesaghi B, Bianchi PA. Effect of cold stress on postprandial lower esophageal sphincter competence and gastroesophageal reflux in hecilthy subjects. Dig Dis Sci 1992;37:1200-5.

133. Kahrilas PJ, Dodds WJ, Hogan WJ, Kern M, Arndorfer RC, Reece A. Esophageal peristaltic dysfunction in peptic esophagitis. Gastroenterology 1986;91:897-904.

134. Liu J, Pehlivanov N, Mittal RK. Baclofen blocks LES relaxation and crural diaphragm inhibition by esophageal and gastric distension in cats. Am J Physiol Gastrointest Liver Physiol 2002;283:G1276-81.

135. Staunton E, Smid SD, Dent J, Blackshaw LA. Triggering of transient LES relaxations in ferrets: role of sympathetic pathways and effects of baclofen. Am J Physiol Gastrointest Liver Physiol 2000;279:G157-62.

136. Lehmann A, Antonsson M, Bremner-Danielsen M, Flardh M, Hansson-Branden L, Karrberg L. Activation of the GABA(B) receptor inhibits transient lower esophageal sphincter relaxations in dogs. Gastroenterology 1999;117:1147-54.

137. Wiersma HE, Van Boxtel CJ, Butter JJ, Van Aalderen WM, Omari T, Benninga MA. Pharmacokinetics of a single oral dose of baclofen in pediatric patients with gastroesophageal reflux disease. Ther Drug Monit 2003;25:93-8.

138. Kiroff GK, Maddern GJ, Jamieson GG. A study of factors responsible for the efficacy of fundoplication in the treatment of gastro-oesophageal reflux. Aust $N Z J$ Surg 1984;54:109-12.

139. Strombeck DR, Griffin DW, Harrold D. Eructation of gas through the gastroesophageal sphincter before and after limiting distension of the gastric cardio or infusion of a beta-adrenergic amine in dogs. Am J Vet Res 1989;50:751-3.

140. Chung RS, Magri J, DenBesten L. Hydrogen ion transport in the rabbit esophagus. Am J Physiol 1975;229:496-500.

141. Chung RS, Johnson GM, Denbesten L. Effect of sodium taurocholate and ethanol on hydrogen ion absorption in rabbit esophagus. Am J Dig Dis 1977;22:582-8.

142. Gillison EW, Nyhus LM, Kusakari K. The nature of the reflux material in reflux oesophagitis. Br J Surg 1972;59:300.

143. Safaie-Shirazi S. Effect of pepsin on ionic permeability of canine esophageal mucosa. J Surg Res 1977;22:5-8.

144. Goldstein JL, Schlesinger PK, Mozwecz HL, Layden TJ. Esophageal mucosal resistance. A factor in esophagitis. Gastroenterol Clin North Am 1990; 19:565-86.

145. Kivilaakso E, Fromm D, Silen W. Effect of bile salts and related compounds on isolated esophageal mucosa. Surgery 1980;87:280-5.

146. Casten DF. Peptic esophagitis, hiatal hernia, and duodenal ulcer. A unified concept. Am J Surg 1967;113:638-41.

147. Goldberg HI, Dodds WJ, Gee S, Montgomery C, Zboralske FF. Role of acid and pepsin in acute experimental esophagitis. Gastroenterology 1969;56:223-30.

148. Lillemoe KD, Gadacz TR, Harmon JW. Bile absorption occurs during disruption of the esophageal mucosal barrier. J Surg Res 1983;35:57-62. 
149. Lillemoe KD, Johnson LF, Harmon JW. Role of the components of the gastroduodenal contents in experimental acid esophagitis. Surgery 1982;92: 276.84 .

150. Salo JA, Kivilaakso E. Role of bile salts and trypsin in the pathogenesis of experimental alkaline esophagitis. Surgery 1983;93:525-32.

151. Hirschowitz BI. A critical analysis, with appropriate controls, of gastric acid and pepsin secretion in clinical esophagitis. Gastroenterology 1991;101:1149-58.

152. Tobey NA, Reddy SP, Khalbuss WE, Silvers SM, Cragoe EJ, Jr., Orlando RC. $\mathrm{Na}^{+}$. dependent and -independent $\mathrm{Cl} / \mathrm{HCO}_{3}$ - exchangers in cultured rabbit esophageal epithelial cells. Gastroenterology 1993;104:185-95.

153. Tobey NA, Orlando RC. Mechanisms of acid injury to rabbit esophageal epithelium. Role of basolateral cell membrane acidification. Gastroenterology 1991;101: 1220-8.

154. Spechler SJ. Epidemiology and natural history of gastro-oesophageal reflux disease. Digestion 1992;51 Suppl 1:24-9.

155. Brunnen PL, Karmody AM, Needham CD. Severe peptic oesophagitis. Gut $1969 ; 10: 831-7$.

156. Helm JF, Dodds WJ, Riedel DR, Teeter BC, Hogan WJ, Arndorfer RC. Determinants of esophageal acid clearance in normal subjects. Gastroenterology 1983;85: 607.12.

157. Stanciu C, Bennett JR. Oesophageal acid clearing: one factor in the production of reflux oesophagitis. Guł 1974;15:852-7.

158. Kahrilas PJ, Dodds WJ, Dent J, Logemann JA, Shaker R. Upper esophageal sphincter function during deglutition. Gastroenterology 1988;95:52-62.

159. Schoeman MN, Holloway RH. Integrity and characteristics of secondary oesophageal peristalsis in patients with gastro-oesophageal reflux disease. Gut 1995;36:499-504.

160. Sonnenberg A, Steinkamp U, Weise A, Berges W, Wienbeck M, Rohner HG, Peter P. Salivary secretion in reflux esophagitis. Gastroenterology 1982;83:889-95.

161. Shay SS, Bomeli S, Richter J. Multichannel intraluminal impedance accurately detects fasting, recumbent reflux events and their clearing. Am J Physiol Gastrointest Liver Physiol 2002;283:G376-83.

162. Hirschowitz BI. Gastric acid and pepsin secretion in patients with Barrett's esophagus and appropriate controls. Dig Dis Sci 1996;41:1384-91.

163. Collen MJ, Lewis JH, Benjamin SB. Gastric acid hypersecretion in refractory gastroesophageal reflux disease. Gastroenterology 1990;98:654-61.

164. Cadiol G, Bruhat A, Rigaud D, Coste T, Vuagnat A, Benyedder Y, Vallot T, Le Guludec D, Mignon M. Multivariate analysis of pathophysiological factors in reflux oesophagitis. Gut 1997;40:167-74.

165. Miller LS, Vinayek R, Frucht H, Gardner JD, Jensen RT, Maton PN. Reflux esophagitis in patients with Zollinger-Ellison syndrome. Gastroenterology 1990;98:341-6. 
166. Fletcher J, Wirz A, Young J, Vallance R, McColl KE. Unbuffered highly acidic gastric juice exists at the gastroesophageal junction after a meal. Gastroenterology $2001 ; 121: 775-83$.

167. Kuiken S, Van Den Elzen B, Tytgat G, Bennink R, Boeckxstaens G. Evidence for pooling of gastric secretions in the proximal stomach in humans using single photon computed tomography. Gastroenterology 2002;123:2157-8.

168. Washington N, Moss HA, Washington C, Greaves IL, Steele RJ, Wilson CG. Noninvasive detection of gastro-oesophageal reflux using an ambulatory system. Gut 1993;34:1482-6.

169. Wright J, Evans D, Gowland P, Mansfield P. Validation of antroduodenal motility measurements made by echo-planar magnetic resonance imaging. Neurogastroenterol Motil 1999;11:19-25.

170. Katz PO. Review article: the role of non-acid reflux in gastro-oesophageal reflux disease. Aliment Pharmacol Ther 2000;14:1539-51.

171. Cross F, Wagensteen $O$. Role of bile and pancreatic juice in production of oesophageal erosions and anemia. Proc Soc Exper Biol Med 1951;77: 862-6.

172. Helsingen N. Esophagitis following total gastrectomy. Acta Chir Scand $1959 ; 118: 190201$.

173. Palmer ED. Subacute erosive peptic esophagitis associated with achlorhydria. NEJM 1960;262:9279.

174. Morrow D, Passaro ER, Jr. Alkaline reflux esophagitis after total gastrectomy. Am J Surg 1976;132:287-91.

175. Matikainen $M$, Laatikainen T, Kalima T, Kivilaakso $E$. Bile acid composition and esophagitis after total gastrectomy. Am J Surg 1982;143:196-8.

176. Orlando RC, Bozymski EM. Heartburn in pernicious anemia--a consequence of bile reflux. N Engl J Med 1973;289:522-3.

177. Gotley DC, Morgan AP, Ball D, Owen RW, Cooper MJ. Composition of gastrooesophageal refluxate. Gut 1991;32:1093-9.

178. Stein HJ, Barlow AP, DeMeester TR, Hinder RA. Complications of gastroesophageal reflux disease. Role of the lower esophageal sphincter, esophageal acid and acid/alkaline exposure, and duodenogasłric reflux. Ann Surg 1992;216:35-43.

179. Lin KM, Ueda RK, Hinder RA, Stein HJ, DeMeester TR. Etiology and importance of alkaline esophageal reflux. Am J Surg 1991;162:553-7.

180. Attwood SE, DeMeester TR, Bremner CG, Barlow AP, Hinder RA. Alkaline gastroesophageal reflux: implications in the development of complications in Barrett's columnar-lined lower esophagus. Surgery 1989;106:764-70.

181. Mattioli S, Pilotti V, Felice V, Lazzari A, Zannoli R, Bacchi ML, Loria P, Tripodi A, Gozzetti G. Ambulatory 24-hr pH monitoring of esophagus, fundus, and antrum. A new technique for simultaneous study of gastroesophageal and duodenogastric reflux. Dig Dis Sci 1990;35:929-38. 
182. Champion G, Richter JE, Vaezi MF, Singh S, Alexander R. Duodenogastroesophageal reflux: relationship to $\mathrm{pH}$ and importance in Barrett's esophagus. Gastroenterology 1994; 107:747-54.

183. Caldwell MT, Lawlor P, Byrne PJ, Walsh TN, Hennessy TP. Ambulatory oesophageal bile reflux monitoring in Barrett's oesophagus. Br J Surg 1995;82:657-60.

184. Kaver WK, Peters JH, DeMeester TR, Ireland AP, Bremner CG, Hagen JA. Mixed reflux of gastric and duodenal juices is more harmful to the esophagus than gastric juice alone. The need for surgical therapy re-emphasized. Ann Surg 1995;222:52531.

185. Vaezi MF, Richter JE. Role of acid and duodenogastroesophageal reflux in gastroesophageal reflux disease. Gastroenterology 1996;111:1192-9.

186. Miettinen TA, Siurala M. Bile salts, sterols, sterol esters, glycerides and fatty acids in micellar and oil phases of intestinal contents during fat digestion in man. Z Klin Chem Klin Biochem 1971;9:47-52.

187. Schweitzer EJ, Bass BL, Batzri S, Harmon JW. Bile acid accumulation by rabbit esophageal mucosa. Dig Dis Sci 1986;31:1105-13.

188. Schweitzer EJ, Harmon JW, Bass BL, Batzri S. Bile acid efflux precedes mucosal barrier disruption in the rabbit esophagus. Am J Physiol 1984;247:G480-5.

189. Batzri S, Harmon JW, Schweitzer EJ, Toles R. Bile acid accumulation in gastric mucosal cells. Proc Soc Exp Biol Med 1991;197:393-9.

190. Biancani P, Walsh JH, Behar J. Vasoactive intestinal polypeptide. A neurotransmitter for lower esophageal sphincter relaxation. J Clin Invest 1984;73:963-7.

191. Safaie-Shirazi S, DenBesten L, Zike WL. Effect of bile salts on the ionic permeability of the esophageal mucosa and their role in the production of esophagitis. Gastroenterology 1975;68:728-33.

192. Henderson RD, Mugashe F, Jeejeebhoy KN, Cullen J, Szczepanski M, Boszko A, Marryatt $G$. The role of bile and acid in the production of esophagitis and the motor defect of esophagitis. Ann Thorac Surg 1972;14:465-73.

193. Harmon JW, Johnson LF, Maydonovitch CL. Effects of acid and bile salts on the rabbit esophageal mucosa. Dig Dis Sci 1981;26:65-72.

194. Kidder GW, 3rd, Lillemoe KD, Harmon JW, Maydonovitch CL, Bunte RM, Johnson LF. Evaluation of in vivo measurement of transesophageal electrical resistance as an indicator of early experimental esophageal mucosal injury. J Lab Clin Med 1983; 102:477-86.

195. Kiroff GK, Devitt PG, DeYoung NJ, Jamieson GG. Bile salt-induced injury of rabbit oesophageal mucosa measured by hydrogen ion disappearance. Ausł $N Z 」$ Surg 1987;57:111-7.

196. Kivilaakso E, Fromm D, Silen W. Effect of bile salts and related compounds on esophageal mucosa. Scand J Gastroenterol Suppl 1981;67:119-21.

197. Salo JA, Lehto VP, Kivilaakso E. Morphological alterations in experimental esophagitis. Light microscopic and scanning and transmission electron microscopic study. Dig Dis Sci 1983;28:440-8. 
198. Stockbrügger RW, Cotton PB, Eugenides N, Bartholomew BA, Hill MJ, Walters CL. Intragastric nitrites, nitrosamines, and bacterial overgrowth during cimetidine treatment. Gut 1982;23:1048-54.

199. Drasar BS, Hill MJ, Shiner M. The deconjugation of bile salts by human intestinal bacteria. Lancet 1966; 1:1237-8.

200. Gorbach SL, Tabaqchali S. Bacteria, bile, and the smail bowel. Gut 1969;10: 963-72.

201. Duane WC, Wiegand DM. Mechanism by which bile salt disrupts the gastric mucosal barrier in the dog. I Clin Invest 1980;66:1044-9.

202. Lambert R. Relative importance of biliary and pancreatic secretions in the genesis of esophagitis in rats. Am J Dig Dis 1962;7;1026-33.

203. Mud HJ, Kranendonk SE, Obertop H, Van Houten H, Westbroek DL. Active trypsin and reflux oesophagitis: an experimental study in rats. Br J Surg 1982;69:269-72.

204. Salo JA, Kivilaakso E. Contribution of trypsin and cholate to the pathogenesis of experimental alkaline reflux esophagitis. Scand J Gastroenterol 1984;19:875-81.

205. Gillison EW, De Castro VA, Nyhus LM, Kusakari K, Bombeck CT. The significance of bile in reflux esophagitis. Surg Gynecol Obstet 1972;134:419-24.

206. Shimono M, Clementi F. Intercellular junctions of oral epithelium. II. Ultrastructural changes in rat buccal epithelium induced by trypsin digestion. J Ultrastruct Res 1977;59:101-12.

207. Cenac N, Coelho AM, Nguyen C, Compton S, Andrade-Gordon P, MacNaughton WK, Wallace IL, Hollenberg MD, Bunnett NW, Garcia-Villar R, Bueno L, Vergnolle $N$. Induction of intestinal inflammation in mouse by activation of proteinaseactivated receptor-2. Am J Pathol 2002;161:1903-15.

208. Gotley DC, Flaks B, Cooper MJ. Bile acids do not modify the effects of pepsin on the fine structure of human oesophageal epithelium. Aust N Z J Surg 1992;62:569-75.

209. Bateson MC, Hopwood D, Milne G, Bouchier IA. Oesophageal epithelial ultrastructure after incubation with gastrointestinal fluids and their components. I Pathol $1981 ; 133: 33-51$.

210. Hopwood D, Bateson MC, Milne G, Bouchier IA. Effects of bile acids and hydrogen ion on the fine structure of oesophageal epithelium. Gut 1981;22:306-11.

211. Bachir GS, Collis JL, Joffe SN. The toxicity of bile salt conjugates on human esophageal epithelium grown in tissue culture. J Surg Res 1982;32:547-54.

212. Bachir GS, Collis JL. Effect of perfusion of bile salts solutions into the oesophagus of hiatal hernia patients and controls. Thorax 1976;31:271-7.

213. Fiorucci S, Distrutti E, Di Matteo F, Brunori P, Santucci L, Mallozzi E, Bigazzi U, Morelli A. Circadian variations in gastric acid and pepsin secretion and intragastric bile acid in patients with reflux esophagitis and in healthy controls. Am J Gastroenterol 1995;90:270-6.

214. Kaver WK, Peters JH, DeMeester TR, Feussner H, Ireland AP, Stein HJ, Siewer RJ. Composition and concentration of bile acid reflux into the esophagus of patients with gastroesophageal reflux disease. Surgery 1997;122:874-81. 
215. Iftikhar SY, Ledingham S, Evans DF, Yusuf SW, Steele RI, Atkinson M, Hardcastle JD. Alkaline gastro-oesophageal reflux: dual probe $\mathrm{pH}$ monitoring. Gut 1995;37: 465-70.

216. Nehra D, Howell P, Williams CP, Pye JK, Beynon J. Toxic bile acids in gastrooesophageal reflux disease: influence of gastric acidity. Gut 1999;44:598-602.

217. Vaezi MF, Richter JE. Synergism of acid and duodenogastroesophageal reflux in complicated Barrett's esophagus. Surgery 1995;117:699-704.

218. Stein HJ, Feussner H, Kaver W, DeMeester TR, Siewert JR. Alkaline gastroesophageal reflux: assessment by ambulatory esophageal aspiration and $\mathrm{pH}$ monitoring. Am J Surg 1994;167:163-8.

219. Muller-Lissner SA, Baverfeind P, Blum AL. Bile in the stomach. Gastroenteral Clin Biol 1985;9:72-9.

220. Rhodes J, Barnardo DE, Phillips SF, Rovelstad RA, Hofmann AF. Increased reflux of bile into the stomach in patients with gastric ulcer. Gastroenterology 1969;57: 241-52.

221. Poxon V, Hogg B, Youngs D, Morris DL, Keighley MR. Incidence of bile reflux in gastric ulcer and after partial gastrectomy. Br J Surg 1986;73:295-7.

222. Goldner FH, Boyce HW, Jr. Relationship of bile in the stomach to gastritis. Gastrointest Endosc 1976;22:197-9.

223. Dewar $P$, King $R$, Johnston D. Bite acid and lysolecithin concentrations in the stomach in patients with duodenal ulcer before operation and after treatment by highly selective vagotomy, partial gastrectomy, or truncal vagotomy and drainage. Gut 1982;23:569-77.

224. Crumplin MK, Stol DW, Murphy GM, Collis JL. The pattern of bile salt reflux and acid secretion in sliding hiatal hernia. Br J Surg 1974;61:611-6.

225. Kaver WK, Burdiles P, Ireland AP, Clark GW, Peters JH, Bremner CG, DeMeester TR. Does duodenal juice reflux into the esophagus of patients with complicated GERD? Evaluation of a fiberoptic sensor for bilirubin. Am J Surg 1995; 169:98-103

226. Vaezi MF, Singh S, Richter JE. Role of acid and duodenogastric reflux in esophageal mucasal injury: a review of animal and human studies. Gastroenterology 1995; 108:1897.907.

227. Sifrim D, Holloway R, Silny J, Xin Z, Tack J, Leruł A, Janssens J. Acid, nonacid, and gas reflux in patients with gastroesophageal reflux disease during ambulatory 24 hour $\mathrm{pH}$-impedance recordings. Gastroenterology 2001;120:1588-98.

228. Chen YM, OHt DJ, Gelfand DW, Munitz HA. Multiphasic examination of the esophagogastric region for strictures, rings, and hiatal hernia: evaluation of the individual techniques. Gastrointest Radial 1985;10:311-6.

229. DeVault KR, Achem SR. Functional Gastroesophageal Reflux Disease (GERD). Curr Treat Options Gastroenterol 2000;3:295-302.

230. Johnston BT, Troshinsky MB, Castell JA, Castell DO. Comparison of barium radiology with esophageal $\mathrm{pH}$ monitoring in the diagnosis of gastroesophageal reflux disease. Am J Gastroenterol 1996;91:1181-5. 
231. Chen MY, OH DJ, Sinclair JW, WU WC, Gelfand DW. Gastroesophageal reflux. disease: correlation of esophageal $\mathrm{pH}$ resting and radiographic findings. Radiology 1992;185:483-6.

232. Savary M, Miller G. L'oesophage. Manuel eł Atlas d'endoscopie. Gassmann Verlag, 1977.

233. Johnsson F, Joelsson B, Gudmundsson K, Greiff L. Symptoms and endoscopic findings in the diagnosis of gastroesophageal reflux disease. Scand J Gastroenterol $1987 ; 22: 714-8$.

234. Johnson LF, Demeester TR. Twenty-four-hour $\mathrm{pH}$ monitoring of the distal esophagus. A quantitative measure of gastroesophageal reflux. Am J Gastroenterol 1974;62: 325-32.

235. Bernstein LM, Baker LA. A clinical test for esophagitis. Gastroenterology 1958; $34: 760$.

236. Tolin RD, Malmud LS, Reilley J, Fisher RS. Esophageal scintigraphy to quantitate esophageal transit (quantitation of esophageal transit). Gastroenterology 1979;76:1402-8.

237. Houghton PW, Mortensen NJ, Thomas WE, Cooper MJ, Morgan AP, Davies ER. Intragastric bile acids and scintigraphy in the assessment of duodenogastric reflux. $\mathrm{Br}\lrcorner$ Surg 1986;73:292-4.

238. Eriksson B, Emas S, Jacobsson H, Larsson SA, Samuelsson K. Comparison of gastric aspiration and HIDA scintigraphy in detecting fasting duodenogastric bile reflux. Scand J Gastroenterol 1988;23:607-10.

239. Matikainen $M$, Taavitsainen $M$, Kalima TV. Duodenogastric reflux in patients with heartburn and oesophagitis. Scand J Gastroenterol 1981;16:253-5.

240. Krog M, Gustavsson S, Jung B. Studies on oesophagitis--no evidence for pyloric incompetence as a primary etiological factor. a scintigraphic study with $99 \mathrm{Tcm}$ Solco-HIDA. Acta Chir Scand 1982;148:439-42.

241. Liron R, Parrilla P, Martinez de Haro LF, Ortiz A, Robles R, Lujan JA, Fuente T, Andres B. Quantification of duodenogastric reflux in Barrett's esophagus. Am J Gastroenterol 1997;92:32-6.

242. Drane WE, Karvelis K, Johnson DA, Silverman ED. Scintigraphic evaluation of duodenogastric reflux. Problems, piffalls, and technical review. Clin Nucl Med 1987; 12:377-84.

243. Dent J. A new technique for continuous sphincter pressure measurement. Gastroenterology 1976;71:263-7.

244. DeMeester TR, Wang Cl, Wernly JA, Pellegrini CA, Little AG, Klementschitsch $P$, Bermudez G, Johnson LF, Skinner DB. Technique, indications, and clinical use of 24 hour esophageal pH monitoring. J Thorac Cardiovasc Surg 1980;79:656-70.

245. Vitale GC, Cheadle WG, Sadek S, Michel ME, Cuschieri A. Computerized 24-hour ambulatory esophageal $\mathrm{pH}$ monitoring and esophagogastroduodenoscopy in the reflux patient. A comparative study. Ann Surg 1984;200:724-8. 
246. Mattioli S, Pilotti V, Spangaro M, Grigioni WF, Zannoli R, Felice V, Conci A, Gozzetti G. Reliability of 24-hour home esophageal $\mathrm{pH}$ monitoring in diagnosis of gastroesophageal reflux. Dig Dis Sci 1989;34:71-8.

247. Schlesinger PK, Donahue PE, Schmid B, Layden TJ. Limitations of 24-hour intrcesophageal pH monitoring in the hospital setting. Gastroenterology 1985;89:797-804.

248. Fuchs $\mathrm{KH}$, DeMeester TR, Albertucci $M$. Specificity and sensitivity of objective diagnosis of gastroesophageal reflux disease. Surgery 1987; 102:575-80.

249. Schindlbeck NE, Heinrich C, Konig A, Dendorfer A, Pace F, Müller-Lissner SA. Optimal thresholds, sensitivity, and specificity of long-term $\mathrm{pH}$-metry for the detection of gastroesophageal reflux disease. Gastroenterology 1987;93:85-90.

250. Bianchi Porro G, Pace F. Comparison of three methods of intraesophageal $\mathrm{pH}$ recordings in the diagnosis of gastroesophageal reflux. Scand J Gastroenterol 1988;23:743-50.

251. Wiener GJ, Richter JE, Copper JB, WU WC, Castell DO. The symptom index: a clinically important parameter of ambulatory 24 -hour esophageal $\mathrm{pH}$ monitoring. Am J Gastroenterol 1988;83:358-61.

252. Murphy DW, Yuan Y, Castell DO. Does the intraesophageal pH probe accurately detect acid reflux? Simultaneous recording with two $\mathrm{pH}$ probes in humans. Dig Dis Sci 1989;34:649-56.

253. Singh S, Bradley LA, Richter JE. Determinants of oesophageal 'alkaline' $\mathrm{pH}$ environment in controls and patients with gastro-oesophageal reflux disease. Gut 1993;34:309-16.

254. DeVault KR, Georgeson S, Castell DO. Salivary stimulation mimics esophageal exposure to refluxed duodenal contents. Am J Gastroenterol 1993;88:1040-3.

255. Johnston BT, MCDougall N, Collins JS, McFarland RJ, Love AH. Association of symptoms with acid reflux during esophageal $\mathrm{pH}$ monitoring. Dig Dis Sci 1994;39:1593-4.

256. Breumelhof $R$, Smout AJ. The symptom sensitivity index: a valuable additional parameter in 24-hour esophageal pH recording. Am J Gastroenterol 1991;86: $160-4$.

257. Weusten BL, Roelofs JM, Akkermans LM, Van Berge-Henegouwen GP, Smout AJ. The symptom-association probability: an improved method for symptom analysis of 24-hour esophageal pH data. Gastroenterology 1994;107:1741-5.

258. Bechi P, Pucciani F, Baldini F, Cosi F, Falciai R, Mazzanti R, Castagnoli A, Passeri A, Boscherini S. Long-term ambulatory enterogastric reflux monitoring. Validation of a new fiberoptic technique. Dig Dis Sci 1993;38:1297-306.

259. Fein M, Fuchs KH, Bohrer T, Freys SM, Thiede A. Fiberoptic technique for 24-hour bile reflux monitoring. Standards and normal values for gastric monitoring. Dig Dis Sci 1996;41:216-25.

260. Johnson LF, DeMeester TR. Development of the 24-hour intraesophageal pH monitoring composite scoring system. J Clin Gastroenterol 1986;8 Suppl 1:52-8. 
261. Vaezi MF, Lacamera RG, Richter JE. Validation studies of Bilitec 2000: an ambulatory duodenogastric reflux monitoring system. Am 」 Physiol 1994;267: G1050-7.

262. Stipa F, Stein HJ, Feussner H, Kraemer S, Siewert JR. Assessment of non-acid esophageal reflux: comparison between long-term reflux aspiration test and fiberoptic bilirubin monitoring. Dis Esophagus 1997;10:24-8.

263. Tack J, Koek G, Demedts I, Sifrim D, Janssens J. Gastro-esophageal reflux disease poorly responsive to proton pump inhibitors: acid reflux, bile reflux or both? submitted for publication 2003.

264. Trudgill NJ, Smith LF, Kershaw J, Riley SA. Impact of smoking cessation on salivary function in healthy volunteers. Scand J Gastroenterol 1998;33:568-71.

265. Mathus-Vliegen LM, Tytgat GN. Twenty-four-hour $\mathrm{pH}$ measurements in morbid obesity: effects of massive overweight, weight loss and gastric distension. Eur $J$ Gastroenterol Hepatol 1996;8:635-40.

266. Schweitzer EJ, Bass BL, Johnson LF, Harmon JW. Sucralfate prevents experimental peptic esophagitis in rabbits. Gastroenterology 1985;88:611-9.

267. Orlando RC, Tobey NA. Why does sucralfate improve healing in reflux esophagitis? The role of sucrose octasulfate. Scand J Gastroenterol Suppl 1990;173:17-21.

268. Dobrozsi DJ, Smith RL, Sakr AA. Comparative mucoretention of sucralfate suspensions in an everted rat esophagus model. Int J Pharm 1999;189:81-9.

269. Hetzel DJ, Dent J, Reed WD, Narielvala FM, Mackinnon M, McCarthy JH, Mitchell B, Beveridge BR, Laurence BH, Gibson GG, ef al. Healing and relapse of severe peptic esophagitis after treatment with omeprazole. Gastroenterology 1988;95:903-12.

270. Dehn TC, Shepherd HA, Colin-Jones D, Kettlewell MG, Carroll NJ. Double blind comparison of omeprazole (40 $\mathrm{mg}$ od) versus cimetidine (400 $\mathrm{mg} \mathrm{qd}$ ) in the treatment of symptomatic erosive reflux oesophagitis, assessed endoscopically, histologically and by $24 \mathrm{~h} \mathrm{pH}$ monitoring. Gut 1990;31:509-13.

271. Klinkenberg-Knol EC, Festen HP, Meuwissen SG. Pharmacological management of gastro-oesophageal reflux disease. Drugs 1995;49:695-710.

272. Sontag SJ, Hirschowitz BI, Holt S, Robinson MG, Behar J, Berenson MM, McCullough A, Ippoliti AF, Richter JE, Ahtoridis G, et al. Two doses of omeprazole versus placebo in symptomatic erosive esophagitis: the U.S. Multicenter Study. Gastroenterology 1992;102:109-18.

273. Robinson M, Sahba B, Avner D, Jhala N, Greski-Rose PA, Jennings DE. A comparison of lansoprazole and ranitidine in the treatment of erosive oesophagitis. Multicentre Investigational Group. Aliment Pharmacol Ther 1995;9:25-31.

274. Earnest DL, Dorsch E, Jones J, Jennings DE, Greski-Rose PA. A placebo-controlled dose-ranging study of lansoprazole in the management of reflux esophagitis. Am J Gastroenterol 1998;93:238-43.

275. Klinkenberg-Knol EC, Meuwissen SG. Combined gastric and oesophageal 24-hour $\mathrm{pH}$ monitoring and oesophageal manometry in patients with reflux disease, resistant to treatment with omeprazole. Aliment Pharmacol Ther 1990;4:485-95. 
276. Holloway RH, Dent J, Narielvala F, Mackinnon AM. Relation between oesophageal acid exposure and healing of oesophagitis with omeprazole in patients with severe reflux oesophagitis. Gut 1996;38:649-54.

277. Fackler WK, Ours TM, Vaezi MF, Richter JE. Long-term effect of H2RA therapy on nocturnal gastric acid breakthrough. Gastroenterology 2002;122:625-32.

278. Triadafilopoulos G, DiBaise JK, Nostrant T, Stollman NH, Anderson PK, Wolfe MM, Rothstein RI, Wo JM, Corley DA, Patti MG, Antignano LV, Goff JS, Edmundowicz SA, Castell DO, Rabine JC, Kim MS, Utley DS. The Stretta procedure for the treatment of GERD: 6 and 12 month follow-up of the U.S. open label trial. Gastrointest Endosc 2002;55:149-56.

279. Ginsberg GG, Barkun AN, Bosco JJ, Burdick JS, Isenberg GA, Nakao NL, Petersen BT, Silverman WB, Slivka A, Kelsey PB. Endoscopic anti-reflux procedures. Gastrointest Endosc 2002;56:625-8.

280. Ye W, Chow WH, Lagergren J, Boffetta P, Boman G, Adami HO, Nyren O. Risk of adenocarcinomas of the oesophagus and gastric cardia in patients hospitalized for asthma. Br J Cancer 2001;85:1317-21.

281. Spechler SJ, Goyal RK. Cancer surveillance in Barrett's esophagus: what is the end point? Gastroenterology 1994;106:275-7. 


\section{Chapter 2}

Aims of the study and outline of the thesis 
Chapter 2 


\section{Aims of the study and outline of the thesis}

This thesis attempts to provide further insight into the role of duodenogastro-esophageal reflux (DGER) in the development of esophageal symptoms and lesions. As we based most of the investigations on the use of the Bilitec ${ }^{*}$ probe, we also needed to assess the most appropriate way to apply the Bilitec ${ }^{\text {B }}$ method in the study of reflux disease.

In general, we aimed at answering the following questions: Does the Bilitec $^{*}$ probe adequately detect appearance and disappearance of duodenal contents in the esophagus? Which dietary restrictions are required during Bilitec monitoring? How should Bilitec" results be analyzed and interpreted? Which factors underlie reflux of duodenal contents to the stomach? How is duodenal contents cleared from the esophagus? Does DGER contribute to the occurrence of symptoms in patients with gastro-esophageal reflux disease (GERD)? What is the contribution of DGER, relative to acid reflux, in the genesis of esophageal lesions in GERD patients? Is DGER a factor that plays a role in the incomplete response of GERD to acid suppressive therapy? Does DGER respond to a promotility type of treatment?

In different chapters, several aspects of DGER were investigated. The extended introduction, preceding this part, outlines the current understanding of the physiology and pathophysiology of reflux to the stomach and esophagus, the available methods to investigate reflux to the esophagus and a brief survey of reflux disease treatment (chapter 1). As reflux of duodenal content (DC) to the stomach is a prerequisite for DGER, we studied the role of gastric and duodenal motility in relation to duodeno-gastric reflux events (chapter 3 ).

To assess whether different mechanisms determine esophageal clearance of an acid or a DC bolus, we used combined radionucleotide, $\mathrm{pH}$ and Bilite $^{(8)}$ investigation, presented in chapter 4 . In chapter 5 we investigated the necessity of dietary restrictions during Bilitec ${ }^{B}$ monitoring and in chapter 6 we studied the optimal way to analyze 24 hours Bilitec measurements.

The respective roles of acid and DGER events in the development of typical reflux symptoms are studied in chapter 7 . In chapter 8 we used a multivariate analysis to determine the respective roles of acid and DGER in the occurrence of esophagitis and Barrett's esophagus.

In chapter 9 we investigated whether DGER plays a role in GERD patients with incomplete response to acid suppressive therapy. Finally, a new 
therapeutic approach for DGER based on inhibition of transient lower esophagus sphincter relaxations (TLESRs) is presented in chapter 10. The overall summary and implication of these studies is discussed in chapter 11, followed by suggestions for further studies. 


\section{Chapter 3}

\section{Mechanisms underlying duodeno-gastric reflux in man}

GH Koek, R Vos, D Sifrim, R Cuomo, J Janssens, J Tack

Submitted for publication 


\section{Abstract}

\section{Backgrounds}

Recent studies suggest that duodeno-gastro-esophageal reflux (DGER) may contribute to lesions in patients with gastro-esophageal reflux disease. Duodeno-gastric reflux (DGR) is a prerequisite for DGER to occur. The mechanisms underlying DGR are poorly understood.

\section{Aims}

To study the occurrence of DGR in man in relation to interdigestive and postprandial gastro-duodenal motor activity.

\section{Subjects and methods}

Ten healthy subjects (eight men, age $24 \pm 0.7$ ) underwent stationary gastro-duodenal manometry with simultaneous duodenal and antral Bilitec $c^{\text {tecording. Motility and Bilitec }}$ values were registered up to four hours before and five hours after ingestion of a mixed liquid meal. A second group of eight healthy volunteers (five women, age 24 44.2 ) underwent a similar study, with administration of erythromycin $100 \mathrm{mg}$ i.v. two hours postprandially.

\section{Results}

In the interdigestive period all volunteers had short periods of DGR which mainly occurred during phase II. After the meal, DGR occurred in all subjects, on average $39 \pm 28$ minutes after the start of the meal, and was cleared from the stomach after $241.7 \pm 23.3$ minutes. Induction of increased antral motility and of a premature phase III, by administration of erythromycin, was associated with faster DGR clearance from the stomach. However, there was no convincing temporal relationship between erythromycininduced gastric phase III and erythromycin-induced DGR clearance.

\section{Conclusion}

In healthy subjects, DGR occurs sporadically in the interdigestive state and is a normal phenomenon in the postprandial period. Erythromycin induces faster clearance of DGR from the stomach, which seems to depend on enhanced antral phasic contractile activity rather than premature occurrence of phase III. 


\section{Introduction}

The pathological role of acid reflux to the esophagus in gastroesophageal reflux disease (GERD) is well established: typical symptoms of heartburn are mimicked by esophageal acid perfusion', esophageal $\mathrm{pH}$ monitoring is used to quantify GERD ${ }^{2}$ and acid-suppressive drugs are the corner stone of medical treatment of GERD symptoms and lesions. ${ }^{3}$ Recently, several observations suggest that duodeno-gastro-esophageal reflux (DGER) is also involved in the pathophysiology of GERD.

The occurrence of erosive esophagitis in patients with achlorhydria and after total gastrectomy ${ }^{4,5}$ argues in favor of a role for reflux of duodenal content (DC) in the pathogenesis of esophageal mucosal lesions. From histological examination of gastric biopsies it has been suggested that an increased prevalence of bile reflux gastritis was found in patients with Barrett's esophagus, providing further evidence for the pathological role of DC in esophageal lesions. ${ }^{6}$ Using prolonged Bilitec ${ }^{*}$ monitoring of esophageal bilirubin concentration, it has been shown that DGER is more common in patients with severe esophagitis and Barrett's esophagus than in patients without or with minor esophagitis. ${ }^{7.8}$ These observations suggest that DGER plays at least a complimentary role in the pathogenesis of esophageal mucosal lesions.

It is clear that duodeno-gastric reflux (DGR) is a prerequisite for DGER to occur, but the underlying mechanisms have not been elucidated. Aspiration studies suggested that DGR is a physiological phenomenon, occurring mainly postprandially.12 and at night. ${ }^{13}$ In the interdigestive state, reflux of bile has been shown to occur during duodenal phase $11 .{ }^{14}$ Retrograde duodenal pressure waves have been described during the late part of the duodenal phase $1 \mathrm{III}{ }^{15}$ Although this duodenal retroperistalsis is associated with alkalinisation of the antrum, probably through refluxed duodenal bicarbonate, no increase in gastric bile salt concentration seems to occur at the same time. ${ }^{14}$

The mechanisms involved in clearance of refluxed bile from the stomach are also unclear. A decreased occurrence of gastric phase III has been suggested to be present in patients with duodeno-gastric bile reflux ${ }^{16}$, but no temporary link between phase III activity and clearance of bile from the stomach was established. At present, therefore, our understanding of the timing and clearance of DGR events and of the underlying duodenal and gastric motor phenomena is far from complete. 
The Bilitec ${ }^{\circledast 0}$ probe allows to directly measure the presence of bilirubin in a semi-quantitative way. Validation studies confirmed a good correlation between Bilitec $^{*}$ measurements and bile acid concentrations. ${ }^{17.22}$ Ambulatory aspiration studies found a significant correlation between the total bilirubin concentration of aspirated samples and the fiberoptic reading of bilirubin concentration. ${ }^{23}$

The aim of the present study is to investigate the occurrence of DGR, measured with the Bilitec ${ }^{(\sqrt{3})}$ probe, in healthy man in relation to the interdigestive and postprandial gastro-duodenal motor activity. We hypothesized that DGR would occur during duodenal phase III in the interdigestive period, and during the fed state. We also hypothesized that gastric phase III activity would be the mechanism that clears bile from the stomach. In that case, a close temporal correlation should be found between gastric phase 111 and the end of the postprandial gastric bile exposure. Furthermore, pharmacologically induced gastric phase III should be shortly preceded by the end of postprandial gastric bile exposure.

\section{Materials and methods}

Two separate protocols, approved by the Ethical Committee of the University Hospital Gashuisberg, Leuven, Belgium, were performed.

\section{Study subjects}

Ten healthy volunteers (mean age 24 years \pm 0.7 , two women, eight men) participated in the first protocol, which did not involve pharmacological intervention. In the second study, which involved a pharmacological intervention, eight volunteers took part (three men and five women; mean age $24 \pm 4.2$ ). All volunteers fell within the normal body weight range.

The subjects had no symptoms or a history of gastrointestinal disease. None had undergone a surgical intervention of the gastrointestinal tract. With exception of oral contraceptives no other medication was allowed in the week prior to the study. Informed consent was obtained from each volunteer.

\section{Recording technique}

Antro-duodenal manometry was performed after an overnight fast. The recording of the antro-duodenal intraluminal pressures was performed 
using an eight-channel polyvinyl catheter (outer diameter $6 \mathrm{~mm}$ ) with a latex bag at its end that could be filled with mercury during positioning the catheter.

The probe was introduced via the mouth and positioned under fluoroscopic control in such a way that three of the proximal sensors, which were $3 \mathrm{~cm}$ apart, were located in the antrum (Figure 3.1). The three other sensors were located in the small bowel, respectively at 25, 50 and $75 \mathrm{~cm}$ more distally. The two remaining catheters were used for filling and emptying the mercury bag. This catheter assembly allowed an adequate simultaneous monitoring of the migrating motor complex in the distal antrum, duodenum and jejunum during the entire experiment. The recording catheters were continuously perfused with water by means of a low compliance pneumohydraulic infusion pump (Arndorfer Medical Specialities Inc., Greendale, Winconsin, USA), at a flow rate of $0.4 \mathrm{ml} / \mathrm{min}$, and were connected to external pressure transducers (Siemens Elema 746, Siemens, Iselin, New Yersey, USA).

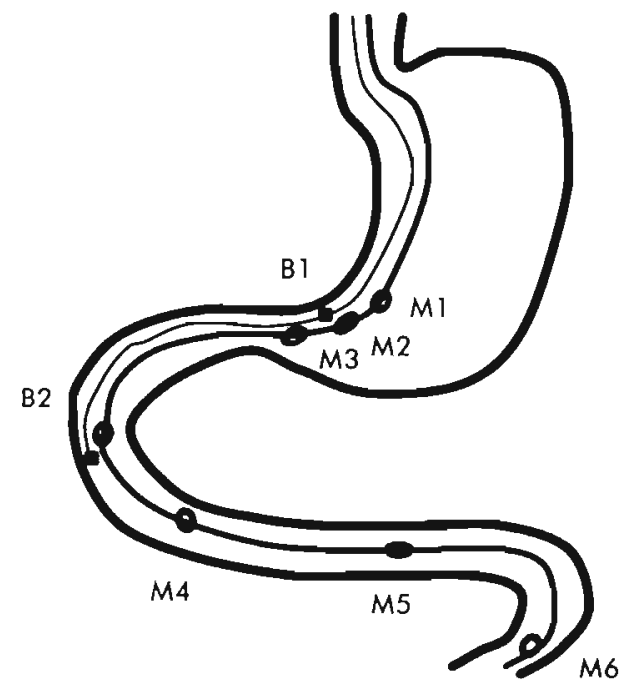

Figure 3.1. Position of the manometric catheter in antrum, duodenum and jejunum with Bilitec ${ }^{\text {s }}$ probes between $2^{\text {nd }}$ and $3^{\text {rd }}$ and $4^{\text {th }}$ and $5^{\text {th }}$ sensors. $M x=$ manometric channel, $\mathrm{Bx}=$ Bilitec $^{\mathrm{B}}$ probe.

The fiber-optic spectrophotometer Bilitec 2000 (Synectics, Stockholm, Sweden) was used to quantify DGR. The system consists of a miniaturized probe of $5 \mathrm{~mm}$ diameter that carries light signals into the stomach and duodenum and back via a plastic fiber-optic bundle. Before each study, the probe was calibrated in water. 
The probe was connected to a portable digital recording device (Digitrapper, Synectics, Sweden). Data were read and evaluated with a computer program (Synectics, Sweden).

One Bilitec ${ }^{\text {(6) }}$ probe was fixed with adhesive tape near the $2^{\text {nd }}$, the second probe $13 \mathrm{~cm}$ proximally to the $4^{\text {th }}$ sensor of the polyvinyl catheter (Figure 3.1). In the second study only the intragastric Bilitec ${ }^{\circledR}$ probe was introduced.

\section{Study design}

After an overnight fast, the catheter and Bilitec ${ }^{(\pi)}$ probes were positioned under fluoroscopy.

The healthy volunteer was sitting on a bed in a $45^{\circ}$ upright position during the study time. In the first study the interdigestive period continued for four hours or until the occurrence of two activity fronts. Subsequently, the subjects were asked to consume one mixed liquid meal (MLM) $(200 \mathrm{ml} ; 300 \mathrm{kcal})$ with the chemical composition of $40 \% \mathrm{fat}, 45 \%$ carbohydrates and $15 \%$ protein, not interfering with Bilitec ${ }^{(\nexists)}$ readings. Subjects were not allowed to eat or drink anything else. They were also asked to refrain from smoking. The recording continued for five hours or until a postprandial activity front appeared (Figure 3.2).

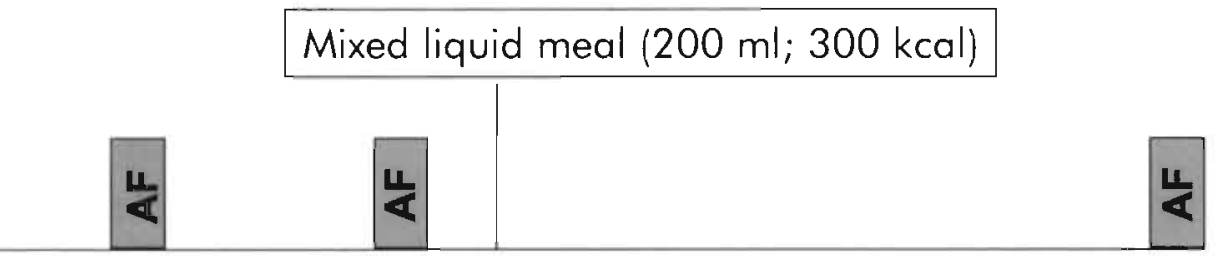

4 hours or two activity fronts

5 hours or one postprandial activity front

Figure 3.2. Study design: the mixed liquid meal $(200 \mathrm{ml}, 300 \mathrm{Kcal})$ was given either after two phase III activity fronts (AF) or after four hours interdigestive period. The postprandial or fed phase ended with a phase III activity front or after five hours.

In the second, medical intervention, study participants were sitting in the same position and the same liquid meal was given after one activity front or four hours after the start of the interdigestive recording. Two hours after the liquid meal $200 \mathrm{mg}$ of erythromycin was administered 
intravenously over 15 minutes. The recording continued until one phase III activity front passed or until two hours post medication (Figure 3.3).
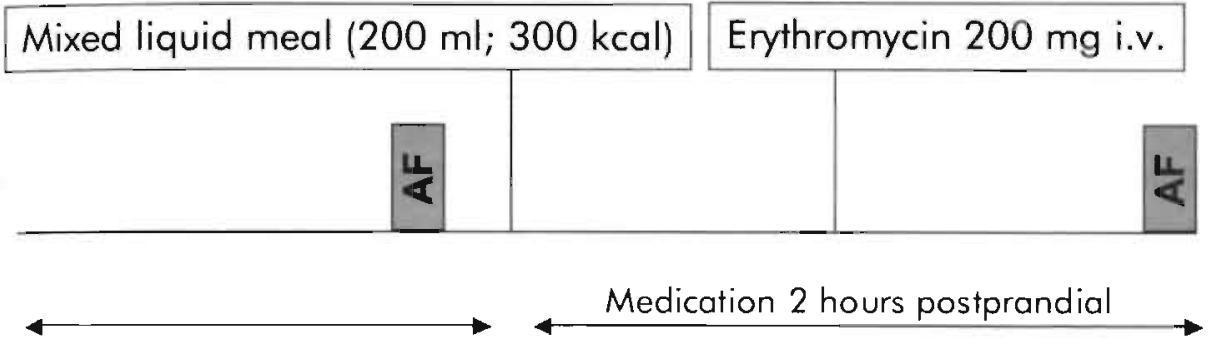

4 hours or one activity front 2 hours post medication or one activity front

Figure 3.3. Study design: the mixed liquid meal $(200 \mathrm{ml}, 300 \mathrm{Kca}$ ) was given either after one phase III activity fronts (AF) or after four hours interdigestive period. Two hours after the liquid meal $200 \mathrm{mg}$ erythromycin was given intravenously for 15 minutes. The study ended after a phase III AF or two hours after the medication was given.

Analysis of motility parameters

At the end of the study the data stored in the Digitrapper were transferred to a personal computer for visual display and analysis. Visual inspection was used to mark the different motility phases. We used generally accepted criteria for analyzing the manometric data defined as migrating motor complex (MMC) phase I, II, III and fed phase. The MMC consists of three phases with distinctive differences in their motor patterns. During phase I no contractile activity is found, the bowel is at rest. This phase is followed by phase II in which contractions occur at irregular intervals. Phase II is followed by phase III in which contractions appear in the highest possible frequency. Phase III is followed by phase I. Eating interrupts the MMC. This motor activity is called the fed phase. The fed phase ends after a period of a few hours with reappearance of phase III. The subsequent analysis was done with a computer program developed and validated in our unit and described in detail elsewhere. ${ }^{24}$ Pressure activity, which reflects the amplitude and frequency of contractions for a defined period of time, was quantified in the form of the motility index (MI), which was calculated by a computer program.

\section{Analysis of Bilitec ${ }^{\mathbb{B}}$ monitoring}

The data of the Bilitec ${ }^{(1)}$ measurements were analyzed with the aid of commercially available software (Gastrosoft Inc. Synetics Medical, Irvine, 
Texas, USA). An episode of DGR was defined as a rise of absorbance above the cut-off value lasting longer than 10 seconds. If no bile colored fluid was measured during a period longer than 10 minutes it was defined as the absence of DGR. The time to clearance was defined as the period in which DGR was cleared from the stomach. In cases where no clearance occurred during the whole postprandial measurement period of five hours, the time to clearance was set at 300 minutes, which was an under-estimation of the exact clearance time. We used previously described cut-off values for DGR $\left(\geq 0.14\right.$ defined by Bechi ${ }^{20}$ and $\geq 0.25$ according to the investigations of Fein ${ }^{22}$ ).

\section{Statistics}

Manometric parameters were calculated as means of the values recorded by one pressure point in the antrum (channel 2) and one in the small intestine (channel 4). Motor activities were compared either by paired t-test (two-tailed) or by Wilcoxon Signed Rank test. Changes in contractile activity over time during the fed period were analyzed with analysis of variance for repeated measurements.

Bilitec $^{\text {Bo }}$ values are expressed as mean and standard error of the mean (SEM). Results were compared with the t-test. P-values were considered to be significant if $<0.05$.

\section{Results}

Study without medical intervention

The mean recording time was $467 \pm 18$ minutes. The mean duration of the interdigestive phase recording before the subjects consumed their meal was $168 \pm 17$ minutes. The mean time of registration after the MLM was $299 \pm 17$ minutes.

Interdigestive motility

In the preprandial time, all volunteers had small intestinal phase III contractions; in four one phase III, in five two phases III and in one three phases III. In six volunteers, this phase III activity front propagated from the stomach to the small intestine. In three healthy volunteers two gastric phases III and in three volunteers one gastric phase III were observed. Four volunteers had no gastric component to the phase III contractions during four hours of interdigestive gastric motility recording. Duration of the three phases and motility indices of phase three are summarized in 
Table 3.1. No correlation was found between the gastric and duodenal motility indices in the fasting state.

Table 3.1. Duration of the different phases for the whole interdigestive period in the stomach and small bowel given in minutes. Characteristics of the phase III motility are given in minutes.

\begin{tabular}{lcc}
\hline Interdigestive motility & Stomach & Small bowel \\
\hline Phase I duration (min) & $40.9 \pm 12.1$ & $18.3 \pm 4.5$ \\
Phase II duration (min) & $136.3 \pm 17.5$ & $145.6 \pm 14.4$ \\
Phase III duration (min) & $4.7 \pm 1.6$ & $10.4 \pm 1.8$ \\
$\quad$ Mean total contractions & $87.8 \pm 12.8$ & $475.7 \pm 55.1$ \\
Mean amplitude & $64.8 \pm 6.8$ & $28.5 \pm 2.1$ \\
Mean duration & $5.9 \pm 0.4$ & $3.4 \pm 0.1$ \\
Mean area & $226.8 \pm 57.7$ & $52.9 \pm 5.9$ \\
Mean motility index & $4.4 \pm 0.3$ & $4.9 \pm 0.2$ \\
\hline
\end{tabular}

Interdigestive bile exposure

Table 3.2 summarizes the characteristics of the bilirubin absorbance $\geq 0.14$. For the Bilitec ${ }^{\otimes}$ probe located in the stomach, the mean $\%$ of time bilirubin absorbance above $\geq 0.14$ was $15.3 \pm 8.4 \%$. Taking $\geq 0.25$ as a cut-off for bilirubin absorbance, the mean $\%$ of time was $0.40 \pm 0.2 \%$. No significant differences were observed between both cut-off values (data for 0.25 cut-off are not shown in detail). The majority of bile reflux episodes occurred during phase II, but the highest exposure to bilirubin occurred during phase III. No difference in stomach reflux episodes and duration of the reflux period could be observed between the first and second half of phases II and III in the interdigestive state.

In the small intestine, the mean \% of time bilirubin absorbance above $\geq 0.14$ was $56.2 \pm 5.2 \%$ and the mean $\%$ of time bilirubin absorbance above $\geq 0.25$ was $39.8 \pm 5.6 \%$. The highest exposure to bilirubin occurred during phase 11 . No correlation was found between the gastric and duodenal bilirubin absorbance in the fasting state.

\section{Fed phase motility}

Ingestion of the meal induced fed motility in all segments in all subjects. The postprandial motility index for the stomach was $2.8 \pm 0.4$ and for the small bowel $5.2 \pm 0.2(p=0.0002)$. During the five hours postprandial recording, three volunteers had one gastric activity front, which propagated to the small intestine (Figure 3.4). In six healthy volunteers one to three small intestinal phase III contractions without gastric component occurred (Figure 3.5). 
Table 3.2. Characteristics of the Bilitec ${ }^{8}$ measurements in stomach and small bowel during the different motility phases in the interdigestive period.

\begin{tabular}{|c|c|c|c|}
\hline \multicolumn{4}{|c|}{ Bilite $c^{*}$ measurement interdigestive period } \\
\hline & Stomach & Small bowel & $p$-value \\
\hline \multicolumn{4}{|l|}{ Phase III } \\
\hline \multirow{2}{*}{\multicolumn{4}{|c|}{$\begin{array}{l}\text { Mean fotal number } \\
\text { reflux episodes }\end{array}$}} \\
\hline & & & \\
\hline Mean total time & $0.9 \pm 0.5$ & $2.3 \pm 1.5$ & NS \\
\hline Mean \% & $22.9 \pm 14.8$ & $28.8 \pm 10.1$ & NS \\
\hline \multicolumn{4}{|l|}{ Phase I } \\
\hline Mean total number & $1.6 \pm 1.3$ & $1.0 \pm 0.6$ & NS \\
\hline \multicolumn{4}{|l|}{ reflux episodes } \\
\hline Mean total time & $2.3 \pm 4.7$ & $1.3 \pm 0.9$ & NS \\
\hline Mean \% & $3.0 \pm 1.8$ & $6.0 \pm 4.5$ & NS \\
\hline \multicolumn{4}{|l|}{ Phase II } \\
\hline Mean total number & $6.7 \pm 1.8$ & $18.5 \pm 4.1$ & 0.0203 \\
\hline \multicolumn{4}{|l|}{ reflux episodes } \\
\hline Mean total time & $21.0 \pm 10.6$ & $92.6 \pm 14.1$ & 0.0063 \\
\hline Mean \% & $16.4 \pm 8.5$ & $63.6 \pm 6.7$ & 0.073 \\
\hline
\end{tabular}

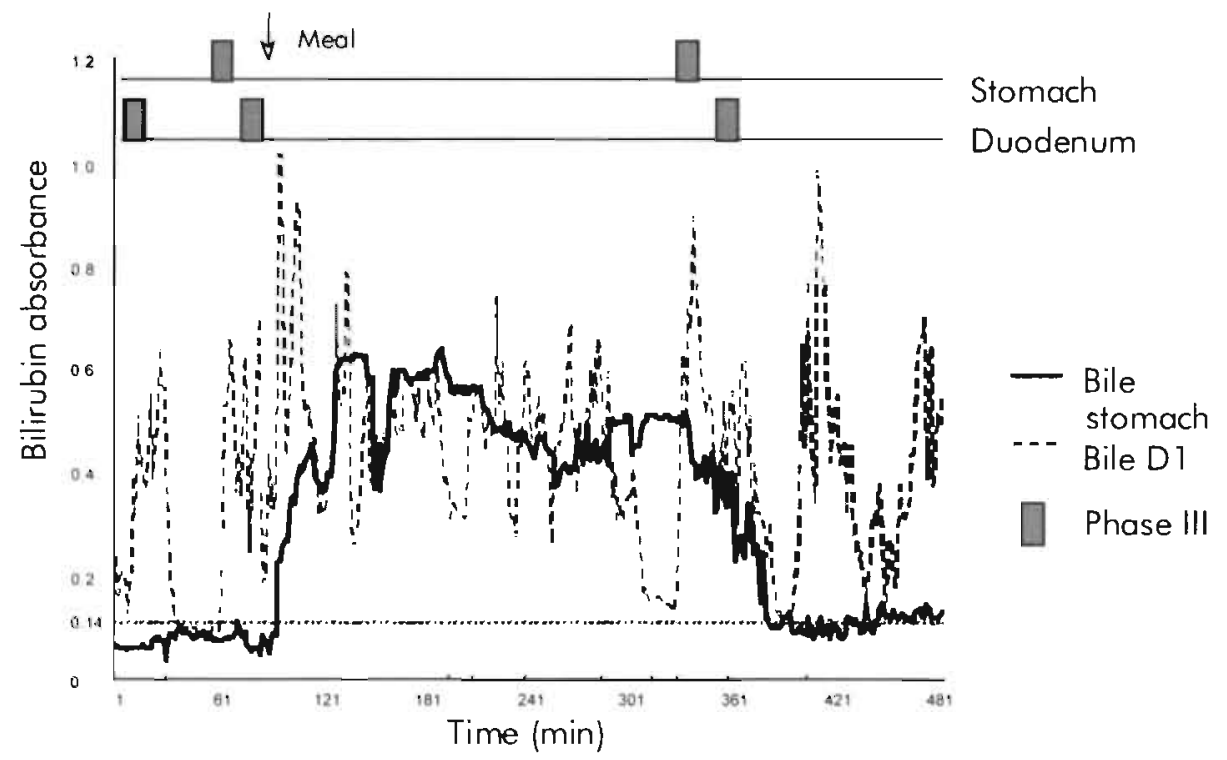

Figure 3.4. Example of a Bilitec tracing from the stomach and small bowel. In this figure DGR starts after ingestion of the MLM and ends with a phase III activity front. Longer and shorter periods of DGR diminishing without a phase III in the stomach. 
Fed phase bilirubin exposure

After the MLM, bilirubin-containing fluid entered the stornach on average $39 \pm 28$ minutes after the start of the meal. Table 3.3 summarizes the characteristics of postprandial bilirubin $\geq 0.14$. Using a bilirubin absorbance $\geq 0.25$, similar results were found (data not shown). The mean $\%$ of postprandial time the stomach was exposed to fluid of duodenal origin using an absorbance cut-off $\geq 0.14$ was $58.7 \pm 8.7 \%$ and this was significantly higher than during the interdigestive phase $(15.3 \pm 8.4 \% ; \mathrm{p}=0.0016)$.

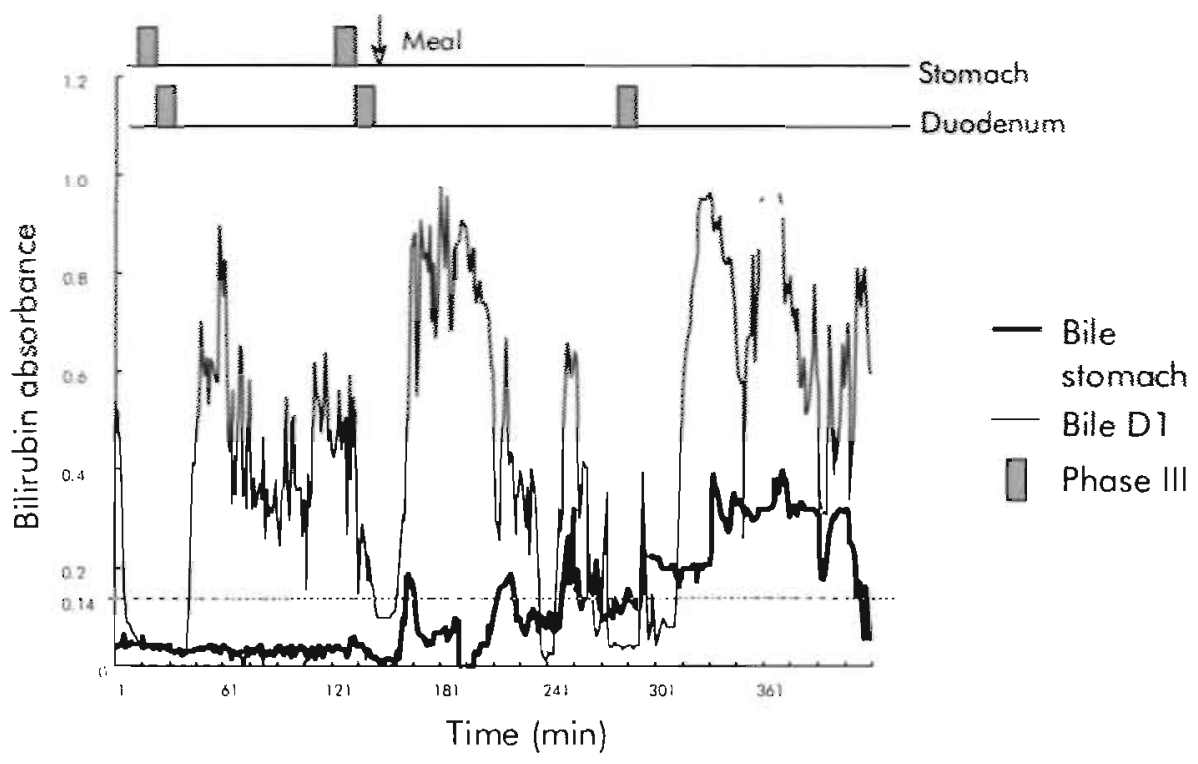

Figure 3.5. Example of a Bilitec tracing in which can be seen that DGR starts after ingestion of the MLM but does not end with a phase III activity front.

Taking $\geq 0.25$ as cut-off for bilirubin absorbance, the mean $\%$ of postprandial DGR time was $23.4 \pm 9.9 \% \quad(p=0.04$ compared to the interdigestive state). No difference in DC reflux episodes and duration of the DC reflux period could be observed between the first and second half of the fed phase.

In three healthy volunteers where no clearance occurred during five hours postprandial monitoring, the clearance time was set at 300 minutes. The mean clearance time for all healthy volunteers was $241.7 \pm 23.3$ minutes. In the four healthy volunteers who had no phase III of stomach and small bowel the mean clearance time was $259.3 \pm 51.3$ 
minutes. This did not differ significantly from the three volunteers who had a gastric phase III $(264.3 \pm 36.2$ minutes after the meal, $p=0.9)$ and from the volunteers who had a small intestinal phase III (195.7 \pm 36.8 minutes, $p=0.6$ ) during the postprandial period.

In addition, we assessed the temporal relationship between DC clearance from the stomach and gastric or small intestinal phase III activity. In three healthy volunteers with a gastric phase III, bilirubin colored fluid was cleared from the stomach 16.6 12.9 minutes before the start of the phase III. In three volunteers with a small intestinal phase III, bilirubin was cleared from the stomach on average $29.3 \pm 49.6$ minutes after the start of the phase III.

In the small intestine, the mean \% of time the bilirubin absorbance $\geq 0.14$ was $82.1 \pm 4.0 \%$, which was significantly longer than during the interdigestive phase $(56.2 \pm 5.2 \% ; p=0.004)$. Taking $\geq 0.25$ as cut-off the mean $\%$ of time was $66.9 \pm 4.7 \%$, which was also significantly longer than in the interdigestive period $(39.8 \pm 5.5 \% ; p=0.005)$ (Table 3.3).

Table 3.3. Characteristics of the Bilitec ${ }^{*}$ measurements of stomach and small bowel in the fed phase. P-values are measured between stomach and small.

\begin{tabular}{lccc}
\hline Bilitec" measurement fed Phase & & & \\
& Stomach & Small bowel & p-value \\
\hline & $\geq 0.14$ & $\geq 0.14$ & \\
Duration in minutes & $232 \pm 26.2$ & $216 \pm 31.6$ & NS \\
Mean total number & $12.4 \pm 3.1$ & $21.8 \pm 6.4$ & NS \\
reflux episodes & & & NS \\
Mean total time & $129.5 \pm 21.0$ & $181.5 \pm 30.8$ & 0.0185 \\
Mean \% & $58.7 \pm 8.7$ & $82.1 \pm 4.0$ & \\
\hline
\end{tabular}

Study with medical intervention

Healthy volunteers with medical intervention

The mean recording time was $299 \pm 21$ minutes. The mean duration of the interdigestive phase recording, before the subjects consumed their meal, was $78 \pm 20$ minutes. The mean duration of the fed phase was $220 \pm 8$ minutes and the mean recording time after erythromycin was $94 \pm 10$ minutes.

In seven volunteers a phase III activity front was observed before the meal; in three volunteers the phase III originated in the stomach and propagated to the small bowel. In this period the mean $\%$ of time the stomach was exposed to bile containing fluid was $12.9 \pm 4.7 \%$ for $\geq 0.14$ 
as cut-off for absorbance (Table 3.4). Using a bilirubin absorbance $\geq 0.25$, similar results were found (data not shown).

Table 3.4. Bilitec ${ }^{3}$ measurements during the interdigestive period of the erythromycin treated group in the stomach in the different motility phases.

\begin{tabular}{lc}
\hline Bilifec $^{*}$ measurement interdigestive period erythromycin treated & \\
& Stomach \\
\hline Phase III & $\geq 0.14$ \\
Mean total number reflux episodes & $0.5 \pm 0.5$ \\
Mean total time & $1.0 \pm 1.0$ \\
Mean \% & $7.2 \pm 7.2$ \\
Phase I & \\
Mean total number reflux episodes & $0.3 \pm 0.3$ \\
Mean total time & $1.0 \pm 1.0$ \\
Mean \% & $4.1 \pm 4.1$ \\
Phase II & $3.5 \pm 1.6$ \\
Mean total number reflux episodes & $5.9 \pm 3.7$ \\
Mean total time & $14.3 \pm 8.3$ \\
Mean \% & \\
\hline
\end{tabular}

\section{Fed phase motility}

In six volunteers erythromycin induced a gastric phase III with $(n=2)$ or without propagation to the small intestine, which began $50.3 \pm 15.9$ minutes after the start of the infusion and 170.3 15.9 minutes after the ingestion of ND.

Fed phase bile exposure

The mean $\%$ of time the bilirubin absorbance $\geq 0.14$ was $34.2 \pm 5.9 \%$ and this was significantly longer than in the interdigestive phase $(12.9 \pm 4.7 \% ; p=0.0064)$. Taking $\geq 0.25$ as cut-off, the mean $\%$ of time bilirubin absorbance was $15.7 \pm 4.0 \%$ and this was significantly longer than in the interdigestive phase $(0.8 \pm 0.5 \% ; p=0.0057)$.

All healthy volunteers cleared bilirubin form the stomach after a mean time of $176.5 \pm 12.8$ minutes after ingestion of $M L M$, which was significantly shorter than the untreated group $(241.7 \pm 23.3$ minutes; $p=0.018$, Figure 3.6).

The healthy volunteers with a gastric phase III or phase III like activity cleared DC form the stomach after a mean time of $184.0 \pm 13.3$ minutes after the start of the MLM which was significant shorter that the three healthy volunteers with a phase III in the untreated group (259.3 \pm 51.3 minutes; $p=0.017$ ). 
Duodenal content clearance time

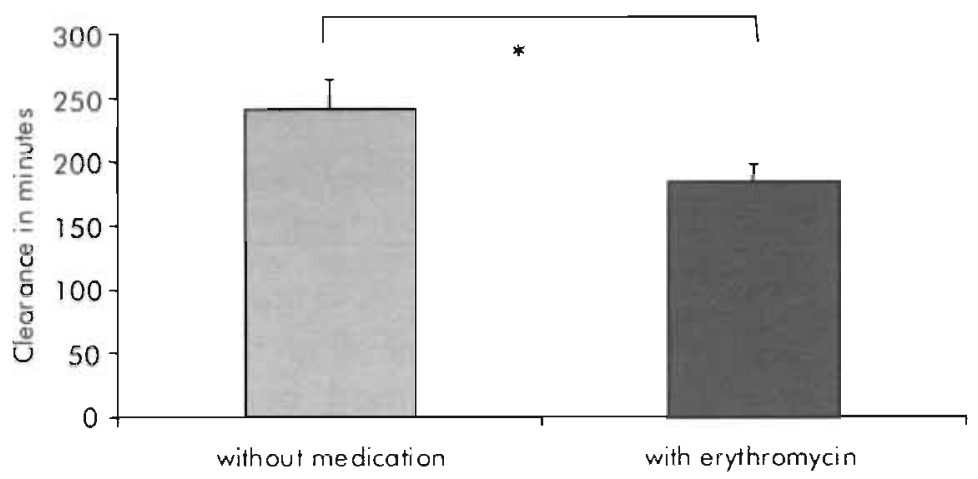

Figure 3.6. Clearance time in minutes \pm SEM for healthy volunteers. With $200 \mathrm{mg}$ erythromycin intravenously a significantly $\left({ }^{*}\right)$ faster clearance was measured compared to persons taking no medication.

Bilirubin colored fluid was cleared from the stomach $14.4 \pm 19.5$ minutes after the start of the erythromycin-induced gastric phase III activity. Until 90 minutes after drug administration, the postprandial $\mathrm{Ml}$ in the stomach was significantly higher after erythromycin (Table 3.5).

Table 3.5. Comparison of motility index for untreated and erythromycin treated group starting 30 minutes after the drug was given intravenously. Mean time in minutes $( \pm$ SEM) compared with t-test.

\begin{tabular}{lccl}
\hline $\begin{array}{l}\text { Motility index stomach } \\
\text { Minutes }\end{array}$ & Untreated group & Treated group & p-value \\
\hline 30 & $1.31 \pm 0.34$ & $3.58 \pm 0.4$ & 0.0007 \\
60 & $1.84 \pm 0.37$ & $3.63 \pm 0.49$ & 0.01 \\
90 & $2.5 \pm 0.49$ & $4.33 \pm 0.51$ & 0.02 \\
120 & $3.08 \pm 0.52$ & $3.87 \pm 0.54$ & 0.3 \\
\hline
\end{tabular}

\section{Discussion}

To our knowledge this is the first study using antro-duodenal manometry combined with antral and duodenal Bilitec ${ }^{2}$ measurement. We demonstrated sporadic DGR during phase II and III of the interdigestive migrating motor complex. We consistently observed the occurrence of DGR after a meal, confirming that postprandial DGR is a physiological process. $^{9 \cdot 13}$ 
Both, Bechi and Fein attempted to standardize Bilitec ${ }^{*}$ studies of the stomach. In the studies by Bechi et al., dietary restrictions were imposed while Fein et al. did not impose dietary restrictions except for the avoidance of coffee. Bechi ${ }^{20}$ defined $\geq 0.14$ as the lowest value of absorbance that can be considered an actual measurement of bilirubin containing fluid. Fein et al defined the threshold at $\geq 0.25$, the maximum absorbance measured with fluid and food in their studies, as the lowest absorbance unit avoiding interference with food. ${ }^{22}$

In the present study we compared both cut-off values and it is obvious that longer periods of DGR were registered when using a lower threshold value. We used liquid meals during our experiment because the use of solid foods during Bilitec ${ }^{(8)}$ monitoring is associated with an unacceptably high prevalence of meal-impaction artifacts as we showed in previous studies of esophageal Bilitec ${ }^{8}$ monitoring. ${ }^{25}$

Comparability between studies assessing gastric bile exposure with the Bilitec ${ }^{\text {(i) }}$ is low due to different positions of the probe: one study located the probe $5 \mathrm{~cm}$ below the LES ${ }^{22}$, another in the lower part of the gastric corpus $^{20}$ and we located the Bilitec ${ }^{\otimes 0}$ probe in the antrum, fixed to the manometry catheter. The location in the antrum may allow more detailed information about smaller amounts of DC fluid reflux and the clearance from the stomach.

It is obvious that different factors play a role in the occurrence of DGR. Besides the motility of stomach, pylorus and duodenum, and the amount and concentration of bile salts, pancreatic and duodenal bicarbonate secretions, food intake and composition are likely to determine the duration and quantity of DGR. Sonnenberg et al. showed that a lipid meal was associated with higher reflux rates, and a higher gastric concentration and total amount of duodenal contents than a protein meal. ${ }^{26}$ This was attributed to slower gastric emptying and increased DGR after a lipid meal, but the underlying motor patterns remained uninvestigated. ${ }^{26}$

In the present study, we could not demonstrate a specific relationship between interdigestive small intestinal motor patterns and the occurrence of DGR events. We demonstrated that DGR invariably occurred in the postprandial state, which is probably related to the presence of a greater amount of bilirubin containing fluid in the duodenum after a meal, and enhanced duodenal motor activity. In view of the presumed role of MMC phase III activity as a gastrointestinal housekeeper, a role of gastric 
phase III in clearing bile from the stomach seems likely. During the postprandial measurement period used in the present study, only a limited number of postprandial gastric phase III occurred, but there seemed to be a close temporal relationship between gastric bile clearance and gastric, but not duodenal, phase III. To further establish a temporal relationship between both events, we administered erythromycin during the postprandial period. This induced a premature gastric phase III in the majority of subjects, and was associated with a significantly more rapid clearance of bilirubin colored fluid from the stomach. However, there was no convincing temporal relationship between erythromycin-induced gastric phase III and erythromycininduced clearance of DC. Administration of erythromycin was associated with significantly stronger postprandial gastric motor activity. These data suggest that the overall prokinetic effects of erythromycin, and the enhanced postprandial gastric motor activity, are the main factors underlying this faster gastric clearance.

These findings partly confirm the observations of Rezende-Filho ef al. who showed that, in patients with severe dyspepsia, cisapride reduced biliary reflux by increasing fasting antral motility in the absence of alterations in MMC characteristics. The stimulatory effect of cisapride was confined to phase II activity expressed as a significant increase of the motility index. ${ }^{27}$

Our observations have potential therapeutic implications. As DGER is considered a mechanism that contributes to esophageal mucosal damage, and as DGR is a prerequisite for DGER to occur, shortening $D G R$, especially in the postprandial state, might be a viable therapeutic option. The findings of the present study suggest that stimulation of antral motility, and not necessarily earlier induction of gastric phase III activity, could be a means to achieve this goal. Of course, separate studies will be required to investigate this possibility.

In summary, DGR is a normal physiological process, which occurs mainly in the postprandial period. Clearance of bilirubin colored fluid from the stomach is faster after treatment with a prokinetic agent. This effect seems to depend mainly on enhanced antral phasic contractile activity, as no convincing temporal relationship with gastric phase III activity could be demonstrated. 


\section{References}

1. Richter JE, Johns DN, Wu WC, Castell DO. Are esophageal motility abnormalities produced during the intraesophageal acid perfusion test? JAMA 1985;253:1914-7.

2. Johnson LF, DeMeester TR. Twenty-four-hour $\mathrm{pH}$ monitoring of the distal esophagus. A quantitative measure of gastroesophageal reflux. Am 」 Gastroenterol 1974; 62:325-32.

3. Hatlebakk JG, Berstad A. Prognostic factors for relapse of reflux oesophagitis and symptoms during 12 months of therapy with lansoprazole. Aliment Pharmacol Ther $1997 ; 11: 1093-9$.

4. Helsingen N. Esophagitis following total gastrectomy. Acta Chir Scand 1957; 118:190-201.

5. Palmer ED. Subacute erosive peptic esophagitis associated with achlorhydria. NEJM 1960;262:927-9.

6. Dixon MF, Neville PM, Mapstone NP, Moayyedi P, Axon AT. Bile reflux gastritis and Barrett's oesophagus: further evidence of a role for duodenogastro-oesophageal reflux? Gut 2001;49:359-63.

7. Champion G, Richter JE, Vaezi MF, Singh S, Alexander R. Duodeno-gastroesophageal reflux: relationship to $\mathrm{pH}$ and importance in Barrett's esophagus. Gastroenterology 1994; 107:747-54.

8. Vaezi MF, Richter JE. Synergism of acid and duodenogastroesophageal reflux in complicated Barrett's esophagus. Surgery 1995;1 17:699-704.

9. Mackie C, Hulks G, Cuschieri A. Enterogastric reflux and gastric clearance of refluxate in normal subjects and in patients with and without bile vomiting following peptic ulcer surgery. Ann Surg 1986;204:537-42.

10. Müller-Lissner SA, Fimmel CJ, Sonnenberg A, Will N, Müller-Duysing W, Heinzel F, Müller R, Blum AL. Novel approach to quantify duodenogastric reflux in healthy volunteers and in patients with type I gastric ulcer. Gut 1983;24:510-8.

11. King PM, Pryde A, Heading RC. Transpyloric fluid movement and antroduodenal motility in patients with gastro-oesophageal reflux. Gut 1987;28:545-8.

12. Schindlbeck NE, Heinrich C, Stellaard F, Paumgartner G, Müller-Lissner S. Healthy controls have as much bile reflux as gastric ulcer patients. Gut 1987;28:1577-83.

13. Fiorucci S, Distrutti E, Di Matteo F, Brunori P, Santucci L, Mallozzi E, Bigazzi U, Marelli A. Circadian variations in gastric acid and pepsin secretion and intragastric bile acid in patients with reflux esophagitis and in healthy controls. Am J Gastroenterol 1995;90:270-6.

14. Dalenback J, Fandriks L, Olbe L, Sjovall H. Mechanisms behind changes in gastric acid and bicarbonate outputs during the human interdigestive motility cycle. Am J Physiol 1996;270:G1 13-22. 
15. Bjornsson ES A.brahamsson $\mathrm{H}$. Nocturnal antral $\mathrm{pH}$ rises are related to duodenal phase ill retroperistalsis. Dig Dis Sci 1997;42:2432-8.

16. Testoni PA, Fanti L, Bagnolo F, Passaretti S, Guslandi M, Masci E, Tittobello A. Manometric evaluation of the interdigestive antroduodenal motility in subjects with fasting bile reflux, with and without antral gastritis. Gut 1989;30:443-8.

17. Caldwell MT, Byrne PJ, Brazil N, Crowley V, Attwood SE, Walsh TN, Hennessy TP. An ambulatory bile reflux monitoring system: an in vitro appraisal. Physiol Meas $1994 ; 15: 57-65$.

18. Kaver WK, Peters JH, DeMeester TR, Ireland AP, Bremmer CG, Hagen JAI. Mixed reflux of gastric and duodenal juices is more harmful to the esophagus than gastric juice alone. The need for surgical therapy re-emphasized. Ann Surg 1995;222: 525-31.

19. Bjornsson ES, Abrahamsson H. Interdigestive gastroduodenal manometry in humans. Indication of duodenal phase III as a retroperistaltic pump. Acta Physiol Scand 1995;153:221-30.

20. Bechi P, Pucciani F, Baldini F, Cosi F, Falciai R, Mazzanti R, Castagnoli A, Passeri A, Boscherini $S$. Long-term ambulatory enterogastric reflux monitoring. Validation of a new fiberoptic technique. Dig Dis Sci 1993;38:1297-1306.

21. Vaezi MF, Lacamera RG, Richter JE. Validation studies of Bilitec 2000: an ambulatory duodenogastric reflux monitoring system. Am J Physiol 1194;267:G1050-7.

22. Fein M, Fuchs KH, Bohrer T, Freys SM, Thiede A. Fiberoptic technique for 24-hour bile reflux monitoring. Standards and normal values for gastric monitoring. Dig Dis Sci 1996:41:216-25.

23. Stipa $F$, Stein HJ, Feussner $H$, Kraemer S, Siewert JR. Assessment of non-acid esophageal reflux: comparison between long-term reflux aspiration test and fiberoptic bilirubin monitoring. Dis Esophagus 1997;10:24-8.

24. Andrioli A, Wilmer A, Coremans G, Vantrappen G, Janssens J. Computer supported analysis of 24 hour ambulatory manometric recordings in the human small bowel. Med Biol Eng Comput. 1996;34:336-43.

25. Tack J, Bisschops R, Koek GH, Sifrim D, Lerut T, Janssens J. Dietary restrictions during ambulatory monitoring of duodeno-gastro-esophageal reflux. In press for Dig Dis Sci.

26. Sonnenberg A, Müller-Lissner SA, Weiser HF, Müller-Duysing W, Heinzel F, Blum AL. Effect of liquid meals on duodenogastric reflux in humans. Am J Physiol 1982; 243:G42-7.

27. Rezende-Filho J, Di Lorenzo C, Dooley CP, Valenzuela JE. Cisapride stimulates antral motility and decreases biliary reflux in patients with severe dyspepsia. Dig Dis Sci 1989;34:1057-62. 


\section{Chapter 4}

\section{Esophageal clearance of acid and bile: a combined radionuclide, $\mathrm{pH}$ and Bilitec ${ }^{\circledR}$ study}

GH Koek, R Vos, R Flamen, D Sifrim, F Lamment, B Vanbilloen, J Janssens, J Tack 


\section{Abstract}

\section{Backgrounds}

Studies combining $\mathrm{pH}$ and Bilitec ${ }^{3}$ monitoring found a high prevalence of both acid and duodeno-gastro-esophageal reflux in severe reflux disease. Clearance of refluxed material is a major defense mechanism against reflux. Several studies have been devoted to esophageal acid clearance, but esophageal clearance of refluxed duodenal content (DC) has hardly been addressed.

\section{Aim}

To compare esophageal acid and DC clearance.

\section{Methods}

Ten healthy volunteers (five women, mean age $23 \pm 1$ years) were studied. First, a balloon tip catheter, positioned in the duodenum under fluoroscopy, was used to aspirate DC after stimulation by a high caloric liquid meal $(200 \mathrm{ml}, 300 \mathrm{Kcal})$. During a second session a $\mathrm{pH}$ and Bilitec ${ }^{.}$probe were positioned $5 \mathrm{~cm}$ above the lower esophageal sphincter and a small infusion catheter was introduced in the proximal esophagus. The subject was placed supine under a gamma camera. One of two different solutions (DC mixed with $0.2 \mathrm{mCi} \mathrm{Tc}^{99 \mathrm{~m}}$ pertechnetate or citric acid $\mathrm{pH} 2$ mixed with $0.2 \mathrm{mCi} \mathrm{Tc}{ }^{99 \mathrm{~m}}$ pertechnetate) was infused in the proximal esophagus and the subject was instructed to swallow at 20 seconds intervals. Clearance was assessed using scintigraphy (dynamic acquisition, one frame per second in anterior view; calculation of time to clear peak counts to background level), $\mathrm{pH}$ (time $\mathrm{pH}<4$ ) or Bilitec ${ }^{5}$ (time absorbance>0.14) monitoring, with or without continuous saliva aspiration. Each condition was studied twice in a randomized design; measurement time was four minutes, interrupted by water flushing and two minutes rest. Results are given as mean \pm SEM and compared by Student's t-test and Pearson correlation.

\section{Results}

Scintigraphic evaluation showed a volume clearance time of $29 \pm 3$ seconds for acid and $28 \pm 9$ seconds for DC (NS). Saliva aspiration had no significant influence on volume clearance of acid and DC (respectively $28 \pm 4$ and $30 \pm 13$ seconds, NS). Ph monitoring showed an acid clearance time of $217 \pm 15$ seconds, which was significantly prolonged to $324 \pm 30$ seconds during saliva aspiration $(p<0.05)$. Bilitec $c^{*}$ monitoring showed a DC clearance time of $131 \pm 27$ seconds, which was not significantly prolonged by saliva aspiration (176 \pm 36 seconds, $p=0.08)$. DC clearance was faster than acid clearance, either without or with saliva aspiration (respectively $p<0.055$ and $p<0.05$ ).

\section{Conclusions}

Under experimental conditions, liquid acid and DC solutions have comparable volume clearances. Chemical clearance occurs slightly faster for DC than for acid, and saliva plays a major role in the clearance of acid only. 


\section{Introduction}

Clearance of refluxed material is a major defense mechanism against mucosal damage caused by gastro-esophageal reflux. Reflux of gastric contents into the esophagus causes distention which triggers peristaltic bolus clearance of refluxed material into the stomach. ' The importance of gastric acid in the pathophysiology of reflux disease is clearly established. Besides peristaltic clearance, often referred to as volume clearance, so-called chemical clearance is an additional defense mechanism against acid reflux and consists of swallowed saliva and secretions of esophageal glands. The presence of bicarbonate in these secrefions is important in neutralizing the aggressive effect of acid on the mucosal. $^{2}$

Animal studies suggest that refluxed duodenal contents (DC), which contains bile acids, bile salts and pancreatic juice, may act in synergy with acid to induce esophageal lesions. ${ }^{3.5}$ Since the introduction of the fiber-optic spectrophotometer Bilitec $^{{ }^{8}}$ probe, duodeno-gastroesophageal reflux (DGER) can also be quantified in man. Combined $\mathrm{pH}$ and Bilitec monitoring studies found a high prevalence of both acid reflux and DGER, especially in severe reflux disease and Barrett's esophagus..$^{6.9}$ The mechanism by which DC is cleared from the esophagus has not been studied extensively. The peristaltic volume clearance mechanism is likely to have an effect on a bolus of DC refluxate, but it is unclear whether other clearance mechanisms are also involved.

Moreover, bile reflux episodes measured with the Bilitec ${ }^{\circledR}$ last significantly longer than acid reflux episodes measured with $\mathrm{pH}$ electrodes. ${ }^{8,10,11}$ One reason might be the absence of a chemical clearance mechanism for DC, in comparison to acid reflux. Another possible explanation might be the Bilitec ${ }^{*}$ probe configuration, which consists of a small cup, which may be prone to trapping of liquid. ${ }^{6.11}$

Therefore the aim of this study was to compare esophageal acid and DC clearance and to evaluate the mechanisms involved in the esophageal clearance of DC. 


\section{Materials and methods}

\section{Healthy volunteers}

Ten healthy volunteers (five women) with a mean age of $23 \pm 1$ years took part in this study. None of the volunteers had symptoms or a history of reflux disease or of surgery to the upper gastrointestinal tract or thorax. No medication was used except oral contraceptives. All volunteers were known to have normal esophageal motility based on a previous esophageal manometry study. Volunteers were asked not to smoke the morning of the test and not to eat at least 10 hours before. All volunteers signed informed consent for the study, which had been approved by the Ethics Committee of the hospital.

\section{Duodenal content aspiration}

In the first session, duodenal content (DC) was collected through a tube with a balloon, which was positioned into the second part of the duodenum under fluoroscopic control. The balloon serves to prevent mixing of gastric contents or food with duodenal contents. After the balloon was insufflated with air (Figure 4.1), a high caloric drink was given $\left(200 \mathrm{ml}\right.$ Nutridrink $^{*}$; $300 \mathrm{Kcal}^{\mathrm{K}} 13 \%$ proteins, $48 \%$ carbohydrates, and $39 \%$ lipids. Nutricia, Belgium). The aspiration was performed until about $20 \mathrm{ml}$ was collected. Preliminary studies revealed that this was the maximal duodenal fluid volume that consistently could be aspirated under the circumstances of the study. The fluid was divided into $4 \mathrm{ml}$ portions and frozen at $-80^{\circ}$ Celsius.

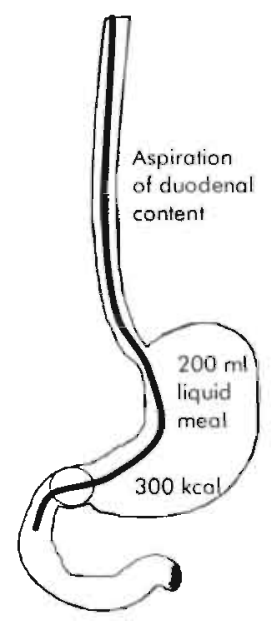

Figure 4. 1 . Scheme of the DC aspiration catheter with balloon insufflated after drinking a liquid meal of $200 \mathrm{ml}$ (300 Kcal). 
Analysis of duodenal fluid

The viscosity of the aspirated $D C$ was determined at $37^{\circ} \mathrm{C}$ by capillary viscometer. ${ }^{12}$ For characterization of the DC lipid composition, bile salt concentrations were determined employing the 3alpha-hydroxysteroid dehydrogenase assay. ${ }^{13}$ Total phospholipid levels were determined using phospholipase D and choline oxidase. ${ }^{14}$

The $\mathrm{pH}$, the composition and the viscosity of the aspirated DC were analyzed. Concentrations of bile salts, total lipids, phospholipids and the bile salt/phospholipid ratio, as well as amylase and lipase concentrations were measured.

Acid- and duodenal fluid labeling

One hour before the scintigraphic investigation took place, the four portions of duodenal fluid were defrosted and every $4 \mathrm{ml}$ was mixed with $0,1 \mathrm{ml} 0.20 \mathrm{mCi}$ of $\mathrm{Tc}^{99 \mathrm{~m}}$ pertechnetate. The fluid was shielded from light by aluminum paper wrapped around the syringes.

Four portions of acidic fluid were made and consisted of citric acid,

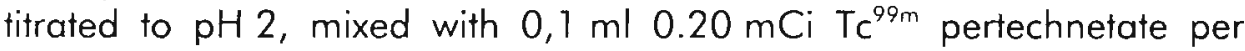
$4 \mathrm{ml}$. The total maximum exposure of the volunteer to labeled DC and acid together was approximately $1 \mathrm{mSv}$.

$\mathrm{pH}$ monitoring

Esophageal $\mathrm{pH}$ monitoring was performed using an antimony $\mathrm{pH}$ electrode with a separate skin reference electrode (Synectics Medical, Stockholm, Sweden). The data were stored on a portable digital recorder (Digitrapper Mk III, Synectics Medical, Stockholm, Sweden). Before each study, the $\mathrm{pH}$ probe was calibrated in buffer solutions of $\mathrm{pH} 7$ and 1 .

Bilitec $^{\text {B }}$ monitoring

The fiber-optic spectrophotometer Bilitec 2000 (Synectics, Stockholm, Sweden) was used to quantify the presence of DC in the esophagus. The system consists of a miniaturized probe of $5 \mathrm{~mm}$ diameter that carries light signals into the esophagus and back via a plastic fiber-optic bundle. Before each study, the probe was calibrated in water.

\section{Study protocol}

During the second session, a pH and Bilitec ${ }^{\mathbb{B}}$ probe were positioned $5 \mathrm{~cm}$ above the lower esophageal sphincter, assessed by manometric investigation, and controlled by fluoroscopy. The fluoroscopic control 
never exceed three seconds, at a radiation exposure of 20 microSv per second. A small infusion catheter was introduced in the proximal esophagus $4 \mathrm{~cm}$ past the upper esophagus sphincter (Figure 4.2). After positioning of the probes, a 60 minute accommodation period was provided prior to the start of the acquisitions. Subsequently, the subject was placed supine under a gamma camera to rule out gravity forces.

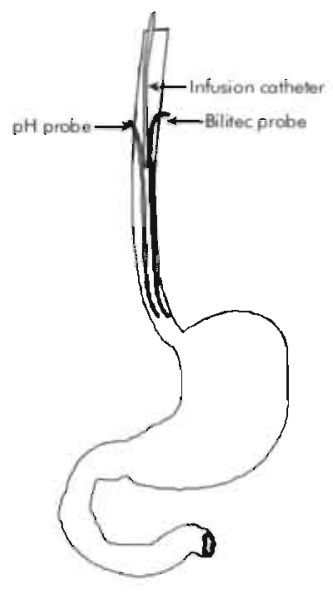

Figure 4.2. Scheme with the positioning of the $\mathrm{pH}$ and Bilitec $\mathrm{c}^{\text {a }}$ probe $5 \mathrm{~cm}$ above the lower esophagus sphincter and the localization of the infusion catheter about $4 \mathrm{~cm}$ below the upper esophagus sphincter.

In each subject, a total of eight clearance measurements (four DC and four acid solutions) were performed under combined fluoroscopic and $\mathrm{pH} /$ Bilitec $^{3}$ monitoring. A $4 \mathrm{ml}$ bolus of labeled fluid was introduced through the infusion catheter as a bolus in 2-3 seconds and one $\mathrm{ml}$ of air was used to clear the catheter of fluid. Four boluses of DC were instilled, and each time the subjects were asked to swallow every 20 seconds. During the second and the fourth session, saliva was aspirated using a dentist's tube. The order of experiments was not randomized to maintain simplicity of the acquisition protocol. After every bolus clearance measurement, the volunteer drank $5 \mathrm{ml}$ water to wash out the tracer fluid and to neutralize the esophagus, and an additional two minutes of rest was taken. Subsequently, the study protocol was repeated using four boluses of labeled acidic fluid. Shortly before each bolus administration a four minutes planar dynamic acquisition (240 frames; one second per frame) was started in anterior view. 
Data analysis

Bilitec ${ }^{(8)}$ and $\mathrm{pH}$ data were analyzed with the aid of commercially available software (Gastrosoft Inc. Synectics Medical, Irvine, Texas, USA). The acid clearance time (ACT) was defined as the time needed to reach a $\mathrm{pH}>4$ after the $\mathrm{pH}$ drop below 4 induced by instillation of the acidic fluid bolus. The duodenal content clearance time (DCCT) was defined as the time to reach an absorbance below 0.14 after an initial rise of absorbance above 0.14 induced by instillation of the DC bolus.

Volume clearance times (VCT) were analyzed by constructing dynamic time activity curves from the scintigraphic data. The esophagus was divided along its longitudinal axis into three equal anatomical regions (proximal, medial and distal) and scintigraphic measurements were analyzed for the total esophagus and for each section separately. For each bolus administration, the maximum count activity ( $\mathrm{Cmax}$ ) was determined. To rule out overlap with material accumulating in the proximal stomach, the range of interest was set manually (Figure 4.3). In the beginning of the experiment the counts returned to the original baseline after bolus passage. With prolonged duration of the experiment, scatter from material pooled in the fundic area influenced the return to baseline level. To minimize the influence of this scattering, the mean counts over the last 30 seconds of the measurement was calculated $\left(C_{210.240}\right)$, assuming complete esophageal clearance at that time. The VCT in seconds was defined as the time needed to reach a count intensity of $\mathrm{C}_{210-240}$ plus $25 \%$ of the maximum counts $(0.25 \mathrm{Cmax}$ ) over the region of interest. Expressed as a formula:

$$
\text { VCT }=\text { Time }\left(C_{210.240}+0.25 * C_{\text {max }}\right) \text {. }
$$

The acid volume clearance time (AVCT) was defined as the time needed to clear a labeled acidic fluid bolus. The duodenal content volume clearance time (DCVCT) was defined as the time needed to clear a labeled DC bolus, using similar calculations.

Statistical analysis

Values are expressed as mean \pm standard error of the mean (SEM). Clearance times were compared using Student's t-test. The Pearson's correlation coefficient between different clearance times was calculated by linear regression analysis. P-values were considered to be significant if $<0.05$. 


\section{Results}

\section{Fluid constitution}

The mean $\mathrm{pH}$ of the $\mathrm{DC}$ fluid was $6.7 \pm 0.3$. The fluid was representative for normal duodenal content ${ }^{12}$, and showed a mean total lipid concentration of $0.58 \pm 0.26 \mathrm{~g} / \mathrm{dl}$. The mean bile salt concentration was $9.3 \pm 4.8 \mathrm{mmol} / \mathrm{L}$, and the mean phospholipid concentration was $715 \pm 228 \mathrm{mmol} / \mathrm{L}$, resulting in a molar phospholipid to bile salt ratio of $0.19 \pm 0.16$. The viscosity of the DC fluid was significantly higher than the viscosity of the acid solution $\left(0.996 \pm 0.05\right.$ vs. $\left.0.7 \pm 0 \mathrm{mPA}^{*} \mathrm{~s}, \mathrm{p}<0.05\right)$. The levels of amylase and lipase activities in the aspirated duodenal fluid were $72800 \pm 8000 \mathrm{U} / \mathrm{L}$ and $173800 \pm 89400 \mathrm{U} / \mathrm{L}$ respectively.

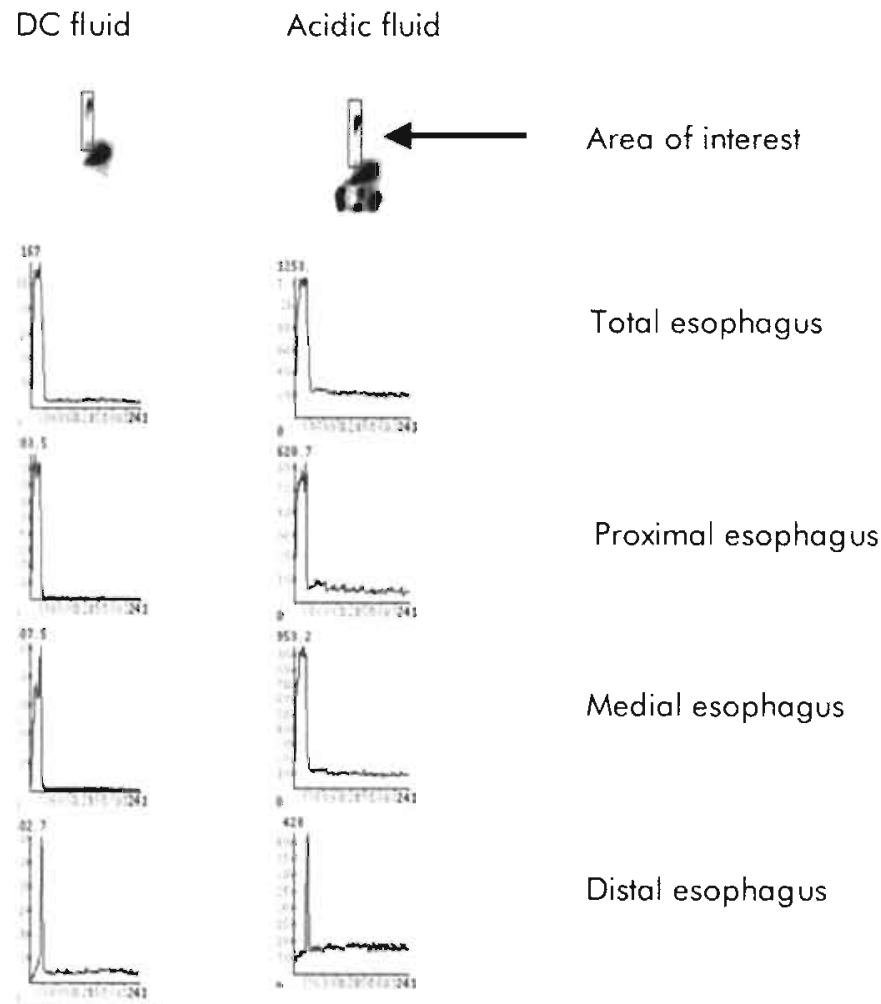

Figure 4.3. Example of a scintigraphic analysis for the volume clearance of acidic and DC fluid, divided into four ranges of interest for the calculations; total, proximal, medial and distal area. The x-axis on each graph represent time in seconds. 


\section{Scintigraphy}

The volume clearance times for acid (AVCT) and DC (DCVCT) are summarized in Table 4.1. AVCT and DCVCT did not differ significantly for total proximal $_{t}$ medial and distal areas of interest (Figure 4.4). In the distal esophagus, AVCT and DCVCT were significantly longer compared to the proximal esophagus. The distal esophageal AVCT and DCVCT were significantly correlated $(R=0.75, p=0.01)$. All other segmental AVCT and DVCT were not significantly correlated at any level fall $R<0.47$; all $p>0.05$.

There was no significant correlation belween fluid viscosity and volume clearance times without aspiration of saliva $(R<0.01$ and $R=-0.08$ respectively for $A V C T$ and $D C V C T$; both $p>0.05$ ).

Toble 4.1. Volume decronce times are expressed in seconds (SEM) for acidic fluid (AVCT) and duodenal contents (OCVCT), with and without saiva aspiration. Significont difference between proximot and distal volume dearance time is maked with". Volume clearance did not differ with and without aspiration for any of the parameters at any level.

\begin{tabular}{lcccccc}
\hline Solwa & \multicolumn{2}{c}{ Not aspirated } & p-wolve & \multicolumn{2}{c}{ Aspirated } & p-walue \\
& Acid & DC & & Acid & DC & NS \\
\hline Total & $29.3(2.5)$ & $29.6(11.5)$ & NS & $27.8(3.9)$ & $30.4(13.8)$ & NS \\
Proximal & $22.4(4.2)$ & $19.8(5.9)$ & NS & $20.2(6.0)$ & $22.9(7.2)$ & NS \\
Medial & $25.8(3.7)$ & $24.1(6.1)$ & NS & $24.6(3.4)$ & $24.5(5.3)$ & NS \\
Distal & $28.5(3.1)$ & $28.2(8.9)$ & NS & $28.0(4.3)$ & $29.9(13.1)$ & NS \\
\hline
\end{tabular}

Volume clearance

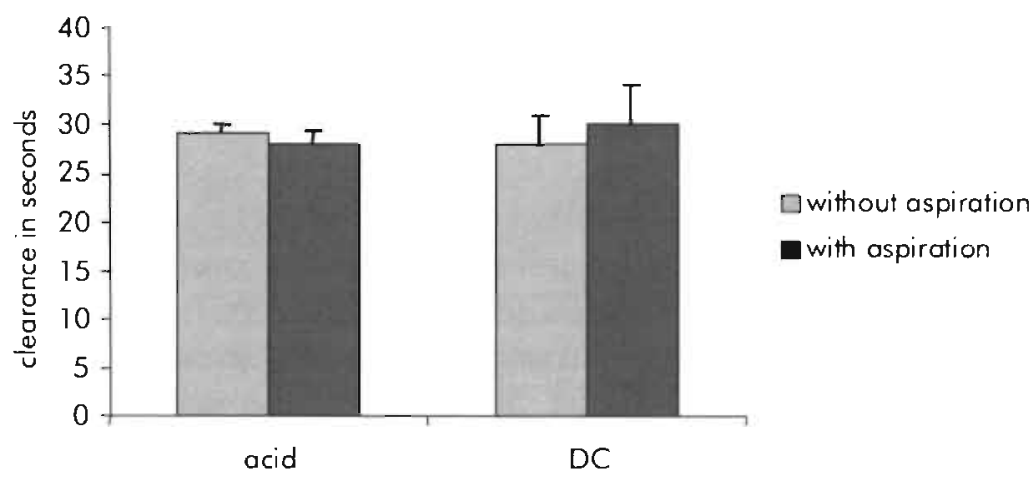

Figure 4.4. Bar diagram comparing acid and DC volume clearance in seconds (SEM) with and without saliva aspiration. 


\section{Ph and Bilitec monitoring}

The mean acid clearance time (ACT) determined by $\mathrm{pH}$ monitoring was $217 \pm 15$ seconds, which was significantly longer than the mean duodenal content clearance time (DCCT) of $131 \pm 27$ seconds determined by Bilitec monitoring $(p<0.05$; Figure 4.5).

$A C T$ and DCCT were not significantly correlated $(R=0.55 ; p>0.05)$. Chemical clearance times, both for acid and $D C$, were significantly longer than volume clearance times (all $p<0.005$ ). A significant correlation was present between ACT and AVCT $(R=0.74 ; p<0.05)$ and between DCCT and DCVCT $(R=0.78 ; p<0.05)$. There was no significant correlation between fluid viscosity and chemical clearance times without aspiration of saliva $(R<0.01$ and $R=0.017$ respectively for $A C T$ and DCCT, both $p>0.05$ ).

\section{Chemical clearance}

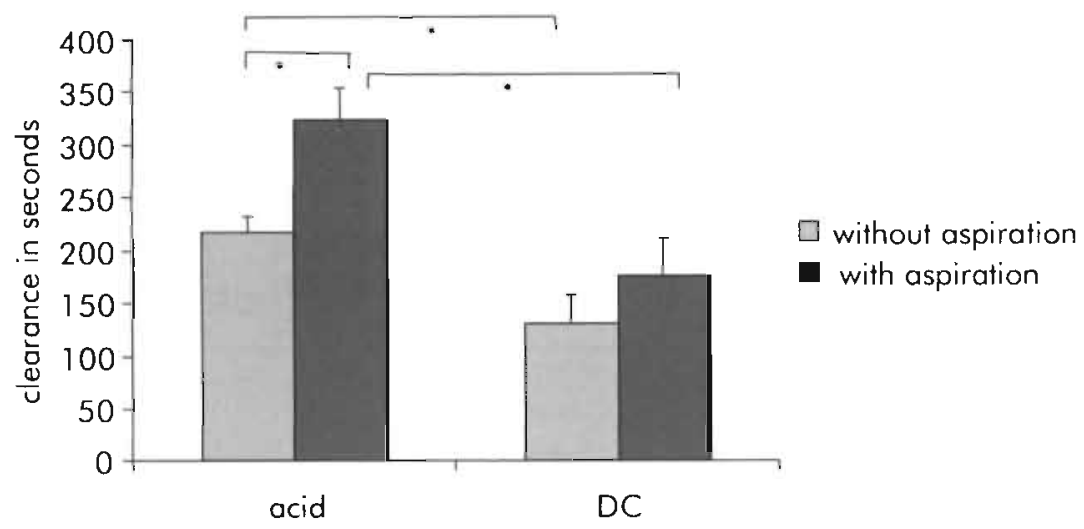

Figure 4.5. Bar diagram comparing acid and DC chemical clearance time in seconds (SEM) and without saliva aspiration. Significant difference is marked with *.

Influence of saliva aspiration

Aspiration of saliva had no significant influence on volume clearance times (Table 4.1, Figure 4.4). DCVCT, but not AVCT, with and without saliva aspiration were significantly correlated (respectively $R=0.79$, $p=0.01$ and $R=-0.12, p>0.05$ ). Saliva aspiration caused a significant increase of ACT (from $217 \pm 15$ to $324 \pm 30$ seconds, $p<0.05$ ), but did not significantly alter DCCT $(131 \pm 27$ to $175 \pm 36$ seconds, $p>0.05)$ (Figure $4.5)$. ACT with or without aspiration were not significantly correlated $(R=0.31, p>0.05)$, but a significant correlation was found between 
DCCT with and without aspiration $(R=0.75, p=0.01)$ and between DCCT and ACT with aspiration $(R=0.74, p=0.01)$.

There was no significant correlation between fluid viscosity and volume clearance times with aspiration of saliva $(R<0.01$ and $R=-0.36$ respectively for AVCT and DCVCT; both $p>0.05$ ).

\section{Discussion}

Although several studies have been devoted to esophageal acid clearance mechanisms ${ }^{1,16,17}$, the clearance of refluxed duodenal content (DC) has not been addressed. By injecting radio-labeled acid fluid into the distal esophagus, Helm et al. demonstrated that the elimination of acid from the esophagus is a two-step phenomenon. The bulk of the acid bolus was cleared by a secondary peristaltic wave, which was referred to as volume or bolus clearance. The clearance of the residual acidic fluid that sticks to the wall was significantly delayed by oral saliva aspiration, suggesting neutralization of acid by swallowed saliva. This second step was referred to as chemical clearance. ${ }^{16}$ In keeping with these observations, Shaker ef al. showed that an increase in swallow frequency accelerated the clearance of acid from the esophageal mucosal. ${ }^{17}$ In addition, esophageal mucosal defense mechanisms may also provide protection against noxious elements in the refluxate. ${ }^{18,19}$

In the present study, we confirmed the findings of Helm et al. on the influence of saliva aspiration on chemical clearance and not on volume clearance of an acidic fluid bolus. ${ }^{16}$ The $4 \mathrm{ml}$ boluses we used were smaller than the $15 \mathrm{ml}$ boluses used by Helm et al., but they demonstrated that no significant difference could be observed in clearance velocity using boluses of 2,5 or $15 \mathrm{ml} .^{16}$ It seems, therefore, that esophageal peristalsis provides clearance of refluxed duodenal contents while peristalsis and chemical clearance provide clearance of refluxed acid.

Studies combining $\mathrm{pH}$ and Bilitec ${ }^{B}$ monitoring in patients with severe esophagitis and Barrett's esophagus revealed that DGER episodes last significantly longer than acid reflux episodes., ${ }^{8,10}$ The reasons underlying this difference have not been elucidated, but they could be related to a slower volume clearance of DGER, to the absence of a chemical clearance mechanism for DGER or to the physical characteristics of the Bilitec ${ }^{*}$ probe, which may be prone to liquid entrapment in the tip. In addition, the biophysical characteristics and the volume of the refluxate may be different for DGER episodes compared to acid reflux episodes. 
Using scintigraphy and instillation of labeled boluses, we did not find any difference in volume clearance between acid and DC fluid, for any segment of the esophagus. The chemical clearance of a standardized DC fluid bolus measured with the Bilitec probe was significantly shorter than the chemical clearance of an acid bolus measured with a $\mathrm{pH}$ probe. As expected, saliva aspiration prolonged acid chemical clearance but did not affect DC clearance.

The bile salt concentrations in the aspirated duodenal fluids are higher compared to bile salt concentrations commonly reported for esophageal fluid in healthy volunteers as well as in patients with reflux disease ${ }^{20}$ This probably reflects the absence of a diluting effect of gastric juice to which the duodeno-gastro-esophageal refluxate is normally exposed in patients without gastric surgery. When gastro-esophageal reflux occurs, the refluxate will usually be a mixture of gastric acid, fluid from duodenal origin and food. Our study provides information on the clearance time of two of these components in their purest form. As the chemical clearance of acid was slower than the chemical clearance of DC, our findings suggest that further dilution of the $D C$ by gastric juice might prolong chemical clearance times for DC, thereby promoting toxic effects of much lower concentrations of bile salts in the esophagus.

The finding that DCCT was significantly shorter than ACT certainly argues against entrapment of liquid in the small cup at the tip of the

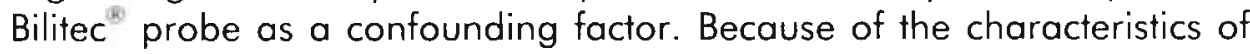
the probes, it is in theory conceivable that the $\mathrm{pH}$ probe compared to the Bilitec $^{(i)}$ probe more easily reaches small amounts of fluid adherent to the mucosa, although the scintigraphy did not reveal any differences between both. If DC fluid is in the same way adherent to the mucosa, the Bilitec $^{(8)}$ probe might even underestimate the presence of DC fluid in the esophagus, but until now no in vivo experiments have provided evidence for this possibility.

The constitution of the fluid, including its viscosity, may also be a relevant factor explaining the difference in chemical clearance. In the present study, the internal cohesive forces of the DC fluid were significantly stronger than those of the acidic fluid, potentially allowing for more complete evacuation during peristalsis. However, no correlation was found between bolus and chemical clearance with viscosity of the acid fluid and of the DC fluid, suggesting that viscosity was not the major determinant of the clearance velocity. Handling of refluxate by the esophageal mucosa is another potentially contributing factor. Bicarbonate secretion by esophageal submucosal glands is likely to 
facilitate intraluminal neutralization of acid. ${ }^{21}$ In addition, a small mucus layer, probably the result of mucus secretion in saliva and in esophageal submucosal glands, also provides protection of the esophageal mucosal cells. ${ }^{22}$ This surfactant layer may act to prevent direct contact between the cell membranes and lipophilic liquids, and differences in diffusion of fluid into this layer could be another explanation for the difference in clearance times between the acidic and DC fluid. ${ }^{18,19}$ Similar to the stomach $^{23}$, the mucus layer on the esophageal mucosa may not attract DC because of the liphophylic character, whereas acid could more easily diffuse because of the hydrogen ion content. ${ }^{24}$ If not neutralized, acid that has diffused into the mucus layer may be less readily cleared by peristalsis compared to acid present within the lumen of the esophagus. Furthermore, if the $\mathrm{pH}$ probe is also embedded in the mucus, trapping of acid ions in this micro-environment may result in prolonged clearance times. The mucus layer may help to provide a barrier against adherence of bile salts to the cell membranes, which is thought to constitute the damaging effect of bile salts on the esophagus mucosal. ${ }^{25}$

The present clearance studies, which failed to demonstrate a prolonged volume or chemical clearance for DC compared to acid, do not readily explain the longer duration of DGER episodes during ambulatory monitoring. Previous analyses have shown that most DGER episodes occur at acidic $\mathrm{pH}$, and are in fact mixtures of acid and DGER. ${ }^{8}$ it seems conceivable, therefore, that episodes of DGER constitute a higher volume of refluxate than episodes of acid reflux alone, and that this accounts for the longer clearance time of these episodes. Preliminary data, showing that patients with pathological exposure of the distal esophagus to both acid and DGER have more reflux in the proximal esophagus than patients with pathological acid exposure alone, are in keeping with this hypothesis. ${ }^{26}$ Further studies will clearly be needed to address this issue.

In conclusion, under experimental conditions, volume clearance of acidic fluid and of DC fluid is comparable and depends on esophageal peristalsis. Chemical clearance of acid is slower than chemical clearance of DC. Neutralization by saliva plays a major role in the chemical clearance of acid only. We found no evidence for entrapment of the DC bolus in the Bilitec probe, thereby artificially prolonging DGER episodes. The physical characteristics of the liquid, especially viscosity, may influence peristaltic clearance. 


\section{References}

1. Holloway RH. Esophageal body motor response to reflux events: secondary peristalsis. Am J Med 2000;108 suppl 4a:20-6.

2. Helm JF, Dodds WJ, Hogon WJ. Salivary response to esophageal acid in normal subjects and patients with reflux esophagitis. Gastroenterology 1987;93:1393-7.

3. Lillemoe KD, Johnson LF, Harmon JW. Role of the components of the gastroduodenal contents in experimental acid esophagifis. Surgery 1982;92: 276-84.

4. Salo JA, Kivilaakso E. Role of bile salts and trypsin in the pathogenesis of experimental alkaline esophagitis. Surgery 1983;93:525-32.

5. Kiroff GK, Devitt PG, DeYoung NJ, Jamieson GG. Bile salt-induced injury of rabbit oesophageal mucosa measured by hydrogen ion disappearance. Aust $\mathrm{N} Z \mathrm{Z}$ Surg 1987;57:111-7.

6. Champion G, Richter JE, Vaezi MF, Singh S, Alexander R. Duodenogastroesophageal reflux: relationship to $\mathrm{pH}$ and importance in Barrett's esophagus. Gastroenterology 1994;107:747-54.

7. Caldwell MT, Lawlor P, Byrne PJ, Walsh TN, Hennessy TP. Ambulatory esophageal bile reflux monitoring in Barrett's esophagus. Br J Surg 1995;82:657-60.

8. Kaver WK, Peters JH, DeMeester TR, Ireland AP, Bremner CG, Hagen JA. Mixed reflux of gastric and duodenal juices is more harmful to the esophagus than gastric juice alone. The need for surgical therapy re-emphasized. Ann Surg 1995;222: 525-31.

9. Vaezi MF, Richter JE. Role of acid and duodenogastrooesophageal reflux in gastroesophageal reflux disease. Gastroenterology 1996;111:1192-9.

10. Marshall RE, Anggiansah A, Owen WA, Owen WJ. The relationship between acid and bile reflux and symptoms in gastro-esophageal reflux disease. Gut 1997;40:182-7.

11. Okholm M, Sorensen H, Wallin L, Boesby S. Bile reflux into the esophagus. Bilitec 2000 measurements in normal subjects and in patients after Nissen fundoplication. Scand J Gastroenterol 1999;34:653-7.

12. Ramakrishnan $S$, Grebe $R$, Singh $M$, Schmid-Schönbein $H$. Evaluation of hemorheological risk factor profile in plasmacytoma patients. Clin Hemorheol Microcirc 1999;20:11-19.

13. Turley SD, Dietschy JM. Re-evaluation of the 3 alpha-hydroxysteroid dehydrogenase assay for total bile acids in bile. J Lipid Res 1978;19:924-8.

14. Takayama $M$, Itoh S, Nagasaki T, Tanimizu L. A new enzymatic method for determination of serum choline-containing phospholipids. Clin Chim Acta 1977;79: 93-8. 
15. Venkataramani A, Strong RM, Anderson DS, Gilmore IT, Stokes $K$, Hofmonn AF. Abnormal duodenal bile composition in patients with acalculous chronic cholecystitis. Am J Gastroenterol 1998;93:434-41.

16. Helm JF, Dodds WJ, Pelc LR, Palmer DW, Hogan WJ, Teeter BC. Effect of esophageal emptying and saliva on clearance of acid from the esophagus. NEJM 1984;310:284-8.

17. Shaker R, Dodds WJ, Helm JF, Kern MK, Hogan WJ. Regional esophageal distribution and clearance of refluxed gastric acid. Gastroenterology 1991; 101:355-9.

18. Namiot Z, Rourk RM, Piascik R, Hetzel DP, Sarosiek J, McCallum RW. Interrelationship between esophageal challenge with mechanical and chemical stimuli and salivary protective mechanisms. Am J Gastroenterol 1994;89:581-7.

19. Dixon J, Strugala V, Griffin SM, Welfare MR, Dettmar PW, Allen A, Pearson JP. Esophageal mucin: an adherent mucus gel barrier is absent in the normal esophagus but present in columnar-lined Barrett's esophagus. Am J Gastroenterol $2001 ; 96: 2575-83$.

20. Nehra D, Howell P, Williams CP, Pye JK, Beynon J. Toxic bile acids in gastrooesophageal reflux disease: influence of gastric acidity. Gut 1999;44:598-602.

21. Long JD, Orlando RC. Esophageal submucosal glands: structure and function. Am J Gastroenterol 1999;94:2818-24.

22. Rayment SA, Liu B, Offner GD, Oppenheim FG, Troxler RF. Salivary Mucin: a factor in the lower prevalence of gastroesophageal reflux disease in African-Amdericans? Am J Gastroenterol 2000;95:3064-70.

23. Hills BA, Butler BD, Lichtenberger LM. Gastric mucosal barrier: hydrophobic lining to the lumen of the stomach. Am J Physiol 1983;244:G561-8.

24. Hills BA. Oesophageal surfactant: evidence for a possible mucosal barrier on oesophageal epithelium. Aust N Z J Med 1994;24:41-6.

25. Kivilaakso $E$, Fromm D, Silen W. Effect of bile salts and related compounds on isolated esophageal mucosa. Surgery 1980;87:280-5.

26. Cool M, Poelmans J, Koek G, Sifrim D, Feenstra L, Janssens J, Tack J. Characteristics and clinical relevance of proximal esophaeal $\mathrm{pH}$ monitoring. 2003 Submitted for publication. 


\section{Chapter 5}

\section{Dietary restrictions during ambulatory monitoring of duodeno-gastro-esophageal reflux}

J Tack, R Bisschops, GH Koek, D Sifrim, T Lerut, J Janssens

Dig Dis Sci: $2003 ; 48: 1213-20$ 


\section{Abstract}

\section{Background}

To avoid food impaction artifacts during ambulatory bile reflux monitoring (Bilitec ${ }^{2}$ ), some groups have allowed only a liquid diet, while others omitted the meal and postprandial periods from the analysis.

Aim

To study whether Bilitec ${ }^{\oplus}$ monitoring requires the use of a liquid diet.

\section{Methods \\ In 40 healthy subjects and 211 consecutive patients evaluated for suspected gastro- esophageal reflux disease, we performed an ambulatory 24 hours esophageal $\mathrm{pH}$ and Bilitec $^{\text {int }}$ monitoring. The subjects were randomized to use either solid or liquid meals during the procedure. All patients underwent an upper gastrointestinal endoscopy.}

\section{Results}

In healthy subjects, liquid and solid diets were followed by similar acid exposure of the distal esophagus. During bile reflux monitoring, major meal artifacts occurred in $19 \%$ of the patients using solid meals, but in none of the patients using liquid meals. With liquid meals, but not with solid meals, a progressive increase in duodeno-gastro-esophageal reflux occurred with increasing severity of endoscopic lesions. With liquid meals, but not with solid meals, the prevalence of pathological exposure to duodeno-esophageal reflux increased with increasing severity of endoscopic lesions. With liquid meals, the results of $\mathrm{pH}$ monitoring and bile reflux monitoring correlated better than with solid meals.

\section{Conclusions}

Ambulatory Bilitec monitoring requires the use of liquid meals, as the use of solid meals is associated with too many meal artifacts and a poorer correlation with acid reflux and severity of endoscopic lesions. 


\section{Introduction}

Reflux of duodenal contents via the stomach into the esophagus has long been suspected to be of pathophysiological relevance to mucosal lesions in gastro-esophageal reflux disease (GERD). Stationary aspiration studies were able to demonstrate the presence of bile in esophageal aspirates from patients with esophagitis. ${ }^{12}$ Some studies reported a good correlation between biliary scintigraphy and gastric bile acids, but the method is at best semiquantitative, only suitable for short study periods, and several technical problems may interfere with the measurement. ${ }^{3}$ Direct and prolonged quantification of duodeno-esophageal reflux has been difficult to achieve. It has been suggested that alkaline periods during esophageal $\mathrm{pH}$ monitoring might represent duodeno-gastro-esophageal reflux (DGER). ${ }^{4}$ However, combined aspiration and $\mathrm{pH}$ monitoring studies have shown that this is not the case ${ }^{5}$, and most alkaline episodes on esophageal $\mathrm{pH}$ monitoring are due to swallowed saliva.,

More recently, Bilitec ${ }^{\text {E }} 2000$, a fiber-optic spectrophotometric probe, was developed to quantify bile reflux in an ambulatory fashion. Bilirubin, the most common pigment in bile, has a characteristic absorbance spectrum, and by continuous monitoring of the absorbance of two light emitting diodes at two different wavelengths of the esophageal refluxate, the presence of bilirubin can be detected. Validation studies confirmed a good correlation between Bilitec ${ }^{B}$ measurements and bile acid concentrations. ${ }^{8.10}$ Ambulatory aspiration studies found a significant correlation between the total bilirubin concentration of aspirated samples and the fiber-optic reading of bilirubin concentration. "Moreover, a good correlation was found between total bilirubin content and the concentrations of pancreatic enzymes in the refluxate, suggesting that bilirubin is a good tracer for DGER." Using the Bilitec probe, several recent studies have demonstrated a progressive increase in DGER across the spectrum of GERD, with a particularly high prevalence in patients with Barrett's esophagus. ${ }^{12-17}$ In addition, a good correlation was found between the results of $\mathrm{pH}$ monitoring data and Bilitec ${ }^{60}$ monitoring. ${ }^{12,15-17}$

Due to its construction, the Bilitec probe is prone to solid food impaction causing measurement artifacts (Figure 5.1). Moreover, foods such as soups, tea and coffee give high Bilitec ${ }^{k}$ readings that may interfere with adequate bile reflux monitoring. ${ }^{10}$ Several strategies have been used to avoid artifacts due to food impaction during Bilitec recording. In some 
studies only liquid meals were used. ${ }^{12.17}$ Others used solid meals, but eliminated food that interferes with bilirubin absorbance, or excluded the meal and postprandial period from the analysis (interprandial bile reflux). ${ }^{13,16}$ The aim of the present study was to establish which dietary restrictions are required during Bilite ${ }^{\circledR}$ recording. As a gold standard to measure DGER is lacking, we used a) the correlation with lesions, b) the correlation with the $\mathrm{pH}$-metry and c) the occurrence of artifacts to evaluate the performance of Bilitec ${ }^{\text {(i) }}$ monitoring using different dietary restrictions.

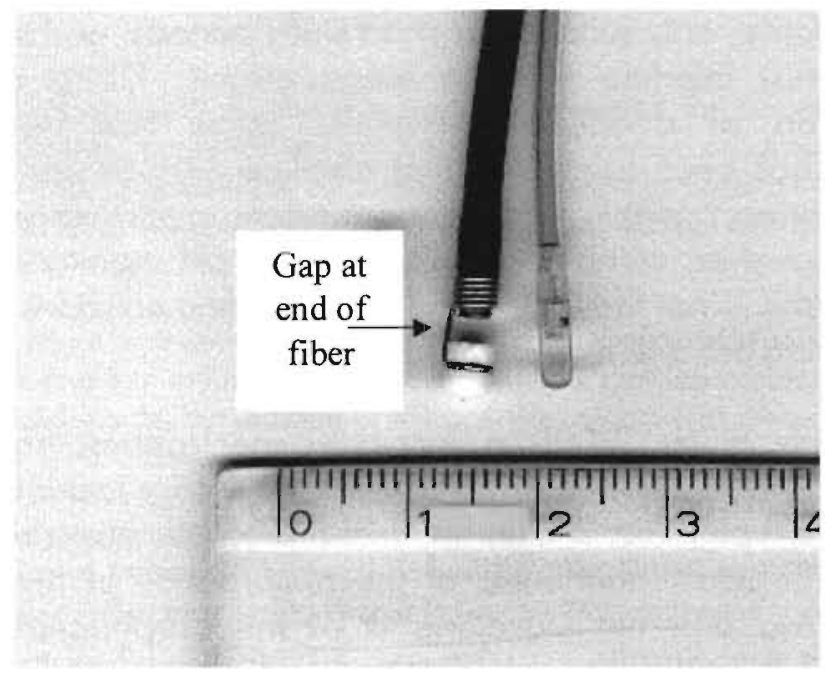

Figure 5.1. Photograph of a Bilitec probe. Food impaction occurs in the $2 \mathrm{~mm}$ gap between the white Teflon tip and the end of the optical fiber.

\section{Materials and methods}

Study subjects.

Forty healthy controls (24 men and 16 women; age 19-41 years; mean age $26 \pm 0.9$ years) and 211 patients evaluated for suspected gastroesophageal reflux disease (118 men and 93 women; age 18-81 years; mean age $45.2 \pm 1.0$ years) participated in this study. The patients were significantly older than the healthy subjects $(p<0.001)$. None of the healthy subjects had symptoms or a history of gastrointestinal disease or drug allergies, nor were they taking any medication. Patients were eligible for the study if they were evaluated for suspected gastro- 
esophageal reflux disease and if they had a normal serum bilirubin level. Exclusion criteria were: peptic ulcer disease, previous esophageal, gastric or biliary surgery, previous abdominal or thoracic radiotherapy, active gastrointestinal bleeding, presence of esophageal or fundic varices, esophageal or upper small intestinal Crohn's disease, herpetic or Candida esophagitis or active solid tumor neoplastic disease.

\section{Upper gastrointestinal endoscopy}

All subjects underwent classical upper gastrointestinal endoscopy. If necessary, they were sedated by intravenous administration of diazepam (up to $10 \mathrm{mg}$ ) or midazolam (up to $4 \mathrm{mg}$ ). During endoscopy, the presence of esophagitis was noted and graded according to the modified classification of Savary and Miller, which is the basis for reimbursement of proton pump inhibitors in Belgium. ${ }^{18,19}$ In addition, the presence and extent of Barrett's esophagus and of a hiatal hernia was noted.

\section{Ambulatory $\mathrm{pH}$ monitoring}

Ambulatory esophageal $\mathrm{pH}$ monitoring was performed using an antimony $\mathrm{pH}$ electrode with a separate skin reference electrode (Synectics Medical, Stockholm, Sweden). The data were stored on a portable digital recorder (Digitrapper Mk III, Synectics Medical, Stockholm, Sweden). Before each study, the $\mathrm{pH}$ probe was calibrated in buffer solutions of $\mathrm{pH}$ 7 and 1. An episode of acid reflux was defined as a decrease in esophageal $\mathrm{pH}$ to less than 4 during more than 10 seconds.

Measurement of duodeno-gastro-esophageal reflux

The fiber-optic spectrophotometer Bilitec 2000 (Synectics, Stockholm, Sweden) was used to quantify DGER. The system consists of a miniaturized probe of $5 \mathrm{~mm}$ diameter that carries light signals into the esophagus and back via a plastic fiber-optic bundle. Before each study, the probe was calibrated in water. An episode of bile reflux is defined as an increase in esophageal bilirubin absorbance $>0.14$ for more than 10 seconds. ${ }^{13,16}$

\section{Study protocol}

The study protocol was accepted by the Ethics Committee of the hospital. In 40 healthy subjects and 211 consecutive patients evaluated for suspected gastro-esophageal reflux disease, we performed an upper gastrointestinal endoscopy, followed by an ambulatory 24 hours

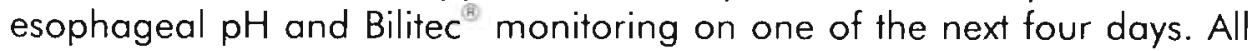


drugs potentially affecting gastrointestinal motility and gastrointestinal secretion were discontinued at least one week prior to the study.

On the day of the ambulatory monitoring, probes for assessing acid and DGER were introduced via a nasal orifice into the esophagus $5 \mathrm{~cm}$ proximal to the lower esophageal sphincter, defined by preceding stationary esophageal manometry. The probes were then attached with adhesive tape to the subjects nose and cheek. In addition, appropriate positioning in the esophagus was confirmed by fluoroscopy. Data collection devices were connected to the probes and worn in a belt on the patient's waist. Registration of acid or DGER lasted for approximately 22 hours after which the probes were removed and the data transferred to a personal computer for analysis with the aid of commercially available software (Gastrosoft Inc., Synectics Medical, Irvine, Texas, USA). Patients recorded the time of food or fluid consumption and posture changes on a diary card. They were requested to avoid coffee and fruit juices during the recording, and to stay upright during the daytime.

\section{Meals}

Volunteers and patients were randomized to use either normal meals $(n=20$ volunteers and 105 patients), or to take only liquid meals ( $n=20$ volunteers and 106 patients) during the ambulatory monitoring. When solid meals were used, the subjects were instructed to avoid foods that are known to interfere with Bilitec ${ }^{B}$ readings, and to drink two glasses of water after each meal. When liquid meals were used, subjects were instructed to drink two to four units of a commercially available preparation $(200 \mathrm{ml}, 300 \mathrm{kcal}, 13 \%$ proteins, $48 \%$ carbohydrates, $39 \%$, Nutridrink , Nutricia, Belgium) at each meal. In vitro, we established that submersion of the Bilitec ${ }^{\circ}$ probe into this liquid meal does not cause a change in absorbance at the detected wavelength (data not shown).

\section{Data analysis}

Acid and duodenal reflux were quantified separately with the following variables obtained from computerized analysis: number of reflux episodes per hour, number of reflux episodes lasting longer than 5 minutes per hour, fraction of time of acid or DGER. Analysis was done separately for the total recording time and for the interprandial period, which was obtained by omitting the meal and two hours postprandial periods from the recording. ${ }^{13}$ Major meal artifacts were defined as rises of bilirubin absorbance at the time of meal, persisting without variation until the next meal or the night time. ${ }^{13}$ Because of their long duration, it 
seems highly unlikely that these represent true reflux events. The periods in which major meal artifacts occurred were eliminated from further analysis. The upper limit of the normal (95\% confidence interval) for acid and DGER was calculated from the data in healthy volunteers. The $\%$ of patients with abnormal acid or DGER was determined for different grades of esophagitis.

Values are presented as means \pm SEM for parametric data and median (interquartile range) for non-parametric data. Normally distributed data were compared by Student's t-test and not normally distributed data by the Mann-Whitney test. Spearman's rank test was used to study the correlation between the percentage of time acid and duodenal reflux. The chi-square test was used to compare the prevalence of abnormal acid reflux or DGER exposure in patients with different endoscopic grades of esophagitis. P-values were considered to be significant if $<0.05$.

\section{Results}

Characteristics of patients and healthy subjects

Two hundred and eleven patients (91 women, mean age $46 \pm 1$ year) and 40 healthy subjects were included in the study. Upper gastrointestinal endoscopy revealed no esophagitis in 99 patients $(47 \%)$ and grade 1, 2 and 3 esophagitis in respectively 27 (15\%), $38(18 \%)$ and $6(3 \%)$ patients. Twenty-nine patients (14\%) had a Barrett's esophagus, two $(1 \%)$ had a peptic stricture and five $(2 \%)$ had a peptic esophageal ulcer. They were all grouped as grade 4 esophagitis. None of the 20 healthy subjects who underwent gastrointestinal endoscopy had esophagitis. Table 5.1 shows the demographic characteristics of the study subjects. There were no differences between subjects having liquid or solid meals (Table 5.1).

\section{Healthy subjects}

The mean duration of the ambulatory $\mathrm{pH}$ and Bilitec ${ }^{\mathbb{1}}$ monitoring study was 22 hours $39 \pm 8$ minutes. The results of the ambulatory $\mathrm{pH}$ monitoring are summarized in Table 5.2. No significant differences in acid exposure of the distal esophagus occurred when solid or liquid meals were used. The upper limit of the normal ( $95^{\text {th }}$ percentile) for acid reflux did not differ between solid or liquid meals (respectively 4.8 and $4.7 \%$ of total time). 
Table 5.1. Characteristics of patients and healthy subjects according to dietary restrictions used.

\begin{tabular}{llccc}
\hline & Characteristic & Solid meals & Liquid meals & p \\
\hline Healthy & Number & 20 & 20 & \\
subjects & Male / female & $11 / 9$ & $13 / 7$ & NS \\
& Mean age & $26.5 \pm 1.2$ & $25.3 \pm 1.3$ & NS \\
Patients & Number & 105 & 106 & \\
& Male / female & $61 / 44$ & $57 / 49$ & NS \\
& Esophagitis grade & $45 / 13 / 23 / 5 / 19$ & $54 / 19 / 15 / 1 / 17$ & NS \\
& $0 / 1 / 2 / 3 / 4$ & $45.4 \pm 1.4$ & $44.5 \pm 3.4$ & NS \\
\hline
\end{tabular}

In contrast, whether solid or liquid meals were used had a major impact on the results of Bilitec ${ }^{B}$ monitoring (Table 5.3). The percentage of time that DGER was present in the distal esophagus, the number of DGER episodes and the number of DGER episodes lasting longer than five minutes were all significantly higher when solid meals were used. In addition, the upper limit of the normal $\left(95^{\text {th }}\right.$ percentile) for DGER showed a very large difference between solid or liquid meals (respectively 31.9 and $4.6 \%$ of total time).

Table 5.2. Characteristics of $\mathrm{pH}$ monitoring according to dietary restrictions in healthy subjects.

\begin{tabular}{lccc}
\hline Characteristic & Solid meals & Liquid meals & $\mathrm{P}$ \\
\hline Number of reflux episodes & $32(11-52)$ & $27(12-50)$ & $\mathrm{NS}$ \\
Number of reflux episodes $>5$ minutes & $0.0(0-0)$ & $0.0(0-1)$ & $\mathrm{NS}$ \\
$\%$ of total time $\mathrm{pH}<4$ & $1.5(0.6-1.9)$ & $1.7(0.2-2.4)$ & $\mathrm{NS}$ \\
$\%$ of upright time $\mathrm{pH}<4$ & $2.3(0.6-3.0)$ & $2.3(0.4-2.8)$ & $\mathrm{NS}$ \\
$\%$ of interprandial time $\mathrm{pH}<4$ & $1.1(0.3-1.6)$ & $1.9(0.2-2.3)$ & $\mathrm{NS}$ \\
$\%$ of meal time $\mathrm{pH}<4$ & $0.7(0.0-2.7)$ & $0.0(0.0-2.1)$ & $\mathrm{NS}$ \\
$\%$ of postprandial time $\mathrm{pH}<4$ & $0.7(0.1-4.7)$ & $0.3(0.1-1.9)$ & $\mathrm{NS}$ \\
$\%$ of supine time $\mathrm{pH}<4$ & $0.0(0.0-0.4)$ & $0.0(0.0-0.1)$ & $\mathrm{NS}$ \\
\hline
\end{tabular}

The difference between solid and liquid diets was mainly attributable to an increased number of DGER episodes during the upright period when solid meals were used. Interprandial reflux (eliminating the meal and postprandial period) did not differ significantly between solid and liquid meals, suggesting that the difference is occurring mainly during the meal and postprandial period (Table 5.3). 
Table 5.3. Characteristics of Bilitec monitoring according to dietary restrictions in healthy subjects.

\begin{tabular}{lccc}
\hline Characteristic & Solid meals & Liquid meals & $p$ \\
\hline Number of reflux episodes & $29(11-49)$ & $5(0-20)$ & 0.01 \\
Number of reflux episodes $>5$ minutes & $4(3-7)$ & $0(0-3)$ & 0.002 \\
Number of upright reflux episodes & $24(11-45)$ & $5(0-20)$ & 0.04 \\
Number of inferprandial reflux episodes & $14(4-25)$ & $1(0-13)$ & $\mathrm{NS}$ \\
Number of mealtime reflux episodes & $3(1-6)$ & $0(0-2)$ & 0.03 \\
Number of postprandial reflux episodes & $7(2-9)$ & $0(0-4)$ & 0.01 \\
Number of supine reflux episodes & $0(0-5)$ & $0(0-0)$ & $\mathrm{NS}$ \\
$\%$ of total time absorbance $>0.14$ & $10.9(6.7-19.3)$ & $0.3(0.0-2.8)$ & $<0.001$ \\
$\%$ of upright time absorbance $>0.14$ & $11.9(4.7-30.7)$ & $0.5(0.0-4.3)$ & 0.005 \\
$\%$ of interprandial time absorbance $>0.14$ & $12.3(1.4-17.5)$ & $0.1(0.0-1.3)$ & 0.001 \\
$\%$ of meal time absorbance $>0.14$ & $19.7(2.3-36.8)$ & $0.0(0.0-5.4)$ & 0.03 \\
$\%$ of postprandial time absorbance $>0.14$ & $23.7(6.2-30.5)$ & $0.0(0.0-7.6)$ & 0.005 \\
$\%$ of supine time absorbance $>0.14$ & $0.0(0.0-27.7)$ & $0.0(0.0-0.00)$ & $\mathrm{NS}$ \\
\hline
\end{tabular}

Major meal artifacts were present in two subjects (10\%) with solid meals, and in none with liquid meals. In healthy subjects, regardless of the meal used, no significant correlation existed between the acid exposure and the exposure to DGER in the esophagus.

\section{Patients evaluated for suspected gastro-esophageal reflux disease}

The mean duration of the ambulatory $\mathrm{pH}$ and Bilitec monitoring study was 21 hours $27 \pm 6$ minutes. When liquid meals were used, no major meal artifacts occurred. In contrast, major meal artifacts occurred in 19 (18\%) of the Bilitec ${ }^{(1)}$ studies with solid meals (Figure 5.2; $<<0.001$ ).

To study the relationship between the result of prolonged $\mathrm{pH}$ and Bilitec monitoring and severity of mucosal damage, grade 1 and 2 esophagitis and grade 3 and 4 esophagitis were grouped together. Table 5.4 summarizes the results of $\mathrm{pH}$ and Bilitec ${ }^{*}$ monitoring according to dietary restrictions and severity of mucosal damage. The acid exposure of the distal esophagus increased with increasing severity of esophagitis, both with solid meals or liquid meals (Figure 5.3; Table 5.4): the exposure to acid was significantly lower in endoscopy negative patients than in those with esophagitis grade 1,2 and those with esophagitis grade 3,4 $(p<0.01$ in all cases). The acid exposure for the same degree of esophagitis did not differ between patients using liquid or solid meals (Figure 5.3; Table 5.4). The proportion of patients with abnormal esophageal acid exposure increased with increasing severity of esophagitis, both with solid meals and with liquid meals (Figure 5.4). 


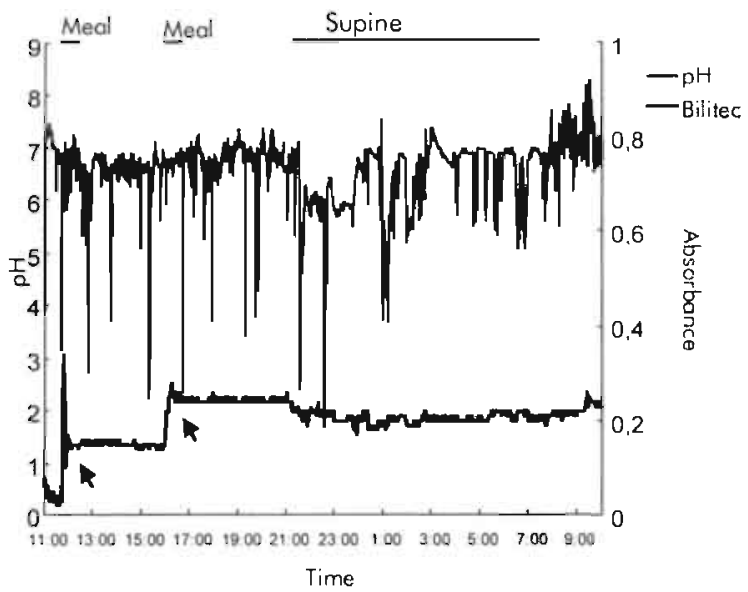

Figure 5.2. Example of an ambulatory $\mathrm{pH}$ and Bilitec monitoring with two major meal artifacts, indicated by arrows. Each meal induces an increase in the intraesophageal absorbance which persists with little variation until the next meal or the night time.

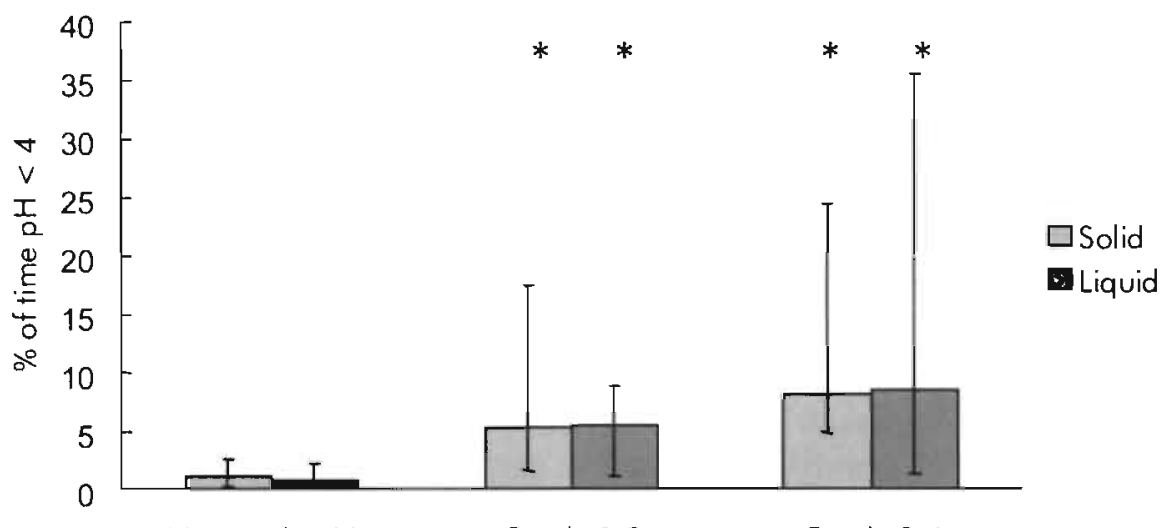

Figure 5.3. Relationship between the results of ambulatory $\mathrm{pH}$ monitoring using solid or liquid meals and the degree of esophagitis in 211 patients evaluated for suspected reflux disease. The bar graph depicts the median value; interquartile ranges are shown as error bars. The acid exposure of the distal esophagus increased with increasing grades of esophagitis, both when solid meals or liquid meals were used. The acid exposure for the same degree of esophagitis did not differ between patients using liquid or solid meals ( ${ }^{*}: p<0.01$ compared to no esophagitis). 
Table 5.4. Results of ambulatory $\mathrm{pH}$ and Bilitec monitoring according to dietary restrictions and grade of esophagitis in patients evaluated for suspected reflux disease. Exposure of the distal esophagus to acid or DGER is given as median (interquartile range).

\begin{tabular}{|c|c|c|c|c|}
\hline & Diet & No esophagitis & Grade 1,2 & Grade 3,4 \\
\hline \multirow[t]{4}{*}{$\mathrm{pH}$} & Solid & $1.3(0.3 ; 2.6)$ & $5.3(1.6 ; 17.4)$ & $8.2(4.8 ; 24.5)$ \\
\hline & Solid interprandial & $0.9(0.2 ; 2.5)$ & $4.4(1.1 ; 11.9)$ & $5.9(0.4 ; 19.1)$ \\
\hline & Liquid & $0.9(0.1 ; 2.2)$ & $5.4(1.1 ; 8.9)$ & $8.5(1.4 ; 35.5)$ \\
\hline & Liquid interprandial & $0.7(0.1 ; 2.3)$ & $5.5(1.5 ; 11.6)$ & $8.7(1.0 ; 31.7)$ \\
\hline \multirow[t]{4}{*}{ Bilitec" } & Solid & $7.7(3.7 ; 17.0)$ & $15.3(4.0 ; 42.1)$ & $15.5(6.1 ; 28.2)$ \\
\hline & Solid interprandial & $3.1(1.4 ; 13.1)$ & $11.1(2.2 ; 39.6)$ & $11.6(2.8 ; 26.4)$ \\
\hline & Liquid & $0.8(0.0 ; 8.9)$ & $3.8(0.5 ; 14.5)$ & $23.0(4.5 ; 44.1)$ \\
\hline & Liquid interprandial & $0.7(0.0 ; 7.2)$ & $4.4(0.5 ; 14.3)$ & $18.2(4.4 ; 39.2)$ \\
\hline
\end{tabular}

With solid meals, the exposure of the distal esophagus to DGER did not increase with increasing grades of esophagitis (Figure 5.5; Table 5.4). Limiting the Bilitec ${ }^{\circledR}$ analysis to the interprandial period did not provide a better relationship with endoscopic lesions (Figure 5.5; Table 5.4). In contrast, when liquid meals were used, the exposure to DGER was significantly higher in patients with esophagitis grade 3,4 than in those with esophagitis grade 1,2 or endoscopy negative patients $(p<0.05$ and $p<0.005$ respectively) (Figure 5.5; Table 5.4). When only interprandial DGER was analyzed, a statistically significant difference was present between endoscopy negative patients and those with esophagitis grade $3,4(p<0.005)$ (Figure 5.5; Table 5.4). When solid meals were used, the proportion of patients with pathological DGER did not increase with increasing severity of esophagitis, even when the analysis was limited to the interprandial period (Figure 5.6). When liquid meals were used, the proportion of patients with pathological DGER increased with increasing severity of esophagitis (Figure 5.6).

When solid meals were used, a very weak correlation existed between the $\%$ of time that the distal esophagus was exposed to acid, and the $\%$ of the total time that the distal esophagus was exposed to DGER $\{R=0.27 ; p=0.02)$. When the analysis was limited to the interprandial period, this correlation was only marginally improved $(R=0.29 ; p=0.02)$. When liquid meals were used, a better correlation between the $\%$ of time that the distal esophagus was exposed to acid, and the $\%$ of the total time that the distal esophagus was exposed to DGER was observed $(R=0.59 ; p=0.001)$. 


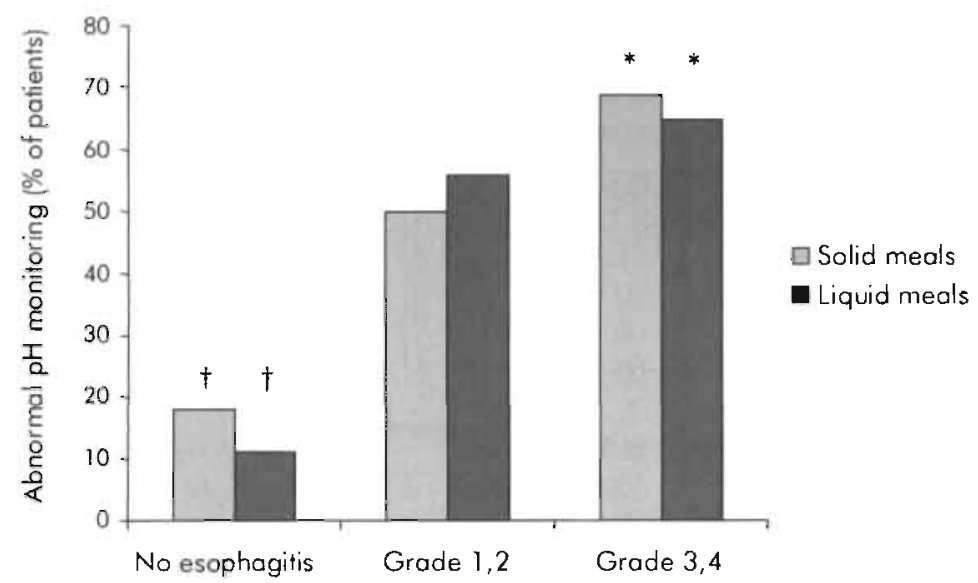

Figure 5.4. Prevalence of abnormal esophageal acid exposure $>95^{\text {th }}$ percentile in 20 healthy subjects) using solid or liquid meals, according to the degree of esophagitis in 211 patients evaluated for suspected reflux disease. The occurrence of pathological acid exposure of the distal esophagus increased with increasing grades of esophagitis, both when solid or liquid meals were used $\left(^{*}: p<0.05\right.$ compared to no esophagitis; $\dagger$ compared to esophagitis grade 1,2$)$.

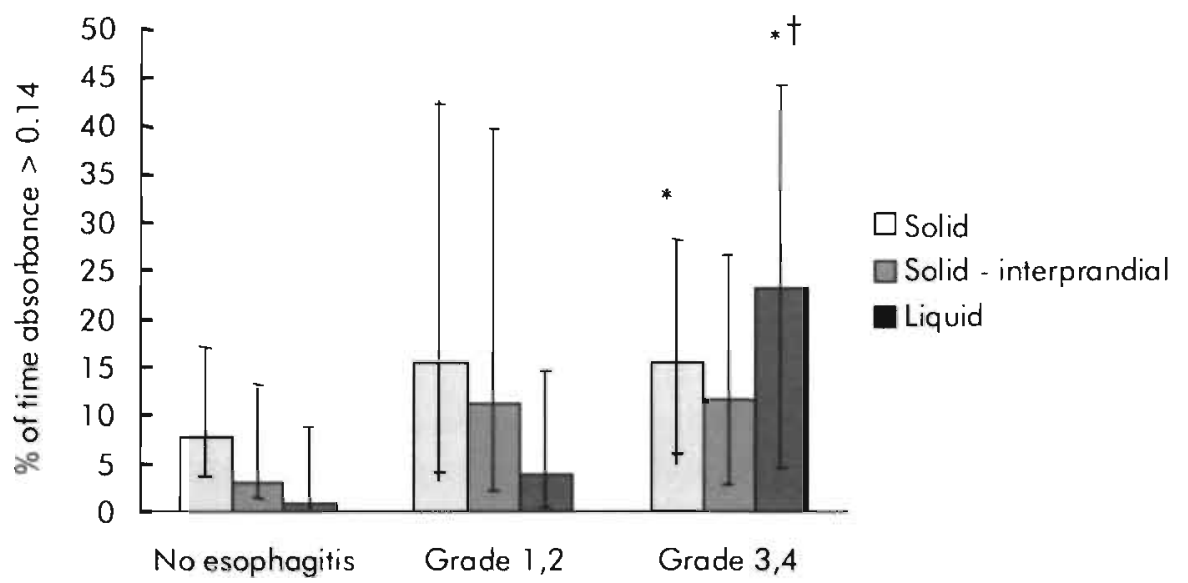

Figure 5.5. Relationship between the results of ambulatory Bilitec ${ }^{3}$ monitoring using solid or liquid meals and the degree of esophagitis in 211 patients evaluated for suspected reflux disease. The bar graph depicts the median value; interquartile ranges are shown as error bars. When solid meals were used, the exposure of the esophagus to DGER did not increase with increasing degrees of esophagitis. Limiting the analysis of solid meals to the interprandial period did not provide a better correlation. With liquid meals, increasing degrees of esophagitis were associated with increasing exposure of the distal esophagus to DGER $\left(^{*}: p<0.05\right.$ compared to no esophagitis; $t: p<0.05$ compared to esophagitis grade 1,2 ). 


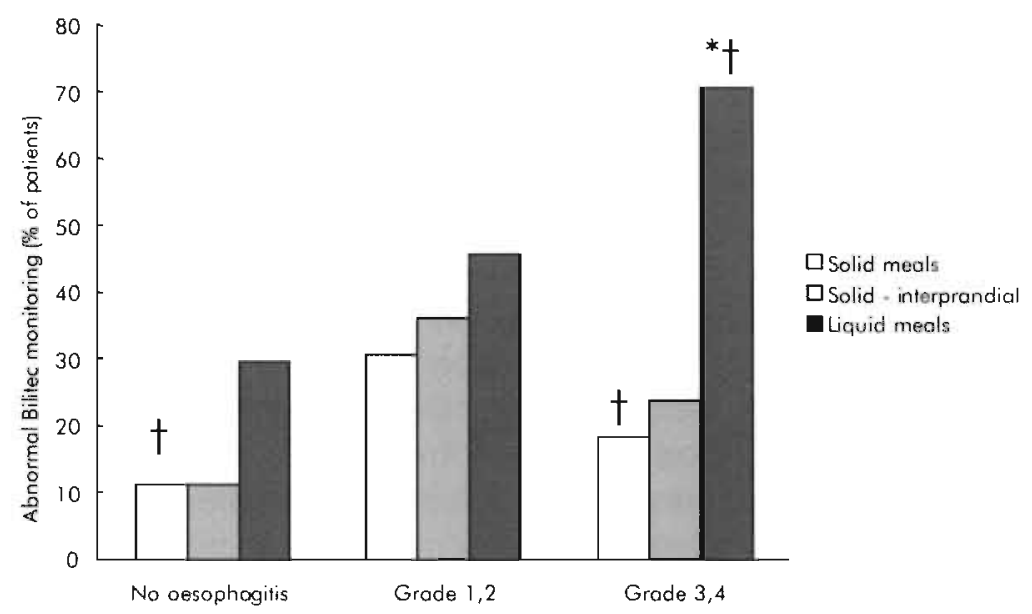

Figure 5.6. Prevalence of abnormal DGER ( $>95^{\text {th }}$ percentile in 20 healthy subjects) using solid or liquid meals, according to the degree of esophagitis in 211 patients evaluated for suspected reflux disease. When solid meals were used, the prevalence of pathological DGER did not increase with increasing degrees of esophagitis. Limiting the analysis of solid meals to the interprandial period did not provide a better correlation. When liquid meals were used, the occurrence of pathological DGER increased with increasing grades of esophagitis $\left({ }^{*}: p<0.05\right.$ compared to no esophagitis, $t$ : compared to esophagitis grade 1,2 ).

\section{Discussion}

The Bilitec ${ }^{(1)}$ probe is prone to solid food impaction causing artifacts, and several common foods give high Bilite ${ }^{(3)}$ readings that may interfere with adequate bile reflux monitoring. ${ }^{10}$ To avoid food impaction or food absorbance artifacts, some groups have restricted the diet during ambulatory bile reflux monitoring to liquid foods not absorbing light of the same wavelength as bilirubin. $8,9,12,17$ However, using such dietary restrictions may be less physiological and may influence the rate of reflux events. Others, therefore, have allowed the patient to use an unrestricted diet and then eliminated the meal and postprandial periods from the analysis which only takes the interprandial period into account. ${ }^{13}$ Others still have allowed patients to use solid diets not interfering with bilirubin absorbance, to avoid the exclusion of meal and postprandial periods from the analysis. ${ }^{16}$

The lack of consensus on the most appropriate protocol for the use of Bilitec $^{\mathbb{*}}$ monitoring hampers its more generalized use in clinical practice. 
Therefore, we performed a prospective randomized study to evaluate the influence of dietary restrictions on the results of combined ambulatory $\mathrm{pH}$ and Bilitec ${ }^{*}$ monitoring. Subjects were either allowed to use only liquid meals not absorbing light of the same wavelength as bilirubin, or they were allowed to use solid food, avoiding diets that interfere with bilirubin absorbance. In keeping with recommendations to minimize restrictions during ambulatory $\mathrm{pH}$ monitoring, we did not standardize the amount of calories used by the subjects. ${ }^{20}$ Both the total recording period and the interprandial period alone were analyzed. As a gold standard for prolonged ambulatory measurement of DGER is lacking, we used the occurrence of major food artifacts, the correlation with esophageal lesions and the correlation with $\mathrm{pH}$ monitoring as criteria to evaluate the performance of each protocol.

In healthy subjects, we established that the diet used did not significantly alter the acid exposure of the distal esophagus. Presumably because of its high lipid content, the liquid diet we used also induces reflux episodes, thus allowing comparison of acid reflux data obtained with either diet. However, the type of diet used did have a major influence on the results of monitoring in healthy subjects. The difference was mainly attributable to higher Bilitec readings in the meal and postprandial period with solid meals. This could be due to enhanced occurrence of DGER after a solid meal, or to interference by food impaction artifacts when using a solid meal.

The results obtained in patients suggest that food impaction artifacts contribute in a major way to the high Bilitec ${ }^{\text {is }}$ readings with solid meals. Solid meals, but not liquid meals, were associated with a very high prevalence of major meal artifacts. It has been reported that DGER is most prevalent in patients with Barrett's esophagus, and that the results of $\mathrm{pH}$ monitoring and of Bilitec ${ }^{\mathrm{s}}$ monitoring correlate well. ${ }^{12,15,17}$ However, when solid meals were used and when the whole recording period was analyzed after the elimination of major meal artifacts, we observed a poor correlation with esophageal lesions and a poor correlation with simultaneous $\mathrm{pH}$ monitoring. In comparison, when liquid meals were used, a better correlation with esophageal lesions and with simultaneous $\mathrm{pH}$ monitoring was obtained. The correlation between $\mathrm{pH}$ monitoring and $\mathrm{Bilitec}^{(8)}$ monitoring we obtained in patients using liquid meals is in the range described in the literature. ${ }^{15.18}$ The lack of correlation between $\mathrm{pH}$ monitoring and Bilitec ${ }^{2}$ monitoring in healthy controls alone is probably due to the small range of variation. So far, literature data only reported correlations between $\mathrm{pH}$ monitoring and 
Bilitec monitoring for patients alone ${ }^{16.18}$, or for patients with controls grouped together. ${ }^{15}$

Similar to the method used by Caldwell et al., we tried to eliminate shortlasting meal artifacts by excluding the meal and postprandial period from the analysis. ${ }^{13}$ However, when solid meals were used, interprandial DGER did not correlate better with esophageal lesions or with $\mathrm{pH}$ monitoring. Presumably, this is because food impaction artifacts, occurring in spite of the use of a diet that avoids interference with bilirubin absorbance, were incompletely eliminated by our method of analysis. Major meal artifacts are readily recognized because of their long duration. Short-lasting meal artifacts are eliminated with the two hours postprandial period when interprandial reflux is quantified. However, any food impaction artifacts lasting longer than two hours postprandially and not extending to the next meal or to the onset of the supine period will not be eliminated, thus worsening the accuracy of the Bilitec $^{(\text {s) }}$ registration when solid meals are used, in spite of a number of precautions.

Our data, therefore, show that when solid meals are used during ambulatory bile reflux monitoring, this is associated with major meal artifacts in $18 \%$ of the patients, a poor correlation with esophageal lesions and a poor correlation with simultaneous $\mathrm{pH}$ monitoring. Limiting the analysis to the interprandial period does not eliminate these problems. In contrast, when only a commercially available liquid food supplement is used, no major meal artifacts are observed, and a good correlation with esophageal lesions and with simultaneous $\mathrm{pH}$ monitoring is obtained. The use of a liquid food supplement does not seem to affect acid gastro-esophageal reflux in healthy controls. We therefore conclude that Bilitec $^{(B)}$ monitoring requires the use of liquid meals. 


\section{References}

1. Johnsson F, Joelsson B, Floren $\mathrm{CH}$, Nilsson A. Bile salts in the esophagus of patients with esophagitis. Scand J Gastroenterol 1988;23:712-6.

2. Gotley DC, Morgan AP, Cooper MJ. Bile acid concentrations in the refluxate of patients with reflux oesophagitis. Br J Surg 1988;75:587-90.

3. Drane WE, Karvelis K, Johnson DA, Silverman ED. Scintigraphic evaluation of gastric reflux. Problems, piffalls, and technical review. Clin Nucl Med 1987;12:377-84.

4. Attwood SEA, De Meester TR, Bremner CG, Barlow AP, Hinder RA. Alkaline gastroesophageal reflux; implications in the development of complications in Barrett's columnar-lined lower esophagus. Surgery 1989;106:764-76.

5. Iftikhar SY, Ledingham S, Evans D, Yusuf SW, Steele RJ, Atkinson M, Hardcastle JD. Alkaline gastro-esophageal reflux: dual $\mathrm{pH}$ probe monitoring. Gut 1995;37: 465-70.

6. Singh S, Bradley LA, Richter JE. Determinants of oesophageal alkaline $\mathrm{pH}$ environment in controls and patients with gastro-oesophageal reflux disease. Gut $1993 ; 34: 309-16$

7. Devault KR, Georgeson S, Castell DO. Salivary stimulation mimics esophageal exposure to refluxed duodenal contents. Am J Gastroenterol 1993;88:1040-3.

8. Bechi P, Paucciani F, Baldini F, Cosi F, Falciai R, Mazzanti R, Castagnoli A, Passeri $A$, Boscherini S. Long-term ambulatory enterogastric reflux monitoring. Validation of a new fiberoptic technique. Dig Dis Sci 1993;38:1297-1306.

9. Vaezi MF, Lacamera RG, Richter JE. Validation studies of Bilitec 2000: an ambulatory duodenogastric reflux monitoring system. Am J Physiol 1994;267:G1050-7.

10. Caldwell MT, Byrne PJ, Brazil N, Crowley V, Attwood SE, Walsh TN, Hennessy TP. An ambulatory bile reflux monitoring system: an in vitro appraisal. Physiol Meas 1994;15:57-65.

11. Stipa F, Stein HJ, Feussner H, Kraemer S, Siewert JR. Assessment of non-acid esophageal reflux: comparison between long-term reflux aspiration test and fiberoptic bilirubin monitoring. Dis Esophagus 1997;10:24-8.

12. Champion G, Richter JE, Vaezi MF, Singh S, Alexander R. Duodenogastroesophageal reflux: relationship to $\mathrm{pH}$ and importance in Barrett's esophagus. Gastroenterology 1994; 107:747-54.

13. Caldwell MT, Lawlor P, Byrne PJ, Walsh TN, Hennessy TP. Ambulatory esophageal bile reflux monitoring in Barrett's esophagus. Br J Surg 1995;82:657-60.

14. Kaver WK, Peters JH, De Meester TR, Ireland AP, Bremner CG, Hagen JA. Mixed reflux of gastric and duodenal juices is more harmful to the esophagus than gastric juice alone. The need for surgical therapy re-emphasized. Ann Surg 1995;222: $525 \cdot 31$. 
15. Vaezi MF, Richter JE. Role of acid and duodenogastrooesophageal reflux in gastroesophageal reflux disease. Gastroenterology 1996;111:1192-9.

16. Marshall REK, Anggiansah A, Owen WA, Owen WJ. The relationship between acid and bile reflux and symptoms in gastro-esophageal reflux disease. Gut 1997;40:182-7.

17. Koek GH, Tack J, Sifrim D, Lerut T, Janssens J. The role of acid and bile reflux in symptomatic gastro-esophageal reflux disease. Am J Gastroenterol 2001;96: 2033-40.

18. Cuomo R, Koek G, Sifrim D, Janssens J, Tack J. Analysis of ambulatory duodenogastro-esophageal reflux moniforing. Dig Dis Sci 2001;45:2463-9.

19. Savary M, Miller G. L'oesophage. Manuel et Atlas d'Endoscopie. Solothurn: Verlag Gassmann, 1977.

20. Armstrong D, Monnier Ph, Nicolet $M$, ef al. The "MUSE" system. In: The esophageal mucosa. Guili R, Tytgat GNJ, DeMeester TR, Galmiche JP (Eds). Amsterdam, NL, Elsevier Science 1994:313-21.

21. Kahrilas PJ, Quigley EMM. Clinical esophageal $\mathrm{pH}$ recording: a technical review for practice guideline development. Gastroenterology 1996;110:1982-96. 


\section{Chapter 6}

\section{Analysis of ambulatory duodeno-gastro-esophageal reflux monitoring}

R Cuomo, GH Koek, D Sifrim, J Janssens, J Tack

Dig Dis Sci 2000;45:2463-9 


\section{Abstract}

\section{Backgrounds}

Some methodological in vitro observations concerning bile reflux monitoring (Bilitec) suggested that Bilitec monitoring is underestimating in an acid environment. Moreover, other studies showed that area above the cut-off level of bilirubin absorbance would provide an adequate quantifative marker for reflux of duodenal contents.

\section{Aims}

To study whether correction for intra-esophageal acidity and area above cut-off during Bilitec monitoring affects the results and the correlation with $\mathrm{pH}$ measurement and esophageal lesions.

\section{Subjects and methods}

In 84 patients ( 46 males; mean age $46 \pm 2.7$ ) evaluated for suspected gastro-esophageal reflux disease, we performed an ambulatory 24 hours esophageal $\mathrm{pH}$ and Bilitec $c^{i \overline{1}}$ monitoring after an upper gastrointestinal endoscopy. We obtained total area, percent total time and correction by computer software. Correction factor for bilirubin absorbance was based on literature data for acidified bile $(0.06$ for $\mathrm{pH}<3.6 ; 0.21$ for $\mathrm{pH}<2.6)$.

\section{Results}

Endoscopy revealed esophagitis grade $1-2$ (E1-2) and 3-4 (E3-4) in 23 and 16 patients respectively. A progressive increase of mixed (acid + bile) reflux occurred with increasing severity of endoscopic lesions (E3-4 vs. no esophagitis, $p<0.05$ ). A pathologic Bilitec monitoring was present in the same 35 patients before and after correction and the correlation between the $\mathrm{pH}$ measurement and percent time of bile reflux was not improved by correction for intra-esophageal $\mathrm{pH}(\mathrm{R}=0.386$ and $\mathrm{R}=0.391 ; p<0.05)$. The total area of bilirubin absorbance above 0.14 (abs $* \min$ ) was $7.8 \pm 2.2$ in patients without esophagitis, $11.7 \pm 4.4$ and $17.0 \pm 4.2$ in El-2 and E3-4 group respectively $(E 3-4$ vs. no esophagitis, $p<0.05$ ). The correlation between the Bilifec monitoring and $\mathrm{pH}$ measurement regarding percent $(R=0.427, p<0.01)$ or area of time below $4(R=0.280$, $p<0.05$ ) was not improved by considering the area of bilirubin absorbance above the cut-off level.

\section{Conclusion}

Correction for intra-esophageal $\mathrm{pH}$ has only a minor effect on the results of ambulatory Bilitec" monitoring. Taking into account the surface rather than the percent of time above the cut-off level for bilirubin absorbance does not improve the correlation of Bilitec with acid 1 eflux and with esophageal lesions. 


\section{Introduction}

Reflux of duodenal contents via the stomach into the esophagus has long been suspected to be of pathophysiological relevance to mucosal lesions in gastro-esophageal reflux disease (GERD). Stationary aspiration studies were able to demonstrate the presence of bile in esophageal aspirates from patients with esophagitis. ${ }^{1,2}$ Some studies reported a good correlation between biliary scintigraphy and gastric bile acids, but the method is at best semiquantitative, only suitable for short study periods, and several technical problems may interfere with the measurement. ${ }^{3}$ Direct and prolonged quantification of duodeno-gastro-esophageal reflux (DGER) has been difficult to achieve. It has been suggested that alkaline periods during esophageal $\mathrm{pH}$ monitoring might represent DGER. ${ }^{4}$ However, combined aspiration and $\mathrm{pH}$ monitoring studies have shown that this is not the case ${ }^{5}$, and most alkaline episodes on esophageal $\mathrm{pH}$ monitoring are due to swallowed saliva. 6,7

More recently, Bilitec 2000 , a fiber-optic spectrophotometric probe, was developed to quantify bile reflux in an ambulatory fashion. Bilirubin, the most common pigment in bile, has a characteristic absorbance spectrum, and by continuous monitoring of the absorbance of two light emitting diodes at two different wavelengths of the esophageal refluxate, the presence of bilirubin can be detected. In vitro validation studies confirmed a good correlation between Bilitec" measurements and bile acids concentrations. ${ }^{8.10}$ Ambulatory aspiration studies found a significant correlation between the total bilirubin concentration of aspirated samples and the fiberoptic reading of bilirubin concentration." Moreover, a good correlation was found between total bilirubin content and the concentrations of pancreatic enzymes in the refluxate, suggesting that bilirubin is a good tracer for DGER." Using the Bilitec" probe, several recent studies have demonstrated a progressive increase in DGER across the spectrum of GERD, with a particularly high prevalence in patients with Barrett's esophagus. ${ }^{12-15}$ In addition, a good correlation was found between the results of $\mathrm{pH}$ monitoring data and Bilitec monitoring. ${ }^{12-15}$

However, several methodological aspects concerning the analysis of Bilitec ${ }^{1}$ data have not been addressed. Until now, the percentage of time that bilirubin absorbance is higher than a threshold value of 0.14 has been used as a measure to quantify DGER. Bilitec ${ }^{3}$ absorbance increases linearly with the concentration of bilirubin. ${ }^{9}$ Bilirubin is not the caustic agent in duodeno-gastro-esophageal refluxate, but its concentration has 
been shown to correlate well with the concentration of putative caustic factors such as bile acids. ${ }^{8}$ Hence, Bilitec ${ }^{6}$ absorbance can be considered an adequate quantitative marker for putative caustic factors in duodenogastro-esophageal refluxate. It seems conceivable, therefore, that the calculated area above the cut-off level for bilirubin is providing a better quantification of the caustic effect of refluxed duodenal contents, thus establishing a better correlation with the presence of esophageal lesions. Moreover, in vitro experimental studies demonstrated that Bilitec ${ }^{B}$ monitoring is underestimating bilirubin concentration in an acid environment. ${ }^{9}$ Mixed reflux of both acid and duodenal contents is occurring frequently in patients with gastro-esophageal reflux disease. $1,2,16$ it is unknown to what extent underestimation due to simultaneous acid reflux might affect the results of ambulatory Bilitec ${ }^{B}$ monitoring in man.

The aims of the present study were to study whether correction of ambulatory Bilitec ${ }^{\text {(6) }}$ monitoring for intra-esophageal acidity and the area rather the time above cut-off during Bilitec ${ }^{*}$ monitoring affect the results and the correlation with $\mathrm{pH}$ measurement and esophageal lesions. As a gold standard to measure DGER is lacking, we used a) the correlation with lesions and $b$ ) the correlation with pHmonitoring.

\section{Materials and methods}

\section{Study subjects}

Eighty-four patients evaluated for suspected gastro-esophageal reflux disease (46 men and 38 women; age 18-83 years; mean age $46 \pm 2.7$ years) participated in this study. Patients were eligible for the study if they were evaluated for suspected gastro-esophageal reflux disease and if they had a normal serum bilirubin level. Exclusion criteria were: peptic ulcer disease, previous esophageal, gastric or biliary surgery, previous abdominal or thoracic radiotherapy, active gastrointestinal bleeding, presence of esophageal or fundic varices, esophageal or upper small intestinal Crohn's disease, herpetic or Candida esophagitis or active solid tumor neoplastic disease.

\section{Upper gastrointestinal endoscopy}

All subjects underwent classical upper gastrointestinal endoscopy. If necessary, they were sedated by intravenous administration of diazepam (up to $10 \mathrm{mg}$ ). During endoscopy the presence of esophagitis was noted 
and graded according to the modified classification of Savary and Miller. ${ }^{17,18}$

\section{Ambulatory $\mathrm{pH}$ monitoring}

Ambulatory esophageal $\mathrm{pH}$ monitoring was performed using an antimony $\mathrm{pH}$ electrode with a separate skin reference electrode (Synectics Medical, Stockholm, Sweden). The data were stored on a portable digital recorder (Digitrapper Mk III, Synectics Medical, Stockholm, Sweden). Before each study, the $\mathrm{pH}$ probe was calibrated in buffer solutions of $\mathrm{pH}$ 7 and 1.

\section{Measurement of duodeno-gastro-esophageal reflux}

The fiber-optic spectrophotometer Bilitec 2000 (Synectics, Stockholm, Sweden) was used to quantify DGER. The system consists of a miniaturized probe of $2.5 \mathrm{~mm}$ diameter that carries light signals into the esophagus and back via a plastic fiber-optic bundle. Before each study, the probe was calibrated in water.

\section{Study protocol}

In 84 consecutive patients evaluated for suspected gastro-esophageal reflux disease, we performed an upper gastrointestinal endoscopy, followed by an ambulatory 24 hours esophageal $\mathrm{pH}$ and Bilitec monitoring on one of the next four days. All drugs potentially affecting gastrointestinal motility and gastrointestinal secretion were discontinued at least one week prior to the study.

On the day of the ambulatory monitoring, probes for assessing acid and DGER were introduced via a nasal orifice into the esophagus to the distance previously determined as $5 \mathrm{~cm}$ proximal to the lower esophageal sphincter by manometry. The probes were then attached with adhesive tape to the subjects nose and cheek. In addition, appropriate positioning in the esophagus was confirmed by fluoroscopy. Data collection devices were connected to the probes and worn in a belt on the patient's waist. Registration of acid or DGER lasted for approximately 22 hours after which the probes were removed and the data transferred to a personal computer for analysis with the aid of commercially available software (Gastrosoft Inc., Synectics Medical, Irvine, Texas, USA). To avoid meal artifacts, subjects were instructed to drink at breakfast, lunch and dinner one to four units of a commercially available preparation $(200 \mathrm{ml}, 300 \mathrm{kcal}$, 13\% proteins, $48 \%$ carbohydrates, $39 \%$, Nutridrink $^{8}$, Nutricia, Belgium). Patients recorded the time of Nutridrink or other fluid consumption and posture changes on a diary card. They 
were requested to avoid coffee and fruit juices during the recording, and to stay upright during the daytime.

\section{Data analysis}

Acid and duodenal refluxes were quantified separately with some variables obtained from computerized analysis. We calculated both the percent total time and the total area of bilirubin above cut-off level of 0.14 and percent total time of $\mathrm{pH}<4$ and the total area of acid reflux respectively. Moreover, utilizing a spreadsheet software (Excel, Microsoff) we corrected bilirubin absorbance with a defined correction factor. This factor, based on literature data for acidified bile in vitro", was 0.06 for $\mathrm{pH}$ values between 3.5 and 2.6 , and 0.21 for $\mathrm{pH}$ values between 2.5 and 1.5. The percent of patients with abnormal acid or DGER was determined for different grades of esophagitis according to previous determined normal values. ${ }^{19}$ To study the relationship between the result of prolonged $\mathrm{pH}$ and Bilitec ${ }^{8}$ monitoring and severity of mucosal damage, grade 1 and 2 esophagitis and grade 3 and 4 esophagitis were grouped together.

Statistical analysis

Values are presented as means \pm SEM. Data were compared by unpaired t-test and by unpaired t test with Welch's correction when samples not have equal variance. Spearman's rank test was used to study the correlation between the percentage of time acid and duodenal reflux. The Fisher exact's test was used to compare the prevalence of abnormal acid reflux or DGER exposure in patients with different endoscopic grades of esophagitis. P-values were considered to be significant if $<0.05$.

\section{Results}

\section{Characteristics of patients}

Eighty-four patients (46 men and 38 women; age 18-83 years; mean age $46 \pm 2.7$ years) participated in this study. Upper gastrointestinal endoscopy revealed no esophagitis in 45 patients $(54 \%)$ and grade 1-2 and $3-4$ esophagitis in respectively $23(27 \%)$ and $16(19 \%)$ patients. Ten patients $(67 \%)$ of esophagitis 3-4 group had a Barrett's esophagus. Table 6.1 shows the demographic characteristics of the study subjects. 
Toble 6.1. Characteristics of patients with and without endoscopic esophagitis graded by modified classification of Savary-Miller.

\begin{tabular}{lccc}
\hline & No Esophagitis & Esophagitis 1-2 & Esophagitis 3-4 \\
\hline Number (\%) & $45(54)$ & $23(27)$ & $16(19)$ \\
Males $(\%)$ & $18(40)$ & $12(52)$ & $11(69)$ \\
Age range & $21-83$ & $20-78$ & $24-62$ \\
Age (mean \pm SEM) & $47 \pm 2.1$ & $47 \pm 3.3$ & $43 \pm 2.5$ \\
\hline
\end{tabular}

Analysis of Bilitec ${ }^{(*)}$ and $\mathrm{pH}$ monitoring

A pathological acid and/or bile reflux was present in 50 patients (60\%). Bilitec $^{(2)}$ monitoring showed a pathological reflux ( $\%$ of time above 0.14 $>4.6)$ in 15 patients, $12(27 \%)$ in no-esophagitis group and, $1(5 \%)$ and $2(12 \%)$ in esophagitis $1-2$ and $3-4$ group respectively. Moreover, pathological acid reflux ( $\%$ of time below $\mathrm{pH} 4>4$ ) was present in $4(9 \%)$ patients without endoscopic esophagitis, in $8(35 \%)$ with esophagitis $1-2$ and in $3(19 \%)$ with esophagitis 3-4. Five patients $(17 \%)$ in the group noesophagitis had pathological mixed reflux and, $7(30 \%)$ and $8(50 \%)$ in the groups with esophagitis $1-2$ and $3-4$ respectively (Figure 6.1). The statistical analysis of percent distribution in each group showed a significant increase of mixed reflux positively correlated to severity of esophagitis (esophagitis $3-4$ vs. no-esophagitis, $p<0.01$ ) (Figure 6.1 ).

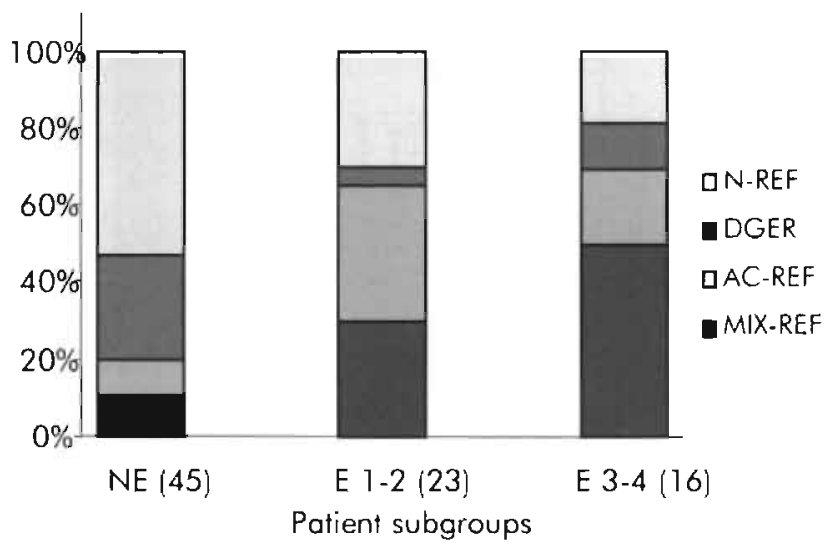

Figure 6.1. Stacked columns depict percentual distribution of different refluxes in each subgroup of patients evaluated for suspected gastro-esophageal reflux disease. Patients are divided in subjects without esophagitis (NE) and with esophagitis of grade 1-2 (E 1-2) and 3-4 (E3-4). Percent distribution of mixed reflux increase according to the severity of esophagitis (E3-4 vs. NE, $p<0.01$ ). Mixed reflux =MIX-REF; acid reflux =AC-REF; DGER=DGER; without reflux $=N-R E F$. Number of patients is in the brackets. 
Bilitec $^{\circledast 2}$ data correction for intra-esophageal acidity

Prior to the correction, the percent total time of bilirubin with absorbance above 0.14 was $6.1 \pm 1.5$ in patients without esophagitis, $8.5 \pm 2.6$ in patients with esophagitis grade $1-2$, and $16.1 \pm 4.2$ in patients with esophagitis grade $3-4 \quad(p<0.01$ compared to no esophagitis) (Figure 6.2). In this condition, a poor but significant correlation was present between the $\mathrm{pH}$ measurement $(\%$ total time $\mathrm{pH}<4)$ and Bilitec ${ }^{(3)}$ monitoring $(\mathrm{R}=0.386 ; \mathrm{p}<0.05)$ (Figure 6.3). Esophageal $\mathrm{pH}$ values below 3.6 or below 2.6 were present in respectively $73(87 \%)$ and 66 $(79 \%)$ patients. Correction for acid exposure caused a mean increase in esophageal bilirubin exposure of $1.96 \pm 0.76 \%$, with a maximum increase of $50.24 \%$ in one patient. After correction for intra-esophageal $\mathrm{pH}$, the percent total time that bilirubin absorbance was above 0.14 was $6.2 \pm 1.5$ in patients without esophagitis, $8.6 \pm 2.6$ in patients with esophagitis grade $1-2$, and $16.3 \pm 4.2$ in patients with esophagitis grade $3-4$ ( $p<0.01$ compared to no esophagitis) (Figure 6.2). After correction,

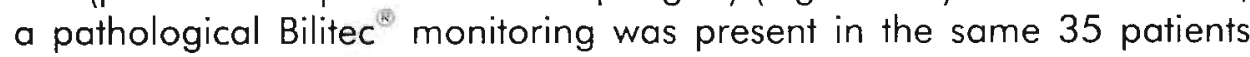
than before correction. The correlation between the $\mathrm{pH}$ measurement and Bilitec ${ }^{\text {(3) }}$ monitoring was not improved by correction for intraesophageal $\mathrm{pH}(\mathrm{R}=0.39, \mathrm{p}<0.05)$ (Figure 6.3).

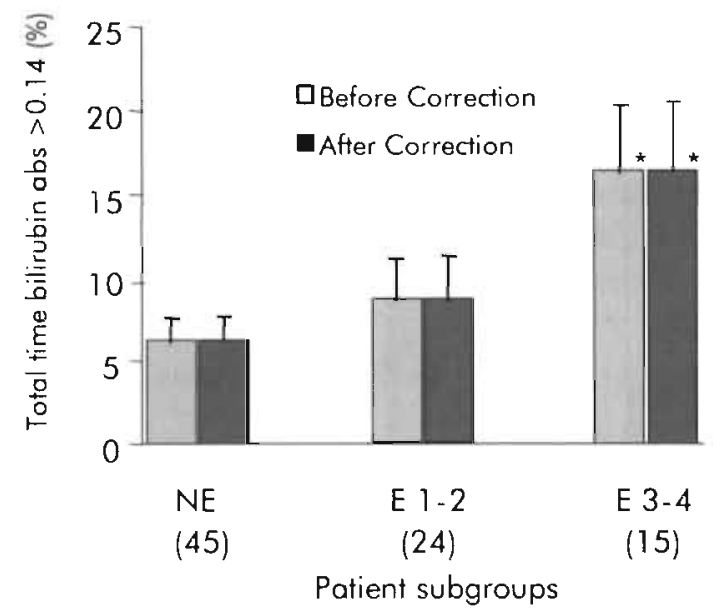

Figure 6.2. Bar graphs (mean \pm SEM) depict percent total time of bilirubin with absorbance above 0.14 in studied patients with and without esophagitis, before and after correction by defined factor. This correction consisting of increase of 6 and $21 \%$ when pH values are below 3.6 and 2.6 respectively. Before and after correction the same significant difference was found between group without esophagitis (NE) and with esophagitis grade 3-4 $\left({ }^{*} p<0.01\right.$ vs. NE). 

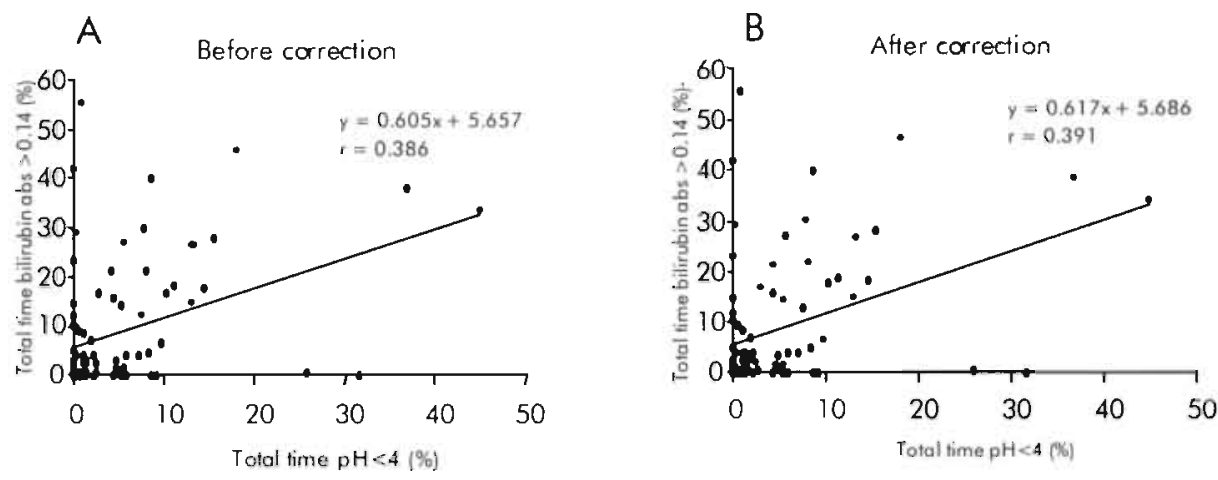

Figure 6.3. Correlation between total time of bilirubin absorbance above 0.14 and total time of $\mathrm{pH}$ below 4 of studied patients before $(A)$ and after $(B)$ intraesophageal $\mathrm{pH}$ correction. Significant correlation $(R=0.386 ; p<0.05)$ was found but no improvement after correction $(R=0.391, p<0.05)$.

Area versus time above cut-off level of Bilitec ${ }^{\sqrt{8}}$

The total area of bilirubin absorbance above 0.14 (abs*min) was $7.8 \pm 2.2$ in patients without esophagitis, $11.7 \pm 4.4$ in patients with esophagitis grade $1-2$ and $17.0 \pm 4.2$ in patients with esophagitis grade $3-4$ ( $p<0.05$ compared to no esophagitis) (Figure 6.4).

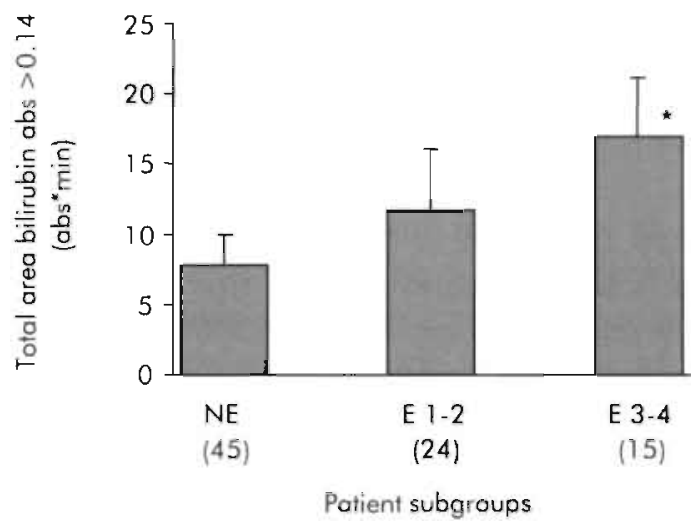

Figure 6.4. Bar graphs (mean \pm SEM) depict total area of bilirubin with absorbance above 0.14 (abs*min) in studied patients with and without esophagitis. Data confirm general trend showing DGER increase with severity of esophagitis ( ${ }^{*} p<0.5$ vs. NE). Total area of bilirubin absorbance does not improve compared to percent total time the discriminant power among esophageal lesions. 
Comparison with data expressed as percent of time shows that area did not increase discriminant power among esophageal lesions. The correlation between the Bilitec monitoring and $\mathrm{pH}$ measurement as percent of time was not improved by considering the area of bilirubin absorbance above cut-off level ( $R=0.427, p<0.01)$ (Figure 6.5). Taking into account the area of acid reflux, also failed to improve the correlation with the area of bilirubin absorbance above cut-off level $(R=0.280$, $p<0.05$ ) (Figure 6.5).
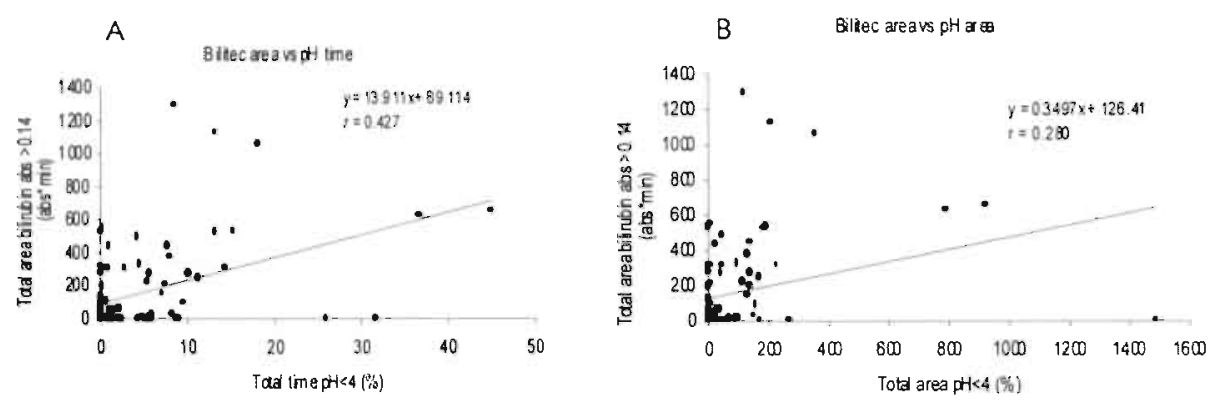

Figure 6.5. Correlations between total area of bilirubin absorbance above 0.14 and percent total time (A) or total area (B) of $\mathrm{pH}$ below 4 . Significant correlation with percent time $(R=0.427 ; p<0.05)$ was found while the total area of $p H$ decreases the correlation value even if it remains significant $(R=0.280$, $\mathrm{p}<0.05)$.

\section{Discussion}

The relative contribution of DGER to the development of reflux-related lesions and symptoms has been controversial and difficult to study until recently. The new ambulatory system, Bilitec $2000^{\circ}$, quantifies DGR and DGER by evaluation of bilirubin concentration. ${ }^{8}$ The correlation between total bilirubin content and the concentrations of bile acids contained in the esophageal refluxate suggests that bilirubin is a good tracer for nonacid, duodenal or intestinal reflux in the esophagus. 'However, duodenal contents in the esophagus exist at wide range of $\mathrm{pH}$ and this has implications not only for the damage, but also for the measurement of bilirubin. ${ }^{9,20}$ Simultaneous monitoring of esophageal $\mathrm{pH}$ and bilirubin showed a close association between the percent of time that $\mathrm{pH}$ was $<4$

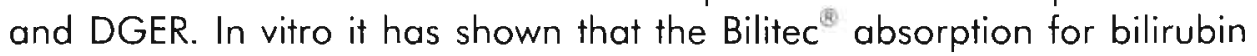
remained unchanged at $\mathrm{pH} 7.5-3.5$ but at $\mathrm{pH} 2.5$ and 1.5 at $37^{\circ} \mathrm{C}$ a decrease of absorption occurred from $24 \%$ up to $36 \%$. Because of this 
fact, the reliability of the Bilitec methodology, during the acid esophageal exposure has been questioned., 15

In our experience, mixed reflux of both acid and duodenal reflux was often present in each group of patients complaining of reflux symptoms, and the exposure to mixed reflux increased with the severity of esophagitis. However, we observed a significant underestimation of bilirubin measurement by Bilitec ${ }^{\text {B }}$ monitoring due to simultaneous $\mathrm{pH}$ values below 3.6. We found a poor, but significant correlation between $\mathrm{pH}$ measurement and bile reflux without any improvement after $\mathrm{pH}$ correction.

Correction for acid exposure caused a very low mean increase in esophageal bilirubin exposure and only one patient had a marked increase. The number of patients with pathological bile reflux did not increase after correction for intra-esophageal acidity. Hence, we observed that correction for intra-esophageal $\mathrm{pH}$ has only a minor effect on the results of ambulatory Bilitec ${ }^{\text {E. }}$. Moreover, the correlation of Bilitec ${ }^{(3)}$ results with acid reflux and with lesions was not improved by correcting for intra-esophageal $\mathrm{pH}$. We conclude that the error in bilirubin absorbance measurement during esophageal acid exposure has no clinical impact and correction for intra-esophageal acidity is not necessary. We also analyzed the impact of correlation of area under the curve of bilirubin absorbance above 0.14 . We found a fair correlation of the percentage of total time below four and area of time absorbance. Using the area of bilirubin absorbance instead of percentage of time did not enhance differences according to the severity of esophagitis in the groups. Hence, it seems that bilirubin concentration, reflected as area of bilirubin absorbance above 0.14 , is not proportional to the caustic factor in duodenal-gastro-esophageal reflux.

In conclusion, our study shows that the error in bilirubin absorbance measurement during esophageal acid exposure has no clinical impact. Moreover evaluation of bilirubin concentration measured by the time of absorbance above 0.14 is better than the area. Although further studies are needed to elucidate the composition of all refluxes, included nonacid non-bile reflux, we believe that the Bilitec method reliably identifies the presence of bilirubin and it has made feasible to quantitatively detect DGER of bile. 


\section{References}

1. Johnsson F, Joelsson B, Floren $\mathrm{CH}$, Nilsson A. Bile salts in the esophagus of patients with esophagitis. Scand J Gastroenterol 1988;23:712-6.

2. Gotley DC, Morgan AP, Cooper MJ. Bile acid concentrations in the refluxate of patients with reflux oesophagitis. Br J Surg 1988;75:587-90.

3. Drane WE, Karvelis K, Johnson DA, Silverman ED. Scintigraphic evaluation of duodenogastric reflux. Problems, piffalls, and technical review. Clin Nucl Med $1987 ; 12: 377-84$.

4. Attwood SEA, De Meester TR, Bremner CG, Barlow AP, Hinder RA. Alkaline gastroesophageal reflux; implications in the development of complications in Barrett's columnar-lined lower esophagus. Surgery 1989;106:764-76.

5. Iftikhar SY, Ledingham S, Evans D, Yusuf SW, Steele RJ, Atkinson M, Hardcastle JD. Alkaline gastro-esophageal reflux: dual $\mathrm{pH}$ probe monitoring. Gut 1995;37: 465-70.

6. Singh S, Bradley LA, Richter JE. Determinants of oesophageal alkaline $\mathrm{pH}$ environment in controls and patients with gastro-oesophageal reflux disease. Gut 1993;34:309-16.

7. Devault KR, Georgeson S, Castell DO. Salivary stimulation mimics esophageal exposure to refluxed duodenal contents. Am J Gastroenterol 1993;88:1040-3.

8. Bechi P, Pucciani F, Baldini F, Cosi F, Falciai R, Mazzanti R, Castagnoli A, Passeri A, Boscherini S. Long-term ambulatory enterogastric reflux monitoring. Validation of a new fiberoptic technique. Dig Dis Sci 1993;38:1297-306.

9. Vaezi MF, Lacamera RG, Richter JE. Validation studies of Bilitec 2000: an ambulatory duodenogastric reflux monitoring system. Am J Physiol 1994;267:G1050-7.

10. Caldwell MT, Byrne PJ, Brazil N, Crowley V, Attwood SE, Walsh TN, Hennessy TP. An ambulatory bile reflux monitoring system: an in vitro appraisal. Physiol Meas 1994; 15:57-65.

11. Stipa F, Stein HJ, Feussner H, Kraemer S, Siewert JR. Assessment of non-acid esophageal reflux: comparison between long-term reflux aspiration test and fiberoptic bilirubin monitoring. Dis Esophagus 1997;10:24-8.

12. Champion G, Richter JE, Vaezi MF, Singh S, Alexander R. Duodenogastroesophageal reflux: relationship to $\mathrm{pH}$ and importance in Barrett's esophagus. Gastroenterology 1994;107:747-54.

13. Caldwell MT, Lawlor P, Byrne PJ, Walsh TN, Hennessy TP. Ambulatory esophageal bile reflux monitoring in Barrett's esophagus. Br J Surg 1995;82:657-60. 
14. Kaver WK, Peters JH, De Meester TR, Ireland AP, Bremner CG, Hagen JA. Mixed reflux of gastric and duodenal juices is more harmful to the esophagus than gastric juice alone. The need for surgical therapy re-emphasized. Ann Surg 1995;222: 525-31.

15. Vaezi MF, Richter JE. Role of acid and duodenogastrooesophageal reflux in gastroesophageal reflux disease. Gastroenterology 1996;111:1192-9.

16. Marshall REK, Anggiansah A, Owen WA, Owen WJ. The relationship between acid and bile reflux and symptoms in gastro-esophageal reflux disease. Gut 1997;40:182-7.

17. Savary M, Miller G. L'oesophage. Manuel et Atlas d'Endoscopie. Solothurn: Verlag Gassmann 1977.

18. Armstrong D, Monnier Ph, Nicolet $M$, et al: The "MUSE" system. In The esophageal mucosa. Guili R, Tytgat GNJ, DeMeester TR, Galmiche JP (eds). Amsterdam, NL, Elsevier Science 1994;313-21.

19. Tack J, Bisschops R, Koek G, Sifrim D, Lerut T, Janssens J. Dietary restrictions during ambulatory monitoring of duodeno-gastro-esophageal reflux. Dig Dis Sci 2003; 48:1213-20.

20. Marshall RE, Anggianah A, Owen WA, Owen WJ. The temporal relationship between esophageal bile reflux and $\mathrm{pH}$ in gastro-esophageal reflux disease. Eur $J$ Gastroenterol Hepatol 1998; 10:385-92. 


\section{Chapter 7}

The role of acid- and duodeno-gastroesophageal reflux in symptomatic gastroesophageal reflux disease

GH Koek, J Tack, D Sifrim, T Lerut, J Janssens

Am J Gastroenterol 2001;96:2033-40 


\section{Abstract}

\section{Backgrounds}

Mixed reflux of acid and duodenal contents frequently occurs in patients with gastroesophageal reflux disease (GERD).

\section{Aim}

The aim of this study was to establish the contribution of acid and DGER to symptoms in patients with presumed GERD.

\section{Methods}

72 patients ( 37 women), mean age 45 years ( \pm 2 years), underwent 24 hours ambulatory $\mathrm{pH}$ and Bilitec monitoring. The patient pressed a marker button when experiencing typical symptoms. For each symplom episode, minimal $\mathrm{pH}$ and maximal bilirubin absorbance in a two and four minutes interval were calculated. For each patient, the symptom index (SI) and symptom-association probability (SAP) for acid and for bile reflux were determined.

\section{Results}

544 symptom episodes were identified. Using a two minutes interval, 28\% were associated with acid reflux, $9 \%$ with DGER and $12 \%$ with mixed reflux. No significant difference was found when a four minutes interval was used. A positive SI for acid reflux was present in $21 \%$ of the patients and for DGER in 14\%. All patients with a positive SI for DGER had also a positive SI for acid reflux. A positive SAP for acid reflux was present in $22 \%$ of the patients, for DGER in $7 \%$ of the patients and for mixed reflux in $10 \%$ of the patients.

\section{Conclusion}

Symptom episodes in patients with presumed GERD are more related to acid reflux than to DGER. DGER does not play a major role in producing typical esophageal symptoms. 


\section{Introduction}

Heartburn and regurgitation are the most typical symptoms of gastroesophageal reflux disease (GERD), one of the most common disorders affecting the gastrointestinal tract. Infusion of hydrochloric acid solutions in the mid-esophagus is able to reproduce symptoms of heartburn, and with increasing acid concentrations, the time of infusion needed to induce heartburn is gradually decreasing. 'While this observation suggests that the duration and the amount of esophageal acid exposure determine the occurrence of heartburn, ambulatory $\mathrm{pH}$ monitoring studies have shown a much more complicated relationship between intra-esophageal acid exposure and spontaneously occurring symptoms of heartburn. ${ }^{2.5}$

The pathological role the different substances play in the refluxate has been evaluated in endoscopy ${ }^{6,7}$, with HIDA scintigraphy, in aspiration studies $^{9,10}$ and esophageal $\mathrm{pH}$ monitoring. ${ }^{11,12}$ Alkaline reflux that is found with $\mathrm{pH}$ monitoring is not equivalent with duodeno-gastroesophageal reflux (DGER). These methods are insufficient to qualify and quantify the role of DGER.

The recently developed Bilitec 2000 device is a fiber-optic spectrophotometric probe developed to quantify DGER in an ambulatory fashion. Bilirubin, the most common pigment in bile, has a characteristic absorbance spectrum, and by continuous monitoring of the absorbance of two light emitting diodes at two different wavelengths of the esophageal refluxate, the presence of bilirubin can be detected. Bilitec ${ }^{\text {it }}$ is a validated method to study DGER and several recent studies using the Bilitec ${ }^{\text {s. }}$ probe have demonstrated a particularly high prevalence of DGER in patients with Barrett's esophagus. ${ }^{13-17}$ Patients with complicated Barrett's esophagus have greater amounts of acid reflux and DGER than patients with uncomplicated Barrett's esophagus. ${ }^{16,18}$ These data suggest that a synergistic activity of acid reflux and DGER contribute to the occurrence of high grade esophageal lesions in patients with GERD.

In contrast to its role in inducing esophageal lesions, the contribution of DGER to the occurrence of typical symptoms of GERD has remained largely unstudied. Therefore, the aim of the present study was to investigate the role of acid reflux and DGER in the induction of symptoms in patients with presumed reflux disease. To quantify a temporal relationship between symptoms and acid reflux, several indices have 
been developed. The most frequently used is the symptom index (SI), defined as the percentage of reflux related symptom episodes measured in a time window that begins two minutes before the occurrence of the symptom and ends at the time of the symptom. ${ }^{19,20}$ More recently, it has been suggested that a four minutes window centered around the symptom episode might be more appropriate for Bilitec ${ }^{5}$ recordings. ${ }^{21}$ To overcome several limitations of the $\mathrm{SI}$, the symptom-association probability (SAP) was developed as a method that calculates the probability that the observed association between gastro-esophageal reflux and symptoms is not caused by chance. ${ }^{22}$ We analyzed the SI and the SAP both for acid reflux and DGER for the "classical" two minutes interval before the onset of symptoms and for a four minutes time window; two minutes before and two minutes after the symptom event, in consecutive patients evaluated for suspected GERD.

\section{Materials and methods}

\section{Patients}

Seventy-two patients evaluated for suspected gastro-esophageal reflux disease participated in this study. Patients were eligible for the study if they were evaluated for suspected gastro-esophageal reflux disease and if they had a normal serum bilirubin level. Exclusion criteria were: peptic ulcer disease, previous esophageal, gastric or biliary surgery, previous abdominal or thoracic radiotherapy, active gastrointestinal bleeding, presence of esophageal or fundic varices, esophageal or upper small intestinal Crohn's disease, herpetic or Candida esophagitis or active solid tumor neoplastic disease.

\section{Upper gastrointestinal endoscopy}

All subjects underwent classical upper gastrointestinal endoscopy. If necessary, they were sedated by intravenous administration of diazepam (up to $10 \mathrm{mg}$ ). During endoscopy, the distance from the incisor teeth to the esophago-gastric junction was documented exactly. In addition, the presence of esophagitis was noted and graded according to the modified classification of Savary and Miller ${ }^{23,24}$ : grade 0, normal mucosa; grade 1, single or isolated erosions, oval or linear, over less than $10 \%$ of the esophageal circumference; grade 2, multiple erosions, confluent over more than $10 \%$ but less than $50 \%$ of the esophageal circumference; grade 3, multiple erosions over more than $50 \%$ of the esophageal 
circumference; and grade 4, complications of esophagitis such as ulcers, strictures or columnar-lined mucosa.

\section{Ambulatory $\mathrm{pH}$ monitoring}

Ambulatory esophageal $\mathrm{pH}$ monitoring was performed using an antimony $\mathrm{pH}$ electrode with a separate skin reference electrode (Synectics Medical, Stockholm, Sweden). The data were stored on a portable digital recorder (Digitrapper Mk III, Synectics Medical, Stockholm, Sweden). Before each study, the $\mathrm{pH}$ probe was calibrated in buffer solutions of $\mathrm{pH}$ 7 and 1. An episode of acid reflux was defined as a decrease in esophageal $\mathrm{pH}$ to less than 4 during more than 10 seconds.

Measurement of duodeno-gastro-esophageal reflux

The fiber-optic spectrophotometer Bilitec 2000 (Synectics, Stockholm, Sweden) was used to quantify DGER. The system consists of a miniaturized probe of $5 \mathrm{~mm}$ diameter that carries light signals into the esophagus and back via a plastic fiber-optic bundle. Before each study, the probe was calibrated in water. A symptom episode of DGER is defined as an increase in esophageal bilirubin absorbance $>0.14$ for more than 10 seconds. ${ }^{21.25}$

\section{Study protocol}

The Ethics Committee of the hospital accepted the study protocol. Patients were asked to fill out a detailed questionnaire about symptoms and frequency, smoking and drinking habits, weight and height. In all patients, we subsequently performed an upper gastrointestinal endoscopy, followed by an ambulatory 24 hours esophageal $\mathrm{pH}$ and Bilitec $^{3}$ monitoring on one of the next four days. All drugs potentially affecting gastrointestinal motility and gastro-intestinal secretion were discontinued at least one week prior to the study.

In 57 of the 72 patients (79\%), a stationary esophageal manometry was performed to determine the distance of the external nasal orifices to the lower esophageal sphincter. In the 15 remaining patients, the distance from the incisor teeth to the esophago-gastric junction was documented exactly during endoscopy, and considered equal to the distance from the external nasal orifices to a location five $\mathrm{cm}$ proximal to the high-pressure zone. $^{26}$

Probes for assessing acid and DGER were introduced via a nasal orifice into the esophagus to the distance previously determined as five $\mathrm{cm}$ proximal to the lower esophageal sphincter. The probes were then attached with adhesive tape to the subject's nose and cheek. In addition, 
appropriate positioning in the esophagus was confirmed by fluoroscopy. Data collection devices were connected to the probes and worn in a belt on the patient's waist. Registration of acid or DGER lasted for approximately 22 hours after which the probes were removed and the data transferred to a personal computer for analysis with the aid of commercially available software (Gastrosoft Inc., Synectics Medical, Irvine, Texas, USA). Patients recorded the time of food or fluid consumption and posture changes on a diary card. They were instructed to stay upright during the daytime. During the recording time, only liquid meals $\left(200 \mathrm{ml}\right.$ Nutridrink ${ }^{\circledR} ; 300 \mathrm{kcal}: 13 \%$ proteins, $48 \%$ carbohydrates, $39 \%$ lipids. Nutricia, Belgium), not interfering with Bilitec monitoring were used. ${ }^{17}$ Patients were asked to preferably drink water and to avoid coffee, tea and fruit juices during the recording. Patients were instructed to indicate the occurrence of heartburn by pressing a marker button on the data collection device.

\section{Data analysis}

The data were analyzed with the aid of commercially available software (Gastrosoft Inc. Synetics Medical, Irvine, Texas, USA). Acid and duodenal reflux were quantified separately with the following variables obtained from computerized analysis: number of reflux episodes, number of reflux episodes lasting longer than five minutes, fraction of time of acid or duodeno-esophageal reflux. The recording was divided in meal, postprandial (two hours after a meal), interdigestive, upright and supine periods.

For each symptom episode, indicated by the patient, the minimal $\mathrm{pH}$ value and the maximal bilirubin absorbance value in a classical two minutes interval ${ }^{20}$ were calculated.

Marshall et $\mathrm{al}^{21}$ suggested that a window of four minutes might be preferable for DGER studies. We therefore compared the classical two minutes interval before, a two minutes period after the symptom episode, and a four minutes interval.

Pathological acid reflux was defined as a drop of $\mathrm{pH}$ below 4.0 and pathological DGER as bilirubin absorbance $>0.14$. The SI was calculated for each patient in relation to both acid and DGER episodes. For acid reflux the $\mathrm{SI}$ was calculated as the number of symptoms with $\mathrm{pH}<4$ divided by the total number of symptoms multiplied by $100 \%$. The SI for DGER was calculated by the formula: number of symptoms with bilirubin absorbance more than 0.14 divided by the total number of symptoms multiplied by $100 \%$. A positive symptom index was defined if $>75 \%$ of the symptoms were associated with pathological reflux. 
The SAP was calculated for each patient in relation to both acid and DGER episodes. The SAP is calculated by dividing the 24 hours esophageal $\mathrm{pH}$ - and Bilitec ${ }^{\bar{B}}$ monitoring into two minutes periods. All two minutes periods preceding the onset of symptom episodes were analyzed for the presence of reflux and classified as reflux-positive or refluxnegative as proposed by Weusten et al. ${ }^{22} \mathrm{~A}$ two minutes period was considered reflux-positive if either a decrease in $\mathrm{pH}$ below 4 lasting five seconds or more or a decrease in $\mathrm{pH}$ of more than $1 \mathrm{pH}$ unit (within five seconds) had occurred during that period. ${ }^{22}$. For the DGER the two minutes period was considered reflux-positive if the bilirubin absorbance was more than 0.14 lasting more than five seconds. A modified chisquare test was used to calculate the probability $(\mathrm{p})$ that the observed distribution could have been brought about by chance. The SAP is calculated as $(1-p)^{*} 100 \%$. SAP values greater than $95 \%$ are positive.

A modification of the SAP calculation was adapted for the four minutes interval; dividing the time period in four minutes instead of the two minutes before the symptom episode, and compared to the classical SAP.

Statistical analysis

Values are expressed as mean and standard deviation (SD) for parametric data and median for non-parametric data. The t-test or Chisquare test compared results (mean \pm SEM) wherever appropriate. The relationship between the percentage of time acid and bilirubin reflux was evaluated using linear regression analysis. P-value were considered to be significant if $<0.05$.

\section{Results}

\section{Patient characteristics}

The mean age of the 35 men and 37 women was 45 years ( \pm 2 years), 30 patients were smokers and 11 patients took daily alcohol.

All 72 patients filled out the symptom questionnaire. Heartburn was the main symptom; in $64 \%$ of the patients moderate to severe. Mild to severe chest pain was found in $54 \%$ of the patients. Regurgitation was present in $53 \%$ of the patients. Dysphagia, nausea and vomiting were less important symptoms, present in $43 \%, 46 \%$ and $36 \%$ of patients respectively (Table 7.1$)$. 
Table 7.1. Frequency and severity grading from symptom scores for reflux symptoms in 72 patients evaluated for suspected GERD. Expressed in absolute numbers and percentage (\%).

\begin{tabular}{lcccr}
\hline Symptom & Absent & Mild & Moderate & Severe \\
\hline Heartburn & $16(22)$ & $10(14)$ & $22(31)$ & $24(33)$ \\
Chest pain & $33(46)$ & $10(14)$ & $16(22)$ & $13(18)$ \\
Regurgitation & $34(47)$ & $13(18)$ & $17(24)$ & $8(11)$ \\
Dyspaghia & $41(57)$ & $8(11)$ & $12(17)$ & $11(15)$ \\
Nausea & $39(54)$ & $12(17)$ & $11(15)$ & $10(14)$ \\
Vomiting & $46(64)$ & $9(13)$ & $11(15)$ & $6(8)$ \\
\hline
\end{tabular}

\section{Endoscopy}

In all patients the endoscopic investigation took place before the 24 hours measurements. In 30 patients (42\%) no esophageal lesions were found. According to the modified Savary and Miller classification esophagitis grade 1 or 2 was seen in 39 patients (54\%) and esophagitis grade 3 or 4 in 3 patients (4\%). A hiatal hernia was found in $24(33 \%)$ patients.

Symptoms and reflux episodes

A total of 544 symptom episodes were identified, of which 22 episodes (4\%) occurred during the meal, 132 (24\%) during the postprandial period, $306(57 \%)$ during the interdigestive period and $84(15 \%)$ during the night (Figure 7.1).

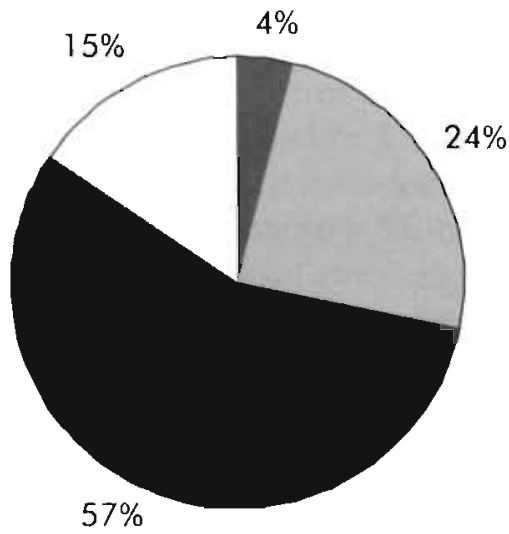

Meal

$\square$ Postprandial

- Interdigestive

Supine

Figure 7.1. Symptom episodes distribution: 306 symptom episodes were registered during the interdigestive period, 132 in the postprandial period, 84 in the supine position and 22 during the meal. 
Two minutes interval before symptom episode

The mean $\mathrm{pH}$ and bilirubin absorbance in this period were $4.4( \pm 0.09)$ and $0.11( \pm 0.007)$ respectively (Table 7.2$)$. In this "classical" interval patients pushed the symptom marker button on 150 occasions (28\%) in association with acid reflux alone, on 47 occasions $(9 \%)$ in association with DGER and on 67 occasions (12\%) in association with combined reflux (Figure 7.2). A positive symptom index for acid reflux was found in $11(15 \%)$ patients, for DGER in one (1\%) patient and for mixed reflux in 10 (14\%) patients (Table 7.3).

The calculated SAP was significant in 16 patients $(22 \%)$ with acid reflux, in five patients $(7 \%)$ with DGER and in seven patients $(10 \%)$ with mixed reflux (Table 7.3).

Table 7.2. Influence of measurement interval on the association of symptom episodes with reflex events. Three different measurement intervals (two minutes before, two minutes after the patient pushed the symptom button and four minutes interval) were studied. Significance of difference between two and four minutes interval is indicated in the last column. The choice of interval did not influence the number and types of reflux episodes associated with symptomatic events.

\begin{tabular}{lccccc}
\hline \multicolumn{7}{c}{2 min before } & 2 min after & 4 min interval & pi-value \\
\hline Reflux parameters associated with symptomatic events \\
Mean pH & $4.4( \pm 0.09)$ & $4.2( \pm 0.09)$ & $3.8( \pm 0.09)$ & $<0.05$ \\
Mean bile absorbance & $0.11( \pm 0.007)$ & $0.11( \pm 0.007)$ & $0.13( \pm 0.007)$ & NS \\
Types of reflux episodes associated with symptomatic events $(\%)$ & & \\
Acid & $150(28)$ & $165(30)$ & $182(34)$ & NS \\
DGER & $47(9)$ & $38(7)$ & $40(7)$ & NS \\
Mixed & $67(12)$ & $76(14)$ & $97(18)$ & NS \\
\hline
\end{tabular}

Two minutes interval after onset of symptoms

The mean $\mathrm{pH}$ and bilirubin absorbance in this period were $4.2( \pm 0.09)$ and $0.11( \pm 0.007)$ respectively (Table 7.2). Patients pushed the symptom button on 165 occasions (30\%) in association with acid reflux, on 38 occasions $(7 \%)$ in association with DGER and on 76 occasions $(14 \%)$ in association with combined reflux. A positive SI was found for acid reflux in $12(17 \%)$ patients, for DGER in one patient $(1 \%)$ and for mixed reflux in eight patients (11\%). 


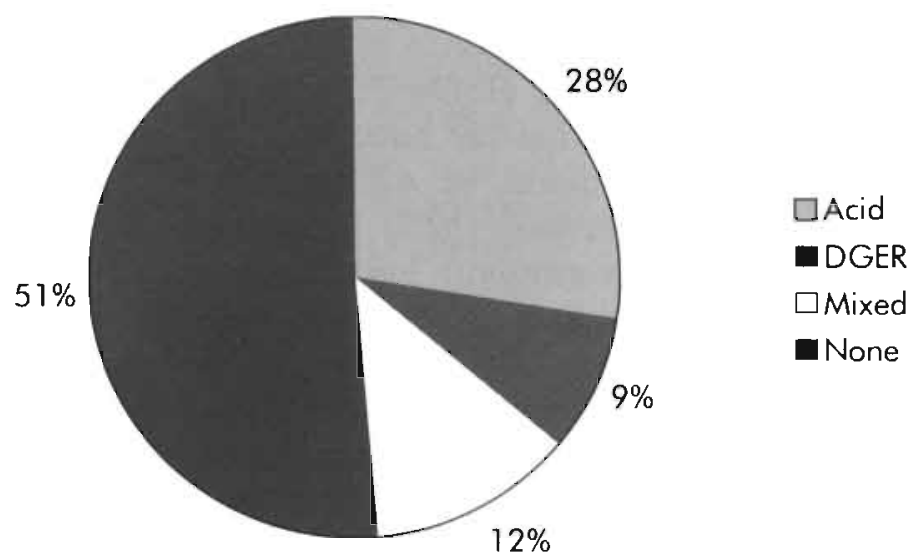

Figure 7.2. Reflux associated symptom episodes in 72 patients: 165 symptom episodes occurred during acid reflux, 38 during bile reflux, 84 during combined reflux and 257 episodes occurred in the absence of pathological reflux.

Table 7.3. Comparison between classical two minutes interval and four minutes interval for symptom index and symptom association probability (SAP) in absolute number of patients (percentage of patients). No significant difference was observed between the two- and four minutes interval for symptom index and SAP.

\begin{tabular}{lccc}
\hline Positive SI (\%) & 2 minutes & 4 minutes & $\mathrm{p}$ \\
\hline Acid & $11(15)$ & $12(17)$ & 0.48 \\
DGER & $1(1)$ & $0(0)$ & 0.32 \\
Mixed & $10(14)$ & $11(15)$ & 0.31 \\
Positive SAP (\%) & & & \\
Acid & $16(22)$ & $10(14)$ & 0.19 \\
DGER & $5(7)$ & $6(8)$ & 0.75 \\
Mixed & $7(10)$ & $6(8)$ & 0.77 \\
\hline
\end{tabular}

Four minutes interval

Using a four minutes window (two minutes before and two minutes after the patient pushed the symptom marker button), the mean $\mathrm{pH}$ was 3.8 $( \pm 0.09)$ and the mean bilirubin absorbance $0.13( \pm 0.007)$. In the four minutes interval a significantly lower $\mathrm{pH}$ was measured in comparison with both two minutes intervals (Table 7.2).

In 182 (34\%) episodes acid reflux was observed, in $40(7 \%)$ episodes DGER, in $97(18 \%)$ episodes mixed reflux and in $225(41 \%)$ episodes no reflux was found (Table 7.2). 
A positive symptom index $(>75 \%)$ for acid reflux alone was found in 12 (17\%) patients, none for DGER alone and 11 (15\%) for both. The calculated modified SAP was significant in 10 patients $(14 \%)$ with acid reflux, in six patients $(8 \%)$ with DGER and in six patients $(8 \%)$ with mixed reflux (Table 7.3).

\section{Measurement intervals}

The proportion of reflux associated symptom episodes increased from $46 \%$ to $52 \%$ when the symptom interval was increased from two to four minutes. This reached no statistical significance (Chi-square). The proportions of acid reflux or DGER or combined reflux associated symptom episodes did not differ significantly when a two or a four minutes interval were used.

\section{Subgroup with positive $\mathrm{pH}$ monitoring}

Pathological acid reflux, defined as the $\mathrm{pH}$ below 4 more than $4 \%$ of the time, was found in $44(61 \%)$ out of 72 patients. In the 24 men and 20 women, with a mean age of 45 ( \pm 1.7 years), the endoscopic findings were: no esophagitis in 13 patients $(42 \%)$, grade 1 and 2 esophagitis in 28 patients (54\%) and grade 3 and 4 esophagitis in two patients (4\%) according to the Savary and Miller classification.

In this subgroup 337 symptom events were registered, of which 131 were associated with acid reflux (39\%), 23 with DGER (7\%) and $74(22 \%)$ with combined reflux (Figure 7.3). A positive SI for acid reflux was found in 10 (23\%) patients, for DGER in one patient $(2 \%)$ and for mixed reflux in nine patients $(21 \%)$. The SAP was significant in 11 patients $(15 \%)$ for acid reflux, in three patients $(7 \%)$ for DGER and in five patients $(10 \%)$ for combined reflux.

\section{Subgroup with esophagitis}

In the subgroup of 42 patients with esophagitis, 321 symptom events were registered, of which 107 were associated with acid reflux (33\%), 31 with DGER (10\%) and $50(16 \%)$ with combined reflux (Figure 7.4$)$. A positive SI for acid and mixed reflux was found in five (12\%) patients. The SAP was significant in 13 patients $(31 \%)$ for acid reflux, in three patients $(7 \%)$ for DGER and in four patients $(9.5 \%)$ for combined reflux. 


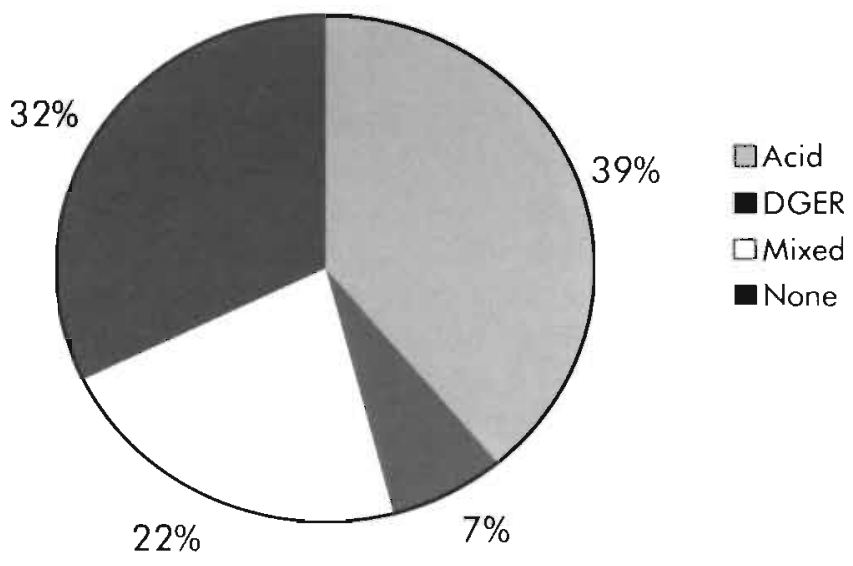

Figure 7.3. Reflux associated symptom episodes in 44 patients with pathological esophageal acid exposure. 131 symptom episodes occurred during acid reflux, 23 during DGER, 74 during combined reflux and 106 episodes occurred in the absence of pathological reflux.

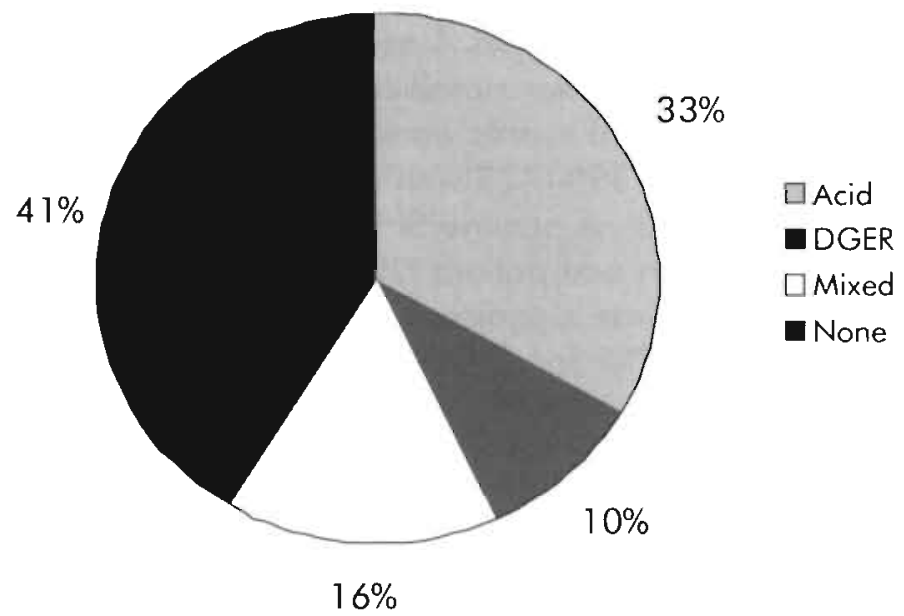

Figure 7.4. Reflux associated symptom episodes in 42 patients with esophagitis. 107 symptom episodes occurred during acid reflux, 31 during DGER, 50 during combined reflux and 133 episodes occurred in the absence of pathological reflux. 


\section{Discussion}

The most typical clinical symptoms of GERD are heartburn and acid regurgitation. Although provocation tests using acid perfusion demonstrated a good correlation between the duration and the amount of acid administered and the induction of heartburn, ambulatory $\mathrm{pH}$ monitoring studies showed a less consistent and much more complicated relationship between intra esophageal $\mathrm{pH}$ and spontaneously occurring symptoms of heartburn. In the present study, we investigated the contribution of acid reflux and of DGER to spontaneously occurring symptoms of heartburn using ambulatory $\mathrm{pH}$ and $\mathrm{Bilite}^{\left({ }^{(}\right)}$monitoring in patients with suspected GERD. We observed that acid reflux and not DGER is the main contributant to typical esophageal symptoms in our study population. In association with $53 \%$ of 544 symptom episodes, pathological reflux was observed. Most symptom episodes (30\%) occurred during acid reflux alone, $16 \%$ occurred during combined reflux and only $7 \%$ during DGER alone. A positive SI for acid was present in $21 \%$ of the patients, and for combined acid and DGER in $14 \%$ of the patients. The SAP was positive for acid reflux in $22 \%$ of the patients, for combined reflux in $10 \%$ and for DGER alone in $7 \%$.

The role of acid and non-acid reflux in the induction of symptoms and mucosal lesions has been addressed in different studies. In a study of partial gastrectomy patients, Vaezi et al. showed that typical reflux symptoms like heartburn and regurgitation occurred mainly in relation to both acid and DGER reflux. Atypical symptoms such as nausea, vomiting and distention were related to DGER alone. ${ }^{27}$ Esophageal lesions occur in about $50 \%$ of patients with heartburn and regurgitation, the main complaints of patients with GERD. ${ }^{28,29}$ No consistent relation has been found with the severity of symptoms and the lesions seen at endoscopy. In 24 hours esophageal acid exposure studies the severity of esophageal lesions seems to be correlated to the duration of reflux which is particularly prolonged in Barrett's esophagus, but considerable overlap exists. ${ }^{30,31}$ Not only the duration of reflux but probably the composition of the refluxate is important in the induction of lesions. Reflux of duodenal contents into the stomach, especially postprandially, is a physiological event. ${ }^{25}$ Hence, it is not unusual for gastro-esophageal refluxate to contain bile, duodenal and pancreatic secretions. Using the Bilitec ${ }^{\text {(8) }}$ spectophotometric probe, it was shown that patients with Barrett's metaplasia had a higher prevalence of abnormal esophageal bilirubin exposure in comparison with those with erosive injury or without esophagitis. ${ }^{13.16}$ In complicated Barrett's esophagus a greater amount of 
acid and duodenal reflux was observed in comparison with uncomplicated Barrett. ${ }^{14}$ In these studies a synergistic activity of acid and DGER is suggested in the induction of esophageal lesions. Recent studies suggest that DGER alone is also able to induce esophageal lesions. In critically ill, mechanically ventilated, patients who were receiving stress ulcer prophylaxis with ranitidine, the presence of esophagitis was found to be related to pathological DGER in the absence of pathological acid reflux. ${ }^{32}$

The role of DGER in inducing or in contributing to typical reflux symptoms has received little attention. Marshall et al. studied the association of reflux symptoms with both acid and DGER using the symptom index. ${ }^{21}$ Their observation that symptomatic episodes were mostly related to acid reflux and not to DGER, is in line with the findings of the present study. However, some differences between both studies may be relevant. Because elimination of the viscous bilirubin-containing fluid from the esophageal mucosa and from the optical probe may be slow, Marshall et al. used an interval of four minutes around symptom events in their analysis, rather than the classical two minute interval. ${ }^{21,22}$ in our sfudy we compared the classical two minutes with four minutes interval and we failed to observe a significant difference in the association of symptoms with different types of reflux. We therefore concluded that also for DGER, like acid reflux, the two minutes time interval preceding the symptom episode is adequate. Due to its construction, the Bilitec ${ }^{\otimes}$ probe is prone to solid food impaction causing measurement artifacts. In order to avoid artifacts, Marshall et al. excluded the meal and postprandial period from the analysis, whereas others have used a liquid diet. ${ }^{14,22}$ As a recent study found that the use of solid foods during Bilitec ${ }^{8}$ monitoring is associated with an unacceptably high prevalence of meal-impaction artifacts ${ }^{17}$, we used liquid meals during ambulatory $\mathrm{pH}$ and Bilitec ${ }^{B}$ monitoring. This allowed us to also analyze the symptom episodes occurring during the meal- and postprandial period, which was $28 \%$ of the total number of events. Marshall et al. used the SI to analyze the relationship between symptoms and reflux events. ${ }^{21}$ However, this method has a number of methodological flaws, such as the failure to take into account the total number of reflux events. In the present paper, we used the SAP, which is a more appropriate calculation of the probability that the observed association between reflux and symptoms is not caused by chance. ${ }^{22}$

In conclusion, even when the meal-, and postprandial period is incorporated, when a two minutes window is used and when statistical 
analysis is made using the SAP, typical symptom episodes in patients with presumed gastro-esophageal reflux disease are most often related to acid reflux and rarely to DGER. DGER does not seem to play a major role in the induction of typical symptoms of reflux like heartburn and acid regurgitation. Further studies are needed to evaluate the role of DGER in the development of atypical reflux symptoms. 


\section{References}

1. Smith JL, Opekun AR, Larkai E, Graham DY. Sensitivity of the esophageal mucosa to $\mathrm{pH}$ in gastroesophageal reflux disease. Gastroenterology 1989;96:683-9.

2. Baldi F, Ferrarini F, Longanesi A, Ragazzini M, Barbara L. Acid gastroesophageal reflux and symptoms occurrence. Analysis of some factors influencing their association. Dig Dis Sci 1989;34:1890-3.

3. Janssens J, Vantrappen G, Vos R, Ghillebert $G$. The acid burden over and extended period preceding a reflux episode is a major determinant in the development of heartburn. Gastroenterology 1992;103:A90.

4. Singh, S, Richter JE, Bradley, Haile JM. The symptom index. Differential usefulness in suspected acid-related complaints of heartburn and chest pain. Dig Dis Sci 1993;38:1402-8.

5. Shi G, Bruley des Varannes S, Scarpignato C, Le Rhun M, Galmiche JP. Refluxrelated symptoms in patients with normal oesophageal exposure to acid. The acid hypersensitive esophagus. Gut 1995;37:457-64,

6. Nasrallah SM, Johnston GS, Gadacz TR, Kim KM. The significance of gastric bile reflux seen at endoscopy. J Clin Gastroenterol 1987;9:514-7.

7. Stein HJ, Smyrk TC, DeMeester TR, Rouse J, Hinder RA. Clinical value of endoscopy and histology in the diagnosis of duodenogastric reflux disease. Surgery $1992 ; 112: 796-804$.

8. Drane WE, Karvelis $K$, Johnson DA, Silverman ED. Scintigraphic evaluation of duodenogastric reflux. Problems, piffalls, and technical review. Clin Nucl Med 1987; 1 2:377-84.

9. Johnsson F, Joelsson B, Floren $\mathrm{CH}$, Nilsson A. Bile salts in the esophagus of patients with esophagitis. Scand J Gastroenterol 1988;23:712-6.

10. Gotley DC, Morgan AP, Cooper MJ. Bile acid concentration in the refluxate of patients with reflux esophagitis. Br J Surg 1988;75:587-90.

11. Iftikhar SY, Ledingham S, Evans D, Yusuf SW, Steele RJ, Atkinson M, Hardcastle JD. Alkaline gastro-esophageal reflux: dual $\mathrm{pH}$ probe monitoring. Gut 1995;37: 465-70.

12. Just RJ, Leite LP, Castell DO. Changes in overnight fasting intragastric $p H$ show poor correlation with duodenogastric bile reflux in normal subjects. Am J Gastroentrol 1996;91:1567-70.

13. Champion G, Richter JE, Vaezi MF, Singh S, Alexander R. Duodeno-gastroesophageal reflux: relationship to $\mathrm{pH}$ and importance in Barrett's esophagus. Gastroenterology 1994;107:747-54.

14. Caldwell MT, Lawlor P, Byrne PJ, Walsh TN, Hennessy TP. Ambulatory oesophageal DGER monitoring in Barrett's esophagus. Br J Surg 1995; 82:657-60. 
15. Kaver WK, Peters JH, DeMeester TR, Ireland AP, Bremner CG, Hagen JA. Mixed reflux of gastric and duodenal juices is more harmful to the esophagus than gastric juice alone. The need for surgical therapy re-emphasized. Ann Surg 1995; 222:525-31.

16. Vaezi MF, Richter JE. Synergism of acid and duodenogastroesophageal reflux in complicated Barrett's esophagus. Surgery 1995;1 17:699-704.

17. Tack J, Bisschops R, Koek G, Sifrim D, Lerut T, Janssens J. Dietary restrictions during ambulatory monitoring of duodeno-gastro-esophageal reflux. Dig Dis Sci 2003;48:1213-20.

18. Nehra D, Howell P, Williams CP, Pye JK, Beynon J. Toxic bile acids in gastrooesophageal reflux disease: influence of gastric acidity. Gut 1999;44:598-602.

19. Wiener GJ, Richter JE, Copper JB, WU WC, Castell DO. The symptom index: a clinically important parameter of ambulatory 24 -hour esophageal $\mathrm{pH}$ monitoring. Am J Gastroenterol 1988;83:358-61.

20. Lam HG, Breumelhof R, Roelofs JM, Van Berge Henegouwen GP, Smout AJ. What is the optimal time window in symptom analysis of 24-hour oesophageal pressure and $\mathrm{pH}$ data. Dig Dis Sci 1994;39:402-9.

21. Marshall RE, Anggiansah A, Owen WA, Owen WJ. The relationship between acid and bile reflux and symptoms in gastro-esophageal reflux disease. Gut 1997;40:182-7.

22. Wuesten BLAM, Roelofs JMM, Akkermans LMA, Van Berge-Henegouwen GP, Smouł AJ. The symptom-association probability: An improved method for symptom analysis of 24-hour esophageal pH data. Gastroenterology 1994;107:1741-5.

23. Savary M, Miller G. L'oesophage. Manuel et Atlas d'Edoscopie. Solothurn, Switzerland: Verlag Gassmann, 1977.

24. Armstrong D, Monnier Ph, Nocolet $M$, ef al. The "MUSE" system. In: Giuli R, Tytgat GNJ, DeMeester TR, Galmiche JP, eds. The esophageal mucosa. Amsterdam: Elsevier Science, 1994: 313-21.

25. Caldwell MT, Byrne PJ, Brazil N, Crowley V, Attwood SE, Walsh TN, Hennessy TP. An ambulatory bile reflux monitoring system: an in vitro appraisal. Physiol Meas $1994 ; 15: 57-65$.

26. Walther B, DeMeester TR. Placement of the esophageal pH electrode for 24 hour esophageal pH monitoring. In: DeMeester TR, Skinner DB, eds. Esophageal disorders: pathophysiology and therapy. New York: Raven press, 1985: 539-41.

27. Vaezi M.F, Richter JE. Contribution of acid and duodenogastro-oesophageal reflux to oesophageal mucosal injury and symptoms in partial gastrectomy patients. Gut 1997;41:297-302.

28. Johnsson F, Joelsson B, Gudmundsson K, Greiff L. Symptoms and endoscopic findings in the diagnosis of gastroesophageal reflux disease. Scand J Gastroenterol 1987;22:714-8.

29. Zeitoun $P$, Carteret $E$. Natural history of reflux esophagitis in adults. In: Mignon $M$, Calmiche J-P, eds. Control of acid secretion. Paris, London: J Libbey, 1988:225-38. 
30. Stein HJ, Barlow AP, DeMeester TR, Hinder RA. Complications gastoesophageal reflux disease. Ann Surgery 1992;216:35-43.

31. Parrilla P, Ortiz A, Martinez de Haro LF, Aguayo $J$, Ramirez P. Evaluation of the magnitude of gastro-oesophageal reflux in Barrett's oesophagus. Gut 1990;31:964-7.

32. Wilmer A, Tack J, Frans E, Diłs H, Vanderschueren S, Gevers A, Bobbaers H. Duodenogastroesophageal reflux and esophageal mucosal injury in mechanically ventilated patients. Gastroenterology 1999;1 16:1293-9. 


\section{Chapter 8}

\section{Determining factors in the etiology of esophagitis and Barrett's esophagus}

GH Koek, D Sifrim, T Lerut, J Janssens, R Stockbrügger, J Tack 


\section{Abstract}

\section{Background}

Acid- and duodeno-gastro-esophageal reflux (DGER) frequently occurs in patients with gastro-esophageal reflux disease (GERD).

Aim

The present study was to clarify the relationship between esophageal lesions, demographic, anatomical, physiological factors, acid- and DGER exposure.

\section{Methods}

In 422 patients (221 men, age 46.8 \pm 0.7 ) evaluated for suspected GERD, upper gastrointestinal endoscopy, esophageal manometry and 24 hours $\mathrm{pH}$ and Bilite $(\mathbb{R}$ monitoring were performed. In addition, demographic variables, body mass index, smoking and alcohol consumption were registered. The percentage of time that the esophagus was exposed to acid and DGER was calculated. Data (mean \pm SEM) were analyzed by stepwise logistic regression to assess factors associated with the presence of esophagitis, the severity of esophagitis and the presence of Barrett's esophagus. Odds ratios $(O R)$ and $95 \%$ confidence intervals $(\mathrm{Cl})$ were computed.

\section{Results}

$54 \%$ of the patients had no esophagitis, $36 \%$ had grade $1-2,3 \%$ had grade $3-4$, excluding Barrett's esophagus and 7\% had Barrett's esophagus. The presence of esophagitis was associated with the presence of a hiatus hernia, an elevated body mass index and with DGER exposure. The severity of esophagitis was associated with esophageal acid exposure. The presence of Barrett's esophagus was associated with male sex, exposure to DGER and acid.

\section{Conclusions}

Several independent factors are associated with the presence of esophageal lesions in GERD. The risk to develop esophagitis depends on the presence of a hiatus hernia, a higher body mass index and DGER exposure. The severity of esophagitis depends on acid exposure and the development of a Barrett's esophagus is associated with male sex and the exposure of acid and DGER. These results suggest the important role of combined reflux and require adequate chronic treatment. 


\section{Introduction}

Gastro-esophageal reflux disease (GERD) is one of the most common disorders affecting the gastrointestinal tract. GERD is defined by the presence of symptoms and/or lesions that can be attributed to the reflux of gastric contents into the esophagus. The most typical clinical symptoms of reflux disease are heartburn and regurgitation, but GERD can manifest itself through a variety of other esophageal and extraesophageal symptoms.

GERD may or may not be accompanied by esophageal lesions. Peptic esophagitis and Barrett's esophagus are the specific lesions associated with GERD, but it is well established that a large proportion of patients with typical GERD symptoms do not have endoscopic or pathological evidence of esophagitis. ${ }^{1-3}$

The refluxate that reaches the esophagus might be highly acidic $(\mathrm{pH}$ below 4), moderately or lightly acidic ( $\mathrm{pH}$ between 4-7) or non-acidic $(\mathrm{pH} 7$ or above). Furthermore, it can consist of any mixture of food, gas, including acid and or bile or both. Reflux esophagitis and reflux symptoms are classically attributed to the reflux of the acid component of gastric content into the esophagus. However, although esophageal acid exposure increases with increasing severity of esophagitis and is highest in patients with Barrett's esophagus, the presence or severity of lesions cannot be explained by acid exposure alone.

A number of observations support the idea that non-acid reflux may also contribute to symptoms and lesions. Reflux of duodenal contents into the stomach is a physiological phenomenon, mainly occurring postprandially. ${ }^{4.8}$ Hence, it is not unusual for gastro-esophageal refluxate to contain duodenal secretions, pancreatic secretions and bile. Animal studies have indicated that the esophageal mucosa is relatively resistant to reflux of acid alone, unless it occurs at very high concentrations $(\mathrm{pH}<1.0)$. Addition of pepsin at low concentrations induces esophageal lesions at $\mathrm{pH}$ values below 2.9-11 Bile acids, especially when conjugated, are injurious to the rabbit esophageal mucosa at acidic $\mathrm{pH}^{12}$, and unconjugated bile acids are even harmful at neutral $\mathrm{pH} .{ }^{13}$

Stationary aspiration studies were able to demonstrate the presence of bile in esophageal aspirates from patients with esophagitis, but at a concentration that rarely reaches that found in experimental models to 
cause esophageal damage, and no clear relation between bile acid concentration and severity of esophagitis was found. ${ }^{14,15}$ More recently, a method for ambulatory refluxate aspiration was developed. This confirmed that reflux into the esophagus of both bile and pancreatic enzymes occurs frequently in patients with reflux disease. ${ }^{16}$

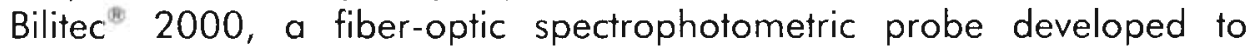
quantify duodeno-gastro-esophageal reflux (DGER) in an ambulatory fashion, uses bilirubin as a marker for the presence of duodenal contents. Bilirubin has a characteristic absorbance spectrum, and by continuous monitoring of the absorbance at two optical wavelengths by the esophageal refluxate, the presence of bilirubin can be determined. Several studies have reported a good correlation between Bilitec ${ }^{*}$ measurements and bile acid concentrations. ${ }^{17-19}$ Ambulatory aspiration studies found a significant correlation between the total bilirubin concentration of aspirated samples and the fiberoptic reading of bilirubin concentration. ${ }^{20}$ Moreover, a good correlation was found between total bilirubin content and the concentrations of pancreatic enzymes in the refluxate, suggesting that bilirubin is a good marker for the entire DGER. Because the Bilitec ${ }^{6}$ probe is prone to food impaction, dietary restrictions are recommended during measurements. A recent study from our group recommended to use liquid meals during the measurement period. ${ }^{21}$ Although it could be argued that it is not physiological to administer liquid meals, not representing a normal mixed meal, we established that the diet used did not significantly alter the acid exposure of the distal esophagus in healthy volunteers. Presumably because of its high lipid content, the liquid diet used in this study also induces reflux episodes, thus allowing comparison of acid reflux data obtained with those during normal diet.

The pathological role of duodenal contents (DC), consisting of bilirubin, bile acids and pancreatic enzymes, mainly trypsin, has been suggested in patients developing esophagitis after total gastrectomy and gastritis in patients with achlorhydria. ${ }^{22-25}$ Similar to $\mathrm{pH}$ monitoring, several studies have demonstrated a progressive increase in DGER across the spectrum of GERD, with a particularly high prevalence in patients with Barrett's esophagus. ${ }^{26-32}$ Patients with complicated Barrett's esophagus have greater amounts of acid reflux and DGER than patients with uncomplicated Barrett's esophagus. ${ }^{33,34}$ Combined Bilitec ${ }^{18}$ and $\mathrm{pH}$ studies showed that simultaneous esophageal exposure to both acid and DGER is the most prevalent reflux pattern and that the majority of DGER episodes occur in an acidic environment. ${ }^{28,34,35}$ Taken together, these studies suggest that a synergistic activity of acid reflux and DGER may 
contribute to the occurrence and severity of esophageal lesions in patients with GERD.

We observed that, with increasing severity of esophagitis, increasing exposure to both acid and DGER was found. ${ }^{21}$ It is unknown whether damage by DGER in higher-grade lesions occurs secondarily to increased reflux events, as reflected by the higher acid exposure, or whether this is an independent factor contributing to the development of esophageal lesions. The purpose of the present study, therefore, was to evaluate which factors are involved in the pathophysiology of esophageal lesions in GERD, by means of multivariate analysis.

\section{Materials and methods}

\section{Patients}

Over a $2 \frac{1}{2}$ years time period, 637 patients were referred to our gastrointestinal research unit for suspected GERD by general practitioners, gastroenterologists, and surgeons. The main inclusion criteria for the present evaluation were typical GERD symptoms (heartburn and/or regurgitation) and a normal serum bilirubin level.

Exclusion criteria were: peptic ulcer disease, previous esophageal, gastric or biliary surgery; previous abdominal or thoracic radiotherapy; active gastrointestinal bleeding; presence of esophageal or fundic varices; diabetes mellitus; Zollinger-Ellison syndrome; progressive systemic sclerosis; Raynaud's syndrome and other vascular diseases; neurological disorders; esophageal or upper small intestinal Crohn's disease; herpetic or Candida esophagitis or active solid fumor neoplastic disease. Patients were also required to be off proton pump inhibitors (PPIs) for at least four weeks. After these exclusions 422 patients (66\%) were eligible for the study.

\section{Study protocol}

The Ethics Committee of the University Hospital Gasthuisberg Leuven, Belgium approved the study protocol. Patients were asked to fill out a detailed questionnaire about occurrence of symptoms and their frequency, smoking and drinking habits, weight and height. In all patients, we subsequently performed an ambulatory 24 hours esophageal $\mathrm{pH}$ and Bilitec ${ }^{3}$ monitoring. All drugs potentially affecting gastrointestinal motility and gastrointestinal secretion were discontinued at least four weeks prior to the study. 
Probes for assessing acid and DGER were introduced via a nasal orifice into the esophagus five $\mathrm{cm}$ proximal to the lower esophageal sphincter, previously defined by stationary esophageal manometry. The probes were then attached with adhesive tape to the subject's nose and cheek. In addition, appropriate positioning in the esophagus was confirmed by fluoroscopy.

Data collection devices were connected to the probes and worn in a belt on the patient's waist. Registration of acid or DGER lasted for approximately 22 hours after which the probes were removed and the data transferred to a personal computer for analysis. Patients recorded the time of liquid food or fluid consumption and posture changes on a diary card. They were instructed to stay upright during the daytime. During the recording time, only a free amount of liquid meals $(200 \mathrm{ml}$ Nutridrink $^{\infty} ; 300 \mathrm{kcal}: 13 \%$ proteins, $48 \%$ carbohydrates, and $39 \%$ lipids. Nutricia, Belgium), were used. ${ }^{21}$ Patients were asked to preferably drink water and to avoid coffee, tea and fruit juices during the recording.

\section{Upper gastrointestinal endoscopy}

Before the test for acid reflux and DGER all subjects underwent an upper gastrointestinal endoscopy. If necessary, they were sedated by intravenous administration of diazepam (up to $10 \mathrm{mg}$ ). During endoscopy, the presence of esophagitis was noted and graded according to the modified classification of Savary and Miller ${ }^{36}$ (which is the basis for proton pump inhibitor reimbursement in Belgium). The presence and extent of Barrett's esophagus, defined as an extension of columnar lined epithelium of at least one $\mathrm{cm}$ into the tubular esophagus, was also noted and biopsy specimens were obtained in all patients suspected to have Barrett's esophagus to diagnose intestinal metaplasia. Gastric biopsies were taken to determine the Helicobacter pylori (HP) status in 292 (69\%) patients.

\section{Stationary esophageal manometry}

Patients underwent a manometry before the introduction of the $\mathrm{pH}$ and Bilitec" probe after an overnight fast applying the pull-through method using a Dent sleeve. ${ }^{37}$ This was to determine the position of the LES and to exclude severe motility disorders of the esophagus.

Esophageal manometry was performed using an eight lumen manometric assembly incorporating a sleeve sensor. Intragastric pressure was recorded by a side-hole located one $\mathrm{cm}$ beyond the distal margin of the sleeve. Side-holes at the proximal sleeve margin and at 4, 8, 12 and $16 \mathrm{~cm}$ more proximally recorded motility in the esophageal body, and a side-hole in the pharynx monitored swallowing. The sleeve, gastric and 
esophageal side-holes were perfused with distilled water at a rate of 0.6 $\mathrm{ml} / \mathrm{min}$ using a low compliance pneumohydraulic capillary infusion system. The pharyngeal side-hole was perfused at a rate of $0.3 \mathrm{ml} / \mathrm{min}$, in order to obtain an accurate indication of swallowing but minimize the effect of the assembly on the swallow rate. Each lumen was connected to external pressure transducers (pvb, Medizintechnik GMBH, Germany). With the sleeve adequately positioned across the gastro-esophageal junction, 10 wet swallows $(5 \mathrm{ml}$ water) were administered at 30 seconds intervals.

Basal LES pressure was measured at end-expiration and referenced to intragastric pressure. The amplitude of esophageal contractions was obtained by averaging the amplitudes from the two most distal channels during the 10 wet swallows.

\section{Ambulatory $\mathrm{pH}$ monitoring}

Ambulatory esophageal $\mathrm{pH}$ monitoring was performed using an antimony $\mathrm{pH}$ electrode with a separate skin reference electrode (Synectics Medical, Stockholm, Sweden). The data were stored on a portable digital recorder (Digitrapper Mk III, Synectics Medical, Stockholm, Sweden). Before each study, the $\mathrm{pH}$ probe was calibrated in buffer solutions of $\mathrm{pH}$ 7 and 1. An episode of acid reflux was defined as a decrease in esophageal $\mathrm{pH}$ to less than 4 for more than 10 seconds. ${ }^{38,39}$

The ambulatory recording data were analyzed with the aid of commercially available software (Gastrosoft Inc. Synetics Medical, Irvine, Texas, USA). Acid reflux was quantified with the following variables obtained from computerized analysis: number of reflux episodes, number of reflux episodes lasting longer than five minutes per hour, percentage of time with $\mathrm{pH} \leq 4$. The recording was divided into meal, postprandial (two hours after a meal), interdigestive, upright and supine periods.

Measurement of duodeno-gastro-esophageal reflux

The fiber-optic spectrophotometer Bilitec 2000 (Synectics, Stockholm, Sweden) was used to quantify DGER. The data were stored on a portable digital recorder, loaded into a personal computer and analyzed with dedicated software (Synectics Medical, Stockholm, Sweden). Before each study, the probe was calibrated in water. An episode of DGER was defined as an increase in esophageal bilirubin absorbance $>0.14$ for more than 10 seconds. ${ }^{38,39}$

The ambulatory recording data were analyzed with the aid of commercially available software (Gastrosoft Inc. Synetics Medical, Irvine, Texas, USA). Duodenal reflux was quantified with the following variables 
obtained from computerized analysis: number of reflux episodes, number of reflux episodes lasting longer than five minutes per hour, percentage of time with bilirubin absorbance $\geq 0.14$. The recording was divided into meal, postprandial (two hours after a meal), interdigestive, upright and supine periods.

Statistical analysis

Values are expressed as mean and standard error (SEM) for parametric data and median and interquartile range for non-parametric data. Results were compared using student's $\dagger$-test, Mann-Whitney $U$ test or Chi-square test wherever appropriate.

A univariate analysis compared patients with and without esophagitis, patients with low $(1,2)$ and with high $(3,4)$ grade esophagitis, and patients with and without Barrett's esophagus. P-value were considered to be significant if $<0.05$.

Parameters differing significantly according to the univariate analysis $(p<0.05)$ between the six groups were included in a multivariate logistic regression analysis. Acid and DGER exposure were continuous variables. Independent significant parameters were identified using an ascending selection procedure (Proc Logistic Regression, SAS 6.08, Cary, NC, USA). $P$ values of 0.05 and 0.1 were chosen as cut-off points to enter and exit the stepwise procedure. Odds ratios (OR) and $95 \%$ confidence interval (Cl) were calculated.

From the independent variables determined by multivariate logistic regression analysis, a second analysis was performed using different cutoffs for these variables. Odds ratios and $95 \%$ confidence interval were computed.

\section{Results}

\section{Patient characteristics}

Four hundred and twenty two patients were recruited for the study: 201 $(48 \%)$ men and 221 women (52\%). The mean age was $46.8 \pm 0.7$ years, 103 patients (24\%) were active smokers and $125(30 \%)$ patients took daily alcohol. The mean weight was $73.0 \pm 0.7 \mathrm{~kg}$, the mean length $170 \pm 0.4 \mathrm{~cm}$ and the mean body mass index $25.2 \pm 0.2$. 


\section{Endoscopy}

In all 422 patients the endoscopic investigation took place before the 24 hours measurements. In 228 patients (54.0\%) no esophageal lesions were found. According to the modified Savary and Miller classification esophagitis grade 1 was found in $99(23.4 \%)$ patients, grade 2 in 54 $(12.8 \%)$, grade 3 in $7(1.7 \%)$ and in $34(8.1 \%)$ grade 4 . Four patients had ulcers or strictures and 30 had a Barrett's esophagus. The mean length of the Barrett's esophagus was $4.0 \pm 0.3 \mathrm{~cm}$. A hiatus hernia was found in 154 patients $(36.5 \%)$ (Figure 8.1 ). The mean length of the hiatus hernia was $5.5 \pm 0.2 \mathrm{~cm}$.

Helicobacter pylori was negative in $238(81 \%)$ and positive in 54 patients (19\% of patients who underwent a gastric biopsy).

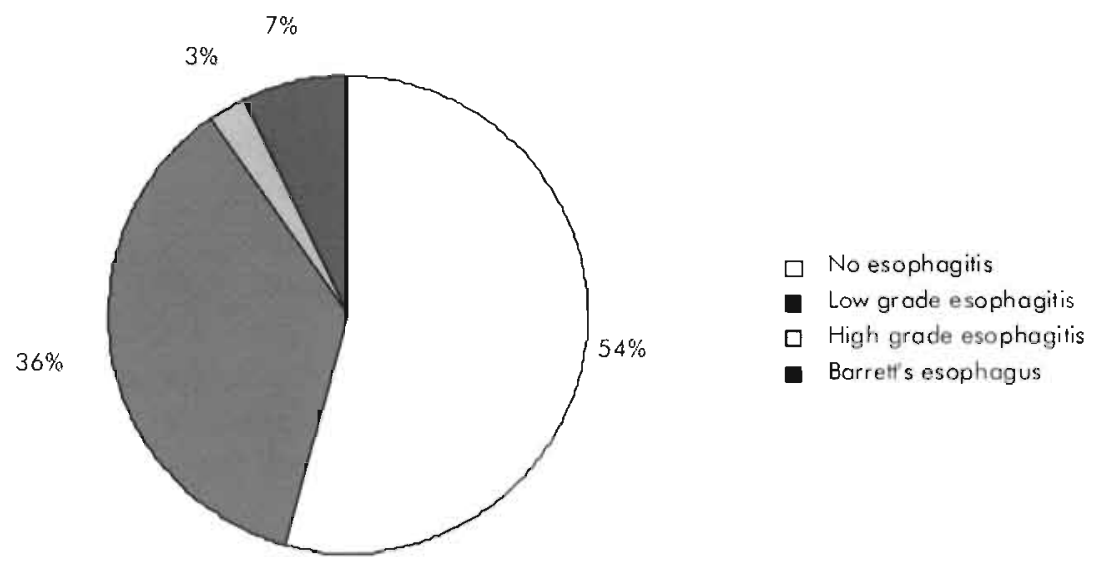

Figure 8.1. Endoscopic findings in 422 patients evaluated for gastro-esophageal reflux disease. The chart shows the prevalence of absence of lesions, low grade esophagitis (grade 1 and 2 according to the Savary Miller classification), high grade esophagitis (grade 3 and 4 according to the Savary Miller classification), and Barrett's esophagus.

Bilitec $^{\sqrt{8}}$ and $\mathrm{pH}$ measurements

The mean time for the combined measurement was $21.2 \pm 1.6$ hours. The median percentage of time the $\mathrm{pH}$ was below 4 was $2.4 \%(0.6 ; 7.5)$ and the median time bile absorbance above 0.14 was $4.9 \%(0.8-20.2)$. The median number of reflux episodes and of reflux episodes longer than five minutes was $43(16-91)$ and $1(0-3)$, respectively, during $\mathrm{pH}$ monitoring. With the Bilitec ${ }^{*}$ the median number of total reflux episodes was 15 (4-37) and the median number of reflux episodes longer than 
five minutes $2(0-6)$ (Table 8.1). Table 8.1 summarizes the data for the upright and supine periods.

Table 8.1. Characteristics of $\mathrm{pH}$ and Bilitec ${ }^{\text {te }}$ recording time: total time, upright and supine position in respect to percentage of time $\mathrm{pH}$ below 4 , bile absorbance above 0.14 , number of reflux episodes, number of reflux episodes longer than five minutes for acid and DGER. Values are given in median, first and third inter quartile range.

\begin{tabular}{lccc}
\hline & Total time & Upright position & Supine position \\
\hline Mean recording time & $21.2( \pm 1.6)$ & $12.2( \pm 2.2)$ & $8.7( \pm 1.6)$ \\
\% time $\mathrm{pH}<4$ & $2.4(0.6-7.6)$ & $2.8(0.7-8.7)$ & $0.3(0-4.9)$ \\
$\mathrm{N}$ acid reflux episodes & $43(16-91)$ & $34(11-69)$ & $3(0-16)$ \\
$\mathrm{N}$ acid reflux episodes $>5$ minutes & $1(0-3)$ & $0(0-2)$ & $0(0-1)$ \\
\% time bilirubin absorbance $>0.14$ & $4.9(0.8-20.2)$ & $5.9(0.9-22.3)$ & $0(0-15.4)$ \\
$\mathrm{N}$ DGER episodes & $15(4-37)$ & $12(3-30)$ & $0(0-7)$ \\
$\mathrm{N}$ DGER episodes $>5$ minutes & $2(0-6)$ & $2(0-4)$ & $0(0-2)$ \\
\hline
\end{tabular}

For the univariate analysis 33 factors were analyzed: gender, age, body mass index, helicobacter status, hiatus hernia, smoking, alcohol use, lower esophageal sphincter pressure and esophageal contraction amplitude, as well as all parameters obtained from the reflux measurements. These included for acid reflux and DGER the total number of reflux episodes, number of reflux episode longer than five minutes and the percentage of time $\mathrm{pH} \leq 4$ or absorbance $\geq 0.14$; each of these for the total time, and for the upright and the supine position period.

Comparison of demographics, $\mathrm{pH}$ and $\mathrm{Bilitec}^{(\circledast)}$ monitoring in different esophageal lesions.

To define the risk factors associated with esophagitis, patients without and with esophagitis, excluding Barrett's esophagus, were compared. To define risk factors for severe lesions patients with grade 1, 2 were compared to grade 3, 4 lesions, excluding Barrett's esophagus. Finally we compared patients with and without Barrett's esophagus.

\section{Factors associated with erosive esophagitis}

The comparison between patients with and without lesions is summarized in Table 8.2. In the univariate analysis, esophagitis patients had a significantly higher body mass index and a lower LES pressure compared to patients without esophagitis. All acid reflux and DGER parameters were higher in esophagitis patients, for total as well as upright and supine times (Table 8.2 ). 
No relation was found between alcohol intake and esophagitis, but smoking was significantly more prevalent in patients with esophagitis (Table 8.2) (Figure 8.2).

Table 8.2. Univariate comparison of $\mathrm{pH}$ and Bilitec $\mathrm{c}^{\text {in }}$ measurements in GERD patients with and without esophagitis (excluding Barrett's esophagus). The periods are subdivided in total time, upright and supine position.

\begin{tabular}{|c|c|c|c|}
\hline & No esophagitis & Grade $1,2,3,4$ & p-value \\
\hline Number & 228 & 164 & \\
\hline Age & $47.4 \pm 1.0$ & $45.7 \pm 1.1$ & NS \\
\hline BMI & $24.6 \pm 0.3$ & $25.8 \pm 0.4$ & $<0.001$ \\
\hline Smoking (\%) & $20 \%$ & $29 \%$ & $<0.05$ \\
\hline Alcohol use (\%) & $28 \%$ & $28 \%$ & NS \\
\hline Hiatus hernia & $23 \%$ & $53 \%$ & $<0.0001$ \\
\hline LES pressure & $18.5 \pm 0.6$ & $16.0 \pm 0.7$ & $<0.001$ \\
\hline \multicolumn{4}{|l|}{ Total time acid reflux } \\
\hline$N$ reflux episodes & $36(12 ; 63.2)$ & $58(22 ; 104)$ & $<0.0001$ \\
\hline $\mathrm{N}$ reflux episodes $>5$ minutes & $0(0 ; 2)$ & $2(0 ; 4\}$ & $<0.0001$ \\
\hline$\% \mathrm{pH}<4$ & $1.7(0.4 ; 5.1)$ & $3.8(1 ; 8.7)$ & $<0.0001$ \\
\hline \multicolumn{4}{|l|}{ Upright position acid reflux } \\
\hline$N$ reflux episodes & $28.5(9 ; 56.3)$ & $41(15 ; 85)$ & 0.005 \\
\hline $\mathrm{N}$ reflux episodes $>5$ minutes & $0(0 ; 1)$ & $O(0 ; 2)$ & $<0.05$ \\
\hline$\% \mathrm{pH}<4$ & $1.9(0.5 ; 6.0)$ & $3.6(0.9 ; 9.1)$ & $<0.005$ \\
\hline \multicolumn{4}{|l|}{ Supine position acid reflux } \\
\hline Number of reflux episodes & $2(0 ; 9.5)$ & $6(0 ; 24)$ & $<0.0005$ \\
\hline Total reflux episodes $>5$ minutes & $0(0 ; 0)$ & $0(0 ; 2)$ & $<0.0005$ \\
\hline$\% \mathrm{pH}<4$ & $0.1(0 ; 1.6)$ & $1.1(0 ; 9.8)$ & $<0.0005$ \\
\hline \multicolumn{4}{|l|}{ Total time DGER } \\
\hline Number of reflux episodes & $11(2 ; 29)$ & $22(7 ; 48)$ & $=0.0001$ \\
\hline Total reflux episodes $>5$ minutes & $1(0 ; 4)$ & $3(1 ; 7)$ & $<0.0001$ \\
\hline$\%$ bile absorbance $>0.14$ & $2.8(0.3 ; 12.4)$ & $8.8(2 ; 25.8)$ & $<0.0001$ \\
\hline \multicolumn{4}{|l|}{ Upright position DGER } \\
\hline Number of reflux episodes & $9.5(2 ; 25)$ & $15(5 ; 33)$ & $=0.001$ \\
\hline Total reflux episodes $>5$ minutes & $1(0 ; 3)$ & $2(1 ; 5)$ & $<0.001$ \\
\hline$\%$ bile absorbance $>0.14$ & $3.7(0.4 ; 13.6)$ & $9.4(1.7 ; 27.8)$ & 0.0001 \\
\hline \multicolumn{4}{|l|}{ Supine position DGER } \\
\hline Number of reflux episodes & $0(0 ; 2)$ & $1(0 ; 13)$ & $<0.0001$ \\
\hline Total reflux episodes $>5$ minutes & $0(0 ; 1)$ & $0(0 ; 3)$ & 0.0001 \\
\hline$\%$ Bile absorbance $>0.14$ & $0(0 ; 5.7)$ & $1.2(0 ; 26)$ & $<0.0001$ \\
\hline
\end{tabular}

The multivariate logistic regression analysis identified the presence of a hiatus hernia, increasing $\mathrm{BMI}$ and increasing DGER exposure as independent risk factors for the presence of esophagitis. The results of the multivariate analysis, at different cut-offs for continuous variables, are shown in Table 8.3. When total acid or DGER exposure were removed, 
the analysis revealed that supine, and not upright, DGER exposure was an independent risk factor for the presence of esophagitis.

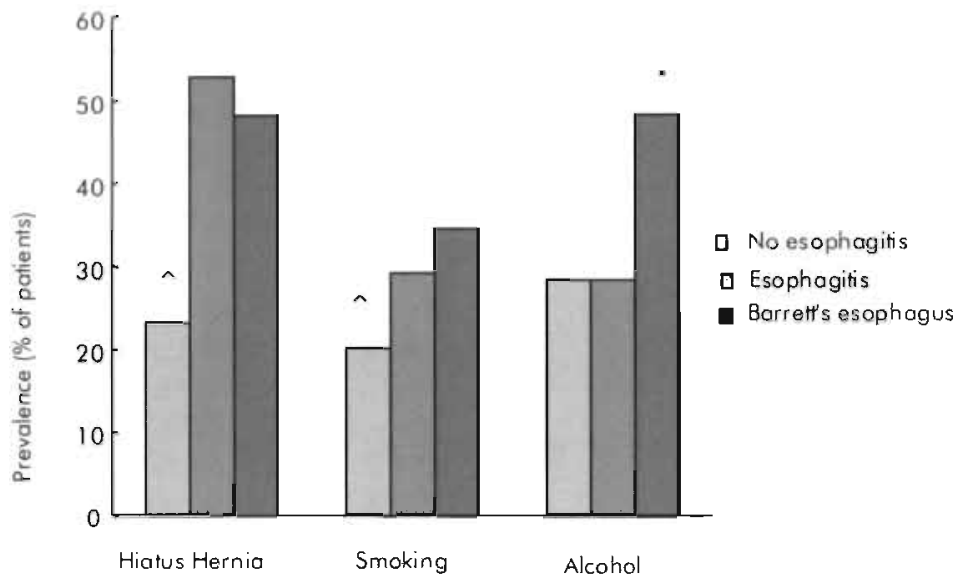

Figure 8.2. Presence of hiatal hernia, smoking and daily alcohol intake according to presence of esophageal lesions. $\left({ }^{\wedge}, p<0.05\right.$ compared to esophagitis; ${ }^{*}$, $\mathrm{p}<0.05$ compared to no Barrett's).

Table 8.3. Multivariate logistic regression analysis of risk factars for esophagitis (excluding Barrett's esophagus) in patients evaluated for GERD. C.I. $=$ confidence intervals.

\begin{tabular}{lccc}
\hline Risk factor & Odds Ratio & $95 \%$ C.I. & p-value \\
\hline Hiatus hernia & 3.26 & $2.02-5.28$ & $<0.0001$ \\
$\%$ time DGER exposure $>4$ & 2.06 & $1.29-3.28$ & 0.003 \\
$\%$ time DGER exposure $>8$ & 2.07 & $1.29-3.31$ & 0.003 \\
$\%$ time DGER exposure $>12$ & 1.77 & $1.09-2.86$ & 0.02 \\
$\%$ time DGER exposure $>15$ & 1.68 & $1.02-2.76$ & 0.04 \\
$\%$ time DGER exposure $>20$ & 2.09 & $1.21-3.60$ & 0.008 \\
$\%$ time supine DGER exposure $>4$ & 1.94 & $1.21-3.12$ & 0.006 \\
$\%$ time supine DGER exposure $>8$ & 2.24 & $1.36-3.69$ & 0.002 \\
$\%$ time supine DGER exposure $>12$ & 2.10 & $1.24-3.56$ & 0.006 \\
$\%$ time supine DGER exposure $>15$ & 2.06 & $1.19-3.57$ & 0.01 \\
$\%$ time supine DGER exposure $>20$ & 2.08 & $1.15-3.76$ & 0.02 \\
BMI $>20$ & 1.03 & $0.99-1.06$ & 0.06 \\
BMI $>22$ & 1.03 & $1.01-1.06$ & 0.01 \\
BMI $>24$ & 1.02 & $1.01-1.02$ & 0.02 \\
BMI $>26$ & 1.03 & $1.01-1.04$ & 0.01 \\
\hline
\end{tabular}


Factors associated with the severity of esophagitis

Table 8.4 summarizes the comparison of patients with low $(1,2)$ and high $(3,4)$ grade esophagitis, excluding Barrett's esophagus. Patients with higher esophagitis grades had a lower LES pressure, a higher total acid exposure and a higher number of DGER episodes (Figure 8.3).

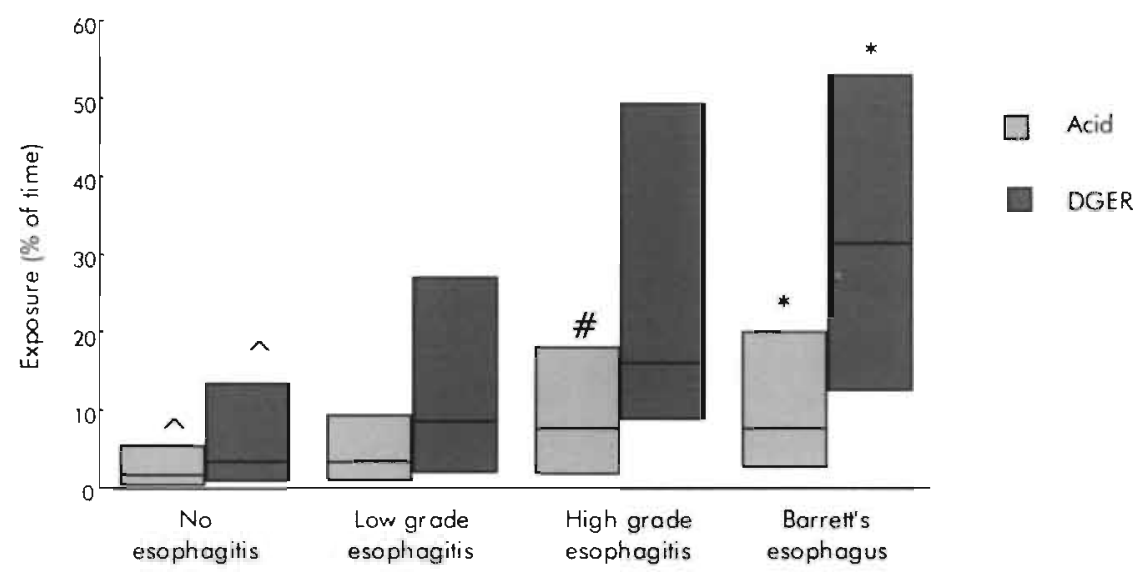

Figure 8.3. Esophageal acid and DGER exposure according to the presence of esophageal lesions. $\left({ }^{\wedge}, p<0.05\right.$ compared to esophagitis; \#, $p<0.05$ compared to low grade esophagitis; ${ }^{*}, p<0.05$ compared to no Barrett's).

The multivariate analysis identified only increasing acid exposure as independent risk factor for the severity of esophagitis. The results of the multivariate analysis, at different cut-offs for acid exposure, are shown in Table 8.5. Analysis for upright and supine position revealed that only upright acid exposure was a borderline significant risk factor for severity of esophagitis.

Factors associated with Barrett's esophagus

The comparison between patients with and without Barrett's esophagus is summarized in Table 8.6. In the univariate analysis, Barrett's patients had a lower LES pressure compared to patients without Barrett's esophagus (Figure 8.4). All acid reflux and DGER parameters were higher in esophagitis patients, for total as well as upright and supine times (Table 8.6). No relation was found between smoking and Barrett's esophagus, but alcohol intake was significantly more prevalent in patients with Barrett's (Table 8.6). 
Table 8.4. Comparison of $\mathrm{pH}$ and Bilitec ${ }^{8}$ measurements in GERD patients with grade 1, 2 and grade 3, 4 esophagitis, excluding Barrett's esophagus. The periods are subdivided in total time, upright and supine position. The values are given in means and standard deviation and compared with the Mann-Whitney test.

\begin{tabular}{|c|c|c|c|}
\hline Esophagitis & Grade 1, 2 & Grade 3, 4 & $p$-value \\
\hline Number & 153 & 11 & \\
\hline Age: & $45.5 \pm 1.2$ & $47.5 \pm 5.6$ & NS \\
\hline $\mathrm{BMI}$ & $25.7 \pm 0.4$ & $26.7 \pm 1.3$ & NS \\
\hline Smoking $(\%)$ & $28 \%$ & $32 \%$ & NS \\
\hline Alcohol use (\%) & $28 \%$ & $33 \%$ & NS \\
\hline Hiatus hernia $(\%)$ & $52 \%$ & $58 \%$ & NS \\
\hline LES pressure & $16.5 \pm 0.7$ & $10.1 \pm 1.5$ & 0.01 \\
\hline \multicolumn{4}{|l|}{ Total time acid reflux } \\
\hline Number of reflux episodes & $57(22 ; 101)$ & $81(24.5 ; 123.25)$ & NS \\
\hline Total reflux episodes $>5$ minutes & $2(0 ; 4)$ & $4(0 ; 6.25)$ & NS \\
\hline$\% \mathrm{pH}<4$ & $3.2(1 ; 8.4)$ & $7.8(1.9 ; 16.2)$ & $<0.05$ \\
\hline \multicolumn{4}{|l|}{ Upright position acid reflux } \\
\hline Number of reflux episodes & $39(15 ; 81)$ & $71.5(17 ; 108.5)$ & NS \\
\hline Total reflux episodes $>5$ minutes & $0(0 ; 2)$ & $1(0 ; 5.25)$ & NS \\
\hline$\% \mathrm{pH}<4$ & $3.5(0.9 ; 8.8)$ & $10.1(1.3 ; 20.1)$ & NS \\
\hline \multicolumn{4}{|l|}{ Supine position acid reflux } \\
\hline Number of reflux episodes & $6(0 ; 25)$ & $6(0 ; 11.8)$ & NS \\
\hline Total reflux episodes $>5$ minutes & $0(0 ; 2)$ & $0(0 ; 2.25)$ & NS \\
\hline$\% \mathrm{pH}<4$ & $1.1(0 ; 9.1)$ & $3.3(0 ; 20.1)$ & NS \\
\hline \multicolumn{4}{|l|}{ Total time DGER } \\
\hline Number of reflux episodes & $19(6 ; 48)$ & $41.5(27 ; 50.5)$ & $<0.05$ \\
\hline Total reflux episodes $>5$ minutes & $3(1 ; 7)$ & $4.5(3 ; 8.8)$ & NS \\
\hline$\%$ bile absorbance $>0.14$ & $8(1.6 ; 24.8)$ & $15.5(8.2 ; 40.5)$ & NS \\
\hline \multicolumn{4}{|l|}{ Upright position DGER } \\
\hline Number of reflux episodes & $13(5 ; 32)$ & $34.5(27 ; 43.8)$ & $<0.05$ \\
\hline Total reflux episodes $>5$ minutes & $2(1 ; 5)$ & $3.5(2.5 ; 7.5)$ & NS \\
\hline$\%$ bile absorbance $>0.14$ & $8.6(1.7 ; 25.9)$ & $21.1(6.6 ; 32.5)$ & NS \\
\hline \multicolumn{4}{|l|}{ Supine position DGER } \\
\hline Number of reflux episodes & $1(0 ; 12)$ & $3(0.8 ; 16)$ & NS \\
\hline Total reflux episodes $>5$ minutes & $0(0 ; 3)$ & $1.5(0 ; 4)$ & $<0.05$ \\
\hline$\%$ Bile absorbance $>0.14$ & $1(0 ; 25.5)$ & $12.7(0.1 ; 37.0)$ & NS \\
\hline
\end{tabular}

Table 8.5. Multivariate logistic regression analysis of risk factors for high grade esophagitis (excluding Barrett's) in patients evaluated for GERD. C.I. = confidence intervals.

\begin{tabular}{lccc}
\hline Risk factor & Odds Ratio & $95 \%$ C.I. & p-value \\
\hline \% time acid exposure $>10$ & 3.33 & $0.93-11.25$ & 0.05 \\
\% time acid exposure $>12$ & 5.04 & $1.45-17.48$ & 0.01 \\
\% time acid exposure $>15$ & 4.60 & $1.30-17.10$ & 0.02 \\
\% time acid exposure $>20$ & 4.77 & $1.11-20.43$ & 0.04 \\
\% time upright acid exposure $>8$ & 3.66 & $0.98-13.65$ & 0.05 \\
\% time upright acid exposure $>10$ & 3.41 & $0.93-12.51$ & 0.06 \\
\hline
\end{tabular}




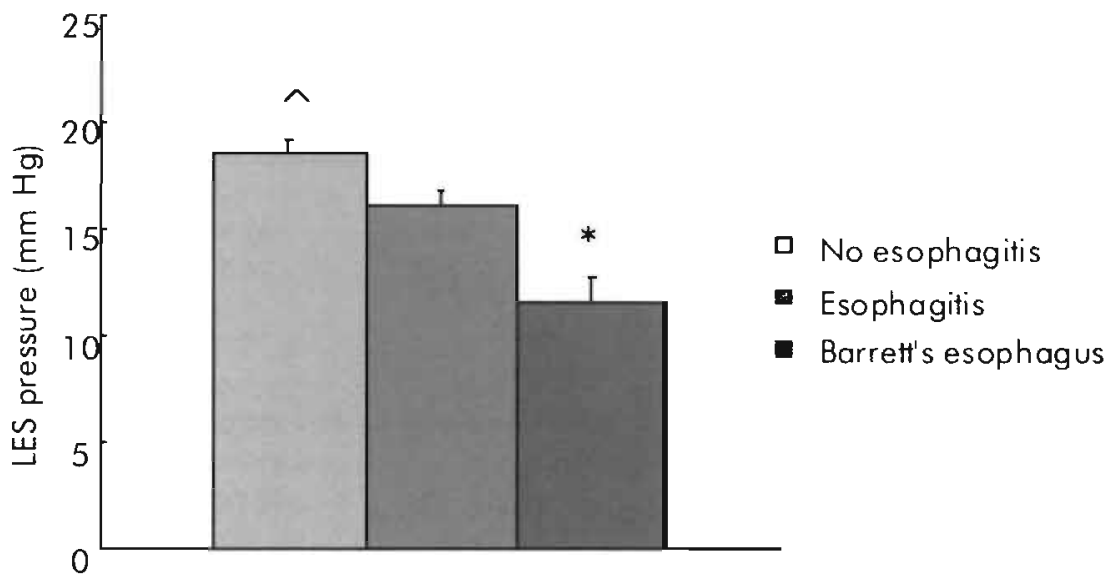

Figure 8.4. LES pressure according to presence of esophageal lesions. $(\uparrow, p<0.05$ compared to esophagitis; ${ }^{*}, \mathrm{p}<0.05$ compared to no Barrett's).

The multivariate logistic regression analysis identified male sex, increasing acid exposure and increasing DGER exposure as independent risk factors for the presence of Barrett's esophagus. The results of the multivariate analysis, at different cut-offs for continuous variables, are shown in Table 8.7. Refining the analysis revealed that upright acid and DGER exposure, and the number of long-lasting acid or DGER reflux episodes, were independent risk factors for the presence of Barrett's esophagus. Smoking or alcohol intake did not present as independent risk factors in the multivariate analysis.

\section{Histology}

Helicobacter pylori was found significantly more often in patients without esophagitis than in patients with grade 1-4 esophagitis (Table 8.8). No relation was observed between $\mathrm{Hp}$ positive patients with lower and higher grade esophagitis excluding Barrett's esophagus, neither comparing patients with and without Barrett's esophagus. Although not in all patients who underwent a gastroscopy biopsies were taken, the groups were comparable and this was not a confounding factor for the interpretation. 
Table 8.6. Comparison of $\mathrm{pH}$ and Bilitec ${ }^{3}$ measurements in GERD patients with and without Barrett's esophagus. The periods are subdivided in total time, upright and supine position. The values are given in means and standard deviation and compared with the Mann-Whitney test.

\begin{tabular}{|c|c|c|c|}
\hline & No Barrett & Barrett & $p$-value \\
\hline Number & 164 & 30 & \\
\hline Age & $46.7 \pm 0.7$ & $49.4 \pm 2.8$ & NS \\
\hline BMI & $25.1 \pm 0.2$ & $26.3 \pm 0.7$ & NS \\
\hline Smoking $(\%)$ & $23 \%$ & $30 \%$ & NS \\
\hline Alcohol use (\%) & $28 \%$ & $48 \%$ & $<0.05$ \\
\hline Hiatus hernia $(\%)$ & $36 \%$ & $48 \%$ & NS \\
\hline LES pressure & $17.4 \pm 0.5$ & $11.5 \pm 1.3$ & $<0.05$ \\
\hline \multicolumn{4}{|l|}{ Total time acid reflux } \\
\hline Number of reflux episodes & $41(14 ; 82)$ & $92(43 ; 206)$ & $<0.0001$ \\
\hline Total reflux episodes $>5$ minutes & $1(0 ; 3)$ & $3(1 ; 10)$ & $<0.001$ \\
\hline$\% \mathrm{pH}<4$ & $2.2(0.6 ; 7.1)$ & $7.8(2.8 ; 17.3)$ & $<0.001$ \\
\hline \multicolumn{4}{|l|}{ Upright position acid reflux } \\
\hline Number of reflux episodes & $32(11 ; 66)$ & $75(35 ; 135)$ & $<0.0001$ \\
\hline Total reflux episodes $>5$ minutes & $0(0 ; 2)$ & $1(0 ; 6)$ & $<0.01$ \\
\hline$\% \mathrm{pH}<4$ & $2.7(0.6 ; 7.8)$ & $10.9(4.1 ; 20.2)$ & $<0.0001$ \\
\hline \multicolumn{4}{|l|}{ Supine position acid reflux } \\
\hline Number of reflux episodes & $3(0 ; 15)$ & $15(1 ; 34)$ & $<0.01$ \\
\hline Total reflux episodes $>5$ minutes & $0(0 ; 1)$ & $2(0 ; 3)$ & $<0.001$ \\
\hline$\% \mathrm{pH}<4$ & $0.2(0 ; 3.8)$ & $7.7(0.2 ; 17.8)$ & $<0.005$ \\
\hline \multicolumn{4}{|l|}{ Total fime DGER } \\
\hline Number of reflux episodes & $14(4 ; 35)$ & $41(19 ; 67)$ & $<0.001$ \\
\hline Total reflux episodes $>5$ minutes & $2(0 ; 5)$ & $6(2 ; 12)$ & $<0.0005$ \\
\hline$\%$ bile absorbency $>0.14$ & $4.4(0.6 ; 16.7)$ & $27.4(12.1 ; 40.4)$ & $<0.0001$ \\
\hline \multicolumn{4}{|l|}{ Upright position DGER } \\
\hline Number of reflux episodes & $11(2 ; 29)$ & $27(13 ; 39)$ & $<0.005$ \\
\hline Total reflux episodes $>5$ minutes & $1(0 ; 4)$ & $5(1 ; 8)$ & $<0.001$ \\
\hline$\%$ bile absorbance $>0.14$ & $5.3(0.7 ; 19.6)$ & $26(7.9 ; 43.3)$ & $<0.0001$ \\
\hline \multicolumn{4}{|l|}{ Supine position DGER } \\
\hline Number of reflux episodes & $0[0 ; 6]$ & $5(0 ; 19)$ & $<0.01$ \\
\hline Total reflux episodes $>5$ minutes & $0(0 ; 2)$ & $1(0 ; 4)$ & $<0.01$ \\
\hline$\%$ Bile absorbance $>0.14$ & $0(0 ; 13.5)$ & $14.3(0 ; 57.1)$ & $<0.05$ \\
\hline
\end{tabular}


Table 8.7. Multivariate logistic regression analysis of $\mathrm{pH}$ and Bilitec ${ }^{\circledR}$ measurements in GORD patients with and without Barrett's esophagitis. The periods are subdivided in total time, upright and supine position. The values are given in means and standard deviation. $\mathrm{Cl}=$ confidence intervals.

\begin{tabular}{lccc}
\hline Risk factor & Odds Ratio & $95 \%$ c.i. & p-value \\
\hline Male sex & 2.77 & $1.17-6.53$ & $<0.05$ \\
$\%$ time acid exposure $>4$ & 1.03 & $1.01-1.04$ & $<0.001$ \\
$\%$ time acid exposure $>8$ & 1.03 & $1.01-1.04$ & $<0.001$ \\
$\%$ time acid exposure $>12$ & 2.70 & $1.12-6.47$ & 0.01 \\
$\%$ time acid exposure $>15$ & 3.03 & $1.22-7.56$ & 0.02 \\
$\%$ time upright acid exposure $>5$ & 2.23 & $0.94-5.26$ & 0.07 \\
$\%$ time upright acid exposure $>10$ & 2.99 & $1.28-7.00$ & $<0.005$ \\
$\%$ time upright acid exposure $>15$ & 2.26 & $0.90-5.66$ & 0.08 \\
N acid reflux episodes $>5$ min $>8$ & 4.05 & $1.51-10.87$ & $<0.01$ \\
$N$ acid reflux episodes $>5$ min $>10$ & 4.67 & $1.46-14.97$ & $<0.01$ \\
$N$ acid reflux episodes $>5$ min $>12$ & 4.42 & $1.27-15.41$ & $<0.05$ \\
N acid reflux episodes $>5$ min $>15$ & 6.78 & $1.81-25.41$ & $<0.005$ \\
$\%$ time DGER exposure $>4$ & 3.32 & $1.30-8.47$ & 0.01 \\
$\%$ time DGER exposure $>8$ & 4.89 & $1.92-12.50$ & $<0.001$ \\
$\%$ time DGER exposure $>12$ & 5.02 & $2.05-12.27$ & $<0.0005$ \\
$\%$ time DGER exposure $>15$ & 4.46 & $1.92-10.33$ & $<0.0005$ \\
$\%$ time DGER exposure $>20$ & 4.78 & $2.11-10.83$ & $<0.0005$ \\
$\%$ time upright DGER exposure $>10$ & 3.50 & $1.40-8.73$ & $<0.01$ \\
$\%$ time upright DGER exposure $>15$ & 3.77 & $1.58-9.00$ & $<0.005$ \\
$\%$ time upright DGER exposure $>20$ & 3.84 & $1.62-9.09$ & $<0.005$ \\
N DGER episodes $>5$ min $>4$ & 3.58 & $1.50-8.54$ & $<0.005$ \\
N DGER episodes $>5$ min $>8$ & 2.99 & $1.25-7.13$ & $<0.05$ \\
\hline
\end{tabular}

Table 8.8. Distribution of Helicobacter pylori in 302 patients who underwent a biopsy compared between the different groups. A significantly higher distribution of $\mathrm{Hp}$ infection was found in patients without esophagitis.

\begin{tabular}{lcrc}
\hline & Helicobacter pos & Helicobacter neg & Total number \\
\hline Total & $54(17 \%)$ & $248(83 \%)$ & 302 \\
No esophagitis & $38(24 \%)$ & $122(76 \%)$ & 160 \\
Esophagitis 1-4 & $16(11 \%)$ & $126(89 \%)$ & 142 \\
Esophagitis 1,2 & $13(13 \%)$ & $86(87 \%)$ & 99 \\
Esophagtitis 3,4 without Barrett's & $0(0 \%)$ & $9(100 \%)$ & 9 \\
Barrett's esophagus & $3(13 \%)$ & $22(87 \%)$ & 23 \\
Non Barrett's esophagitis & $13(11 \%)$ & $104(89 \%)$ & 117 \\
\hline
\end{tabular}




\section{Discussion}

To our knowledge this is the first study in which combined $\mathrm{pH}$ and Bilitec measurements were evaluated in a large group of patients referred for GERD. For a better understanding of the contributing factors, we investigated the association of the presence of esophagitis, severity of esophagitis, and presence of Barrett's esophagus with demographic and patient specific factors, hiatus hernia, LES pressure, and exposure of the distal esophagus to acid reflux and to DGER.

In $46 \%$ of the studied population esophageal lesions were seen during endoscopy, which is comparable to previous reports. ${ }^{40.43}$ The prevalence of hiatus hernia in the present study is also comparable to previous studies. ${ }^{44-47}$ Traditionally, acid reflux is believed to be the most important factor in GERD symptoms and lesions. In the univariate analysis, we observed that GERD patients with esophagitis, compared to GERD patients without lesions, had significantly increased esophageal acid exposure. They also had a higher body mass index, a higher prevalence of hiatus hernia, a lower LES pressure and were more likely to smoke compared to patients without esophagitis.

Wilson et al. showed in a multiple regression analysis that body mass index was associated with esophagitis and found an association between hiatus hernia and body mass index. ${ }^{48}$ In a multivariate analysis of 78 patients, Cadiot et al. identified three independent risk factors for the presence of esophagitis: impaired esophageal acid clearance, hypotonic lower esophageal sphincter and the level of acid secretion. ${ }^{49}$ In these studies, DGER and its role in the occurrence of esophageal lesions were not studied.

As was observed in animal studies, the normal esophagus mucosa is relatively impermeable to luminal acid in normal concentrations, ${ }^{50.52}$ that is aggressive to the mucosa only at a $\mathrm{pH}<1 .{ }^{53}$ When combined with pepsin, which is active between $\mathrm{pH}$ 1.5-2.5, esophageal mucosal damage follows more readily, suggesting that this combination is an important factor in the pathogenesis of esophagitis. ${ }^{10,11,13,54-58}$

The role of duodenal contents, which amongst others contain bilirubin, bile salts, lysolecithin and pancreatic enzymes, mainly trypsin, in inducing esophageal mucosal lesions is still incompletely elucidated. The observation of esophagitis in patients with achlorhydria ${ }^{4,23,59}$ and after total gastrectomy ${ }^{22}$ does suggest a potential damaging effect of DGER on esophageal mucosa in man. Several studies suggest that DGER alone is 
also able to induce esophageal lesions. ${ }^{14,60-62}$ In the present study, we observed that patients with esophagitis, compared to patients without lesions, had significantly higher esophageal DGER exposure.

In the multivariate analysis, only the presence of a hiatus hernia, a higher body mass index and DGER exposure were independent factors associated with the risk of esophagitis. The presence of a hiatus hernia with a lowered LES pressure is a major defect in the anatomic anti reflux barrier. A previous analysis suggested that body mass index was a risk factor for esophagitis, probably through a higher prevalence of hiatus hernia. ${ }^{48}$ Surprisingly, esophageal acid exposure was not an independent risk factor associated with the occurrence of erosive esophagitis. These data might suggest that acid alone is insufficient to induce esophagitis, and that reflux of duodenal contents is required to induce esophageal damage. In experimental animal studies it was shown that the severity of injury to the mucosa increased when duodenal and acidic fluid were attributed together. ${ }^{56,63}$ Vaezi et al showed that $76 \%$ of patients with symptomatic reflux had abnormal esophageal exposure to both acidic and duodenal fluid refluxate, which occurred simultaneously in $70 \%$ $91 \%$ of reflux episodes. It was shown that with increasing severity of esophagitis the exposure to the mixed acid and duodenal refluxate was higher. ${ }^{28}$

We also studied the factors associated with the severity of esophagitis, by distinguishing high grade from low-grade esophageal lesions, excluding patients with Barrett's esophagus. In the univariate analysis, high-grade esophagitis was associated with a lower LES pressure, a higher esophageal acid exposure and a higher number of DGER episodes. However, in the multivariate analysis, only esophageal acid exposure was an independent risk factor for severe esophagitis. These data suggest that, once esophageal lesions are induced, acid exposure is the principal factor determining their severity.

Comparing patients without and with Barrett's esophagus revealed Barrett's patients to have a lower LES pressure, a higher use of alcohol, higher esophageal acid exposure and higher esophageal DGER exposure. Several previous studies have demonstrated increased esophageal acid and DGER exposure in patients with Barreft's esophagus $^{30 \cdot 32.34}$, thereby suggesting a synergistic activity of acid and bile in inducing Barrett's mucosa.

This synergism has been studied recently in the search for the explanation which factors could be responsible for the carcinogenesis in 
Barrett's esophagus. Kaur found that in biopsy material from Barrett's esophagus, brief exposure to bile salts alone increased proliferation, whereas in combination with acid an inhibition was seen. ${ }^{64}$ Tselepsis on the other hand found that acidified bile could be responsible for induction of the oncogene process by upregulation of c-myc oncogen.". Another study showed an increase in cyclooxygenase 2 (COX-2) protein in $41 \%$ of patients with Barrett's epithelium compared to normal esophageal suggesting that COX-2 induction may be an early event in the development of Barrett's esophagus. ${ }^{60}$ Kaur who found that prostaglandin release was induced by combined reflux showed that this was COX-2 dependent, suggesting that a COX-2 inhibiter could be of therapeutic value in the prevention to esophagus adenocarcinoma. ${ }^{67} \mathrm{Life}$ style factors in the development of a Barrett's esophagus to esophageal cancer have been suspected but smoking and drinking could not be found as independent factors in different studies. ${ }^{68-70}$ Alcohol consumption was a significant factor in the univariate analysis but was not an independent factor, probably because the studied group was rather small.

In the multivariate analysis, male sex and both esophageal acid exposure and DGER exposure were identified as independent risk factors for Barrett's esophagus, adding further support to a possible synergism between acid and bile. In contrast to the risk for the presence or severity of esophagitis, presence of Barrett's esophagus was mainly associated with the number of long-lasting acid reflux episodes and long-lasting DGER reflux episodes.

In $17 \%$ of the patients that were biopsied, a Helicobacter pylori infection was found, that is $13 \%$ of the total population. No relation was found between the severity of esophagitis or Barrett's esophagus and an $\mathrm{Hp}$ infection. The group without esophagitis had a significant higher prevalence of $\mathrm{Hp}$ infection as has been observed earlier in a large study by $V$ eith ${ }^{71}$ suggesting that the $\mathrm{Hp}$ infection is protective against esophagitis. This was confirmed in other smaller studies. ${ }^{72,73}$ Eradicating $\mathrm{Hp}$ on the other hand did not influence the frequency of GERD suggesting that the role of $\mathrm{Hp}$ in the pathogenesis or prevalence is still debated and further research is warranted for the role op $\mathrm{Hp}$ in GERD.

In summary, we identified independent risk factors associated with the presence of esophageal lesions in GERD patients. DGER played a role in the development of esophagitis and Barrett's esophagus but was not a determining factor in the severity of esophageal lesions. This study confirms that multiple factors are involved in the pathogenesis of 
esophageal lesions in GERD suggesting a more targeted therapeutic approach in GERD, for which future research is needed. 


\section{References}

1. Venables T, Newland RD, Paiel AC, Hole J, Copeman MB, Turbitt ML. Maintenance treatment for gastro-esophageal reflux disease. A placebo-controlled evaluation of 10 milligrams omeprazole once daily in general practice. Scand J Gastroenterol. 1997;32:627-32.

2. Galmiche JP, Barthelemy P, Hamelin B. Treating the symptoms of gastrooesophageal reflux disease: a double-blind comparison of omeprazole and cisapride. Aliment Pharmacol Ther 1997;1 1:765-73.

3. Carlsson R, Dent J, Watts R, Riley S, Sheikh R, Hatlebakk J, Haug K, de Groot G, van Oudvorst A, Dalvag A, Junghard $O$, Wiklund I. Gastro-oesophageal reflux disease in primary care: an international study of different treatment strategies with omeprazole. Eur. J. Gastroenterol. Hepatol. 1998;10:119-124.

4. Schindlbeck NE, Heinrich C, Stellaard F, Paumgartner G, Muller-Lissner SA. Healthy controls have as much bile reflux as gastric ulcer patients. Gut 1987;28:1577-83.

5. Koek GH, Vos R, Sifrim D, Cuomo R, Janssens J, Tack J. Mechanisms underlying duodeno-gastric reflux in man. submitted for publication 2003.

6. King PM, Pryde A, Heading RC. Transpyloric fluid movement and antroduodenal motility in patients with gastro-oesophageal reflux. Gut 1987;28:545-8.

7. Müller-Lissner SA, Fimmel CJ, Sonnenberg A, Will N, Müller-Duysing W, Heinzel F, Müler R, Blum AL. Novel approach to quantify duodenogastric reflux in healthy volunteers and in patients with type I gastric ulcer. Gut 1983;24:510-8.

8. Mackie C, Hulks G, Cuschieri A. Enterogastric reflux and gastric clearance of reffuxate in normal subjects and in patients with and without bile vomiting following peptic ulcer surgery. Ann Surg 1986;204:537-42.

9. Kivilaakso E, Fromm D, Silen W. Effect of bile salts and related compounds on isolated esophageal mucosa. Surgery 1980;87:280-5.

10. Goldberg HI, Dodds WJ, Gee S, Montgomery C, Zboralske FF. Role of acid and pepsin in ocute experimental esophagitis. Gastroenterology 1969;56:223-30.

11. Casten DF. Peptic esophagitis, hiotal hernia, and duodenal ulcer. A unified concept. Am J Surg 1967;1 13:638-41.

12. Salo JA, Lehto VP, Kivilaakso E. Morphological alterations in experimental esophagitis. Light microscopic and scanning and transmission electron microscopic study. Dig Dis Sci 1983;28:440-8.

13. Salo JA, Kivilaakso E. Role of bile salts and trypsin in the pathogenesis of experimental alkaline esophagitis. Surgery 1983;93:525-32.

14. Johnsson $F$, Joelsson B, Floren $\mathrm{CH}$, Nilsson A. Bile salts in the esophagus of patients with esophagitis. Scand J Gastroenterol 1988;23:712-6. 


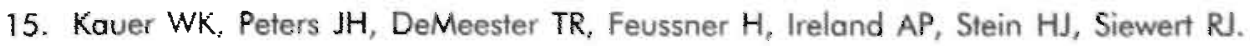
Composition and concentration of bile acid reflux into the esophagus of patients with gastroesophageal reflux disease. Surgery 1997; 1.22:874-81.

16. Stein HJ, Feussner $H$, Kaver W, DeMeester TR, Siewert JR. Alkaline gastroesophageal reflux: assessment by ambulatory esophageal aspiration and pH monitoring. Am J Surg 1994;167:163-8.

17. Vaezi MF, Lacamera RG, Richter JE. Validation studies of Bilitec 2000: an ambulatory duodenogastric reflux monitoring system. Am I Physio! 1994;267:G1050-7.

18. Byrne JP, Romagnoli R, Bechi P, Atwood SE, Fuchs KH, Collard JM. Duodenogastric reflux of bile in health: the normal range. Physiol Meas 1999;20:149-58.

19. Dai $F$, Gong J, Zhang $R$, Luo JY, Zhu YL, Wang XQ. Assessment of duodenogasfric reflux by combined continuous intragastric $\mathrm{pH}$ and bilirubin monitoring. World $J$ Gastroenterol 2002;8:382-4.

20. Stipa F, Stein HJ, Feussner H, Kraemer S, Siewert JR. Assessment of non acid esophageal reflux: comparison between long-term reflux aspiration test and fiberoptic bilirubin monitoring. Dis Esophagus 1997; 10:24-8.

21. Tack J, Bisschops R, Koek GH, Sifrim D, Lerut A, Janssens J. Diełary restrictions during ambulatory monitoring of duodeno-gastro-esophageat reflux. Dig Dis Sci 2003;48:1213-20.

22. Helsingen $N$. Esophagitis following total gastrectomy. Acta Chir Scand $1959 ; 118: 190201$.

23. Orlando RC, Bozymski EM. Heartburn in pernicious anemia--a consequence of bile reflux. NEJM 1973;289:522-3.

24. Matikainen $M$, Laatikainen $T$, Kalima $T$, Kivilaakso $E$. Bile acid composition and esophagitis after total gastrectomy. Am J Surg 1982;143:196-8.

25. Morrow D, Passaro ER, Jr. Alkaline reflux esophagitis after total gastrectomy. Am J Surg 1976;132:287-91.

26. Menges $M$, Muller $M$, Zeitz $M$. Increased acid and bile reflux in Barrett's esophagus compared to reflux esophagitis, and effect of proton pump inhibitor therapy. Am J Gastroenterol 2001;96:331-7.

27. Nehra D, Howell P, Williams CP, Pye JK, Beynon J. Toxic bile acids in gastro.. oesophageal reflux disease: influence of gastric acidity. Gut 1999;44:598-602.

28. Vaezi MF, Richter JE. Role of acid and duodenogastroesophageal reflux in gastroesophageal reflux disease. Gastroenterology 1996;111:1192-9.

29. Marshall RE, Anggiansah A. Ambulatory oesophageal bile reflux monitoring in Barrett's oesophagus. Br J Surg 1996;83:425-6.

30. Kaver WK, Peters JH, DeMeester TR, Ireland AP, Bremner CG, Hagen JA. Mixed reflux of gastric and duodenal juices is more harmful to the esophagus than gastric juice alone. The need for surgical therapy re-emphasized. Ann Surg 1995;222:52531; discussion 531-3. 
31. Caldwell MT, Lawlor P, Byrne PJ, Walsh TN, Hennessy TP. Ambulatory cesophageal bile reflux monitoring in Barrett's oesophagus. Br J Surg 1995;82:657-60.

32. Champion G, Richter JE, Vaezi MF, Singh S, Alexander R. Duodenogastroesophageal reflux: relationship to $\mathrm{pH}$ and importance in Barreft's esophagus. Gastroenterology 1994;107:747-54.

33. Liron R, Parrilla P, Martinez de Haro LF, Ortiz A, Robles R, Lujan JA, Fuente T, Andres B. Quantification of duodenogastric reflux in Barrett's esophagus. Am J Gastroenterol 1997;92:32-6.

34. Vaezi MF, Richter JE. Synergism of acid and duodenogastroesophageal reflux in complicated Barrett's esophagus. Surgery 1995;1 17:699-704.

35. Vaezi MF, Richter JE. Duodenogastroesophageal reflux and methods to monitor nonacidic reflux. Am J Med 2001;111 Suppl 8A:160S-168S.

36. Savary M, Miller G. L'oesophage. Manuel et Atlas d'endoscopie. Gassmann Verlag, 1977.

37. Dent J. A new technique for continuous sphincter pressure measurement. Gastroenterology 1976;71:263-7.

38. Caldwell MT, Byrne PJ, Brazil N, Crowley V, Attwood SE, Walsh TN, Hennessy TP. An ambulatory bile reflux monitoring system: an in vitro appraisal. Physiol Meas 1994;15:57-65.

39. Marshall RE, Anggiansah A, Owen WJ. Bile in the oesophagus: clinical relevance and ambulatory detection. Br J Surg 1997;84:2 I-8.

40. Johnsson F, Joelsson B, Gudmundsson K. Symptoms and endoscopic findings in the diagnosis of gastroesophageal reflux disease. Scand J Gastroenterol 1987;22:71-8.

41. Zeitoun $P$, Carteret E. Natural history of reflux esophagitis in adults. In: Mignon $M$, Calmiche J-P, eds. Control of acid secretion. Paris, London. J Libbey. 1988:225238.

42. Little AG, DeMeester TR, Kirchner PT, O'Sullivan GC, Skinner DB. Pathogenesis of esophagitis in patients with gastroesophageal reflux. Surgery 1980;88:101-7.

43. Behar J. Reflux esophagitis: pathogenesis, diagnosis, and management. Arch Intern Med 1976;136:560-6.

44. Johnson LF, DeMeester TR, Haggitt RC. Endoscopic signs for gastroesophageal reflux objectively evaluated. Gastrointest Endosc 1976;22:151-5.

45. Wright RA, Hurwitz AL. Relationship of hiatal hernia to endoscopically proved reflux esophagitis. Dig Dis Sci 1979;24:311-3.

46. OH DJ, Gelfand DW, Chen YM, Wu WC, Munitz HA. Predictive relationship of hiatal hernia to reflux esophagitis. Gastrointest Radiol 1985;10:317-20.

47. Berstad A, Weberg R, Froyshov Larsen I, Hoel B, Haver-Jensen M. Relationship of hiatus hernia to reflux oesophagitis. A prospective study of coincidence, using endoscopy. Scand J Gastroenterol 1986;21:55-8.

48. Wilson $\sqcup, M a W$, Hirschowitz BI. Association of obesity with hiatal hernia and esophagitis. Am J Gastroenteral 1999;94:2840-4. 
49. Cadiot G, Bruhat A, Rigaud D, Coste T, Vuagnat A, Benyedder Y, Vallot T, Le Guludec D, Mignon M. Multivariate analysis of pathophysiological factors in reflux oesophagitis. Gut 1997;40:167-74.

50. Chung RS, Magri J, DenBesten L. Hydrogen ion transport in the rabbit esophagus. Am J Physiol 1975;229:496-500.

51. Chung RS, Johnson GM, Denbesten L. Effect of sodium taurocholate and ethanol on hydrogen ion absorption in rabbit esophagus. Am J Dig Dis 1977;22:582-8.

52. Safaie-Shirazi S. Effect of pepsin on ionic permeability of canine esophageal mucosa. J Surg Res 1977;22:5-8.

53. Goldstein JL, Schlesinger PK, Mozwecz HL, Layden TJ. Esophageal mucosal resistance. A factor in esophagitis. Gastroenterol Clin North Am 1990; 19:565-86.

54. Bateson MC, Hopwood D, Milne G, Bouchier IA. Oesophageal epithelial ultrastructure after incubation with gastrointestinal fluids and their components. I Pathol 1981; 133:33-51.

55. Lillemoe KD, Kidder GW, Harmon JW, Gadacz TR, Johnson LF, Bunte RM, Hofmann AF. Tauroursodeoxycholic acid is less damaging than taurochenodeoxycholic acid to the gastric and esophageal mucosa. Dig Dis Sci 1983;28:359-64.

56. Lillemoe KD, Johnson LF, Harmon JW. Role of the components of the gastroduodenal contents in experimental acid esophagitis. Surgery 1982;92:27684.

57. Lillemoe KD, Gadacz TR, Harmon JW. Bile absorption occurs during disruption of the esophageal mucosal barrier. J Surg Res 1983;35:57-62.

58. Salo J, Kivilaakso E. Role of luminal $\mathrm{H}+$ in the pathogenesis of experimental esophagitis. Surgery 1982;92:61-8.

59. Palmer ED. Subacute erosive peptic esophagitis associated with achlorhydria. N Engl J Med 1960;262:927 929.

60. Stein HJ, Barlow AP, DeMeester TR, Hinder RA. Complications of gastroesophageal reflux disease. Role of the lower esophageal sphincter, esophageal acid and acid/alkaline exposure, and duodenogastric reflux. Ann Surg 1992;216:35-43.

61. Wilmer A, Tack J, Frans E, Dits H, Vanderschueren S, Gevers A, Bobbaers H. Duodenogastroesophageal reflux and esophageal mucosal injury in mechanically ventilated patients. Gastroenterology 1999;1 16:1293-9.

62. Gotley DC, Morgan AP, Cooper MJ. Bile acid concentrations in the refluxate of patients with reflux oesophagitis. Br J Surg 1988;75:587-90.

63. Harmon JW, Johnson LF, Maydonovitch CL. Effects of acid and bile salts on the rabbit esophageal mucosa. Dig Dis Sci $1981 ; 26: 65-72$.

64. Kaur BS, Ouatu-Lascar R, Omary MB, Triadafilopoulos G. Bile salts induce or blunt cell proliferation in Barrett's esophagus in an acid-dependent fashion. Am J Physiol Gastrointest Liver Physiol 2000;278:G1000-9. 
65. Tselepis C, Morris CD, Wakelin D, Hardy R, Perry I, Luong QT, Harper E, Harrison $R$, Attwood SE, Jankowski JA. Upregulation of the oncogene c-myc in Barrett's adenocarcinoma: induction of c-myc by acidified bile acid in vitro. Gut 2003; 52:174-80.

66. Kandil HM, Tanner G, Smalley W, Halter S, Radhika A, Dubois RN. Cyclooxygenase-2 expression in Barrett's esophagus. Dig Dis Sci 2001;46:785-9.

67. Kaur BS, Triadafilopoulos G. Acid- and bile-induced PGE(2) release and hyperproliferation in Barrett's esophagus are COX-2 and PKC-epsilon dependent. Am J Physiol Gastrointest Liver Physiol 2002;283:G327-34.

68. Caygill CP, Johnston DA, Lopez M, Johnston BJ, Watson A, Reed PI, Hill MJ. Lifestyle factors and Barrett's esophagus. Am J Gastroenterol 2002;97:1328-31.

69. Gray MR, Donnelly RJ, Kingsnorth AN. The role of smoking and alcohol in metaplasia and cancer risk in Barrett's columnar lined oesophagus. Gut 1993;34:727-31.

70. Levi F, Ollyo JB, La Vecchia C, Boyle P, Monnier P, Savary M. The consumption of tobacco, alcohol and the risk of adenocarcinoma in Barrett's oesophagus. Int $\mathrm{J}$ Cancer 1990;45:852-4.

71. Vieth $M$, Masoud $B$, Meining $A$, Stolte $M$. Helicobacter pylori infection: protection against Barrett's mucosa and neoplasia? Digestion 2000;62:225-31.

72. Oberg S, Peters JH, Nigro JJ, Theisen J, Hagen JA, DeMeester SR, Bremner CG, DeMeester TR. Helicobacter pylori is not associated with the manifestations of gastroesophageal reflux disease. Arch Surg 1999;134:722-6.

73. O'Connor HJ, Cunnane K. Helicobacter pylori and gastro-oesophageal reflux disease-.. a prospective study. Ir J Med Sci 1994;163:369-73. 


\section{Chapter}

Gastro-esophageal reflux disease poorly responsive to proton pump inhibitors: acid reflux, bile reflux or both?

J Tack, GH Koek, I Demedts, D Sifrim, J Janssens Am J Gastroenterol: accepted for publication 


\section{Abstract}

\section{Background}

Studies, using ambulatory $\mathrm{pH}$ and esophageal bile reflux monitoring (Bilitec), have shown that both acid reflux and duodeno-gastro-esophageal reflux (DGER) frequently occur in patients with gastro-esophageal reflux disease (GERD). A subset of patients with GERD has persistent reflux symptoms in spite of standard doses of proton pump inhibitors (PPIs).

Aim

The aim of the present study was to investigate the role of acid and DGER in patients with reflux disease poorly responsive to PPls.

\section{Methods}

65 patients (32 men, mean age $44 \pm 2$ years) without Barrett's esophagus and with persistent heartburn or regurgifation during standard PPI doses were studied. They underwent upper gastro-intestinal. endoscopy and 24 hours ambulatory $\mathrm{pH}$ and Bilitec monitoring while PPIs were continued.

\section{Results}

33 patients $(51 \%)$ had persistent esophagitis. Seven patients (11\%) had only pathological acid exposure, $25(38 \%)$ had only pathological DGER exposure and $17(26 \%)$ had pathological exposure to both acid and DGER. Acid exposure under PPI was positive in only $37 \%$, but adding Bilitec ${ }^{*}$, increased the diagnoses of persisting reflux to $75 \%$. Patients with persisting esophagitis had similar acid exposure, but significantly higher DGER exposure than those without esophagitis. The highest prevalence of esophagitis was found in patients with pathological exposure to both acid and DGER; symptoms did not differ according to type of reflux.

\section{Conclusions}

Combined $\mathrm{pH}$ and Bilitec. ${ }^{*}$ monitoring allows to demonstrate: ongoing pathological reflux in $75 \%$ of patients with medically poorly responsive reflux disease. Persistent esophagitis in these patients seems to depend on a synergistic action of acid reflux and DGER. 


\section{Introduction}

Gastro-esophageal reflux disease (GERD), defined as the presence of symptoms or lesions that can be attributed to the reflux of gastric contents into the esophagus, is one of the most common disorders affecting the gastrointestinal tract. ${ }^{1,2}$ The advent of proton pump inhibitors (PPIs), with their strong acid suppressing action, has brought relief to many GERD patients. "Standard doses of different PPIs have been established providing symptom relief and healing of lesions in up to $85 \%$ of patients. ${ }^{3.8}$ A subset of patients, however, have persistent reflux symptoms in spite of therapy with standard doses of PPIs. ${ }^{9,10}$ In about half of the patients with persistent esophagitis and reflux symptoms in spite of standard dose PPI therapy, persisting acid reflux can be demonstrated. 9.10 In the remaining patients the cause of persisting lesions and reflux symptoms remains unclear.

Reflux of duodenal contents via the stomach into the esophagus has long been suspected to be of pathophysiological relevance in GERD. The Bilitec $^{B}$ 2000, a fiber-optic spectrophotometric probe, was developed to quantify duodeno-gastro-esophageal reflux (DGER) in an ambulatory fashion. ${ }^{11}$ Bilirubin, the most common pigment in bile, has a characteristic absorbance spectrum, and by continuous monitoring of the absorbance of two light emitting diodes at two different wavelengths of the esophageal refluxate, the presence of bilirubin can be detected. Validation studies confirmed a good correlation between Bilitec measurements and bile acid concentrations. ${ }^{11.14}$ Ambulatory aspiration studies found a significant correlation between the total bilirubin concentration of aspirated samples and the fiberoptic reading of bilirubin concentration. ${ }^{14}$ Moreover, a good correlation was found between total bilirubin content and the concentrations of pancreatic enzymes in the refluxate, suggesting that bilirubin is an adequate tracer for DGER. ${ }^{14}$

Using the Bilitec ${ }^{8}$ probe, several recent studies have demonstrated a progressive increase in DGER across the spectrum of GERD, with a particularly high prevalence in patients with Barrett's esophagus. ${ }^{15.19}$ The role of persisting DGER in reflux disease poorly responsive to PPIs has not been studied. The aim of our study was to investigate the respective roles, of persistent acid and/or bile reflux in these PPI-refractory patients. 


\section{Materials and methods}

\section{Patient selection}

Patients were eligible for the study if they had a normal serum bilirubin level and if they experienced persistent moderate to severe heartburn or regurgitation for at least three times a week while treated for at least three months with omeprazole $40 \mathrm{mg}$ or lansoprazole $30 \mathrm{mg}$ daily (maintenance therapy with higher doses or with other PPls was not reimbursed in Belgium during the study period). Exclusion criteria were: peptic ulcer disease, previous esophageal, gastric or biliary surgery, previous abdominal or thoracic radiotherapy, active gastrointestinal bleeding, presence of esophageal or fundic varices, diabetes mellitus, Zollinger-Ellison syndrome, progressive systemic sclerosis, Raynaud's syndrome and other vascular diseases, neurological disorders, esophageal or upper small intestinal Crohn's disease, herpetic or Candida esophagitis or active solid tumor neoplastic disease. In addition, all patients with Barrett's esophagus were excluded from the study, as the presence of metaplasia in the distal esophagus is irreversible under medical treatment and may interfere with the assessment of persisting esophagitis lesions. All patients underwent upper gastrointestinal endoscopy and ambulatory $\mathrm{pH}$ and Bilitec monitoring while the PPI therapy was continued.

\section{Reflux symptoms}

All patients were given a 14 symptom questionnaire (heartburn, acid regurgitation, food regurgitation, chest pain, dysphagia, odynophagia, nausea, vomiting, choking, throat ache, hoarseness, nocturnal cough, nocturnal dyspnoea, wheezing), which they scored for severity using a numerical score $(0=$ absent, $1=$ mild, $2=$ moderate, $3=$ severe $)$.

\section{Upper gastrointestinal endoscopy}

All subjects underwent classical upper gastrointestinal endoscopy. If necessary, they were sedated by intravenous administration of diazepam (up to $10 \mathrm{mg}$ ) or midazolam (up to $5 \mathrm{mg}$ ). During endoscopy, the presence of esophagitis was noted and graded according to the modified classification of Savary and Miller. ${ }^{20}$ In addition, the presence and extent of a hiatal hernia and the presence and extent of Barrett's esophagus was noted. In all patients, biopsies were obtained from the gastric antrum and the gastric corpus to assess the presence of Helicobacter pylori. 
Ambulatory $\mathrm{pH}$ monitoring

Ambulatory esophageal $\mathrm{pH}$ monitoring was performed using an antimony $\mathrm{pH}$ electrode with a separate skin reference electrode (Synectics Medical, Stockholm, Sweden). The data were stored on a portable digital recorder (Digitrapper Mk III, Synectics Medical, Stockholm, Sweden). Before each study, the $\mathrm{pH}$ probe was calibrated in buffer solutions of $\mathrm{pH}$ 7 and 1. An episode of acid reflux was defined as a decrease in esophageal $\mathrm{pH}$ to less than 4 during more than 10 seconds. ${ }^{21,22}$

Measurement of duodeno-gastro-esophageal reflux

The fiber-optic spectrophotometer Bilitec 2000 (Synectics, Stockholm, Sweden) was used to quantify DGER. The system consists of a miniaturized probe of $5 \mathrm{~mm}$ diameter that carries light signals into the esophagus and back via a plastic fiber-optic bundle. Before each study, the probe was calibrated in water. An episode of DGER was defined as an increase in esophageal bilirubin absorbance $>0.14$ for more than 10 seconds. ${ }^{21,22}$

\section{Study protocol}

The Ethics Committee of the University Hospital Gasthuisberg Leuven, Belgium approved the study protocol. Patients were asked to fill out a detailed questionnaire about symptoms and frequency, smoking and drinking habits, weight and height. In all patients, we subsequently performed an upper gastrointestinal endoscopy, followed by stationary esophageal manometry and ambulatory 24 hours esophageal $\mathrm{pH}$ and

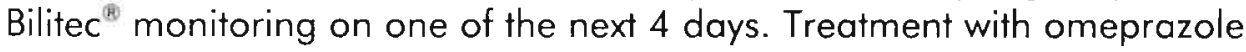
$40 \mathrm{mg}$ or lansoprazole $30 \mathrm{mg}$ daily was continued; all other drugs potentially affecting gastrointestinal motility and gastrointestinal secretion were discontinued at least one week prior to the study.

Probes for assessing acid and DGER were introduced via a nasal orifice into the esophagus $5 \mathrm{~cm}$ proximal to the lower esophageal sphincter, defined by previous stationary esophageal manometry. The probes were then attached with adhesive tape to the subject's nose and cheek. In addition, appropriate positioning in the esophagus was confirmed by fluoroscopy. Data collection devices were connected to the probes and worn in a belt on the patient's waist. Registration of acid or DGER lasted for approximately 22 hours after which the probes were removed and the data transferred to a personal computer for analysis. Patients recorded the time of food or fluid consumption and posture changes on a diary card. They were instructed to stay upright during the daytime. During the 
recording time, only liquid meals $\left(200 \mathrm{ml}\right.$ Nutridrink $^{\oplus} ; 300 \mathrm{kcal}: 13 \%$ proteins, $48 \%$ carbohydrates, and $39 \%$ lipids. Nutricia, Belgium), not interfering with Bilitec ${ }^{(8)}$ monitoring were used. ${ }^{21,22}$ The amount of kcal ingested during the study ranged from 1200-1800. Patients were asked to preferably drink water and to avoid coffee, tea and fruit juices during the recording. Patients were instructed to indicate the occurrence of typical symptoms by pressing a marker button on the data collection device.

\section{Data analysis}

The data were analyzed with the aid of commercially available software (Gastrosoft Inc. Synectics Medical, Irvine, Texas, USA). Acid and duodenal reflux were quantified separately with the following variables obtained from computerized analysis: number of reflux episodes, number of reflux episodes lasting longer than five minutes, fraction of time of acid or DGER. The recording was divided in meal, postprandial (two hours after a meal), interdigestive, upright and supine periods.

Previously, we established normal values for ambulatory $\mathrm{pH}$ and Bilitec ${ }^{3}$ monitoring at our center. ${ }^{21.22}$ Upper limits of normal acid and DGER exposure in healthy volunteers at our center are summarized in Table 9.1. Pathological acid reflux is present when intra-esophageal $\mathrm{pH}$ is below 4 for more than $4 \%$ of the time. Pathological DGER is present when intra-esophageal bilirubin absorbance is above 0.14 for more than $4.6 \%$ of the time. ${ }^{21}$

Table 9.1. Upper limits of normal values $\left(95^{\text {th }}\right.$ percentile $)$ in healthy volunteers at our center.

\begin{tabular}{|c|c|c|c|c|}
\hline & \multicolumn{2}{|c|}{ Percentage of time with reflux } & \multicolumn{2}{|c|}{ Reflux episodes (n) } \\
\hline & $\mathrm{pH}$-monitoring & Bilitec & $\mathrm{pH}$-monitoring & Bilitec $^{\mathrm{gn}}$ \\
\hline Total & 4.7 & 4.6 & 72.2 & 24.4 \\
\hline Upright & 5.1 & 7.8 & 71.2 & 23.4 \\
\hline Supine & 5.2 & 0.0 & 11.2 & 1.0 \\
\hline Postprandial & 7.0 & 11.8 & 16.7 & 6.1 \\
\hline
\end{tabular}

For each symptom episode, indicated by the patient, the minimal $\mathrm{pH}$ value and the maximal bilirubin absorbance value in a preceding two minutes interval were calculated. ${ }^{26}$ Pathological acid reflux was defined as a drop of $\mathrm{pH}$ below 4.0 and pathological DGER as bilirubin absorbance $>0.14$. The $\mathrm{SI}$ was calculated for each patient in relation to both acid and DGER episodes. For acid reflux the SI was calculated as the number of symptoms with $\mathrm{pH}<4$ divided by the total number of 
symptoms multiplied by $100 \%$. The SI for DGER was calculated by the formula: number of symptoms with bilirubin absorbance more than 0.14 divided by the total number of symptoms multiplied by $100 \%$. A positive symptom index was defined if $>75 \%$ of the symptoms were associated with pathological reflux.

Statistical analysis

Values are expressed as mean \pm standard deviation (SD) or median (interquartile range). Data were compared using Student's t-test, Mann Whitney U-test or Chi-square test wherever appropriate. The relationship between the percentage of time the esophagus was exposed to acid reflux and to DGER was evaluated using linear regression analysis. Pvalues were considered to be significant if $<0.05$.

\section{Results}

\section{Patient characteristics}

Between January 1999 and December 2000, 65 consecutive patients (32 men and 33 women, mean age $44.4 \pm 1.9$ years, body mass index $26 \pm 0.8$ ) were studied. Although this treatment had improved their symptoms to some extent, all patients had persisting heartburn or regurgitation while treated for at least three months with omeprazole $40 \mathrm{mg}$ or lansoprazole $30 \mathrm{mg}$ daily, and no Barrett's metaplasia. The symptoms of the patients under PPI therapy are summarized in Table 9.2. In spite of standard dose PPI therapy, $63 \%$ of the patients continued to experience heartburn, $60 \%$ acid regurgitation, $55 \%$ chest pain and $46 \%$ food regurgitation. Fourteen patients were active smokers, 12 had stopped smoking, and six drunk alcohol on a daily basis $(3.7 \pm 1$ units per day). In all patients, upper gastrointestinal endoscopy had been performed prior to the start of the PPI therapy, as mandatory by local reimbursement rules. At the initial endoscopy, $21 \%$ of the patients had been endoscopy negative, grade 1 and 2 esophagitis were present in $15 \%$ and $41 \%$ respectively and grade 3 and grade 4 esophagitis in 15\% and $8 \%$ of the patients. Eight patients (12\%) were Helicobacter pylori (HP) positive. 
Table 9.2. Symptom prevalence in patients with GERD refractory to standard doses of PPI. Al numbers are expressed as percentages of total number of patients.

\begin{tabular}{|c|c|c|c|c|c|c|c|c|c|}
\hline Symptom & All & $\begin{array}{c}\text { No } \\
\text { esophagitis }\end{array}$ & Esophagitis & $p$-value & No reflux & $\begin{array}{l}\text { Acid } \\
\text { reflux }\end{array}$ & $\begin{array}{l}\text { Mixed } \\
\text { reflux }\end{array}$ & DGER & $p$-value \\
\hline Heartburn & 63 & 66 & 61 & NS & 50 & 57 & 65 & 72 & NS \\
\hline $\begin{array}{l}\text { Acid } \\
\text { regurgitation }\end{array}$ & 60 & 53 & 67 & NS & 56 & 71 & 76 & 48 & NS \\
\hline Chest pain & 55 & 44 & 67 & NS & 44 & 57 & 53 & 64 & NS \\
\hline Nausea & 51 & 47 & 55 & NS & 50 & 57 & 41 & 56 & NS \\
\hline $\begin{array}{l}\text { Food } \\
\text { regurgitation }\end{array}$ & 46 & 38 & 55 & NS & 50 & 43 & 53 & 40 & NS \\
\hline Dysphagia & 32 & 28 & 36 & NS & 13 & 71 & 35 & 32 & NS \\
\hline Odynophagia & 31 & 25 & 36 & NS & 19 & 29 & 29 & 40 & NS \\
\hline Vomiting & 28 & 25 & 30 & NS & 19 & 29 & 47 & 20 & NS \\
\hline Throat ache & 28 & 31 & 24 & NS & 13 & 29 & 18 & 44 & NS \\
\hline Choking & 25 & 16 & 33 & NS & 13 & 29 & 18 & 36 & NS \\
\hline $\begin{array}{l}\text { Nocturnal } \\
\text { coughing }\end{array}$ & 21 & 9 & 33 & $<0.02$ & 25 & 14 & 12 & 28 & NS \\
\hline Hoarseness & 20 & 19 & 21 & NS & 19 & 14 & 24 & 20 & NS \\
\hline $\begin{array}{l}\text { Nocturnal } \\
\text { dyspnoe }\end{array}$ & 17 & 13 & 21 & NS & 13 & 14 & 12 & 24 & NS \\
\hline Wheezing & 11 & 9 & 12 & NS & 6 & 14 & 6 & 16 & NS \\
\hline
\end{tabular}

\section{Endoscopy}

While treated for at least three months with omeprazole $40 \mathrm{mg}$ or lansoprazole $30 \mathrm{mg}$ daily, 32 patients $(49 \%)$ had no esophagitis, 15 (23\%) had grade 1, and $14(22 \%)$ grade 2 esophagitis. Grades 3 and 4 (esophageal ulcer) esophagitis occurred in two patients each (3\%). Twenty patients had an esophageal hernia with a size that ranged from 2 to $6 \mathrm{~cm}$ length (on average $3.5 \pm 0.3 \mathrm{~cm}$ ). Although the prevalence of esophageal hernia was not different between endoscopy positive and negative patients $(7 / 32$ and $13 / 33, N S)$, those that did occur were significantly larger in esophagitis patients $(4.1 \pm 0.4$ vs. $2.3 \pm 0.2 \mathrm{~cm}$, $\mathrm{p}<0.01)$.

Demographic characteristics, HP status and smoking and drinking habits did not differ between endoscopy positive and endoscopy negative patients. Except for a significantly higher prevalence of nocturnal coughing in patients with persisting esophagitis, the symptom pattern did not differ between endoscopy positive and negative patients (Table 9.2). There was no difference in demographic features, symptoms, HP status 
and smoking and drinking habits between the high (grades 3 and 4) and low grade esophagitis groups (data not shown).

24 hours reflux monitoring

During standard doses of PPI therapy, ongoing pathological acid exposure was present in 24 patients (37\%), and pathological DGER was found in 42 patients (64\%) (Figure 9.1). In 16 patients (25\%) both $\mathrm{pH}$ and Bilitec ${ }^{(3)}$ monitoring were normal, seven (11\%) had only pathological acid exposure, $25(38 \%)$ had only pathological DGER and $17(26 \%)$ had both acid and DGER pathological exposure. A weak, but significant correlation was present between acid exposure and DGER exposure, both expressed as \% of time $(R=0.48, p<0.001)$. It has been proposed to use the number of reflux episodes, rather that total time of reflux as an estimate for DGER. ${ }^{14}$ When only the number of DGER episodes was taken into account, 41 patients had pathological DGER, $83 \%$ of which had pathological exposure when expressed as \% of time.

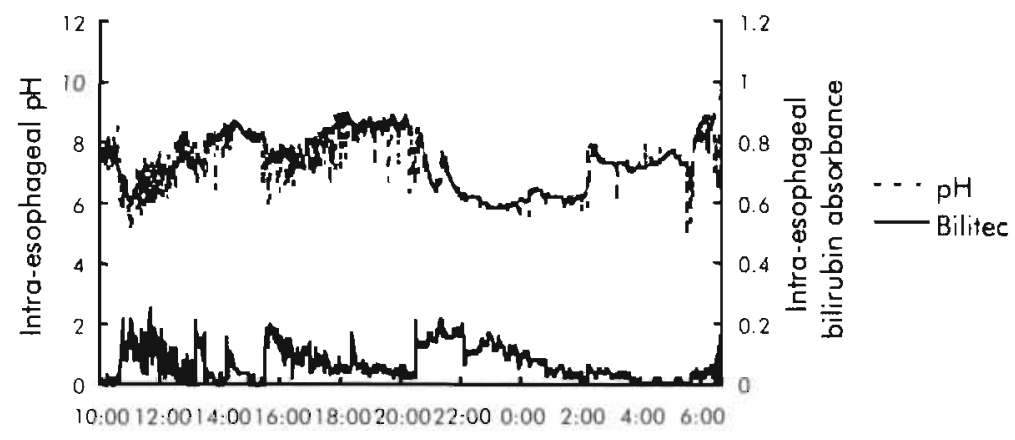

Time

Figure 9.1. Example of a combined $\mathrm{pH}$ and bilitec monitoring in a patient with typical reflux symptoms refractory to standard doses of PPI.

Upright acid exposure was pathological in 14 patients $(21 \%)$, and 19 patients $(29 \%)$ had pathological supine acid exposure. Total acid exposure was pathological in all but one of these patients. Upright DGER exposure was pathological in 35 patients (54\%), and supine DGER exposure was pathological in 34 patients (52\%). Total DGER exposure was pathological in all but four of these patients.

Relationship of 24 hours monitoring with lesions and symptom pattern

None of the acid reflux parameters differed significantly between endoscopy negative patients and patients with esophagitis (Table 9.3) 
(Figure 9.2). Compared to endoscopy negative patients, patients with persisting esophagitis had a higher number of DGER episodes and a longer exposure to DGER. DGER parameters in the upright position did not differ between both groups, but patients with esophagitis under PPI treatment had a higher number of supine DGER episodes and a longer supine exposure to DGER (Table 9.4) (Figure 9.3).

Table 9.3. Acid reflux parameters.

\begin{tabular}{lcccc}
\hline & Period & No esophagitis & Esophagitis & p-value \\
\hline \% time reflux & Total & $1.9(0.3 ; 3.7)$ & $3.3(0.4 ; 8.7)$ & NS \\
& Upright & $2.3(0.3 ; 3.7)$ & $2(0.4 ; 8.9)$ & NS \\
& Supine & $0.2(0 ; 1.4)$ & $1.2(0 ; 10.4)$ & NS \\
& Postprandial & $1(0.1 ; 3.8)$ & $0.2(0 ; 9.7)$ & NS \\
Number of reflux & Total & $26(11 ; 55)$ & $45(14 ; 103)$ & NS \\
episodes & Upright & $24.5(6 ; 47)$ & $16(11 ; 64)$ & NS \\
& Supine & $1.5(0 ; 9)$ & $7(0 ; 25)$ & NS \\
& Postprandial & $6(1 ; 13)$ & $1(0 ; 18)$ & NS \\
Longest reflux episode & Total & $4(1 ; 16)$ & $8(1 ; 21)$ & NS \\
(minutes) & Upright & $3(1 ; 7)$ & $3(1 ; 11)$ & NS \\
& Supine & $0.5(0 ; 5.5)$ & $2(0 ; 18)$ & NS \\
& Postprandial & $0(0 ; 3)$ & $0(0 ; 7)$ & NS \\
\hline
\end{tabular}
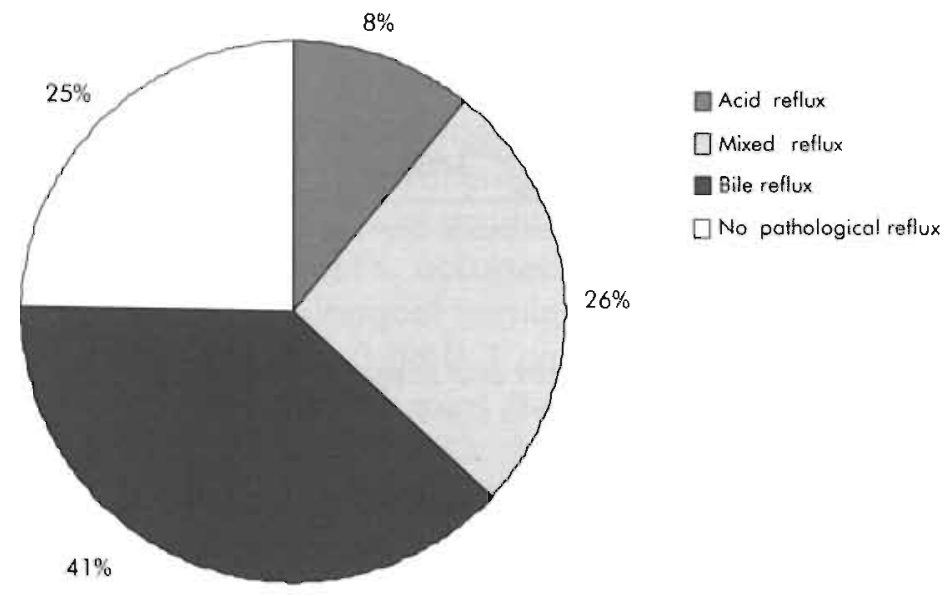

Figure 9.2. Summary of combined $\mathrm{pH}$ and bilitec monitoring in 65 patients with typical reflux symptoms refractory to standard doses of PPI.

In patients with both acid and DGER pathological exposure, the prevalence of persisting erosive esophagitis $(13 / 17)$ was significantly higher compared to the other groups (7/16 in those without pathological reflux, $2 / 7$ in those with pathological acid reflux alone and 11/25 in 
patients with pathological DGER alone; all $p<0.05$ ). Patients with esophagitis had a higher prevalence of persisting mixed acid and DGER pathological reflux (4/32 vs. 13/33, $p<0.05)$ (Figure 9.4).

Table 9.4. Duodeno-gastro-esophageal reflux parameters.

\begin{tabular}{lcccc}
\hline & Period & No esophagitis & Esophagitis & p-value \\
\hline \% time reflux & Total & $6.3(1.7 ; 13)$ & $11.9(4.4 ; 31.2)$ & $<0.05$ \\
& Upright & $6.9(3.1 ; 14.9)$ & $12.1(1.9 ; 29.3)$ & $\mathrm{NS}$ \\
& Supine & $0(0 ; 9.1)$ & $11.2(0 ; 32.6)$ & $<0.05$ \\
& Post-prandial & $5.9(0.2 ; 22)$ & $7.6(1.4 ; 27.1)$ & $\mathrm{NS}$ \\
Number of reflux & Total & $15.5(6.8 ; 47.3)$ & $35(15 ; 69)$ & $<0.05$ \\
episodes & Upright & $15(5.5 ; 34.3)$ & $31(11 ; 54)$ & $\mathrm{NS}$ \\
& Supine & $0(0 ; 6)$ & $9(0 ; 21)$ & $<0.05$ \\
& Post-prandial & $4(1 ; 10.5)$ & $6(2 ; 10)$ & $\mathrm{NS}$ \\
Longest reflux & Total & $27.5(7.8 ; 67)$ & $72(14 ; 108)$ & $\mathrm{NS}$ \\
episode (minutes) & Upright & $18.5(6.3 ; 53.3)$ & $23(5 ; 74)$ & $\mathrm{NS}$ \\
& Supine & $0(0 ; 45)$ & $56(0 ; 173)$ & $<0.05$ \\
& Post-prandial & $4(0.8 ; 24.3)$ & $6(2 ; 26)$ & $\mathrm{NS}$ \\
\hline
\end{tabular}

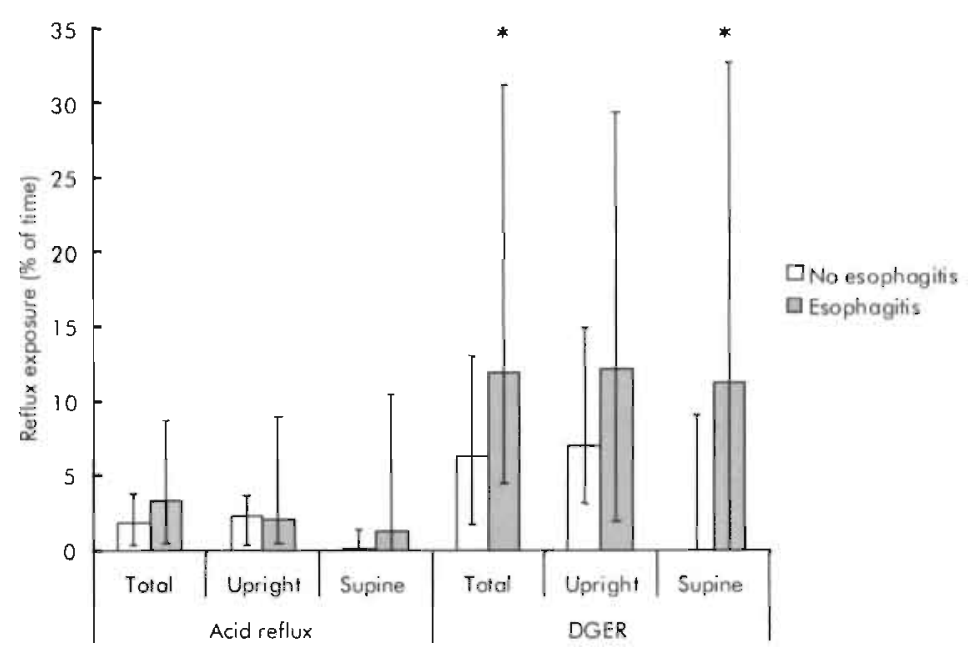

Figure 9.3. Acid and DGER exposure in 65 patients with typical reflux symptoms refractory to standard doses of PPI, according to the absence or presence of esophagitis. Acid exposure did not differ significantly between both groups. Patients with persisting esophagitis had significantly higher DGER exposure for the total recording time and in the

The prevalence of a hiatus hernia was significantly higher in the mixed pathological reflux group (13/25) than in patients in whom no 
pathological reflux was present $(1 / 16, p<0.005)$. The prevalence of HP infection did not differ between the different reflux types. There was no difference in amount or quality of symptoms between patients with different reflux types.

\section{Manometry}

Median resting pressure in the lower esophageal sphincter (LES) was $14.8 \pm 1.2 \mathrm{mmHg}$. LES resting pressure did not differ in relation to the presence or the severity of esophagitis, or in relation to the type of reflux. The majority of patients had a normal stationary manometry. Eighteen patients had low amplitude peristalsis (below $30 \mathrm{mmHg}$ ) in the distal esophagus, and 13 of these had intermittent peristaltic failure. One patient had a nutcracker esophagus and one patient had high-amplitude double-peaked pressure waves in the distal esophagus. The prevalence of intermittent peristaltic failure was higher in patients with persisting esophagitis compared to those without persisting esophagitis $(3 / 32$ vs. $10 / 33, p<0.05)$. Three of four patients with persisting high grade esophagitis had intermittent peristaltic failure, which was significantly more prevalent than in patients with low grade or no esophagitis $(p<0.005)$. Esophageal manometry findings were not related to the type of persisting reflux (data not shown).

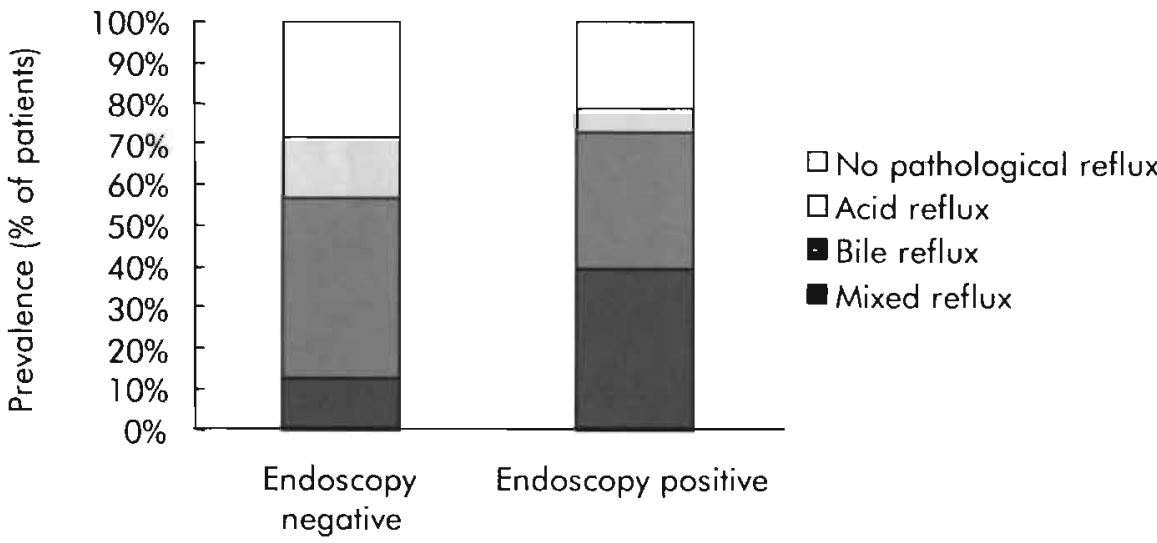

Figure 9.4. Prevalence of the different types of pathologic reflux under standard PPI therapy in endoscopy negative and positive patients. Persisting pathological mixed reflux (both acid and DGER) was significantly more prevalent in patients with persisting esophagitis. 
Symptoms and reflux episodes

The symptom marker was used by 25 patients who indicated a total of 125 symptom episodes. Patients pushed the symptom marker button on nine occasions (7\%) in association with acid reflux alone, on 23 occasions (18\%) in association with DGER and on 13 occasions $(10 \%)$ in association with combined acid and DGER reflux. A positive symptom index for acid reflux was found in three (12\%) patients, for DGER in seven patients (28\%), and for mixed reflux in four patients (16\%).

\section{Discussion}

The high healing rates and symptom relief achieved with PPI therapy constituted a major therapeutic advance in the management of GERD. ${ }^{3,4,23}$ Nevertheless, a subset of patients have persistent typical reflux symptoms in spite of standard doses PPI therapy. In up to half of these patients, persisting acid reflux can be demonstrated. 9,10 The origin of persisting symptoms in the rest of the patients remained unclear, and involvement of other mechanisms than gastro-esophageal reflux has been suggested. $9,24,25$

We used combined $\mathrm{pH}$ and Bilitec ${ }^{(8)}$ monitoring in 65 consecutive patients with reflux symptoms that persisted in spite of standard PPI therapy. In keeping with previous reports, $37 \%$ of these patients still had pathological acid exposure of the distal esophagus while the PPI therapy was being continued. Using the Bilitec ${ }^{\text {ti }}$ probe we demonstrated ongoing pathological DGER in $65 \%$ of the patients, and combined $\mathrm{pH}$ and Bilitec monitoring was able to confirm persisting pathological gastroesophageal reflux in $75 \%$ of the patients. In over half of the patients who used the symptom marker, an association between acid or DGER reflux events and symptom episodes was demonstrated.

The doses of PPI used in the present study are determined by local regulatory authority restrictions and can be considered standard therapeutic doses. Several studies showed small overall benefit of increasing the dose of omeprazole above $40 \mathrm{mg}$ daily or increasing the dose of lansoprazole from 30 to $60 \mathrm{mg} / \mathrm{d}$ with respect to healing rates and symptomatic relief. ${ }^{5.8}$ Although the group of poorly responsive patients might have been smaller when the dose of PPI was allowed to double $e^{5-8,23}$, the principal finding of this study was the high rate of persisting DGER and the group of patients with persisting acid reflux was 
relatively small. It seems less likely therefore that higher doses of acid suppressive drugs would have dramatically altered this prevalence.

Validation studies show a good correlation between Bilitec readings and bile acid concentrations ${ }^{11.14}$, and Bilitec ${ }^{\circledR}$ has been used in several studies to measure DGER. ${ }^{15-19,21,22,26,27}$ In vitro studies suggest that the Bilitec ${ }^{\text {2 }}$ may underestimate DGER by up to $30 \%$ in an acidic medium $(\mathrm{pH}<3.5) .{ }^{12}$ However, we recently demonstrated that this does not significantly affect the outcome of bilitec ${ }^{8}$ studies. ${ }^{21}$. In addition, the design of the fiber-optic catheter is prone to entrapment of liquid at the tip of the recording probe, resulting in excessive duration of DGER reflux episodes. It has been proposed to use the number of reflux episodes, rather than the total time of reflux as an estimation of DGER. ${ }^{16}$ However, we obtained similar results when the number of episodes was used to define pathological DGER exposure, and we used liquid meals to avoid food artefacts. ${ }^{21,22}$ We previously established that the liquid meal we used induces as much acid reflux as solid meals. ${ }^{22}$

The intraluminal esophageal impedance technique allows the detection of non-acid liquid reflux. ${ }^{28} \mathrm{~A}$ recent study, using intraluminal esophageal impedance, showed persisting non-acid reflux in patients under PPI therapy. ${ }^{29}$ However, this was a short-term stationary study in a postprandial supine position, and the nature of the non-acid reflux-food, neutralized gastric secretion or liquid of duodenal origin-remained unclear. The present study confirmed the occurrence of isolated pathological DGER without pathological acid exposure in $38 \%$ of symptomatic patients under PPI, suggesting that at least part of non-acid reflux under PPIs is of duodenal origin.

Ambulatory $\mathrm{pH}$ monitoring under PPI therapy was pathological in only $37 \%$ of the patients. As the combined $\mathrm{pH}$ and Bilitec ${ }^{6}$ monitoring allowed to document persisting reflux in $75 \%$ of the patients, the addition of a Bilitec $^{\otimes}$ probe resulted in a considerable diagnostic gain of $38 \%$. Although the majority of symptom episodes indicated by the symptom marker remained unexplained, addition of DGER monitoring also increased the number of episodes that were attributable to a gastroesophageal reflux event. Establishing ongoing reflux in a patient with persisting symptoms in spite of standard PPI is clinically extremely relevant, as it clarifies the nature of the symptoms and allows to consider a number of additional therapeutic options. In patients in whom no persisting reflux can be demonstrated, other diagnoses with less clear 
therapeutic implications have to be considered, such as esophageal hypersensitivity, or psychological abnormalities. ${ }^{24,25,30}$

Similar to a study in intensive care patients under acid suppression ${ }^{27}$, we found that DGER was more prevalent in patients with endoscopic esophagitis. The highest prevalence of esophagitis was found in patients with pathological exposure to both acid reflux and DGER. Our findings are in keeping with earlier studies that suggested a synergism between acid reflux and DGER in inducing lesions. ${ }^{15.19}$

The therapeutic approach of patients with persisting pathological acid exposure has been well studied. It is known that the number of responders will increase with a further increase of the dose of PPI, or when a PPI with a higher acid-suppressive capacity is used. ${ }^{5 \cdot 10,23,31}$ Although PPI were shown to decrease DGER ${ }^{15,32,33,34}$, persisting lesions and symptoms in most of the remaining patients in the present study seemed to be related to DGER, not responsive to the doses of acid suppressive therapy that were used in the current study. The available litterature suggests that PPls are less efficacious to normalize DGER, compared to their effect on acid reflux. ${ }^{15,32-34}$ The therapeutic approach to patients with persisting DGER has not been well established. The value of prokinetic therapy in treating DGER was only demonstrated in partial gastrectomy patients using high doses of cisapride. ${ }^{35}$ Anti-reflux surgery was shown to adequately reverse DGER ${ }^{34}$, but not all patients are suitable candidates for surgical therapy. Both in stationary and in ambulatory studies, it was established that transient lower esophageal sphincter relaxations (TLESRs) are the main pathophysiological mechanism underlying acid reflux events. ${ }^{36,37}$ Recent data suggest that TLESRs are the principal mechanism underlying non-acidic reflux episodes as well. ${ }^{37}$ It seems conceivable, therefore, that treatment aimed at decreasing the number of TLESRs, such as the $G_{A B A}$ agonist baclofen, might also reduce the exposure of the distal esophagus to nonacid reflux ${ }^{39,40}$, but addressing this question is beyond the scope of the present study.

In summary, we found that patients with poorly responsive gastroesophageal reflux disease have similar reflux characteristics to other GERD patients: acid reflux and DGER offen occur simultaneously and are both related to the severity of endoscopic findings. 


\section{References}

1. Isolauri J, Laippala P. Prevalence of symptoms suggestive of gastroesophageal reflux disease in an adult population. Ann Med 1995;27:67-70.

2. Spechler SJ. Epidemiology and natural history of gastroesophageal reflux disease. Digestion 1992;51 (suppl 1):24-9.

3. Dehn TCB, Sheperd HA, Colin-Jones D, Kettlevell MGW, Carroll NJH. Double blind comparison of omeprazole versus cimetidine in the treatment of symptomatic erosive reflux oesophagitis, assessed endoscopically, histologically and by $24 \mathrm{~h} \mathrm{pH}$ monitoring. Guł 1990;31:509-13.

4. Hetzel DJ, Dent J, Reed WD, Narielvala FM, Mackinnon M, McCarthy JH, Mitchell B, Beveridge BR, Laurence BH, Gibson GG, et al. Healing and relapse of severe peptic esophagitis after treatment with omeprazole. Gastroenterology 1988;95:903-12.

5. Sontag SJ, Hirwhowitz BI, Holt S, Robinson MG, Behar J, Berenson MM, McCullough A, Ippoliti AF, Richter JE, Ahtaridis G, et al. Two doses of omeprazole versus placebo in symptomatic erosive esophagitis: the U.S. Multicenter Study. Gastroenterology 1992; 102:108-18.

6. Klinkenberg-Knol EC, Festen HP, Jansen JB, Lamers CB, Nelis F, Snel P, Luckers A, Dekkers CP, Havu N, Meuwissen SG. Long-term treatment with omeprazole for refractory reflux esophagitis: efficacy and safety. Ann Intern Med 1994;121:161-7.

7. Robinson M, Campbell DR, Sontag S, Sabesin SM. Treatment of erosive reflux esophagitis resistant to $\mathrm{H}_{2}$-receptor antagonist therapy. Lansoprazole, a new proton pump inhibitor. Dig Dis Sci 1995;40:590-7.

8. Eornest D, Dorsch E, Jones J, Jennings DE, Greski-Rose PA. A placebo-controlled dose-ranging study of lansoprazole in the management of reflux esophagitis. Am J Gastroenterol 1998;93:238-43.

9. Holloway RH, Dent J, Narielvala F, Mackinnon AM. Relation between oesophageal acid exposure and healing of oesophagitis with omeprazole. Gut 1996;38:649-54.

10. Klinkenberg-Knol EC, Meuwissen SGM. Combined gastric and esophageal 24-hour $\mathrm{pH}$ monitoring and esophageal manometry in patients with reflux disease resistant to treatment with omeprazole. Aliment Pharmacol Ther 1990;4:485-95.

11. Bechi P, Paucciani F, Baldini F, Cosi F, Falciai R, Mazzanti R, Castagnli A, Pesseri A, Boscherini S. Long-term ambulatory enterogastric reflux monitoring. Validation of a new fiberoptic technique. Dig Dis Sci 1993; 38:1297-306.

12. Vaezi MF, LaCamera RG, Richter JE. Bilitec 2000 ambulatory duodenogastric reflux monitoring system. Studies on its validation and limitations. Am J Phys 1994; 267:G1050-G1057.

13. Stein HJ, Kaver WK, Feussner H, Asiewert JR. Bile acids as components of the duodenogastric refluxate: defection, relationship to bilirubin, mechanism of injury, and clinical relevance. Hepato-gastroenterology 1999;46:66-73. 
14. Stipa F, Stein HJ, Feussner $H_{f}$ Kraemer S, Siewert JR. Assessment of non-acidic esophageal reflux: comparison between long-term reflux aspiration test and fiberoptic bilirubin monitoring. Dis Esophagus. 1997;10:24-8.

15. Champion G, Richter JE, Vaezi MF, Singh S, Alexander $R$. Duodenogastroesophageal reflux: relationship to $\mathrm{pH}$ and importance in Borreft's esophagus. Gastroenterology 1994;107:747-54.

16. Caldwell MT, Lawlor P, Byrne PJ, Walsh TN, Hennessy TP. Ambulatory oesophageal DGER monitoring in Barrett's esophagus. Br J Surg 1995;82:657-60.

17. Kaver WK, Peters JH, DeMeester TR, Ireland AP, Bremner CG, Hagen JA. Mixed reflux of gastric and duodenal juices is more harmful to the esophagus than gastric juice alone. The need for surgical therapy re-emphasized. Ann Surg 1995;222: 525-31.

18. Vaezi MF, Richter JE. Role of acid and duodenogastroesophageal reflux in gastroesophageal reflux disease. Gastroenterology 1996;111:1192-9.

19. Vaezi MF, Richter JE. Synergism of acid and duodenogastroesophageal reflux in complicated Barrett's esophagus. Surgery 1995;1 17:699-704.

20. Savary M. Miller G. L'oesophage. Manuel ef Atlas d'Edoscopie. Solothurn, Switzerland: Verlag Gassmann, 1977.

21. Cuomo R, Koek G, Sifrim D, Janssens J, Tack J. Analysis of ambulatory duodenogastro-esophageal reflux monitoring. Dig Dis Sci 2001;45:2463-9.

22. Tack J, Bisschops R, Koek GH, Sifrim D, Leruł T, Janssens J. Dietary restrictions during ambulatory monitoring of duodeno-gastro-esophageal reflux. Dig Dis Sci; in press.

23. Klinkenberg-Knol E, Nelis F, Dent J, Snel P, Mitchell B, Prichard P, Lloyd D, Hauv N, Frame MH, Roman J, Walan A and Long-term Siudy group. Long-term omeprazole treatment in resistant gastroesophageal reflux disease: efficacy, safety and influence on gastric mucosa. Gastroenterology 2000;1 18:661-9.

24. Fass R, Naliboff B, Higa L, Johnson C, Kodner A, Munakata J, Ngo J, Mayer EA. Differential effect of long-term esophageal acid exposure on mechanosensitivity and chemosensitivity in humans. Gastroenterology 1998;115: 1363-73.

25. Shi G, Bruley des Varannes S, Scarpignato C, Le Rhun M, Galmiche JP. Refluxrelated symptoms in patients with normal esophageal exposure to acid. The acid hypersensitive esophagus. Gut 1995;37: 457-64.

26. Koek GH, Tack J, Sifrim D, Lerut T, Janssens J. The role of acid and bile reflux in symptomatic gastro-esophageal reflux disease. Am 」 Gastroenterol 2001;96: 2033-40.

27. Wilmer A, Tack J, Frans E, Dits H, Vanderschueren, Bobbaers H. Duodenogastroesophageal reflux and esophageal mucosal injury in mechanically ventilated patients. Gastroenterology 1999;116:1293-9.

28. Sifrim D, Holloway R, Silny J, Tack J, Lerut A, Janssens J. Acid, nonacid and gas reflux in patients with gastroesophageal reflux disease during ambulatory 24-hour $\mathrm{pH}$-impedance recordings. Gastroenterology 2001;120:1588-98. 
29. Vela M, Camacho-Lobato L, Srinivasan R, Tutuian R, Katz PO, Castell D. Simultaneous intraesophageal impedance and $\mathrm{pH}$ measurement of acid and nonacid gastroesophageal reflux: effect of omeprazole. Gastroenterology 2001; 120:1599-606.

30. Bradley LA, Richter JE, Pulliam TJ, Haile JM, Scarcini SC, Schan CA, Dalton CB, Salley AN. The relationship between stress and symptoms of gastroesophageal reflux: the influence of psychological factors. Am J Gastroenterol 1993;88:11 1-9.

31. Kahrilas PJ, Falk GW, Johnson DA, Schmitt C, Collins DW, D'Amico D, Hamelin B, Joelsson B. Esomeprazole improves healing and symptom resolution as compared with omeprazole in reflux esophagitis patients: a randomized controlled trial. Aliment Pharmacol Ther 2000;1 4:1249-58.

32. Marshall RE, Anggiansah A, Manifold DK, Owen WA, Owen WJ. Effect of omeprazole $20 \mathrm{mg}$ twice daily on duodenogasric and gastro-osophageal bile reflux in barrett's esophagus. Gut 1998;43: 603-6.

33. Menges $M$, Muller $M$, Zeitz $M$. Increased acid and bile reflux in Barrett's esophagus compared to reflux esophagitis, and effect of proton pump inhibitor therapy. Am J Gastroenterol 2001;96:331-7.

34. Stein HJ, Kaver WK, Feussner $\mathrm{H}$, and Siewert JR. Bile reflux in benign and malignant Barrett's esophagus: effect of medical acid suppression and Nissen fundoplication. J Gastrointest Surg 1998;2:333-41.

35. Vaezi MF, Sears-R, Richter JE. Placebo-controlled trial of cisapride in postgastrectomy patients with duodenogastroesophageal reflux. Dig Dis Sci 1996; 41:754-63.

36. Schoeman MN, Tippett MD, Akkermans LMA, Dent J, Holloway RH. Mechanisms of gastroesophageal reflux in ambulant healthy human subjects. Gastroenterology 1995; 108: 83-91.

37. Penagini R, Schoeman MN, Dent J, Tippett MD, Holloway R. Motor events underlying gastro-esophageal reflux in ambulant patients with reflux esophagitis. Neurogastroenterol Mot 1996;8:131-41

38. Sifrim D, Holloway R, Silny J, Tack J, Lerut A, Janssens J. Composition of the postprandial refluxate in patients with gastroesophageal reflux disease. Am J Gastroenterol 2001;96: 647-55.

39. Holloway RH, Dent J. Medical treatment of gastroesophageal reflux disease beyond the proton pump inhibitors. Dig Dis 2000;18:7-13.

40. Lidums I, Lehmann A, Checklin H, Dent J, Holloway RH. Control of transient lower esophageal sphincter relaxations and reflux by the $\mathrm{GABA}_{8}$ agonist baclofen in normal subjects. Gastroenterology 2000;1 18:7-13. 


\section{Chapter \\ 10}

The effect of the $G_{A B A}$ agonist baclofen in patients with symptoms and duodenogastro-esophageal reflux refractory to proton pump inhibitors 


\section{Abstract}

\section{Backgrounds}

A subset of patients with gastro-esophageal reflux disease (GORD) with refractory symptoms during therapy with proton pump inhibitors (PPIs), have persistent non-acid duodeno-gastro-esophageal reflux (duodenal reflux).

\section{Aim}

The aim of the present study was to investigate the effect of the $\mathrm{GABA}_{8}$ receptor agonist baclofen, which was shown to inhibit the occurrence of transient lower esophageal sphincter relaxations (TLESRs), in patients with persisting non-acid duodenal reflux during $\mathrm{PPI}$ therapy.

\section{Methods}

Patients were eligible for the study if they had persistent reflux symptoms, normal $\mathrm{pH}$ monitoring and pathological Bilitec" monitoring during PPI treatment. Upper gastrointestinal endoscopy and reflux symptom score was performed at the beginning of the study. Baclofen $5 \mathrm{mg}$ three times daily was associated with treatment, and was increased by $5 \mathrm{mg}$ every fourth day until a maintenance dose of $20 \mathrm{mg}$ three times daily was reached. A reflux symptom questionnaire, ambulatory $\mathrm{pH}$ monitoring, and Bilitec" monitoring were repeated four days later while PPI and baclofen were continued. All data are given as mean (SEM) or median (interquartile range) and were compared using the Student's t-test or the Mann-Whitney U-test.

Results

Sixteen patients $(11$ women, mean age 46 (3) years) with persistent heartburn or regurgitation for at least three months, in spite of PPI therapy, were included in the study. Erosive esophagitis was present in seven patients (five with grade 1, two with grade 2). Under PPI therapy alone, all patients had normal acid exposure $10.3(0.05 ; 2.2) \%$ of the time) but pathological duodenal reflux exposure $(13.8(11.8 ; 15.5) \%$ of the time). After addition of baclofen $20 \mathrm{mg}$ three times daily, acid exposure was similar $(0.4(0.15 ; 2.3) \%$ of the time, NS), but duodenal reflux had significantly decreased $(6.1(0.8 ; 10.3) \%$ of the time, $p \times 0.05)$. The number of duodenal reflux episodes and the number of longlasting duodenal reflux episodes (>5 minutes) was decreased, respectively, from $23(14.5 ; 34)$ 10 $12(5 ; 21)(p=0.06)$ and from $5(3 ; 8)$ to $2(0.5 ; 4.5)(p<0.05)$. The cumulative severity score for 14 reflux symptoms decreased from $10.3 \pm 1.7$ to $5.8 \pm 1.3(p<0.01)$. Four patients reported mild side effects of nausea or drowsiness.

\section{Conclusions}

The $\mathrm{GABA}_{B}$ receptor agonist baclofen improves duodenal reflux and associated reflux symptoms that persist during PPI therapy. 


\section{Introduction}

Gastro-esophageal reflux disease (GERD), defined as the presence of symptoms or lesions that can be attributed to the reflux of gastric contents into the esophagus, is one of the most common disorders affecting the gastrointestinal tract. ${ }^{1,2}$ The advent of proton pump inhibitors (PPIs), which strongly inhibit acid gastro-esophageal reflux $x^{3-6}$ and which reduce duodeno-gastro-esophageal reflux (duodenal reflux $)^{7-10}$, has brought relief to many GERD patients. A subset of patients however have persistent reflux symptoms in spite of therapy with high doses of PPIs. ${ }^{11,12}$ In up to half of the patients with persistent esophagitis or reflux symptoms in spite of PPI therapy, persisting acid reflux can be demonstrated. ${ }^{11-13}$ These patients generally respond favorably to a further increase in the dose of PPI. $5,6,11,12$ In the remaining patients, intraluminal impedance monitoring or fiberoptic bilirubin monitoring $\left(\right.$ Bilite $^{\text {(3) }}$ ) has been used to demonstrate ongoing non-acid reflux or duodenal reflux..$^{13-15}$ These studies have shown that persisting lesions ${ }^{13,14}$ and symptoms ${ }^{15}$ can be related to non-acidic gastro-esophageal reflux, of gastric and/or duodenal origin, that cannot be abolished by acid suppression. At present, the therapeutic options in these patients are limited. The value of prokinetic therapy in treating duodenal reflux was demonstrated only in patients who underwent partial gastrectomy and very high doses of cisapride were required. ${ }^{16}$ Antireflux surgery was shown to adequately reverse duodenal reflux but not all patients are suitable candidates for surgical therapy.

In both in stationary and ambulatory studies, it was established that transient lower esophageal sphincter relaxations (TLESRs) are the main pathophysiological mechanism underlying acid reflux events. ${ }^{17-20}$ Studies combining intraluminal impedance monitoring with manometry also suggest that TLESRs are the principal mechanism underlying non-acidic reflux episodes. ${ }^{20}$ Recently, it was shown that acute administration of the gamma-aminobutyric acid $\left(G_{B} A B A_{B}\right)$ receptor agonist baclofen can inhibit the occurrence of TLESRs, thereby significantly decreasing acid reflux after a meal. ${ }^{21,22}$ It seems conceivable, therefore that treatment with baclofen might reduce the exposure of the distal esophagus to duodenal reflux. 
The aim of the present study was to investigate the effect of baclofen on symptoms and duodenal reflux, persisted in spite of high dose PPI therapy.

\section{Materials and methods}

\section{General study design}

Consecutive patients with persisting heartburn or regurgitation while treated for at least three months with omeprazole $20 \mathrm{mg}$ twice daily, underwent ambulatory esophageal $\mathrm{pH}$ and Bilitec $^{8}$ monitoring at our institution while PPI therapy was continued. Prior to $\mathrm{pH}$ and Bilitec monitoring, patients were asked to complete a detailed questionnaire on symptoms and frequency, smoking and drinking habits, weight and height, and all underwent upper gastrointestinal endoscopy followed by simultaneous ambulatory 24 hours esophageal $\mathrm{pH}$ and Bilitec monitoring on one of the next four days. Treatment with omeprazole $20 \mathrm{mg}$ twice daily was continued; all other drugs potentially affecting gastrointestinal motility and gastrointestinal secretion were discontinued at least one week prior to the study.

Patients were eligible for the study if they had a normal serum bilirubin level and if, under omeprazole $20 \mathrm{mg}$ twice daily, they had normal acid exposure $\mathrm{pH}$ monitoring (less than $4 \%$ of the time $\mathrm{pH}<4$ ) and pathological duodenal reflux monitoring (Bilitec ${ }^{\text {(B) }}$ greater than $4.6 \%$ of the time absorbance $>0.14) .{ }^{22}$ These tests served both as pre-entry discrimination and as baseline measurement for the participating patients. Exclusion criteria were: peptic ulcer disease, previous esophageal, gastric, or biliary surgery; previous abdominal or thoracic radiotherapy, active gastrointestinal bleeding; presence of esophageal or fundic varices; diabetes mellitus; Zollinger-Ellison syndrome; progressive systemic sclerosis; Raynaud's syndrome and other vascular diseases; neurological disorders; esophageal or upper small intestinal Crohn's disease; herpetic or Candida esophagitis; or active solid tumor neoplastic disease. In addition, all patients with Barrett's esophagus were excluded from the study as the presence of metaplasia in the distal esophagus is irreversible under medical treatment and may interfere with the assessment of persisting esophagitis lesions.

In patients who agreed to participate in the study; treatment with omeprazole $40 \mathrm{mg}$ daily was continued and baclofen (Lioresal ${ }^{\circledR}$, Novartis, Brussels, Belgium), $5 \mathrm{mg}$ three times daily with meals was added. Every fourth day, the dose of baclofen was increased with $5 \mathrm{mg}$ 
three times daily until a dose of $20 \mathrm{mg}$ three times daily was reached after 10 days. On day 14 , ambulatory $\mathrm{pH}$ and Bilitec monitoring was repeated while treatment with omeprazole $20 \mathrm{mg}$ twice daily and baclofen $20 \mathrm{mg}$ three times daily was continued. The ethics committee of the hospital accepted the study protocol.

\section{Patient selection.}

During 20 consecutive months, 78 patients with persistent heartburn or regurgitation while treated for at least three months with omeprazole $20 \mathrm{mg}$ twice daily underwent ambulatory esophageal $\mathrm{pH}$ and Bilitec ${ }^{\text {(i) }}$ monitoring at our institution while PPI therapy was continued.

Of 20 eligible patients, 16 (five men and 11 women) gave written informed consent for the study.

\section{Reflux symptoms}

Before and at the end of the study, all patients were given a 14 symptom questionnaire (heartburn, acid regurgitation, food regurgitation, chest pain, dysphagia, odynophagia, nausea, vomiting, choking, throat ache, hoarseness, nocturnal cough, nocturnal dyspnoe, wheezing) which they scored for severity using a numerical score $10=$ absent, $1=$ mild, 2 = moderate, 3 = severe).

Upper gastrointestinal endoscopy

All subjects underwent classical upper gastrointestinal endoscopy. If necessary, they were sedated with intravenous administration of diazepam (up to $10 \mathrm{mg}$ ) or midazolam (up to $5 \mathrm{mg}$ ). During endoscopy, the presence of esophagitis was noted and graded according to the modified classification system of Savary and Miller. ${ }^{24}$ In addition, the presence and extent of Barrett's esophagus was noted.

Ambulatory $\mathrm{pH}$ monitoring

Ambulatory esophageal $\mathrm{pH}$ monitoring was performed using an antimony $\mathrm{pH}$ electrode with a separate skin reference electrode (Synectics Medical, Stockholm, Sweden). Data were stored on a portable digital recorder (Digitrapper Mk III; Synectics Medical). Before each study, the $\mathrm{pH}$ probe was calibrated in buffer solutions of $\mathrm{pH} 7$ and 1 . An episode of acid reflux was defined as a decrease in esophageal $\mathrm{pH}$ to $<4$ for more than 10 seconds. ${ }^{23,25}$ 
Measurement of duodeno-gastro-esophageal reflux

The fibreoptic spectrophotometer Bilitec ${ }^{\circledR} 2000$ (Synectics) was used to quantify duodeno-gastro-esophageal reflux. The system consists of a miniaturized probe of $5 \mathrm{~mm}$ diameter that carries light signals into the esophagus and back via a plastic fiber-optic bundle. Before each study, the probe was calibrated in water. An episode of duodenal reflux is defined as an increase in esophageal bilirubin absorbance $>0.14$ for more than 10 seconds. ${ }^{23,25}$

\section{Combined $\mathrm{pH}$ and duodenal reflux monitoring}

Probes for assessing acid and duodeno-gastro-esophageal reflux were introduced via a nasal orifice into the esophagus $5 \mathrm{~cm}$ proximal to the lower esophageal sphincter, defined by stationary esophageal manometry. The probes were then attached with adhesive tape to the subject's nose and cheek. In addition, appropriate positioning in the esophagus was confirmed by fluoroscopy. Data collection devices were connected to the probes and worn in a belt on the patient's waist. Registration of acid or duodeno-gastro-esophageal reflux lasted for approximately 22 hours after which the probes were removed and the data transferred to a personal computer for analysis. Patients recorded the time of food or fluid consumption and posture changes on a diary card. They were instructed to stay upright during the day. During the recording time, only liquid meals $\left(200 \mathrm{ml}\right.$ Nutridrink ${ }^{\circledR} ; 300 \mathrm{kcal}: 13 \%$ proteins, $48 \%$ carbohydrates, and $39 \%$ lipids. Nutricia, Belgium), not interfering with Bilitec ${ }^{18}$ monitoring were allowed. ${ }^{23}$ Patients were asked to preferably drink water and to avoid coffee, tea, and fruit juices during the recording.

\section{Data analysis}

Data were analyzed with the aid of commercially available software (Gastrosoft Inc., Synectics Medical, Irvine, Texas, USA). Acid and duodenal reflux were quantified separately with the following variables obtained from computerized analysis: number of reflux episodes, number of reflux episodes lasting longer than five minutes, fraction of time of acid or duodeno-esophageal reflux. The recording was divided into meal, postprandial (two hours after a meal), interdigestive, upright and supine periods. Individual severity scores (0-3) for 14 reflux-related symptoms were obtained from the questionnaire. An overall severity score (maximum score 42) was calculated by adding the severity scores of all individual symptoms in the questionnaire. We also determined the 
maximum individual severity score for each patient, before and after addition of baclofen.

Statistical analysis

Values are expressed as mean (SEM) for parametric data, and median (interquartile range) for non-parametric data. Data were compared using the Student's t test, the Mann-Whitney $U$ test, or Chi-square test, wherever appropriate. A $p$ value of $<0.05$ was considered significant.

\section{Results}

\section{Patient characteristics}

Sixteen patients (five men, 11 women) with persistent heartburn or regurgitation in spite of omeprazole $20 \mathrm{mg}$ twice daily for at least three months were included in the study after written informed consent was obtained. Mean age of the patients was 46.2 (2.8) years and mean body mass index was $28.3(1.9) \mathrm{kg} / \mathrm{m}^{2}$. Eight patients were smokers and one patient reported regular use of alcohol.

\section{Endoscopy}

In all patients the endoscopic investigation took place before the 24 hours measurements. In nine patients no esophageal lesions were found. According to the modified Savary and Miller classification, esophagitis grade 1 was seen in five patients $(31 \%)$ and esophagitis grade 2 in two patients $(13 \%)$. None of the patients was diagnosed with Barrett's esophagus and in three patients (19\%) a hiatal hernia was found.

Bilitec $^{\circledR}$ and $\mathrm{pH}$ measurements under omeprazole treatment

Under omeprazole therapy alone (20 mg twice daily), all patients had normal esophageal acid exposure (Table 10.1) (Figure 10.1A). On average, intra-esophageal $\mathrm{pH}$ was $<4$ for only $0.3(0.05 ; 2.2) \%$ of the recording time. Patients had $14(2 ; 51)$ acid reflux episodes, none of which lasted longer than five minutes. The acid reflux that persisted during omeprazole therapy occurred almost exclusively in the upright position (Table 10.1). 
Table 10.1. Acid exposure parameters during treatment with omeprazole $20 \mathrm{mg}$ twice daily and with omeprazole $20 \mathrm{mg}$ twice daily plus baclofen $10 \mathrm{mg}$ three times daily.

\begin{tabular}{llccc}
\hline Variable & Period & Omeprazole & $\begin{array}{c}\text { Omeprazole }+ \\
\text { baclofen }\end{array}$ & p-value \\
\hline \% Time $\mathrm{pH}<4$ & Total & $0.3(0.05 ; 2.2)$ & $0.4(0.15 ; 2.3)$ & NS \\
& Upright & $0.4(0 ; 2.9)$ & $0.7(0.25 ; 1.8)$ & NS \\
& Supine & $0(0 ; 0)$ & $0(0 ; 0.2)$ & NS \\
No of acid reflux & Total & $14(2 ; 52)$ & $17(7 ; 36)$ & NS \\
episodes & Upright & $12(2 ; 23.2)$ & $17.5(6.7 ; 31.2)$ & NS \\
& Supine & $0(0 ; 1.5)$ & $0.5(0 ; 3)$ & NS \\
No of acid reflux & Total & $0(0 ; 0.5)$ & $0(0 ; 0)$ & NS \\
episodes lasting $>5$ min & Upright & $0(0 ; 0)$ & $0(0 ; 0)$ & NS \\
& Supine & $0(0 ; 0)$ & $0(0 ; 0)$ & NS \\
\hline
\end{tabular}

As required by the inclusion criteria, all patients had pathological esophageal Bilitec ${ }^{k}$ recordings while they were taking omeprazole $20 \mathrm{mg}$ twice daily (Table 10.2). On average, the distal esophagus was exposed to duodenal reflux for $13.8(11.8 ; 15.5) \%$ of the time. Patients had 24 $(14 ; 34)$ episodes of non-acid reflux, of which $5(3 ; 8)$ lasted longer than five minutes. The majority of duodenal reflux episodes occurred in the upright position $117(10 ; 25)$ episodes, amounting to exposure to duodenal reflux of $16(10.9 ; 21.9) \%$ of the time $)$. In the supine position, $5(1 ; 8)$ episodes of duodenal reflux resulted in $11.2(0.9 ; 18.4) \%$ of time exposure to duodenal reflux (Table 10.2).

Table 10.2. Duodenal reflux exposure parameters during treatment with omeprazole $20 \mathrm{mg}$ twice daily and with omeprazole $20 \mathrm{mg}$ twice daily plus baclofen $10 \mathrm{mg}$ three times daily.

\begin{tabular}{llccr}
\hline Variable & Period & Omeprazole & $\begin{array}{c}\text { Omeprazole }+ \\
\text { baclofen }\end{array}$ & p-value \\
\hline \% Time absorbance & Total & $13.8(11.8 ; 15.5)$ & $6.1(0.8 ; 10.4)$ & $<0.005$ \\
$>0.14$ & Upright & $16(10.9 ; 21.9)$ & $8.6(1.3 ; 16.4)$ & 0.06 \\
& Supine & $11.2(0.9 ; 18.4)$ & $0(0 ; 1.1)$ & $<0.05$ \\
No of duodenal reflux & Total & $23(14.5 ; 33)$ & $12(5 ; 21)$ & 0.06 \\
episodes & Upright & $17(10 ; 25)$ & $12(1 ; 20)$ & 0.07 \\
& Supine & $4.5(0.7 ; 8.2)$ & $0(0 ; 0)$ & $<0.05$ \\
No of duodenal reflux & Total & $5(3 ; 8)$ & $2(0.5 ; 4.5)$ & $<0.05$ \\
episodes lasting $>5$ min & Upright & $4(2.5 ; 5)$ & $2(0.5 ; 4)$ & 0.06 \\
& Supine & $2(0.5 ; 2)$ & $0(0 ; 0)$ & $<0.05$ \\
\hline
\end{tabular}


Bilitec ${ }^{\circledR}$ and $\mathrm{pH}$ measurements during treatment with omeprazole and baclofen

Under combined treatment with omeprazole $20 \mathrm{mg}$ twice daily and baclofen $20 \mathrm{mg}$ three times daily, esophageal acid exposure remained unchanged (Table 10.1) (Figure 10.1B). On average, intra-esophageal $\mathrm{pH}$ was below 4 for $0.4(0.15 ; 2.3) \%$ of the recording time. Patients had $17(7 ; 36)$ acid reflux episodes, none of which lasted longer than five minutes. The persisting acid reflux occurred almost exclusively in the upright position (Table 10.2).

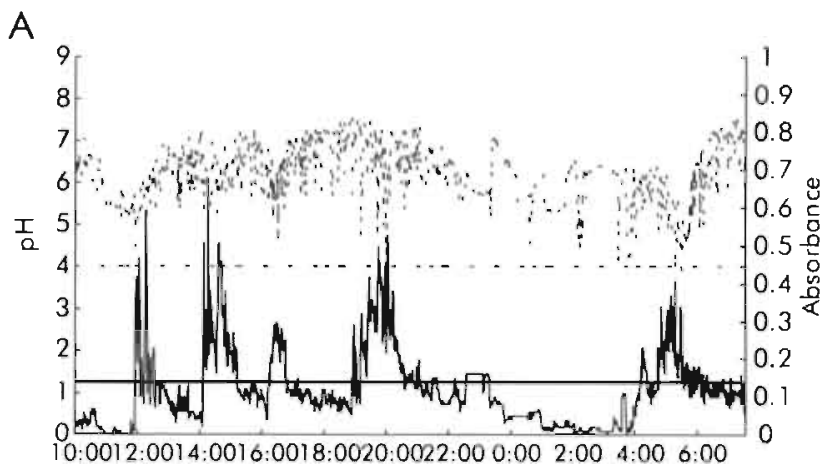

B

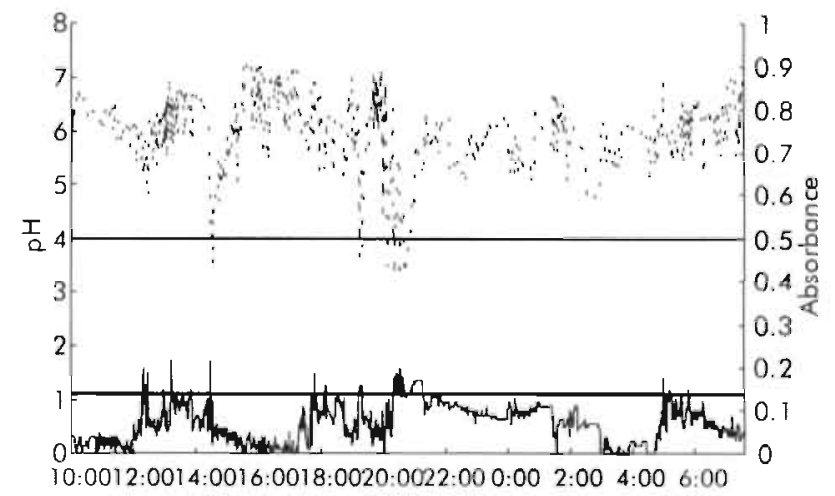

Figure 10.1. Combined $\mathrm{pH}$ and Bilitec" monitoring studies. The x-axis depicts time, the left $y$-axis depicts intra-esophageal $\mathrm{pH}$ and right $y$-axis depicts bilirubin absorbance. Cut offs of normal ranges are indicated $(\mathrm{pH}<4$ and absorbance $>0.14$ ). (A) Combined $\mathrm{pH}$ and Bilitec" monitoring in a patient with typical reflux symptoms during omeprazole $20 \mathrm{mg}$ twice daily treatment, showing normal acid exposure and pathological duodenal reflux exposure. (B) Combined $\mathrm{pH}$ and Bilifec monitoring during omeprazole 20 $\mathrm{mg}$ twice daily and baclofen $20 \mathrm{mg}$ three times daily treatment, showing normal acid exposure and normalized duodenal reflux exposure. 
After the addition of baclofen $20 \mathrm{mg}$ three times daily to omeprazole $20 \mathrm{mg}$ twice daily, distal esophageal exposure duodenal reflux was significantly decreased to $6.1(0.8 ; 10.4) \%$ of the time $(p<0.05)$ (Figure 10.2). The number of duodenal reflux episodes and the number of duodenal reflux episodes lasting longer than five minutes were significantly decreased (Table 10.2) (Figure 10.3). Decreases in duodenal reflux exposure during baclofen treatment occurred both in the upright and supine positions but changes in supine duodenal reflux were most pronounced (Table 10.2).

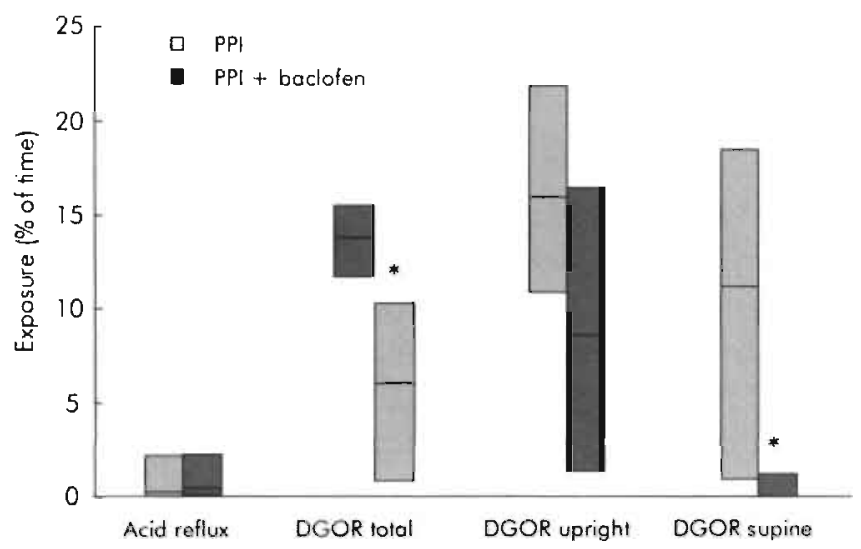

Figure 10.2. Acid and duodenal reflux exposure during treatment with omeprazole 20 mg twice daily and during omeprazole $20 \mathrm{mg}$ twice daily (PPI) plus baclofen $20 \mathrm{mg}$ three times daily.

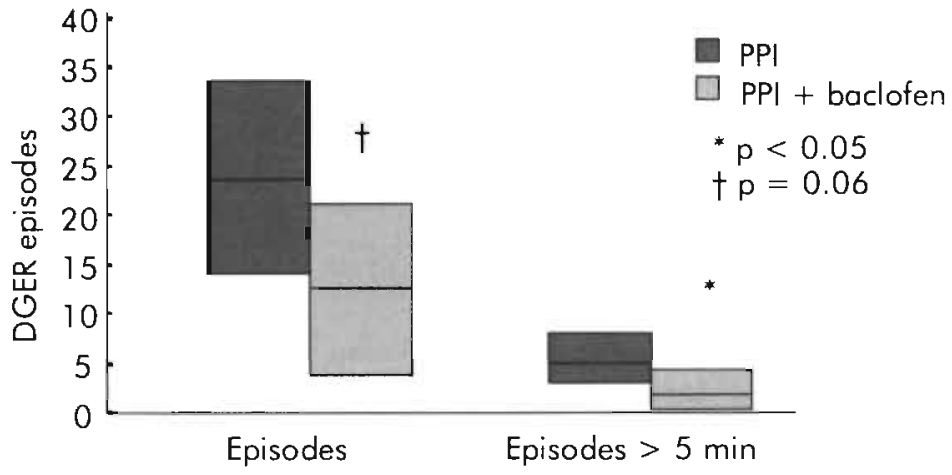

Figure 10.3. Number of duodenal reflux episodes and number of duodenal reflux episodes lasting longer than five minutes during treałment with omeprazole $20 \mathrm{mg}$ twice daily (PPI) and during omeprazole $20 \mathrm{mg}$ twice daily plus baclofen $20 \mathrm{mg}$ three times daily. 


\section{Symptom assessment and side effects}

Symptom severity at baseline is summarized in Table 10.3. During treatment with omeprazole $20 \mathrm{mg}$ twice daily, overall symptom severity was 10.3 (1.7). The most prevalent symptoms were chest pain, heartburn, nausea, throat ache, odynophagia, and acid regurgitation. After the addition of baclofen, overall symptom severity was significantly decreased to $5.8 \pm 1.3(p<0.01)$. Maximum symptom severity decreased from $26(0.1)$ to $1.8 \quad(0.3)(p<0.03)$. The severity of heartburn, odynophagia, and choking was significantly decreased $(p<0.05)$ and a borderline decrease in the severity of throat ache occurred $(p=0.07)$ (Table 10.3).

Treatment with baclofen was generally well tolerated. Mild side effects occurring in four patients were transient nausea $(n=2)$ and drowsiness $(n=3)$. No dose reductions were necessary and none of the patients withdrew from the study.

Table 10.3. Symptom severity scores during treatment with omeprazole $20 \mathrm{mg}$ twice daily and during omeprazole $20 \mathrm{mg}$ twice daily plus baclofen $10 \mathrm{mg}$ three times daily.

\begin{tabular}{lccc}
\hline Symptom & Omeprazole & Omeprazole + baclofen & $p$-value \\
\hline Heartburn & $1.6 \pm 0.4$ & $0.8 \pm 0.3$ & $<0.05$ \\
Acid regurgitation & $0.7 \pm 0.2$ & $0.6 \pm 0.3$ & $\mathrm{NS}$ \\
Food regurgitation & $0.4 \pm 0.2$ & $0.4 \pm 0.2$ & $\mathrm{NS}$ \\
Chest pain & $1.7 \pm 0.3$ & $1.1 \pm 0.3$ & $\mathrm{NS}$ \\
Dysphagia & $0.5 \pm 0.2$ & $0.4 \pm 0.2$ & $\mathrm{NS}$ \\
Nausea & $1.3 \pm 0.3$ & $0.9 \pm 0.2$ & $\mathrm{NS}$ \\
Choking & $0.6 \pm 0.3$ & $0.1 \pm 0.1$ & $<0.05$ \\
Odynophagia & $0.8 \pm 0.3$ & $0.1 \pm 0.1$ & 0.01 \\
Throat ache & $1.1 \pm 0.3$ & $0.6 \pm 0.3$ & 0.07 \\
Hoarseness & $0.5 \pm 0.3$ & $0.4 \pm 0.2$ & $\mathrm{NS}$ \\
Coughing & $0.4 \pm 0.2$ & $0.1 \pm 0.1$ & $\mathrm{NS}$ \\
Dyspnoe & $0.3 \pm 0.2$ & $0.1 \pm 0.1$ & $\mathrm{NS}$ \\
Vomiting & $0.5 \pm 0.3$ & $0.4 \pm 0.2$ & $\mathrm{NS}$ \\
Overall & $10.3 \pm 1.7$ & $5.8 \pm 1.3$ & $<0.01$ \\
\hline
\end{tabular}

\section{Discussion}

In a subset of GERD patients, typical reflux symptoms persist in spite of PPI therapy. In up to half of the patients, ongoing non-acid reflux, for which treatment options are limited, can be demonstrated. ${ }^{3.15}$ The present study was a pilot study to investigate the value of add-on 
treatment with baclofen in patients with adequate control of acid reflux by a PPI but who had persisting reflux symptoms and ongoing duodenal reflux. We demonstrated that addition of the $\mathrm{GABA}_{B}$ agonist baclofen reduced the number of duodenal reflux episodes and the duodenal reflux exposure that persists during PPI therapy. This effect occurred during a short-term treatment course, demonstrating that the favorable effect of baclofen in GERD is preserved during repeated administrations. We also observed improvement of persistent reflux symptom, be it in an uncontrolled setting.

The prerequisite for gastro-esophageal reflux to occur is failure of the antireflux barrier at the gastro-esophageal junction. In healthy subjects and in most patients with mild to moderate GERD, both acid and nonacid reflux occurs, mainly during TLESRs. ${ }^{17-20}$ Pharmacological intervention to reduce TLESRs has been proposed as a non-surgical strategy to improve the antireflux barrier in patients with GERD, and several agents that inhibit the occurrence of TLESRs were identified, including atropine, $\mathrm{CCK}_{\mathrm{A}}$ receptor antagonists, morphine, and nitric oxide synthase inhibitors. ${ }^{27}$ None of these agents has had clinical application in GERD therapy because of an unfavorable pharmacological profile.

More recently, administration of a single $40 \mathrm{mg}$ dose of the $\mathrm{GABA}_{B}$ agonist baclofen was shown to inhibit TLESRs and to increase basal LES pressure, thereby significantly decreasing acid reflux after a meal in healthy controls. ${ }^{22}$ In GERD patients, acute administration of $40 \mathrm{mg}$ baclofen inhibited postprandial TLESRs, without significantly affecting esophageal acid exposure. ${ }^{23}$ Esophageal peristalsis was not altered by baclofen in any of these studies. These observations suggest a therapeutic potential for baclofen in the inhibition of TLESR related acid reflux events. However, currently available acid suppressive therapy is also most successful in patients with mild to moderate reflux disease with predominantly upright TLESR related reflux episodes. ${ }^{3,4,11,12}$ As baclofen addresses a different factor of GERD pathophysiology, baclofen or related agents offer the potential to be used as add-on therapy in GERD patients with incomplete relief by acid suppression and/or in patients with more severe GERD.

In the present study, we used baclofen as add-on therapy in GERD patients with duodenal reflux that persisted during PPI treatment, confirming its therapeutic potential in treating duodenal reflux in a longer-term setting. The dose of baclofen was progressively increased to a dose of $20 \mathrm{mg}$ three times daily after 10 days. Re-evaluation after 14 days of baclofen treatment confirmed a significant decrease in the number of duodenal reflux episodes and a significant decrease in 
esophageal duodenal reflux exposure. In keeping with putative inhibition of TLESRs by baclofen, the number of reflux events and duodenal reflux exposure were decreased during the 24 hours period studied. Contrary to expectations, this beneficial effect was less pronounced in the upright period, and most prominent during the supine period. It is unclear whether this is related to inhibition of TLESRs, or whether the increase in basal LES pressure that was described in previous studies ${ }^{22,23}$ contributes to this effect. Reflux during TLESRs depends on the characteristics of the gastric contents. With adequate acid suppression, patients will have no acid in the stomach, but duodeno-gastric reflux is unlikely to be affected. Previous studies have already established the high prevalence of duodeno-gastric reflux in the supine position. ${ }^{28}$ As a consequence, during PPI therapy, nocturnal TLESRs are readily associated with duodenal refluxate. During night, reflux due to TLESRs occurs during episodes of arousal. ${ }^{29}$ Baclofen therefore may have reduced the number of nocturnal TLESRs or the number of nocturnal arousal episodes, thereby decreasing nocturnal duodenal reflux episodes.

Furthermore, a decrease in number of reflux events seems insufficient to explain all of the changes in duodenal reflux exposure. Treatment with baclofen significantly decreased the number of duodenal reflux episodes that lasted longer than five minutes. This could reflect improved esophageal clearance of duodenal refluxate or decreased volume of the refluxate. The mechanisms involved in clearance of non-acid reflux are incompletely elucidated but previous studies using baclofen failed to show altered esophageal peristaltic activity. ${ }^{22,23}$ Regarding the volume of the refluxate, it will be important to study the effects of baclofen on gastric emptying and on duodeno-gastric reflux episodes. Inhibition of vagal efferent activity by baclofen is likely to decrease vagally driven acid secretion, thereby also decreasing intragastric fluid volumes. ${ }^{30}$ It is unclear whether such a mechanism might still be of relevance during PPI therapy.

Apart from improving Bilitec ${ }^{\hat{B}}$ measurements of duodenal reflux exposure, baclofen also improved a composite score of typical and atypical reflux symptoms, as well as some individual symptoms, such as heartburn, odynophagia, and choking. These findings are encouraging in a particularly difficult group of patients to manage, but confirmation of a clinically relevant effect of baclofen on refractory GERD symptoms awaits placebo-controlled long-term studies.

In summary, in the present study, the $\mathrm{GABA}_{B}$ receptor agonist baclofen was shown to reduce symptoms and duodenal reflux in patients with 
insufficient relief during PPI therapy. These observations confirm that baclofen is able to inhibit reflux during repeated administration and suggest a therapeutic potential as an add-on in GERD patients with incomplete relief by acid suppression. 


\section{References}

1. Isolauri J, Laippala P. Prevalence of symptoms suggestive of gastroesophageal reflux disease in an adult population. Ann Med 1995; 27: 67-70.

2. Spechler SJ. Epidemiology and natural history of gastroesophageal reflux disease. Digestion 1992; 51 (suppl 1): 24-29.

3. Dehn TCB, Sheperd HA, Colin-Jones D, Kettlevell MGW, Carroll NJH. Double blind comparison of omeprazole versus cimetidine in the treatment of symptomatic erosive reflux oesophagitis, assessed endoscopically, histologically and by $24 \mathrm{~h} \mathrm{pH}$ monitoring. Gut 1990;31:509-13.

4. Hetzel DJ, Dent J, Reed WD, Narielvala FM, Mackinnon M, McCarthy JH, Mitchell B, Beveridge BR, Laurence BH, Gibson $G G$,et al. Healing and relapse of severe peptic esophagitis after treatment with omeprazole. Gastroenterology 1088;95:903-12.

5. Klinkenberg-Knol E, Nelis F, Dent J, Snel P, Mitchell B, Prichard P, Lloyd D, Hauv N, Frame MH, Roman J, Walan A. and Long-term Study group. Long-term omeprazole treatment in resistant gastroesophageal reflux disease: efficacy, safety and influence on gastric mucosa. Gastroenterology 2000; 1 18:661-9.

6. Robinson M, Campbell DR, Sontag S, Sabesin SM. Treatment of erosive reflux esophagitis resistant to $\mathrm{H} 2$-receptor antagonist therapy. Lansoprazole, a new proton pump inhibitor. Dig Dis Sci 1995;40:590-7.

7. Marshall RE, Anggiansah A, Manifold DK, Owen WA, Owen WJ. Effect of omeprazole $20 \mathrm{mg}$ twice daily on duodenogastric and gastro-oesophageal bile reflux in barrett's esophagus. Guł 1998;43:603-6.

8. Menges $M$, Muller $M$, Zeitz $M$. Increased acid and bile reflux in Barrett's esophagus compared to reflux esophagitis, and effect of proton pump inhibitor therapy. Am. J. Gastroenterol 2001;96:331-7.

9. Stein HJ, Kaver WK, Feussner H, Siewert JR. Bile reflux in benign and malignant Barrett's esophagus: effect of medical acid suppression and Nissen fundoplication. J Gastrointest Surg 1998;2:333-41.

10. Champion G, Richter JE, Vaezi MF, Singh S, Alexander R. Duodenogastroesophageal reflux: relationship to $\mathrm{pH}$ and importance in Barrett's esophagus. Gastroenterology 1994;107:747-54.

11. Holloway RH, Dent J, Narielvala F, Mackinnon AM. Relation between oesophageal acid exposure and healing of oesophagitis with omeprazole. Gut 1996;38:649-54.

12. Klinkenberg-Knol EC, Meuwissen SGM. Combined gastric and esophageal 24-hour $\mathrm{pH}$ monitoring and esophageal manometry in patients with reflux disease resistant to treatment with omeprazole. Aliment Pharmacol Ther 1990;4:485-95.

13. Tack J, Koek G, Demedts I, Sifrim D, Janssens J. Gastro-esophageal reflux disease poorly responsive to proton pump inhibitors: acid reflux, bile reflux or both? Submitted for publication. 
14. Wilmer A, Tack J, Frans E, Dits H, Vanderschueren, Bobbaers H. Duodenogastroesophageal reflux and esophageal mucosal injury in mechanically ventilated patients. Gastroenterology 1999;116:1293-9.

15. Vela M, Camacho-Lobato L, Srinivasan R, Tutuian R, Katz PO, Castell D. Simultaneous intraesophageal impedance and $\mathrm{pH}$ measurement of acid and nonacid gastroesophageal reflux: effect of omeprazole. Gastroenterology 2001; 120:1599-606.

16. Vaezi MF, Sears-R, Richter JE. Placebo-controlled trial of cisapride in postgastrectomy patients with duodenogastroesophageal reflux. Dig-Dis-Sci 1996; 41:754-63.

17. Dodds WJ, Dent J, Hogan WJ, Helm JF, Hauser R, Patel GK, Egide MS. Mechanisms of gastroesophageal reflux in patients with reflux esophagitis. N Engl J Med 1982; 307): 1547-52.

18. Schoeman MN, Tippett MD, Akkermans LMA, Dent J, Holloway RH. Mechanisms of gastroesophageal reflux in ambulant healthy human subjects. Gastroenterology 1995; 108:83-91.

19. Penagini R, Schoeman MN, Dent J, Tippett MD, Holloway R. Motor events underlying gastro-esophageal reflux in ambulant patients with reflux esophagitis. Neurogastroenterol Mot 1996;8:131-41.

20. Sifrim D, Holloway R, Silny J, Tack J, Lerut A, Janssens J. Composition of the postprandial refluxate in patients with gastroesophageal reflux disease. Am J Gastroenterol 2001;96:647-55

21. Lidums I, Lehmann A, Checklin H, Dent J, Holloway RH. Control of transient lower esophageal sphincter relaxations and reflux by the $G A B A(B)$ agonist baclofen in normal subjects. Gastroenterology 2000;118:7-13.

22. Zhang $Q$, Lehmann $A$, Checklin $H$, et al. Control of transient lower oesophageal relaxations and reflux by the GABAB agonist baclofen in patients with gastrooesophageal reflux disease. Gut 2002;50:19-24.

23. Tack J, Bisschops R, Koek GH, Sifrim D, Lerut T, Janssens J. Dietary restrictions during ambulatory monitoring of duodeno-gastro-esophageal reflux. Dig Dis Sci 2003;48:1213-20.

24. Savary M, Miller G. L'oesophage. Manuel et Atlas d'Edoscopie. Solothurn, Switzerland: Verlag Gassmann, 1977.

25. Cuomo R, Koek G, Sifrim D, Janssens J, Tack J. Analysis of ambulatory duodenogastro-esophageal reflux monitoring. Dig Dis Sci.2001;45: 2463-2469.

26. Hirschowitz BI. A critical analysis, with appropriate controls, of gastric acid and pepsin secretion in clinical esophagitis. Gastroenterology 1991;101:1149-58.

27. Holloway RH, Dent J. Medical treatment of gastroesophageal reflux disease beyond the proton pump inhibitors. Dig Dis 2000;18:7-13.

28. McDermott CM, Abrahams TP, Partosoedarso E, Hyland N, Ekstrand J, Monroe M, Hornby PJ. Site of action of $\mathrm{GABA}(\mathrm{B})$ receptor for vagal motor control of the lower esophageal sphincter in ferrets and rats. Gastroenterology 2001;120:1749-62. 
29. Freidin N, Fisher MJ, Taylor W, Boyd D, Surratt P, McCallum RW, Mittal RK. Sleep and nocturnal acid reflux in normal subjects and patients with reflux oesophagitis. Gut 1991;32:1275-9

30. Marshall RE, Anggiansah A, Owen WA, Manifold DK, Owen WJ. The extent of duodenogastric reflux in gastro-oesophageal reflux disease. Eur J Gastroenterol Hepatol 2001;13:5-10 


\section{Chapter 11}

General discussion and conclusions 
Chapter 11 


\section{Introduction}

Gastro-esophageal reflux disease (GERD) is common in Western society. ${ }^{1,2}$ Reflux of gastric content to the esophagus plays an important role not only in lesions like esophagitis, Barrett's esophagus, strictures and carcinoma, but also in the genesis of symptoms like heartburn and chest pain.

Acid and pepsin are the main constituents of the fluids secreted by the mucosa of the stomach mainly in response to a meal. Reflux of these substances with food takes place in healthy and diseased patients.

Different factors play a role in GERD; esophageal and gastric function and characteristics of the refluxate are all important determinants of reflux disease, suggesting that this is a multifactorial disorder. A multivariate analysis demonstrated that the peak acid output, basal lower esophageal sphincter pressure and impaired esophageal acid clearance were independent factors in the development of esophagitis. ${ }^{3}$ More recently, several studies suggested that not only reflux of acid and pepsin but also reflux of duodenal contents plays a role in the pathogenesis of esophagitis and Barrett's esophagus. ${ }^{4 \cdot 7}$

\section{Role of duodeno-gastro-esophageal reflux (DGER)}

The introduction of a method to study bile reflux (Bilitec ${ }^{(B)}$ ) in an ambulatory manner opened the way to get a better insight in the role of DGER..$^{8-10}$

The suggestion that bile acids and pancreatic enzymes play a role in esophageal lesions was first made in patients after gastrectomy and achlorhydria presenting with severe esophagitis. ${ }^{11,12}$ These observations were confirmed in animal studies: duodenal content could play a role in esophageal mucosal lesions. ${ }^{13.15}$ In humans these experimental observations were confirmed suggesting that the combined effect of acid, pepsin and duodenal content (DC) was important in the genesis of esophageal mucosal lesions and probably of symptoms. ${ }^{4,6}$

To obtain a better understanding about the role DC plays in GERD, pathophysiological, clinical and therapeutic aspects were studied and the results are presented in this thesis. 


\section{Mechanism of duodeno-gastric reflux (DGR)}

It is obvious that when reflux of DC to the esophagus occurs it first has to enter the stomach. Aspiration studies showed that DC could normally be found in the stomach probably as the result of retrograde peristalsis from the duodenum through the pylorus into the gastric antrum ${ }^{16.18}$ from where it can be mixed with gastric fluid. Although this is seen in most normal individuals post-prandially, until now no generally accepted normal values of DC concentration and duration have been established because controversy exists about the method to be used. The problem with aspiration studies is the fact that they are of short duration, the aspiration does not give detailed information about where the fluid is collected and the catheter could influence gastric motility and saliva secretion. The chemical analysis of bile salts and bilirubin is quite elaborative and can only be used in clinical setting in some specialized centers. The scintigraphic method on the other hand is a non-invasive method but has the disadvantage that the patient has to be exposed to radiolabelled substances, that it has to be performed in a non-ambulant setting and that areas of interest are sometimes difficult to distinguish because of overlap.

To solve many of these problems a semi-quantitative method was developed; the Bilitec ${ }^{8}$. With this device it has become possible to study reflux of bilirubin containing fluid in an ambulatory fashion. Discussion has been focused on the cut-off for absorbance, Bechi, who took part in the development of the method, defined 0.14 absorbance units as the lowest level detecting fluid containing bilirubin. ${ }^{19}$ He advised dietary restrictions, which were not necessary according to Fein when taking 0.25 absorbance units as cut-off. ${ }^{10}$ We used liquid meals to rule out the possibility of food impaction in the probe and used 0.14 absorbance units as cut-off value ${ }^{20}$ (chapter 5 ). It could be argued that taking liquid meals is not physiological and does not represent a normal mixed meal. No exact information is available about stomach behavior after consuming liquid meals in contrast to normal varied meals. However, the liquid meals consumed in all patients and healthy volunteers were balanced for the different compounds $113 \%$ proteins, $48 \%$ carbohydrates, $39 \%$ fat $200 \mathrm{ml}, 300 \mathrm{kcal}$. Patients and healthy volunteers were instructed to consume until satiety occurred (generally 2-4 packets per meal). In the presented study (chapter 5), we showed that the diet used, liquid or normal with some restrictions, did not significantly alter the acid exposure of the distal esophagus in healthy volunteers. We concluded that comparison of acid reflux data obtained with either diet is possible because the liquid diet induced comparable reflux episodes presumably by the content of the fluid (highly lipid). 
Another point of discussion is the accuracy of the optically measured bilirubin concentration in an acidic milieu. As has been mentioned, the unconjugated bile salts precipitate in acidic environment. When this happens the irresolvability makes it harmless to the mucosa. In normal situations the unconjugated form of bile salts in DC is in the minority, as about $98 \%$ exist in the conjugated form.

Correcting for the error in bilirubin absorbance measurement during esophageal acid exposure did not lead to any different clinical results. We concluded that the Bilitec ${ }^{\otimes}$ measurements can be expressed as percentage of time that absorbance is above 0.14 and that they are reliable without correction in identifying the presence of bilirubin in fluids (chapter 6).

\section{Duodeno-gastric reflux (DGR)}

DGR is physiologic as has been observed in different studies. 17,18,21,22 The mechanism is not fully understood but motility plays probably the most important role. Retrograde duodenal pressure waves have been described during the late part of the duodenal migrating motor complex (MMC) phase $1 \|^{23}$ suggesting that by this way duodenal content is refluxed into the stomach, as it has also been observed in alkalinisation of the antrum by bicarbonate from the duodenum. ${ }^{24}$ In our study (chapter 3) all volunteers had short periods of DGR in the interdigestive period, which mainly occurred during MMC phase II. DGR occurred in all subjects in the postprandial period. DGR clearance was accelerated by administration of erythromycin, which increased antral motility. No direct temporal relationship with erythromycin-induced gastric MMC phase III was observed. This study confirmed that DGR clearance is a motor phenomenon depending on enhanced antral phasic contractile activity rather than premature occurrence of MMC phase III.

\section{Esophageal clearance mechanism}

Helm et al have described clearance of acid from the esophagus as a two-step mechanism. ${ }^{25}$ The acidic bolus is cleared by peristalsis and the residual acid film is neutralized by swallowed saliva (chemical clearance $\left.{ }^{26}\right)$. Secondary peristalsis, triggered by distention of the esophagus lumen as a reaction to reflux of a fluid bolus from the stomach, is referred to as the volume clearance mechanism. ${ }^{27}$

In the study presented in chapter 4 we were able to confirm the two-step clearance mechanism of an acid bolus instilled in the upper part of the esophagus. For the DC bolus no difference in volume clearance time could be observed compared to the acidic bolus, but the DC chemical clearance time was significantly shorter. The mechanism underlying this 
difference is speculative. We measured a higher viscosity of the DC, possibly suggesting that the cohesive forces of the bolus promote clearance, as the fluid is not spread over the mucosal layer. However, we found no correlation between bolus clearance and viscosity of the acid or DC fluid, suggesting that viscosity was not the major determinant of the clearance velocity.

Because of the ionic form of $\mathrm{H}^{+}$, a more hydrophilic property of the acid bolus is suggested which is more able to penetrate the surfactant layer upon the esophageal mucosal cells. The construction of the $\mathrm{pH}$ probe makes it easier to measure $\mathrm{pH}$ differences, which are close to the mucosa. This is in contrast with the Bilitec probe that is a cup. The suggestion that fluid is trapped in this small cup was not confirmed in our observations and cannot be an explanation for the prolonged periods of DGER that have been observed in patients.

Multivariate analysis

Until now no large study has been performed combining $\mathrm{pH}$ and Bilitec monitoring of the esophagus. From earlier studies it has been suggested that in the progression to more severe esophagitis and Barrett's esophagus, as a complication from long lasting reflux, DGER plays an important role. ${ }^{5,6,28-31}$ Until today controversy exists about the role DC plays in the pathogenesis of reflux related lesions. Different investigators suggest that the role of acid reflux is the culprit in reflux disease and we do not want to deny this role. The successful therapy with acid secretion inhibitory medication shows the important role of $\mathrm{H}^{+}$related lesions. But it has not been clearly explained why certain patients develop more severe lesions than others. And also no evident explanation has been found for the fact that certain patients develop Barrett's esophagus.

To clarify these aspects, a large multivariate analysis was undertaken.

The presented cohort of 422 patients who were analyzed for suspected reflux disease underwent a combined $\mathrm{pH}$ and Bilitec monitoring after a manometry of the esophagus. All patients were asked to fill out the standard questionnaire of our laboratory (chapter 8). None of the patients used anti acid medication and all used only liquid meals on the day of the investigation to avoid food impaction of the Bilitec ${ }^{8}$ probe.

As has been shown by others that in the group of patients suggested having reflux disease, only about $50 \%^{32}$ has visible esophageal lesions. In this study group $48 \%$ of the patients had esophageal lesions and in $36.5 \%$ a hiatus hernia was found. The multivariate analysis of the patients showed that a hiatus hernia was associated with esophagitis suggesting the important role of a defective LES mechanism in the development of esophageal lesions. DGER exposure and elevated body 
mass index were also independent factors in the development of esophagitis.

Comparing more severe lesions (grade 3 and 4 according to the Savary and Miller classification, except Barrett's esophagus) to minor lesions (grade 1 and 2) showed that the acid exposure, the number of DGER episodes and a lower LES pressure played the most important role. In the development of more severe lesions only acid exposure was an independent factor.

For the group with Barrett's esophagus compared to the patients with esophagitis grade 1-4, the multivariate analysis showed that male sex, acid and DGER exposure played the most important role.

This study clearly demonstrates that in the pathogenesis of esophageal lesions the combined reflux of acid and duodenal content is important and that man are more prone to develop Barrett's esophagus.

\section{Medical intervention}

The success of PPIs has made that this therapy is the first option in patients with symptoms suggestive for reflux disease.

The refractory patients as was shown in our study (chapter 9) cannot be fully treated with these drugs probably because DGER plays an important role. Intervention with baclofen as described in chapter 10, successfully diminishes the reflux of DC. Because baclofen also reduces the frequency of the TLESRs, this drug could be a therapeutic option for those patients who are resistant to the regular therapy.

\section{Future perspectives}

The idea that non-acid reflux contributes to the pathophysiology of refluxrelated symptoms and lesions is rapidly gaining acceptance. ${ }^{33}$ The development of the intraluminal impedance technique, which detects all types of reflux events, has importantly contributed to this paradigm shiff. ${ }^{33.35}$ Impedance monitoring requires simultaneous $\mathrm{pH}$ monitoring to identify the acid and the non-acidic or weakly acidic reflux events. Whereas intraluminal impedance monitoring has further substantiated the occurrence and potential relevance of the non-acid component of reflux disease, the Bilitec ${ }^{\text {sits }}$ sysm is the only device apart from $\mathrm{pH}$ monitoring that provides information on the chemical nature of the refluxate. As it is clear that non-acid reflux is probably heterogeneous and may consist of neutralized gastric secretion, meal content or duodenal content, bilirubin monitoring provides a higher level of information. Whereas it seems that impedance monitoring has rapidly gained acceptance, the clinical community for some reason has been reluctant to use Bilitec ${ }^{8}$ monitoring in daily practice. 
Knowledge of pathophysiological mechanisms contributes to a more targeted therapy. As it is obvious that DC play a pathogenetic role at least in more severe esophagitis and Barrett's esophagus, future investigations should give answers to what extent and how this can be influenced. Before this is achieved first of all the role and amount of DGR should be studied.

It is still unclear whether patients with reflux disease have a greater amount of DGR, or whether the motility of the stomach that leads to clearance of refluxed bile differs. The role played by the esophagus in the prevention of reflux events and in the clearance of reflux material requires further study, including the differences in motility patterns and defense mechanisms in patients with reflux esophagitis and healthy controls.

Although we could not demonstrate a prominent role of DC in generating the typical symptom of heartburn, its relevance to the occurrence of regurgitation and especially its relevance to atypical gastrointestinal (like nausea and dyspepsia) and extra-intestinal (noncardiac chest pain, ear, nose and throat manifestations of reflux, non-allergic asthma) symptoms deserve in-depth studies.

Besides these questions of scientific interest, acceptance of the Bilitec system in clinical practice will require a number of developments. First of all the application of the system and the interpretation of the results should be standardized: Which cut off value should be adopted and which dietary restrictions are most appropriate: no dietary restrictions, some restrictions or a standardized meal schedule? In order to establish normal values of DC in the stomach and the esophagus, data should be collected from reference centers in a systematic way in a fixed location (for example antrum, corpus and fundic area and for the esophagus in the same position as the $\mathrm{pH}$ probe) in a substantial group of healthy volunteers. With this approach it could be possible to get an accepted place for the Bilitec monitoring as a diagnostic tool in reflux disease and to diminish the skepticism about the usefulness of the method.

It is clear that the role of the Bilitec ${ }^{*}$ in GERD is not as important as the $\mathrm{pH}$ measurement. It seems logic with our present knowledge that in refractory or complicated GERD the use of both diagnostic tools $\mathrm{pH}$ and Bilite $^{(8)}$ measurements should be advised. The exact place of impedance monitoring versus Bilitec monitoring in this setting will require comparative studies. However, in the absence of a treatment specifically directed at preventing reflux of duodenal contents, it is unclear whether 
determining the nature of the non-acid component would have any therapeutic impact, the results of the baclofen study are hopeful.

The effect of drugs on esophageal and stomach motility and mucosal protective substances should be further investigated. 


\section{References}

1. Lovis E, DeLooze D, Deprez P, Hiele M, Urbain D, Pelckmans P, Deviere J, Deltenre $M$. Heartburn in Belgium: prevalence, impact on daily life, and utilization of medical resources. Eur J Gastroenterol Hepatol 2002;14:279-84.

2. Gallup survey on heartburn across America. Princeton, NJ.: The Callup Organization, Inc., 1988.

3. Cadiot G, Bruhat A, Rigaud D, Coste T, Vuagnat A, Benyedder Y, Vallot T, Le Guludec D, Mignon M. Multivariate analysis of pathophysiological factors in reflux oesophagitis. Gut 1997:40:167-74.

4. Vaezi MF, Richter JE. Role of acid and duodenogastroesophageal reflux in gastroesophageal reflux disease. Gastroenterology 1996;111:1192-9.

5. Vaezi MF, Richter JE. Synergism of acid and duodenogastroesophageal reflux in complicated Barrett's esophagus. Surgery 1995;117:699-704.

6. Kaver WK, Peters JH, DeMeester TR, Ireland AP, Bremner CG, Hagen JA. Mixed reflux of gastric and duodenal juices is more harmful to the esophagus than gastric juice alone. The need for surgical therapy re-emphasized. Ann Surg 1995;222: 525-31.

7. Stein HJ, Kaver WK, Feussner H, Siewert JR. Bile acids as components of the duodenogastric refluxate: detection, relationship to bilirubin, mechanism of injury, and clinical relevance. Hepatogastroenterology 1999;46:66-73.

8. Vaezi MF, Richter JE. Duodenogastroesophageal reflux and methods to monitor nonacidic reflux. Am J Med 2001;111 Suppl 8A:160S-168S.

9. Vaezi MF, Lacamera RG, Richter JE. Validation studies of Bilitec 2000: an ambulatory duodenogastric reflux monitoring system. Am J Physiol 1994;267: G1050-7.

10. Fein M, Fuchs KH, Bohrer T, Freys SM, Thiede A. Fiberoptic technique for 24-hour bile reflux monitoring. Standards and normal values for gastric monitoring. Dig Dis Sci 1996;41:216-25.

11. Helsingen N. Esophagitis following total gastrectomy. Acta Chir Scand 1959;118: 190-201.

12. Orlando RC, Bozymski EM. Heartburn in pernicious anemia--a consequence of bile reflux. N Engl J Med 1973;289:522-3.

13. Bachir GS, Collis JL, Joffe SN. The toxicity of bile salt conjugates on human esophageal epithelium grown in tissue culfure. J Surg Res 1982;32:547-54.

14. Safaie-Shirazi S, DenBesten L, Zike WL. Effect of bile salts on ionic permeability of esophageal mucosa. Surg Forum 1973;24:424-6.

15. Lillemoe KD, Kidder GW, Harmon JW, Gadacz TR, Johnson LF, Bunte RM, Hofmann AF. Tauroursodeoxycholic acid is less damaging than taurochenodeoxycholic acid to the gastric and esophageal mucosa. Dig Dis Sci 1983;28:359-64. 
16. Muller-Lissner SA, Fimmel CJ, Sonnenberg A, Will N, Muller-Duysing W, Heinzel F, Muller R, Blum AL. Novel approach to quantify duodenogastric reflux in healthy volunteers and in patients with type I gastric ulcer. Gut 1983;24:510-8.

17. Mackie C, Hulks G, Cuschieri A. Enterogastric reflux and gastric clearance of refluxate in normal subjects and in patients with and without bile vomiting following peptic ulcer surgery. Ann Surg 1986;204:537-42.

18. King PM, Pryde A, Heading RC. Transpyloric fluid movement and antroduodenal motility in patients with gastro-oesophageal reflux. Gut 1987;28:545-8.

19. Bechi P, Pucciani F, Baldini F, Cosi F, Falciai R, Mazzanti R, Castagnoli A, Passeri A, Boscherini $S$. Long-term ambulatory enterogastric reflux monitoring. Validation of a new fiberoptic technique. Dig Dis Sci 1993;38:1297-306.

20. Tack J, Bisschops R, Koek GH. Dietary restrictions during ambulatory monitoring of duodeno-gastro-esophageal reflux. submitted for publication 2003.

21. Schindlbeck NE, Heinrich C, Stellaard F, Paumgartner G, Muller-Lissner SA. Healthy controls have as much bile reflux as gastric ulcer patients. Gut 1987;28:1577-83.

22. Fiorucci S, Distrutti E, Di Matteo F, Brunori P, Santucci L, Mallozzi E, Bigazzi U, Morelli A. Circadian variations in gastric acid and pepsin secretion and intragastric bile acid in patients with reflux esophagitis and in healthy controls. Am J Gastroenterol 1995;90:270-6.

23. Bjornsson ES, Abrahamsson $\mathrm{H}$. Nocturnal antral $\mathrm{pH}$ rises are related to duodenal phase III retroperistalsis. Dig Dis Sci 1997;42:2432-8.

24. Dalenback J, Fandriks L, Olbe L, Sjovall H. Mechanisms behind changes in gastric acid and bicarbonate outputs during the human interdigestive motility cycle. Am J Physiol 1996;270:G113-22.

25. Helm JF, Dodds WJ, Hogan WJ. Salivary response to esophageal acid in normal subjects and patients with reflux esophagitis. Gastroenterology 1987;93:1393-7.

26. Helm JF. Esophageal acid clearance. J Clin Gastroenterol 1986;8 Suppl 1:5-11.

27. Holloway RH. Esophageal body motor response to reflux events: secondary peristalsis. Am J Med 2000;108 Suppl 4a:20S-26S.

28. Kaver WK, Peters JH, DeMeester TR, Feussner H, Ireland AP, Stein HJ, Siewert RJ. Composition and concentration of bile acid reflux into the esophagus of patients with gastroesophageal reflux disease. Surgery 1997;122:874-81.

29. Caldwell MT, Lawlor P, Byrne PJ, Walsh TN, Hennessy TP. Ambulatory oesophageal bile reflux monitoring in Barrett's oesophagus. $\mathrm{Br} J \mathrm{Surg}$ 1995;82:657-60.

30. Champion G, Richter JE, Vaezi MF, Singh S, Alexander R. Duodenogastroesophageal reflux: relationship to $\mathrm{pH}$ and importance in Barrett's esophagus. Gastroenterology 1994;107:747-54.

31. Vaezi MF, Richter JE. Contribution of acid and duodenogastro-oesophageal reflux to oesophageal mucosal injury and symptoms in partial gastrectomy patients [see commenł]. Gut 1997:41:297-302. 
32. Johnsson F, Joelsson B, Gudmundsson K, Greiff L. Symptoms and endoscopic findings in the diagnosis of gastroesophageal reflux disease. Scand J Gastroenterol $1987 ; 22: 714-8$.

33. Sifrim D, Holloway R, Silny J, Xin Z, Tack J, Lerut A, Janssens J. Acid, nonacid, and gas reflux in patients with gastroesophageal reflux disease during ambulatory 24 hour $\mathrm{pH}$-impedance recordings. Gastroenterology 2001;120:1588-98.

34. Sifrim D, Silny J, Holloway RH, Janssens JJ. Patterns of gas and liquid reflux during transient lower oesophogeal sphincter relaxation: a study using intraluminal electrical impedance. Gut 1999;44:47-54.

35. Sifrim D, Holloway R, Silny J, Tack J, Lerut A, Janssens J. Composition of the postprandial refluxate in patients with gastroesophageal reflux disease. Am J Gastroenterol 2001;96:647-55. 


\section{Chapter 12}

Summary 
Chopter 12 


\section{Summary}

Regurgitation of stomach content to the esophagus can be the cause of symptoms like heartburn, chest pain and of esophageal mucosal lesions like esophagitis, strictures, Barrett's mucosa or esophagus carcinoma. Acid and pepsin are the main constituents of the refluxate, which have been studied intensively and have been found to be responsible for many complaints and lesions. However, also in situations where no acid is produced by the stomach and after total gastrectomy, symptoms and lesions of the esophagus have been observed, likely to be caused by reflux of duodenal contents.

The measurement of acid reflux has been standardized and ambulatory 24 hours esophageal $\mathrm{pH}$ monitoring is at present a widely used, validated, method. About 10 years a fiber-optic spectophotometer system, the Bilitec ${ }^{18}$, became available, which allows to measure reflux of duodenal fluid in a semi-quantitative way. The system consists of a miniaturized probe of $5 \mathrm{~mm}$ diameter with an open grove across which two wavelengths of light are emitted and material sampled. Bilirubin, the most common pigment in bile, has a characteristic absorbance spectrum, and by continuous monitoring of the absorbance of two light emitting diodes at two different wavelengths $(470 \mathrm{~nm}$ with a reference of 565 $\mathrm{nm}$ ), the presence of bilirubin can be detected. The portable photodiode system converts the light into an electrical signal and after amplification the signals are processed by an integrated microcomputer and the difference in absorption between the two diodes is calculated. Dietary restrictions are necessary to avoid food impaction and increases in absorbance that are not related to bile, for instance when drinking coffee.

This thesis describes further studies aimed at clarifying the role of duodeno-gastric reflux to the esophagus (DGER) in patients with gastroesophageal reflux disease (GERD).

Chapter 1 summarizes the current knowledge on the role of gastric and duodenal fluid in the genesis of typical and atypical complaints and mucosal lesions. The pathogenetic roles of gastric and duodenal fluid is discussed, as well as the most widely used methods to investigate reflux disease. We also provided a short overview of the current therapeutic approach to GERD. 
A brief outline of the thesis is summarized in chapter 2. An attempt is made to provide further insight into the role of DGER in the development of esophageal symptoms and lesions. As we based most of the investigations on the use of the Bilitec ${ }^{\text {(i) }}$ probe, we also needed to assess the most appropriate way to apply the Bilitec ${ }^{\bar{B}}$ method in the study of reflux disease.

The following questions were addressed: Does the Bilitec ${ }^{8}$ probe adequately detect appearance and disappearance of duodenal contents in the esophagus? Which dietary restrictions are required during Bilitec ${ }^{\mathbb{B}}$ monitoring? How should Bilitec ${ }^{\circledR}$ results be analyzed and interpreted? Which factors underlie reflux of duodenal contents to the stomach? How is duodenal contents cleared from the esophagus? Does DGER contribute to the occurrence of symptoms in patients with GERD? What is the contribution of DGER, relative to acid reflux, in the genesis of esophageal lesions in GERD patients? Is DGER a factor that plays a role in the incomplete response of GERD to acid suppressive therapy? Does DGER respond to a promotility type of treatment?

In chapter 3 the motility pattern underlying duodeno-gastric reflux in man is investigated. In an experimental setting ten healthy volunteers underwent stationary gastro-duodenal manometry combined with duodenal and antral Bilitec ${ }^{\text {B }}$ measurements. A liquid meal was given after a fixed time period or if the healthy volunteer had two migrating motor complex $(M M C)$, after which the recording was continued for another five hours. In a second group of subjects, the same protocol was applied, but two hours postprandially erythromycin was administered intravenously to induce a premature gastric phase III of the MMC.

In the preprandial period all volunteers experienced short periods of duodeno-gastric reflux during MMC phase II. On average $39 \pm 28$ after the meal DGR occurred in the stomach and was cleared after $242 \pm 23$ minutes. The administration of the prokinetic drug increased antral motility and induced a premature MMC phase III. Clearance of DGR was significantly enhanced by the administration of erythromycin, but no close temporal relationship between the induced $M M C$ phase III and the clearance was observed. It was concluded that DGR is a normal physiological phenomenon occurring in the postprandial period and that the administration of erythromycin induced a faster DGR clearance from the stomach depending on enhanced antral phasic contractility, and not temporarily related to the occurrence of MMC phase III. 
In a combined radionuclide, $\mathrm{pH}$ and Bilitec ${ }^{*}$ study the esophageal clearance of acid and bile was studied (chapter 4). On a separate day duodenal content (DC) collection took place in ten healthy volunteers after stimulation with a liquid meal during obstruction of the duodenal bulb with a balloon. On the study day, the subjects were lying under a gamma camera after the introduction of a $\mathrm{pH}$ and Bilitec ${ }^{B}$ probe $5 \mathrm{~cm}$ above the LES and an infusion catheter just below the upper esophagus sphincter. The two fluids, acid and DC, were mixed with $\mathrm{Tc}^{99 \mathrm{~m}}$ pertechnetate and separately introduced via the catheter into the esophagus in $5 \mathrm{ml}$ boluses. Four sessions per fluid were performed, twice with and twice without aspiration of saliva. The volunteers were instructed to swallow with a frequency once every 20 seconds.

Volume clearances of acid and DC fluid were similar and no difference was seen with aspiration of saliva. DC chemical clearance was significantly faster than acid fluid. The chemical clearance for acid was significantly prolonged from $217 \pm 15$ seconds to $324 \pm 30$ seconds during saliva aspiration. This difference was not observed for DC fluid chemical clearance which was $131 \pm 27$ seconds without aspiration and $176 \pm 36$ seconds with saliva aspiration. Saliva plays a major role in the chemical clearance of acid only. DC chemical clearance is faster than acid fluid whereas the volume clearances of both fluids are similar, independently of saliva aspiration.

In chapter 5 we investigated the necessity for dietary restrictions during ambulatory monitoring of DGER. Due to its construction, food impaction of the Bilitec ${ }^{\text {p }}$ probe is possible making the measurements difficult to interpret. To avoid food impaction some groups allow only liquid meals during the measurement period whereas others omit the meal and postprandial periods from the analysis. To investigate the requirements of liquid meals during Bilitec ${ }^{3}$ monitoring, 40 healthy volunteers and 210 GERD patients were randomly assigned to either consuming liquid or solid meals.

During bile reflux monitoring, major meal artifacts occurred in 19\% of the patients using solid meals, but in none of the patients using liquid meals. With liquid meals, but not with solid meals, a progressive increase in DGER occurred with increasing severity of endoscopic lesions. Similarly, with liquid meals, but not with solid meals, the prevalence of pathological exposure to DGER increased with increasing severity of endoscopic lesions. With liquid meals, the results of $\mathrm{pH}$ monitoring and bile reflux monitoring correlated better than with solid meals. We conclude that ambulatory Bilitec monitoring requires the use of liquid 
meals, as the use of solid meals is associated with too many meal artifacts and a poorer correlation with acid reflux and severity of endoscopic lesions.

Another methodological aspect of the Bilitec ${ }^{(}$method is studied in chapter 6 . In vitro observations concerning bile reflux monitoring suggest

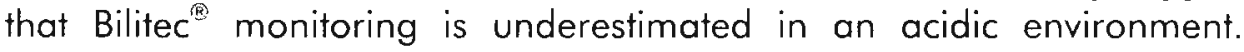
Other studies suggested that the area above the cut-off level of bilirubin absorbance would provide a more adequate quantitative marker for reflux of duodenal contents. Therefore the aim of the study was to investigate whether correction for intra-esophageal acidity and area above cut-off during Bilitec ${ }^{\text {(2) }}$ monitoring affects the results and the correlation with $\mathrm{pH}$ measurement and esophageal lesions.

84 Patients ( 46 man) with a mean age of $46 \pm 2.7$ years were evaluated for suspected gastro-esophageal reflux disease. After an upper gastrointestinal endoscopy an ambulatory 24 hours esophageal $\mathrm{pH}$ and Bilitec $(\AA)$ monitoring was performed. The computer software calculated the total area, percent total time and corrections for bilirubin absorbance based on literature data (for acidified bile 0.06 for $\mathrm{pH}<3.6$ and 0.21 for $\mathrm{pH}<2.6$ ). Endoscopy revealed esophagitis grade $1-2$ and $3-4$ in 23 and 16 patients respectively. With increasing esophagitis severity a progressive increase of mixed reflux was observed. A pathologic Bilitec ${ }^{\circledR}$ monitoring was present in the same 35 patients before and after correction and the correlation between the $\mathrm{pH}$ measurement and percent time of bile reflux was not improved by correction for intra-esophageal $\mathrm{pH}$. We conclude that correction for intra-esophageal $\mathrm{pH}$ has only a minor effect on the results of ambulatory Bilitec monitoring. The correlation of Bilitec with acid reflux and with esophageal lesions does not improve by taking the surface rather than the percent of time above the cut-off level for bilirubin absorbance.

In about $50 \%$ of patients with GERD mucosal lesions of the esophagus are seen during endoscopy suggesting that symptoms are not always correlated to esophagitis alone. In patients with GERD mixed reflux of acid and duodenal contents frequently occur but it is not clear if only acid reflux causes symptoms. Therefore the aim of the study, presented in chapter 7, was to establish the contribution of acid and DGER to symptoms in patients with GERD. After endoscopy and esophageal manometry, 72 patients ( 37 women), with a mean age of $45 \pm 2$ years, underwent a 24 hours ambulatory $\mathrm{pH}$ and Bilitec ${ }^{B}$ monitoring. The patients were instructed to press the marker button when experiencing typical symptoms. For each symptom episode, minimal $\mathrm{pH}$ and maximal 
bilirubin absorbance in both a two and a four minutes interval were calculated. For each patient, the symptom index (SI) and symptomassociation probability (SAP) for acid and for bile reflux were determined. A total of 544 symptom episodes were identified; using a two minutes interval, 28\% were associated with acid reflux, 9\% with DGER and $12 \%$ with mixed reflux. No significant difference was found when a four minutes interval was used. A positive $\mathrm{SI}$ for acid reflux was present in $21 \%$ of the patients and for DGER in $14 \%$. All patients with a positive SI for DGER had also a positive SI for acid reflux. A positive SAP for acid reflux was present in $22 \%$ of the patients, for DGER in $7 \%$ of the patients and for mixed reflux in 10\% of the patients. From this study it can be concluded that in patients with presumed GERD, typical symptom episodes are more related to acid reflux than to DGER. Thus DGER does not play a major role in producing typical esophageal symptoms.

A study of large cohort of patients investigated for GERD is presented in chapter 8 . In 422 patients a combined 24 hours $\mathrm{pH}$ monitoring and Bilitec $^{\widehat{\varepsilon}}$ was performed after endoscopic and manometric investigations of the upper $\mathrm{Gl}$ tract. In addition, demographic variables, smoking and alcohol consumption were registered. In a univariate analysis we identified factors that were associated with presence and severity of esophageal lesions. The significant factors were subsequently entered in a multivariate analysis to calculate the independent risk factors for the presence of reflux esophagitis versus normal endoscopy, the presence of low-grade (Savary and Miller grade 1 and 2) versus high-grade lesions (Savary and Miller grade 3 and 4) and the presence of Barrett's esophagitis.

In total 221 men and 201 women were included with a mean age of $46.8 \pm 0.7$ years. In $46 \%$ of patients esophageal lesions could be detected by endoscopy; $36 \%$ had grade $1-2$ and $10 \%$ had grade $3-4$ esophagitis (including Barrett's esophagus which was 7\%). The presence of esophagitis was associated with the presence of a hiatus hernia, a higher body mass index and with esophageal DGER exposure. The severity of esophagitis was associated with esophageal acid exposure and the presence of Barrett's esophagus with male sex, esophageal exposure to DGER and acid. These results confirm that the presence of esophageal lesions in GERD is multifactorial, including male sex, the presence of a hiatus hernia; higher body mass index, esophageal acid and DGER exposure.

In chapter 9 the characteristics of a group of GERD patients, refractory to proton pump inhibitors, is described. Although the majority of patients 
with GERD symptoms and lesions can be treated effectively with proton pump inhibitors (PPIs), a subset of patients has persistent reflux symptoms. In the studied group an endoscopy and combined ambulatory $\mathrm{pH}$ and Bilitec monitoring was performed to investigate the role of acid and DGER while PPIs were continued. In total 65 patients ( 32 men) with a mean age of $44 \pm 2$ years were included without Barrett's esophagus and with persistent heartburn or regurgitation during standard PPI treatment. In 33 patients (51\%) the esophagitis persisted. Seven patients (11\%) had only pathological acid exposure, $25(38 \%)$ only pathological DGER exposure and $17(26 \%)$ had pathological exposure to both acid and DGER. Acid exposure under PPI was positive in only $37 \%$, but adding Bilitec $^{6}$ increased the diagnoses of persisting reflux to $75 \%$. Patients with persisting esophagitis had similar acid exposure, but significantly higher DGER exposure than those without esophagitis. The highest prevalence of esophagitis was found in patients with pathological exposure to both acid and DGER. The symptom scores did not differ according to the type of reflux. The results of this study suggest that combined $\mathrm{pH}$ and Bilitec ${ }^{(\otimes)}$ monitoring allows demonstrating ongoing pathological reflux in $75 \%$ of patients with medically poorly responsive reflux disease. Persistent esophagitis in these patients seems to depend on a synergistic action of acid reflux and DGER.

Medical intervention for GERD with PPIs is, as described above, not always effective in treating symptoms and esophageal mucosal lesions. Other treatment regimes have been suggested as for example with the $G_{A B A}$ agonist baclofen that was shown to inhibit the occurrence of transient lower esophageal sphincter relaxations (TLESRs). The results of the medical intervention with baclofen are described in chapter 10. In this study, patients with persisting non-acid duodenal reflux under optimal PPI therapy were included to investigate the therapeutic effect of add-on therapy with baclofen. Patients were selected for persisting reflux symptoms, normal $\mathrm{pH}$ monitoring and pathological Bilitec monitoring during PPI treatment. In all patients an upper gastrointestinal endoscopy and reflux symptom score had been performed at the beginning of the study. Baclofen $5 \mathrm{mg}$ three times daily was associated to the PPI treatment, and increased with $5 \mathrm{mg}$ every 4 th day until a maintenance dose of $20 \mathrm{mg}$ three times daily was reached. Reflux symptom questionnaire, ambulatory $\mathrm{pH}$ and Bilitec $^{8}$ monitoring were repeated four days later under ongoing PPI and baclofen treatment. Sixteen patients (11 women) with a mean age of $46 \pm 3$ years with persistent heartburn or regurgitation, in spite of PPI therapy, for at least 3 months were included. Before treatment, gastroscopy revealed erosive 
esophagitis in seven patients (five with grade I, two with grade II according to the Savary and Miller classification) and normal acid exposure. All patients had pathological duodenal reflux exposure measured with the Bilitec ${ }^{3}$ (on average $13.8 \%$ of time). After addition of baclofen $20 \mathrm{mg}$ three times daily, acid exposure was still normal but DGER diminished significantly to $6.1 \%$ of time. The number of DGER episodes diminished and the number of long lasting duodenal reflux episodes (>5 minutes) decreased significantly. The cumulative severity score for 14 reflux symptoms decreased from $10.3 \pm 1.7$ to $5.8 \pm 1.3$ $(p<0.01)$. Side effects were mild; only four patients reported nausea or drowsiness. It can be concluded that the $G_{A B A}$ receptor agonist baclofen improves DGER and associated reflux symptoms that persist during PPI therapy.

GERD is a multifactorial disease, as discussed in chapter 11. DGER plays a role in the genesis of more severe esophageal lesions including Barrett's esophagus. Although the role of Bilitec ${ }^{3}$ monitoring is still debated, no other ambulatory method exists to prove DGER to be present. The Bilitec ${ }^{8}$ monitoring deserves a place in the diagnostic armamentarium of patients which have refractory reflux disease and should be performed in reference gastrointestinal units in a standardized way. 


\section{Chapter 13}

Samenvatting 
Chapter 13 


\section{Samenvatling}

Terugvloed (reflux) van maaginhoud naar de slokdarm (oesophagus) kan de oorzaak zijn van symptomen zoals zuurbranden, pijn op de borst, opboeren van zuur en van slokdarm slijmvlies beschadigingen zoals slokdarm ontsteking, slokdarm-vernauwingen, Barrett slijmvlies en slokdarm-tumoren. Het is vooral zuur met pepsine dat verantwoordeliik gesteld kan worden voor deze letsels en de klachten.

Gebleken is echter dat bij aandoeningen waarbii geen zuur meer geproduceerd wordt door de maag (achloorhydrie) en na verwijderen van de maag, slokdarmslijmvlies beschadigingen kunnen optreden die veroorzaakt worden door teruguloed van dunne darm inhoud (duodenaal vocht) naar de slokdarm.

De combinatie van maag en duodenum sappen speelt waarschijnlijk een versterkende rol bij de slijmvlies beschadiging, zoals die wordt gezien bij het Barrett slijmvlies.

Zoals zure reflux gemeten kan worden met een gevalideerde methode, de ambulante $\mathrm{pH}$ metrie, kan sinds ruim 10 jaar terugvloed van duodenum-inhoud gemeten worden met de Bilitec ${ }^{B}$ methode. Het is een semi-kwantitatieve methode waarbii gebruik gemaakt wordt van het verschil in lichtabsorptie. De te meten vloeistof komt in een kleine sensor die bestaat vit een cubje met twee diodes die licht vitstralen van een bepaalde golflengte; $470 \mathrm{~nm}$ met een referentie frequentie van $565 \mathrm{~nm}$. De in het duodenaal vocht aanwezige kleurstof bilirubine die met de galzouten door de lever wordt uitgescheiden heeft een absorptiespectrum van $470 \mathrm{~nm}$. Het draagbare photodiode systeem zet licht om in een elektrisch signaal dat door de computer omgezet wordt waarna het verschil in absorptie berekend kan worden.

Deze methode is gevoelig voor vloeistoffen zoals koffie en voedsel dat eventueel in het meetcubje van twee $\mathrm{mm}$ kan komen waardoor de meting wordt verstoord en de meetwaarden niet meer juist geïnterpreteerd kunnen worden.

In dit proefschrift wordt de rol beschreven van duodenaal vocht, dat via de maag terugvloeit naar de slokdarm bii patiënten met gastrooesophageale reflux ziekte (GERD).

In hoofdstuk 1 wordt in een literatuur overzicht de rol van maag en duodenum vloeistof ten aanzien van klachten en letsels beschreven. Zowel de typische als atypische klachtenpresentatie, het ontstaansmechanisme van reflux en de consequenties van zure- en duodenaal vocht reflux worden toegelicht. $\mathrm{Na}$ de beschrijuing van de meest 
gebruikte onderzoeksmethode, worden in het kort bestek de thans gangbare behandelingsvormen beschreven.

Het doel van het onderzoek, beschreven in dit proefschrift, wordt toegelicht in hoofdstuk 2. Getracht wordt een antwoord te vinden op de volgende vragen: meet de Bilitec ${ }^{3}$ exact de aanwezigheid van duodenaal vocht in de slokdarm? Welke dieet maatregelen zijn noodzakelijk bij het gebruik van de Bilitec ${ }^{8}$ meting? Hoe moeten de resultaten van de Bilitec meting geanalyseerd en geïnterpreteerd worden? Welke factoren zijn van invloed bij de reflux van duodenaalvocht naar de maag? Hoe wordt vloeistof vit de slokdarm verwijderd (geklaard)?

Draagt DGER bii aan het optreden van symptomen bii patiënten met GERD? Wat is de rol van DGER in relatie tot zure reflux bij het ontstaan van slokdarmletsels in patiënten met GERD? Speelt DGER een rol bii patiënten met GERD die onvoldoende reageren op zuur onderdrukkende therapie? Kan DGER beïnvloed worden door een motiliteit stimulerende behandeling?

Hoofdstuk 3 bevat de resultaten van een experimentele studie waarbii de mechanismen bestudeerd werden die waarschijnlijk een rol spelen bii reflux van duodenaal vocht naar de maag. Tien gezonde vrijwilligers kregen een gecombineerde drukmeting in de maag (antrum) en dunne darm met Bilitec ${ }^{\$ 8}$ metingen in het antrum en duodenum.

De toediening van een vloeibare maaltijd vond plaats nadat de vrijwilligers vier uur nuchter waren of nadat twee migrerende motor complexen (MMC) opgetreden waren. $\mathrm{Na}$ de maaltijd werd in een deel van de studie viif uur gemeten, of totdat een $M M C$ optrad. In het andere deel van de studie kregen de vrijwilligers twee uur na de maaltijd erythromycine toegediend.

In de tijd voorafgaand aan de maaltijd hadden alle vrijwilligers korte perioden van terugvloed van duodenaal vocht naar de maag (DGR) voornamelijk gedurende MMC fase II. Gemiddeld $39 \pm 28$ na de maaltijd trad DGR op en dat was na gemiddeld $242 \pm 23$ minuten uit de maag verdwenen. De toediening van het prokineticum erythromycine verhoogde de antrale motiliteit en induceerde premature MMC fase III activiteit, waardoor duodenaal vocht uit de maag werd verwijderd. DGR is een normaal physiologisch verschijnsel dat na de maaltiid optreedt. De toediening van erythromycine induceert een snellere DGR klaring uit de maag als gevolg van verhoogde antrale fasische contractiliteit, en is niet gerelateerd aan het optreden van een MMC fase III. 
De mechanismen die aan de basis liggen van de slokdarm klaring voor duodenaal vocht en zure vloeistof worden besproken in hoofdstuk 4. De studie bestond uit twee onderdelen. Ten eerste de fase waarin na afsluiting van het duodenum en stimulatie met een vloeibare maaltiid duodenaal vocht werd afgezogen. En de tweede sessie waarbii zowel de opgezogen vloeistof alsook aangezuurd citroenzuur, beide gemengd met $\mathrm{Tc}^{99 \mathrm{~m}}$ pertechnetaat ingespoten werd. De tien proefpersonen werden, na plaatsing van een $\mathrm{pH}$ en Bilitec sonde $5 \mathrm{~cm}$ boven de onderste slokdarm sluitspier en een kleine katheter voorbii de bovenste slokdarmsfincter, onder de gamma camera gelegd. In bolussen van $5 \mathrm{ml}$ werd de vloeistof via de katheter in de slokdarm gespoten; twee sessies waarbii speeksel werd afgezogen en twee sessies zonder afzuigen. De proefpersonen werden gevraagd om de 20 seconden te slikken. De proef werd zowel voor duodenaal vocht als zure vloeistof uitgevoerd. Volume klaring van de zure als duodenaal vocht waren gelijk onafhankeliik van speeksel aspiratie. De chemische klaring daarentegen was significant verlengd voor de zure vloeistof van $217 \pm 15$ seconden naar $324 \pm 30$ seconden tijdens speeksel aspiratie. Dit verschil werd niet gevonden bij de chemische klaring van het duodenaal vocht; de klaring was $131 \pm 27$ versus $176 \pm 36$ met afzuigen van speeksel. De chemische klaring van duodenaal vocht was significant sneller dan van de zure vloeistof. Speeksel speelt alleen een belangrijke rol bij de chemische klaring van zure vloeistof. De chemische klaring van een duodenaal vocht is sneller dan een zure vloeistof, maar de volume klaring voor beide vloeistoffen is overeenkomend en niet te beïnvloeden door speeksel.

In hoofdstuk 5 wordt de rol beschreven van diëtaire maatregelen tijdens het onderzoek met de Bilitec ${ }^{*}$. Door de constructie van de Bilitec ${ }^{\text {* }}$ bestaat de mogelijkheid dat voedsel tussen het cupje raakt waardoor de meting gestoord kan worden. Diverse onderzoekers hebben dit probleem opgelost door voedingsbeperkingen te adviseren of perioden van het onderzoek na de maaltijd niet in de berekeningen op te nemen. In onze studie werden de resultaten vergeleken van het gebruik van vaste en vloeibare voeding. Twee groepen werden gerandomiseerd; 40 gezonde vrijwilligers die of normale of vloeibare voeding consumeerden en 211 patiënten met GERD. Er werd een gecombineerde Bilitec ${ }^{B}$ en $\mathrm{pH}$ metrie uitgevoerd gedurende 24 uur. Bii de patiëntengroep die vast voedsel consumeerden traden significant meer maaltijdartefacten op (19\%) ten opzichte van diegenen die vloeibare maaltijden consumeerden. Er werd een betere correlatie gevonden tussen $\mathrm{pH}$ metrie en Bilitec ${ }^{* 0}$ metingen in de groep die vloeibare maaltijden gebruikte tijdens het onderzoek. Wii 
adviseren vanuit dit onderzoek vloeibare maaltijden te gebruiken tijdens de: 24 uur Bilitec ${ }^{*}$ meting.

Een ander methodologisch aspect van de Bilitec methode wordt in hoofdstuk 6 behandeld. In vitro observaties betreffende de Bilitec meting suggereren dat in een zuur milieu een te lage absorptie waarde voor bilirubine wordt verkregen. Andere studies tonen dat het gebied boven het cut-off punt een adequatere kwantitatieve bepaling zou zijn om reflux van DC te meten.

Het doel van het onderzoek was om te bepalen of correctie voor de zuurtegraad in de slokdarm en het gebied boven de cut-off waarde tijdens de Bilitec meting de correlatie van de $\mathrm{pH}$ meeting en slokdarm letsels beïnvloedt.

Vierentachtig patiënten (46 mannen) met een gemiddelde leeftijd van $46 \pm 2.7$ jaar werden onderzocht in verband met GERD. Na een gastroscopie werd een gecombineerde ambulante 24 uurs oesophageale $\mathrm{pH}$ en Bilitec meting uitgevoerd. De computer software berekende het totale gebied boven de cut-off waarde 0.14 , het percentage van de totale tiijd gecorrigeerd voor bilirubine absorptie gebaseerd op literatuur data (voor $\mathrm{pH}<3.6$ factor 0.06 en voor $\mathrm{pH}<2.6$ factor 0.21 ). Endoscopisch onderzoek toonde slokdarmontsteking graad 1-2 en 3-4 bii respectieveliik 23 en 16 patiënten. Bii toenemende ernst van de slokdarmontsteking werd een toename van gemengde reflux aangetoond. Pathologische Bilitec ${ }^{(*)}$ meting werd gevonden bij dezelfde 35 patiënten voor en na correctie en de correlatie tussen de $\mathrm{pH}$-meting en het percentage galreflux was niet significant veranderd na correctie voor de zuurtegraad in de slokdarm. Correctie voor zuurtegraad in de slokdarm heeft slechts een beperkt effect op de resultaten van de ambulante Bilitec meting. De correlatie van de Bilitec met zure reflux en met oesophageale letsels verbetert niet door het gebied boven de cutoff waarde te nemen in plaats van het percentage van de tijd voor bilirubine absorptie.

Bii 50\% van de patiënten met GERD worden slijmvlies letsels in de slokdarm gezien tijdens endoscopie hetgeen de suggestie wekt dat symptomen niet alleen gecorreleerd zijn aan de slokdarmontsteking. Bii patiënten met GERD treedt gemengde reflux van zuur en duodenaal vocht frequent op, maar het is niet duidelijk of de symptomen alleen veroorzaakt worden door zure reflux. Het doel van het onderzoek, dat in hoofdstuk 7 wordt beschreven, is om de relatie van zuUr en DGER ten aanzien van symptomen te bepalen bij patiënten met GERD. 
Na een endoscopie en slokdarm manometrie, werd bij 72 patiënten (37 vrouwen), met een gemiddelde leeftijd van $45 \pm 2$ jaar, een 24 uurs ambulante $\mathrm{pH}$ en Bilitec meting vitgevoerd. De patiënten werden geïnstrueerd de voor hen kenmerkende symptomen aan te geven door op de knop te drukken van het meetkastje. Voor elke symptoom episode werd de minimale $\mathrm{pH}$ en maximale bilirubine absorptie voor een 2 en 4 minuten interval berekend. Voor elke patiënt werd de symptoom index (SI) en "symptom association probability" (SAP) voor zuur en galreflux bepaald. Totaal werden er 544 symptoom episoden geregistreerd. Daarvan was $28 \%$ geassocieerd met zure reflux, $9 \%$ met DGER en $12 \%$ met gemengde reflux bij gebruik van het twee minuten interval. Geen significant verschil werd gevonden wanneer het vier minuten interval werd gebruikt. Een positieve SI voor zure reflux was aanwezig bii $21 \%$ van de patiënten en voor DGER bij 14\%. Alle patiënten met een positieve SI voor DGER hadden ook een positieve SI voor zure reflux. Een positieve SAP voor zure reflux werd gevonden in $22 \%$ van de patiënten, voor DGER bii $7 \%$ van de patiënten en $10 \%$ voor gemengde reflux. Deze studie toont dat bij patiënten met GERD, symptoom episodes duidelijker gerelateerd zijn aan zure reflux dan aan DGER. DGER speelt dus geen belangrijke rol bij het ontstaan van de typische slokdarmsymptomen.

Studie resultaten van een grote groep van 422 patiënten met GERD worden beschreven in hoofdstuk 8 . Bij deze patiënten werd een gecombineerde 24 uurs $\mathrm{pH}$ meting en Bilitec ${ }^{*}$ uitgevoerd nadat een gastroscopie en slokdarmmanometrie was verricht. Tevens werden patiënt specifieke gegevens verzameld, zoals roken, het gebruik van alcohol en demografische variabelen. In een univariaat analyse werden factoren bepaald die significant verschillend waren voor de verschillende groepen: reflux slokdarm ontsteking versus normale endoscopie, lage graad (Savary en Miller graad 1 en 2) versus hoge graad letsels (Savary en Miller graad 3 en 4) en slokdarmontsteking (graad 1 -4 zonder Barrett slokdarm) versus Barrett slokdarm. Met deze significante variabelen werd met een multivariaat analyse gezocht naar onafhankelijke factoren.

In totaal werden 221 mannen en 201 vrouwen geïncludeerd met een gemiddelde leeftiid van $46.8 \pm 0.7$ jaar. $B$ ii $46 \%$ van de patiënten werd tijdens de endoscopie slokdarmontsteking vastgesteld; $36 \%$ had graad $1-2$ en $10 \%$ had graad 3-4 slokdarmontsteking (7\% Barrett slokdarm). De aanwezigheid van slokdarmontsteking was geassocieerd met de aanwezigheid van een hiatus hernia, een hogere body mass index en met DGER expositie van de slokdarm. De ernst van de slokdarmontsteking was geassocieerd met expositie van zuur en de aanwezigheid van een Barrett slokdarm was geassocieerd met het 
manneliijk gesiacht, de oesophageale expositie van zuur en DGER. Deze resultaten bevestigen de hypothese dat de oorzaak van oesophageale letsels in patiënten met GERD multifactorieel is; het mannelijk geslacht, de aanwezigheid van een hiatus hernia, een hoge body mass index en oesophageale expositie van zuur en DGER zijn de onafhankelijke factoren hiervoor.

In hoofdstuk 9 worden de karakteristieken van een groep patiënten met GERD beschreven die therapie resistent zijn aan proton pomp inhibitoren (PPIs). Ofschoon de meerderheid van de patiënten met GERD succesvol behandeld kunnen worden voor symptomen en slokdarmontstekingen met PPls, blijft er een kleine groep patiënten over die klachten blijft houden. Bii de onderzochte groep werd een gecombineerde ambulante $\mathrm{pH}$ en Bilitec ${ }^{8}$ meting vitgevoerd onder PPI behandeling om de rol van zure en DGER te bestuderen. In totaal werden 65 patiënten (32 mannen) met een gemiddelde leeftiid van $44 \pm 2$ jaar geïncludeerd zonder Barrett slokdarm en met persisterend zuurbranden of regurgitatie tijdens standaard PPI behandeling.

Bii 33 patiënten (51\%) persisteerde de slokdarmontsteking, zeven patiënten (11\%) hadden alleen pathologische zure reflux, $25(38 \%)$ alleen pathologische DGER en bij 17 (26\%) werd een gemengde pathologische reflux aangetoond. Pathologische zure reflux onder PPI behandeling was positief bii slechts $37 \%$. Met inbegrip van de Bilitec meting liep de pathologische reflux op naar 75\%. Patiënten met persisterende slokdarmontsteking hadden gelijke zure reflux maar significant hogere DGER in vergelijking met patiënten zonder slokdarmontsteking. De hoogste prevalentie van slokdarmontsteking werd gevonden in de groep patiënten met gemengde pathologische reflux. Met behulp van de symptoom score kon geen onderscheid gemaakt worden met betrekking tot een bepaald type reflux. Uit de resultaten van deze studie blijkt dat met gecombineerde $\mathrm{pH}$ metrie en Bilitec $^{\text {in. }}$ bij patiënten die onvoldoende reageren op medicamenteuze behandeling voor GERD, bij 75\% persisterende pathologische reflux aangetoond kan worden. Persisterende slokdarmontsteking bij deze patiëntengroep lijkt te berusten op de synergistische werking van zure reflux en DGER.

Medicamenteuze behandeling met PPIs van patiënten met GERD is, zoals boven beschreven, niet altijd succesvol met betrekking tot symptomen en oesophageale letsels. Andere behandelmogelijkheden worden voorgesteld zoals bijvoorbeeld met de $\mathrm{GABA}_{в}$ agonist baclofen dat een remmende werking heeft op het optreden van de kortstondige 
ontspanning van de sluitspier van de onderkant van de slokdarm (transient lower esophagus sphincter relaxations (TLESRs)). De resultaten van de medicamenteuze interventie met baclofen worden beschreven in hoofdstuk 10. Tijdens deze studie werden patiënten geïncludeerd met persisterende DGER onder optimale PPI behandeling om het therapeutisch effect van baclofen te bestuderen.

Een subgroep van GERD patiënten met refractaire symptomen, tijdens de behandeling met PPIs, heeft DGER. Patiënten werden geselecteerd wanneer zii blijvende reflux klachten hadden met een normale $\mathrm{pH}$ meting en pathologische Bilitec ${ }^{(8)}$ meting tijdens de PPI behandeling.

$\mathrm{Bii}$ alle patiënten werd een gastroscopie en reflux symptoom score aan het begin van de studie uitgevoerd. Baclofen $5 \mathrm{mg}$ drie maal daags werd toegevoegd aan de PPI behandeling en verhoogd om de drie dagen met $5 \mathrm{mg}$ totdat een onderhoudsbehandeling van drie maal daags $20 \mathrm{mg}$ was bereikt. De reflux symptoom vragenlijst, de ambulante $\mathrm{pH}$ meting en Bilitec ${ }^{\mathbb{B}}$ meting werden herhaald vier dagen na instelling op de maximum dosis. Zestien patiënten (11 vrouwen) met een gemiddelde leeftijd van $46 \pm 3$ jaar met persisterende zuurbranden of regurgitatie, onder adequate PPI behandeling voor ten minste drie maanden, werden geïncludeerd. Vóór de behandeling werd bii zeven patiënten een slokdarmontsteking vastgesteld (vijf met graad 1, twee met graad 2, volgens de Savary en Miller classificatie) en bii alle patiënten werd een normale zuur expositie van de het onderste gedeelte van de slokdarm gevonden. Alle patiënten hadden pathologische DGER gemeten met de Bilitec ${ }^{*}$ (gemiddeld $13.8 \%$ van de totale tijd). $\mathrm{Na}$ toevoeging van baclofen $20 \mathrm{mg}$ drie maal daags, bleef de zuur expositie van de slokdarm normaal, maar was de DGER significant gedaald naar $6.1 \%$ van de totale tiij. Het aantal DGER episoden was verminderd en het aantal langdurige reflux episoden (>5 minuten) was significant afgenomen. De cumulatieve ernst voor 14 reflux symptomen daalde van $10.3 \pm 1.7$ naar $5.8 \pm 1.3$ ( $p<0.01$ ). Bijwerkingen waren mild; slechts vier patiënten hadden last van misselijkheid en duizeligheid. In de groep patiënten die onder PPI onderhouds behandeling met een klachten bleven houden verminderde de $\mathrm{GABA}_{в}$ receptor agonist baclofen de symptomen en de DGER.

GERD is een multifactoriële aandoening zoals onder andere blijkt vit de discussie van de in de thesis weergegeven onderzoeken (hoofdstuk 11). DGER speelt een rol bij het ontstaan en mogelijk onderhouden van slokdarmontsteking en Barrett slokdarm. Ofschoon de rol van de Bilitec ${ }^{*}$ meting discutabel is, is het thans de enige ambulante methode om DGER aan te tonen. 
De Bilitec ${ }^{*}$ meting verdient een plaats in het diagnostisch instrumentarium voor patiënten met refractaire reflux ziekte en wordt het best uniform in referentie centra voor maag darm leverziekten vitgevoerd. 
Dankwoord 


\section{Dankwoord}

Met de stichting van de Cisterciënzers orde in 1098 in de bossen nabii Cîteaux in Frankrijk door Robert van Molesme en Albericus en Stefanus Harding wordt een begin gemaakt met de systematische ontginning en ontwikkeling van Europa. De monniken legden zich niet alleen toe op de landbouw maar ook op experimenteel wetenschappelijk onderzoek, theologische navorsing en contemplatie. Kenmerkend voor deze orde was het leven in de natuur, teruggetrokken in de stilte om op deze manier zo dicht mogelijk bij de schepping, dus bij God, te zijn. In korte tijd ontstond een zeer vitgebreid netwerk van abdijen dat de basis legde voor de hedendaagse maatschappii. Een zeer harmonieuze bouwstijl, de Romaanse, is een kunstvorm die is overgeleverd en nog steeds door haar pure schoonheid velen boeit. De Franse Revolutie maakte een einde aan deze orde. In de negentiende eeuw ontstond een vernieuwde vorm, de Trappisten orde, bekend van het goede bier (Westvleteren), die nog heden ten dage te vinden zijn, gelegen in afgelegen gebieden.

Kenmerkend voor het kloosterleven is samengevat in de spreuk "Ora ef Labora", bid en werk. Het ritmisch leven bestond vit fysieke arbeid afgewisseld met contemplatief leven. In het gebed werd gedankt voor de vruchten van de arbeid en de natuur. Zo is het ook vandaag; bedanken voor het succes van de arbeid verricht in een samenwerkingsverband, want zoals de monniken bekend was dat alleen door gebundelde kracht grootse werken verricht konden worden, zo geldt het ook voor deze thesis.

$\mathrm{Nu}$ is het moment in mijn leven waarop ik de voorliggende thesis zal verdedigen in de traditie van de medische faculteit van onze universiteiten; de Katholieke Universiteit Leuven, de oudste in de Lage Landen en de jongste, die van Maastricht. Kenmerkend voor universiteiten is de openheid en mogelijkheid om specifieke kennis en ervaring op te doen. En het is deze traditie die werd voortgezet in de samenwerking die is ontstaan tussen Leuven en Maastricht, vandaag tot uiting komend in deze thesis. Het Latijn als wetenschapstaal in de Middeleeuwen heeft plaatsgemaakt voor Engels. In de communicatie voor onze onderzoeken was er geen taal probleem en kon het Vlaams en Nederlands gecombineerd worden.

Zoals danken een onderdeel is van het dagelijks leven in het klooster (ora), zo ook geldt dit voor het einde van dit werk dat natuurlijk niet is ontstaan door één onderzoeker. Ik dank van harte mijn promotor Prof $\mathrm{dr}$ J Tack. Beste Jan, het is door jou dat ik hier kan staan. Je bent een 
wetenschappelijke duizendpoot, altijd in voor nieuwe, vooruitstrevende, aspecten van de Gastroenterologie. Het was niet altijd makkelijk jou snelheid bij te benen tijdens het overleg, maar steeds weer wist je mij te inspireren om door te gaan en kon je op een vlotte manier teksten veranderen zodat het plotseling zoveel mooier en duideliiker werd. Ik heb zeer veel geleerd en dat is natuurlijk de bedoeling van het onderzoekstraject dat we hebben doorlopen.

Mijn Maastrichtse promotor Prof dr RW Stockbrügger, beste Reinhold, ik ben je veel dank verschuldigd voor de vrijheid die iii mij gaf om het onderzoek in Leuven voort te zetten. Dank voor de opbouwende kritiek en de nauwkeurige correcties van de teksten.

De beoordelingscommissie dank ik voor de snelle afhandeling. Hartelijk dank aan de voorzitter Prof Dr JJ Manni, Dr J-W Greve, Prof Dr PW de Leeuw en Prof Dr AJ Smout uit Utrecht. Le Professeur JP Galmiche de Nantes je vous remercie pour votre intérêt dans ce manuscript et pour venir à Maastricht pour la defence mon thèse.

De experimenten zouden niets geworden zijn als niet Rita Vos en Toon De Greef zo behulpzaam waren geweest. Het was nooit teveel gevraagd een extra bepaling of berekening vit te voeren of te herzien. Het was bijzonder plezant de onderzoeken samen uit te voeren in jullie laboratorium voor motiliteit te Leuven. Mijn dank is oprecht groot voor jullie inzet en enthousiasme.

De weg naar hier was lang hetgeen gebruikelijk is voor de opleiding van specialist in Interne Geneeskunde en Maag Darm Leverziekte. Na de basisopleiding in Leiden en agnioschappen in Leidschendam en Rotterdam werd ik aangenomen in Leuven door Prof dr G Vantrappen. De Vlaamse geneeskunde en de -mentaliteit waren anders dan in Nederland en dat was aanvankelijk aanpassen. Was in Nederland het doen van onderzoek een voorwaarde om in opleiding te komen, dit gold niet voor de Leuvense opleiding. "U wordt geen goede dokter door onderzoek te doen maar door patiënten te zien" was de opmerking tijdens het sollicitatiegesprek. Ik kon beginnen na een proefperiode van twee maanden onbezoldigde werken op polikliniek en afdeling. In het begin was het niet makkelijk maar met de ondersteuning van mevrouw Lieve Melckmans en positief ingestelde pro-Nederlandse collega's is het gelukt de opleiding succesvol te doorlopen. Dank aan de Leuvense groep onder leiding van Prof dr J Janssens en Prof dr J Fevery die me geleerd hebben wat Gastroenterologie en Hepatologie inhouden waarbii 
de patiënt centraal staat. Tevens dank ik Prof dr F Nevens, Prof dr P Yap, Prof dr W van Steenbergen, Prof dr P Rutgeerts, Prof dr M Hiele, Prof dr E van Cutsem en Prof dr A-M Gevers voor hun actieve participatie in mijn opleiding.

Philippe van Hooteghem, gewaardeerd collega en vriend die me enthousiast gemaakt heeft voor de Gastroenterologie en de Brugse geschiedenis ben ik eveneens veel dank verschuldigd.

In Maastricht trof ik eveneens enthousiaste MDL artsen en internisten waarmee het goed samenwerken is en die me ruimte gaven om in Leuven verder te werken. Tevens stonden ze open om de contacten met de Leuvense Gastroenterologie vit te bouwen. Bedankt Wim Hameeteman, Robert-Jan Brummer, Maurice Russel, Barbara Ryan, Daisy Jonkers, Eric Schoon, Ton Vrii, Anne-Marie Wensing, Frank Wolters, Mariëlle Romberg, Marc de Bièvre, José Concillo, Jan Kamphuis, Sylvia Sanduleanu Ulrike Günther en Stephano Pallotta.

Dank aan de geweldige secretariele ondersteuning die verzorgd wordt op humoristische en adequate manier door Mietsie Thyssens en Ellie Mares.

Tevens dank aan de endoscopie afdeling Leuven onder leiding van Willy Claes en zijn medewerkers waarmee ik zoveel plezante en enkele choquerende momenten beleefd heb. Jullie hadden veel geduld en waren zeer behulpzaam tijdens mijn opleiding tot endoscopist. De Maastrichtse endoscopie afdeling bedankt voor de goede samenwerking met Ton, Ria, Daisy, Chantal, Nicole, Hélène, Andrea, Monique, Andy, Ina, Marianne, Nathalie, Linda, Corine, Anita en Gea. Het is soms moeilijk met het ongeduld van de "Belgische slavendrijver" te werken, maar het lukt ons toch steeds weer om er iets van te maken.

Het werken op de polikliniek verloop ook steeds weer plezierig door de inzet van Sabine, Yvonne, Manon, Iris, Sharon, Wendy, Jenny, Linda, Anouk, Manon, Edith, Maddy, Christianne en Connie.

Tiny Wouters dank ik voor haar nooit aflatende inzet en enthousiasme bij de afwerking van het proefschrift. Eigenlijk is het kamertje van Tiny de plaats waar je graag wilt zitten want dat betekent dat het einde in zicht komt. Er is altijd wel een snoepje of koekje uit een van de trommels beschikbaar om weer nieuwe energie te krijgen.

Bedankł Noël Jaegers, onze vlijtige office manager, voor de accurate manier van werken en de narrische zotheid. 
Kort na mijn start in Maastricht, bij mijn eerste Zambon weekend ontmoette ik Prof $\operatorname{Dr}$ A Bast die zoals bleek ook net aan de UM begonnen was. Leveronderzoek was je gewend en het was dan ook niet moeilijk om een gezamenlijk onderwerp te vinden. Beste Aalt dank voor de koffie en gespreken die ik op een zo'n gemoedelijke en interessante manier hebben gevoerd en ik hoop op verdere samenwerking samen met Guido Haenen voor toekomstig hepatologisch onderzoek.

Als paranimf koos ik Jan Wille, vriend sinds het begin van de studie. Regelmatig kwam ik bij jullie op bezoek in Koudekerk aan de Rijn in jouw bescheiden onderkomen. Je moeder was altiid bereid ons goed te voeden en op te beuren.

Dank gaat uit naar mijn ouders die mij nooit in de steek gelaten hebben ook niet toen anderen het niet meer zagen zitten. Miin lieve moeder, die er helaas niet meer bii kan zijn, dank voor je niet aflatende steun, liefde, interesse en warmte waarmee je ons tot op het laatste moment hebt omringd. Mijn vader, man van weinig woorden maar daadkracht voor zijn hulp bij allerhande karwijen in en om het huis en als oppas.

Voor mijn broers, Kees, paranimf, die eveneens met veel enthousiasme in de gezondheidszorg werkt en mij heeft gestimuleerd samen met zijn vrouw Margaret. En Peter en schoonzus Wilma, mijn zus Marian en schoonzus Bernadette en Leandro, eenieder vitgevlogen, maar toch verbonden, voor een goede toekomst met veel geluk en liefde.

Dank aan mijn schoonouders en -familie. Geconfronteerd te worden met een Nederlander was voor jullie in het begin niet makkelijk. Het was voor mij niet zo moeilijk om me aan te passen aan jullie bourgondische levensstijl en dat maakte dat de verschillen snel verdwenen waren. Dank aan Rik, schoonvader voor het maken van de tekeningen op de omslag. Na een ochtendje endoscopie was de inspiratie daar.

Ook thuis is er ondersteuning zodat het werken in de gezondheidszorg verzekerd kan blijven. Bedankt Miep en Ben, José en Leo, Bep, en Rietje. Dank voor de vriendschap van Jeannie en OHo Postel die een nieuwe dimensie gaven aan het leven. Fysieke hulp bij karwijen kregen we van Jo Wolfs die altijd wel een oplossing wist te vinden, mijn dank hiervoor.

Lieve Astrid, je geboorte was niet gemakkelijk maar je bent sterk geworden en een plezier om mee te leven. Je bent voor ons een grote 
steun en helpt de zorg om je zusje Clara te verlichten. Clara, grote schat, je hebt het zo moeilijk in je jonge leven; we begrijpen niet waarom je zo ziek geworden bent en daardoor je kansen op een normaal bestaan minder rooskleurig lijken. Het leven is nooit meer zo vanzelfsprekend hierdoor hetgeen alles veel gecompliceerder maakt, maar we laten ons niet doen en vechten verder, al roeiend tegen de stroom op.

Lieve Els, dank voor je ondersteuning al die jaren die we samen zijn. Je bent er altijd en door jouw goede organisatie thuis krijgen we de zaken rond. Je haalt me uit de wolken en zet me terug op de grond. Zonder jouw hulp en liefde was ik hier nooit gekomen, fel bedankt hiervoor.

Nu hoop ik iets meer tijd te krijgen om het huis eens wat beter op te knappen en op te ruimen en de fuin mooier te maken en ik hoop dat we daarnaast meer leuke ontspannende activiteiten kunnen ondernemen. 
Curriculum Vitae 


\section{Curriculum Vitae}

De auteur van deze thesis is geboren in 1958 te Zoetermeer.

Interesse op jeugdige leeftiid in de middeleeuwse- en prehistorische archeologie leidde tot deelname aan diverse opgravingen in de geboortestad en -land, België en Duitsland.

Het was de wetenschappeliike aanpak en systematiek, de nieuwsgierigheid, de inspiratie van Jan Verwers, de passie voor avontuur en het onbekende die doorslaggevend waren voor mijn keuze, om na het behalen van het WWO diploma aan het Erasmus College, te starten met de bijvak studie prehistorische archeologie onder leiding van Prof dr PJR Modderman en Prof dr G-J Verwers aan de Rijksuniversiteit te Leiden. Het propaedeutisch examen van het hoofdvak geschiedenis werd op 8-7-88 gehaald.

Door onderbreking voor de militaire dienst werd de studiekeuze heroverwogen; economische recessie en het beperkte sociaal economisch gehalte van de studies leidde ertoe dat in 1983 gestart werd met de studie geneeskunde aan de Rijksuniversiteit te Leiden. Het artsexamen werd verkregen in januari 1990.

$\mathrm{Na}$ agnioschappen in het Antoniushove te Leidschendam en het Clara ziekenhuis in Rotterdam werd in augustus 1992 begonnen met de opleiding Interne Geneeskunde aan de Katholieke Universiteit Leuven, aanvankelijk onder de leiding van Prof dr G Vantrappen en later Prof dr J Fevery.

De vervolgopleiding tot internist met speciale bekwaamheid in de Gastroenterologie werd in 1998 afgerond en stond onder leiding van Prof $\mathrm{dr} \mathbf{P}$ Rutgeerts en Prof dr J Janssens.

In augustus 1998 werd een onderzoeksmandaat verkregen van de Katholieke Universiteit Leuven voor onderzoek naar refluxziekte waaruit dit proefschrift is voortgekomen, onder leiding van Prof dr J Tack en Prof dr J Janssens.

Van 1998-1999 werd in Maastricht, onder leiding van Prof dr RW Stockbrügger, een aanvullend specialisatie jaar Gastroenterologie gedaan om naast de registratie van internist de inschrijving in het register van de maag darm leverarts te verkriigen (1-9-1999).

Momenteel is de auteur werkzaam als staflid op de afdeling Interne Geneeskunde sectie Maag Darm Leverziekte en houdt hii zich met name bezig met het uitbouwen van een volwaardige Hepatologie in het Academisch Ziekenhuis Maastricht.

De auteur is gehuwd met Els de Brauwer, arts microbioloog in het Atrium MC te Heerlen,en samen hebben ze twee dochters Astrid (1997) en Clara (2000). 
Publications 


\section{Publications}

Sport, beweging in de Geneeskunde, Ger H. Koek, Harm Gijsman, Gertian Dekker, Wim Tissing. 1988, ISBN 9066090219.

Koek GH, Blockmans DE, Hootegem van Ph. Nierinfarct, een vaak gemiste diagnose. Ned Tijdschr Geneeskd 1988;142:2473-6.

Schweitzer DH, Koek GH, Meinders AE, van der Laarse A. A comparison of the vasorelaxant effects of enoximone and dibutyryl cyclic AMP measured in rat aortic rings. Res Commun Chem Pathol Pharmacol 1990;68:291-7.

Nieuwe inzichten in de pathogenese en de behandeling van het ulcus duodeni, ingezonden brief door J.A. Beker en G.H. Koek. Ned Tijdschr Geneeskund $1991 ; 135,3: 107-8$.

Dodelijk verlopende levercelnecrose na gebruik van glafenine. Koek $\mathrm{GH}$, Stricker BHCh, Veldhuizen RW, de Graaf P. Ned Tijdschr Geneeskd $1991 ; 135: 1088-90$.

Schweitzer DH, Koek GH, van der Laarse A. Spontaneous and pharmacologically-induced vasoconstrictive responses of rat aortic rings are attenuated by balloon angioplasty. Res Commun Chem Pathol Pharmacol $1991 ; 72: 285-94$.

Beker JA, Koek GH. [Current insights in the pathogenesis and treatment of duodenal ulcer]. Ned Tijdschr Geneeskd 1991;135:107-8.

Koek GH, Stricker BH, Veldhuizen RW, de Graaf P. [Fatal liver cell necrosis following administration of glafenine]. Ned Tijdschr Geneeskd 1991;135:108890.

Schweitzer DH, Koek GH, van der Laarse A. Spontaneous and pharmacologically-induced vasoconstrictive responses of rat aortic rings are attenuated by balloon angioplasty. Res Commun Chem Pathol Pharmacol $1991 ; 72: 285-94$

Ven van de K, Koek GH, Beker JA.Gastroduodenale invaginatie door een hemangio-pericytoom van de maag. Tijdschr. voor Geneeskunde 1992;48:523. 6. 
Koek GH, Stricker BHCh, Schalm SW, Desmet VJ. Flucloxacillin-associated hepatic injury. Liver 1994:14;225-9.

Koek GH, Stricker BH, Blok AP, Schalm SW, Desmet VJ. Flucloxacillin-associated hepatic injury. Liver 1994;14:225-9.

Koek GH, Tandt $\mathrm{Ch}$, Hootegem van Ph, Naessens $\mathrm{H}$, Cabooter $\mathrm{M}$. Eosinofiele gastroenteritis. Laukens. Tijdschr voor Geneeskunde 1995: 51, 17; 1189-97.

Chronische inflammatoire darmziekten. Ligament, verpleegkundig informatief tijdschrift. 1995: 26, 3; 7-10.

Koek GH, Hootegem van Ph. Pneumatosis cystoides intestinalis European jounal of gastroenterology and hepatology 1997,9:12; A76.

Koek GH, Blockmans DE, Van Hootegem P. [Three patients with a kidney infarct]. Ned Tijdschr Geneeskd 1998; 142:2473-6.

Koek GH, Horsmans Y, Geubel A, Fevery J, Nevens F. Alpha-interferon induces $\mathrm{HbeAg}$ - chronic active liver disease but improves long-term survival in $\mathrm{HbeAg}+$ chronic hepatitis. Journal of hepatology 1998;28:122

Tack J, Bisschops R, Caenepeel P, Cuomo R, Koek G, Setijoso E, Lerut A, Wilmer A, Janssens J. Esophageal bile reflux: fact or fancy? In: Functional disorders of the gastrointestinal tract. Universitaire Press Leuven 1999.

Cuomo R, Koek G, Sifrim D, Janssens J, Tack J. Analysis of ambulatory duodenogastro-esophageal reflux monitoring. Dig Dis Sci 2000;45:2463-9

Koek GH, Tack J, Sifrim D, Lerut T, Janssens J. The role of acid and duodenal gastroesophageal reflux in symptomatic GERD. Am J Gastroenterol 2001;96:2033-40.

Koek GH, Verleden GM, Evenepoel P, Rutgeerts P. Activity related increase of exhaled nitric oxide in Crohn's disease and ulcerative colitis: a manifestation of systemic involvement? Respir Med 2002;96:530-5.

Conchillo JM, Koek GH. Hyperemesis gravidarum and severe liver enzyme elevation. J Hepatol 2002;37:162-3 
Koek GH, Verleden GM, Evenepoel P, Rutgeerts P. Activity related increase of exhaled nitric oxide in Crohn's disease and ulcerative colitis: a manifestation of systemic involvement? Respir Med 2002;96:530-5.

Rennemberg RJ, Koek GH, Van Hootegem P, Stockbrugger RW. Pneumatosis cystoides intestinalis, four cases of a rare disease. Neth J Med 2002;60:22-5.

Pirenne J, Verleden G, Nevens F, Delcroix M, Van Raemdonck D, Meyns B, Herijgers P, Daenen W, De Leyn P, Aerts R, Coosemans W, Decaluwe H, Koek G, Vanhaecke J, Scherz M, Verhaegen M, Cicalese L, Benedetti E. Combined liver and (heart-)lung transplantation in liver transplant candidates with refractory portopulmonary hypertension. Transplantation 2002;73:140-2

Koek GH, Sifrim D, Lerut T, Janssens J, Tack J. Effect of the GABA(B) agonist baclofen in patients with symptoms and duodeno-gastro-oesophageal reflux refractory to proton pump inhibitors. Gut 2003;52:1397-402.

Tack J, Bisschops R, Koek G, Sifrim D, Lerut T, Janssens J. Dietary restrictions during ambulatory monitoring of duodenogastroesophageal reflux. Dig Dis Sci 2003;48:1213-20

Mook van WNKA, Koek GH, Ven van de AJAM, Ceelen ThL, Bos LP. Intestinale spirochetosis. Eur J Gastroenterol Hepatol 2004: Eur J Gastroenterol Hepatol $2004 ; 16: 83-87$.

Sligte te K, Bourass I, Sels JP, Driessen A, Słockbrugger RW, Koek GH. Non-alcoholic steatohepatitis: review of a growing medical problem. EJIM: accepted for publication. 


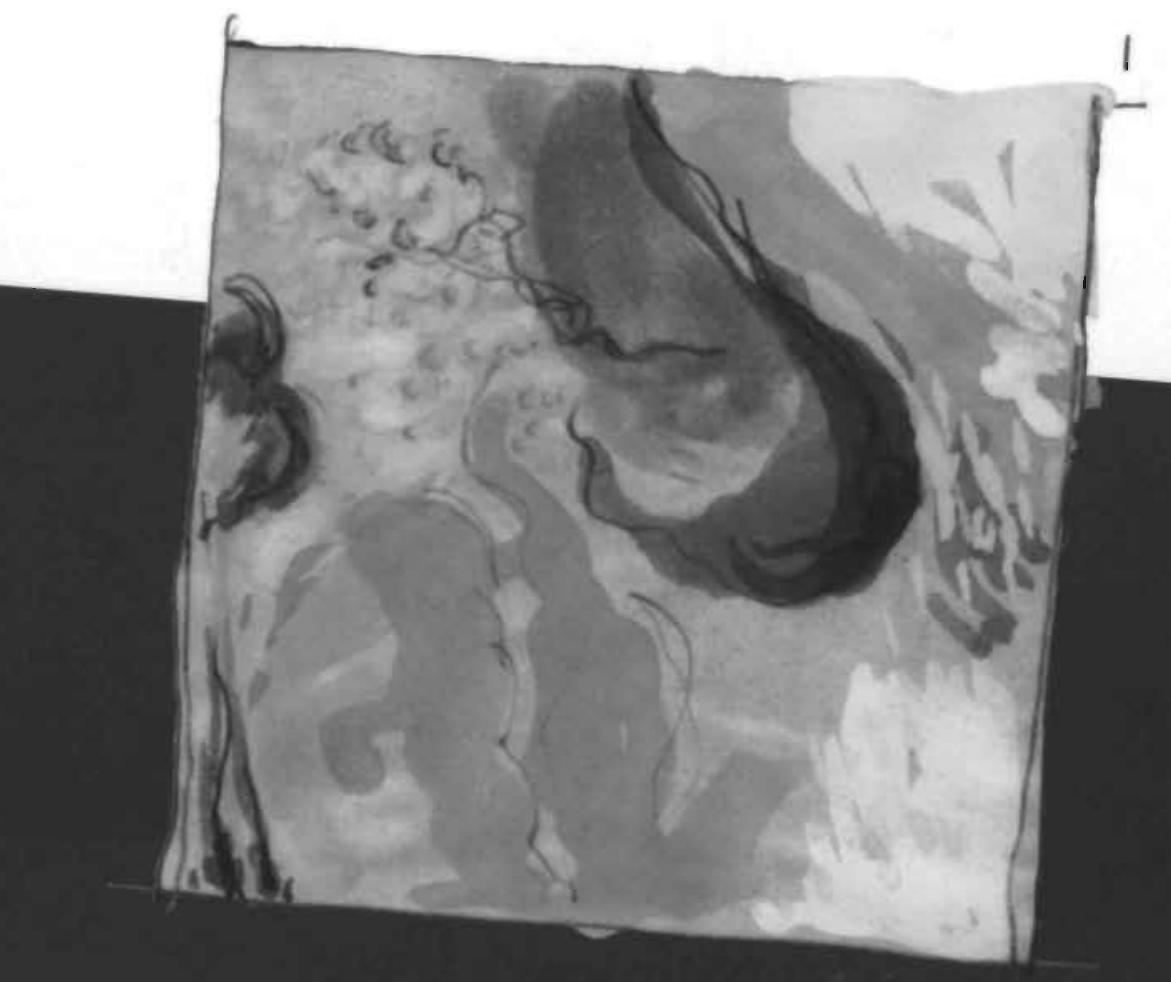

